\title{
A novel role for the E3 ubiquitin ligase FBXO7 in axon-myelin interaction
}

\author{
Ph.D. Thesis \\ In partial fulfillment of the requirements for the degree \\ "Doctor rerum naturalium (Dr.rer.nat)" \\ in the Neuroscience Program \\ at the Georg August University Göttingen, \\ Faculty of Biology
}

submitted by

\section{Sabitha Lis Joseph}

born in

Düsseldorf, Germany

Göttingen 2017

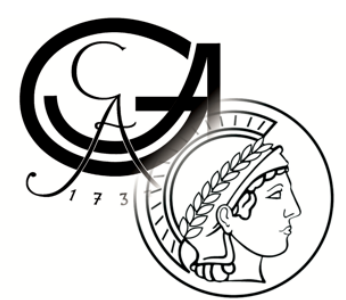





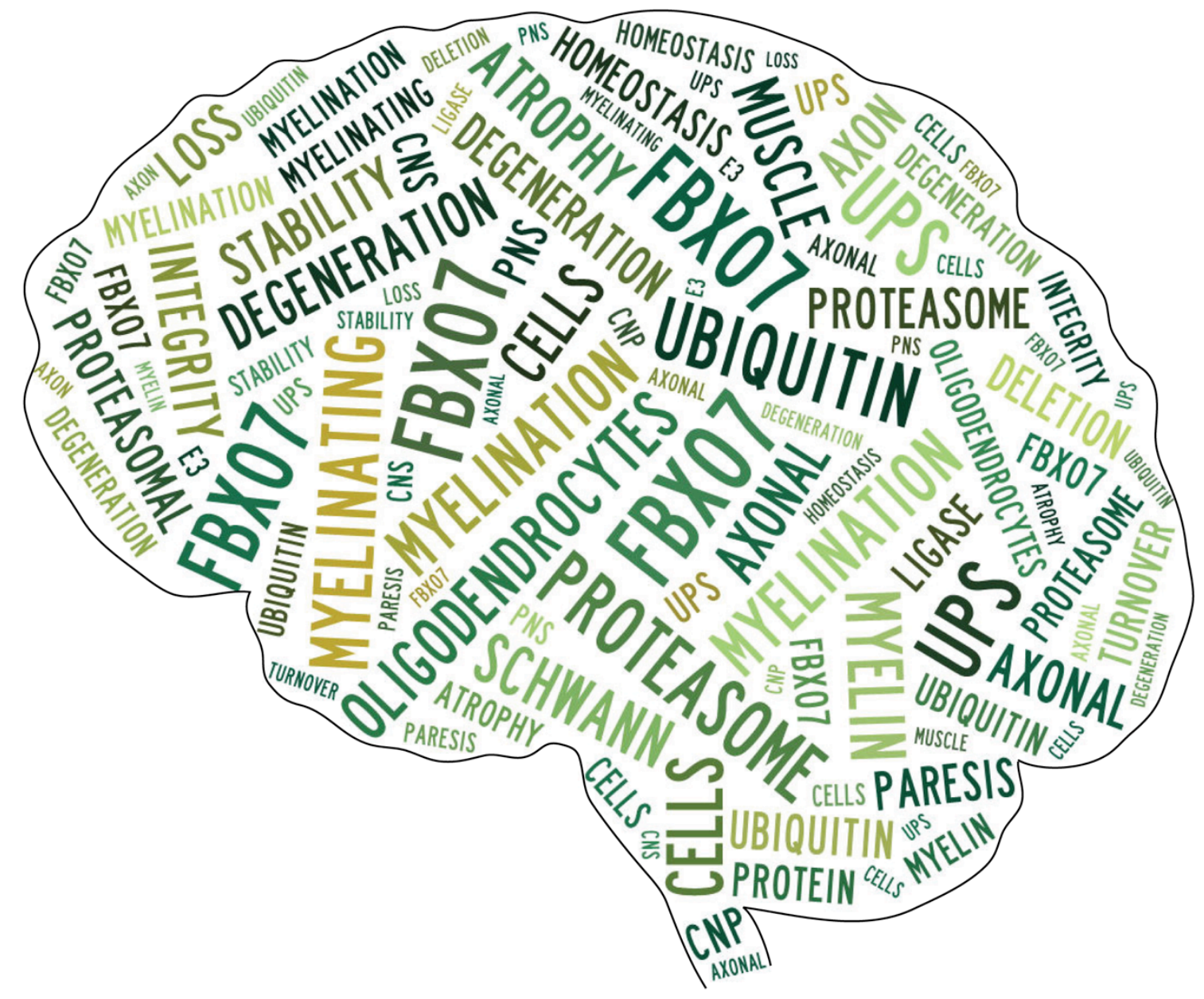




\title{
A novel role for the E3 ubiquitin ligase FBXO7 in axon-myelin interaction
}

\author{
Ph.D. Thesis \\ In partial fulfillment of the requirements for the degree \\ "Doctor rerum naturalium (Dr.rer.nat)" \\ in the Neuroscience Program \\ at the Georg August University Göttingen, \\ Faculty of Biology
}

submitted by

\section{Sabitha Lis Joseph}

born in

Düsseldorf, Germany

Göttingen 2017

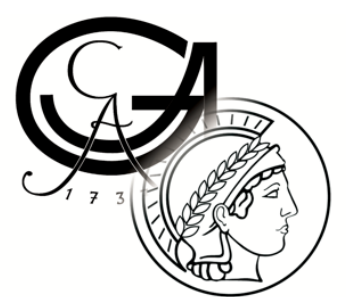




\section{Thesis Committee Members:}

PD Dr. Judith Stegmüller (Reviewer)

Department of Neurology

RWTH University Aachen

Prof. Dr. Wolfgang Brück (Reviewer)

Department of Neuropathology

University Medical Center Göttingen

Prof. Dr. Klaus-Armin Nave

Department of Neurogenetics

Max Planck Institute for Experimental Medicine

Date of oral examination: $29^{\text {th }}$ September 2017 


\section{Affidavit}

I hereby declare that this $\mathrm{PhD}$ thesis entitled "A novel role for the E3 ubiquitin ligase FBXO7 in axon-myelin interaction" has been written independently with no other aid or sources than quoted.

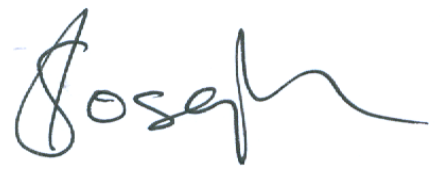

Sabitha Lis Joseph

July 2017

Aachen, Germany 
Für meine Mama. 


\section{Acknowledgments}

Along my way to a $\mathrm{PhD}$, I experienced the kind support of many people, to whom I would like to express my gratitude.

First and foremost, I would like to thank my supervisor PD Dr. Judith Stegmüller for her wonderful supervision. Your support and guidance throughout the years were remarkable and I highly appreciate our scientific discussions and your inspiring expertise that helped me along the way. Thank you for providing the encouraging atmosphere and opportunity for me to develop as a scientist.

Further on, I thank my thesis committee members Prof. Dr. Wolfgang Brück and Prof. Dr. Klaus-Armin Nave for their valuable suggestions and fruitful discussions during my thesis committee meetings.

Moreover, I want to thank my collaborators, Prof. Dr. Klaus-Armin Nave, Dr. Olaf Jahn, Dr. Wiebke Möbius, Dr. Miso Mitkovski, Dr. Hauke Werner, Prof. Dr. Michael Sereda and Prof. Dr. Joachim Weis for their supportive contribution to my PhD project.

I further would like to highlight, how much I appreciate the incredible effort and immense support that the coordinators (Prof. Dr. Michael Hörner and Sandra Drube) of the IMPRS Neuroscience program provided. Thank you Michael and Sandra for making this PhD journey so pleasant and smooth sailing. I am very grateful to have had the opportunity to be part of this program.

I also want to thank Prof. Dr. Jörg Schulz, who welcomed us in the department of Neurology at the University Hospital Aachen, for his interest in my PhD project and his helpful input.

A special, heartfelt thank you goes to my amazing colleges, who made the past years of my PhD so enjoyable. I had the great fortune to have you, Ghergana as my companion and friend since the first day of my journey. Thank you for your mental support, your great sense of humor, your inspiring knowledge and the wonderful time we had. I also like to thank Siv for being an amazing project partner and a great support. Your drive and ambition for science is truly inspiring and it was a delight to work with such a witty person like you. Nicola and David, you were wonderful bay-mates and I thank you for all the great help and advice I received from you whenever I was in doubt. I further want to thank ShihJu, Chaitali, Anna, Anika and Alina for being amazing lab-mates and providing a wonderful atmosphere in lab. Thank you, to all members of AG Awesome for the great 
times we had in and outside of lab. Having said that, I also want to thank Yuhao, Quan and all my other colleagues in Aachen, who welcomed me in the new lab and contributed to the great time I had in the last period of my PhD. Thank you Vibha, for your cheerful attitude and all the amusing conversation we had that made especially tedious incubation times pass so quickly.

Pratibha, Ghergana, Siv and Kathy I would like to thank for prove-reading my dissertation and all the helpful suggestions you provided.

My deepest gratitude however goes to my family. You are the foundation on which I stay and without you I would have not come so far. No words can describe how deeply blessed I feel to have such a loving and supporting family. Your constant encouragement and your tremendous love guide my ways and lift me up in difficult times. Mama and Papa, your hard work, devotion and inspiring achievements in life paved the way, on which Smitha and I are walking on. You strengthen us with your unconditional support and love to reach for the stars and taught us to never loose hope, no matter what challenges life might bring. Smitha you are an amazingly supportive, encouraging and caring sister and the best role model a younger sister can hope to look up to. In all my ups and downs, you have been my greatest advisor and with your courage, fortitude and love you are a true inspiration for me. 


\section{Table of Content}

Table of Content .1

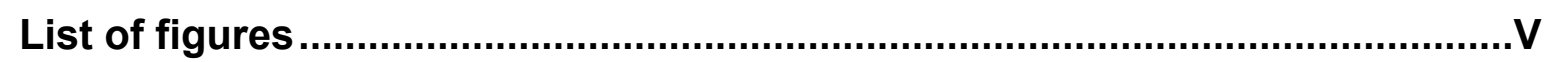

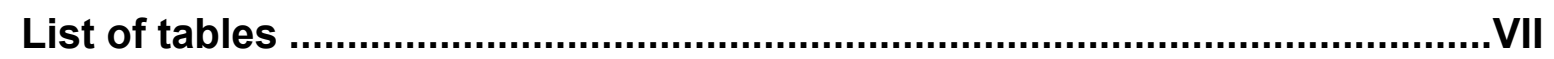

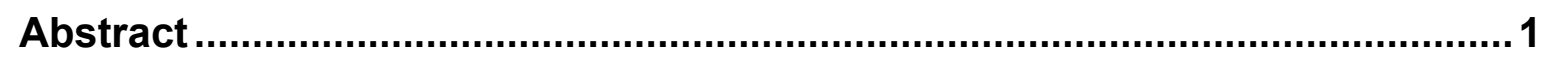

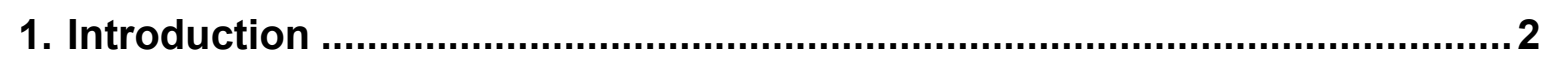

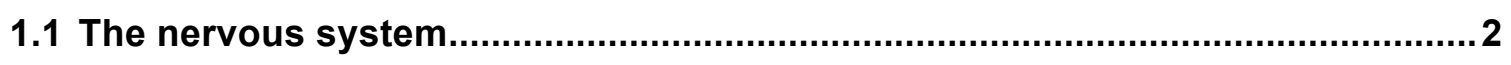

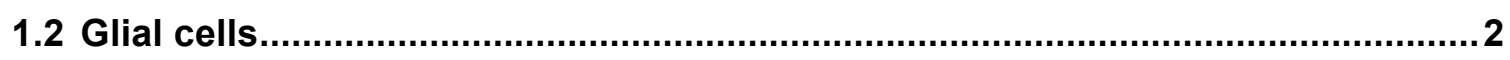

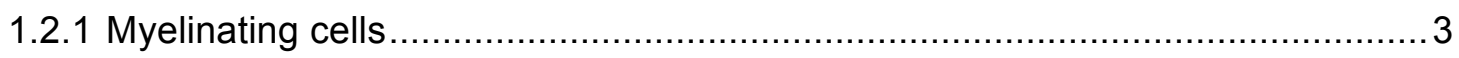

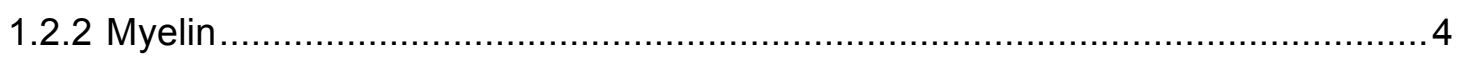

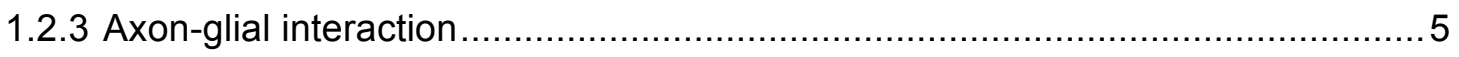

1.2.4 Dysfunctions in myelinating cells induce axonal pathology ........................... 6

1.3 The ubiquitin -proteasome system (UPS) ..................................................... 7

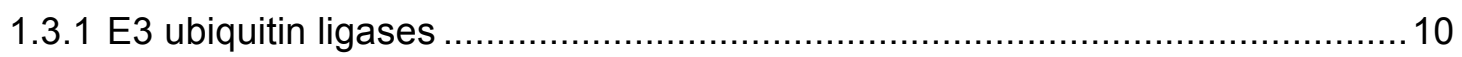

1.3.2 UPS dysfunctions are associated with neurodegenerative diseases................ 11

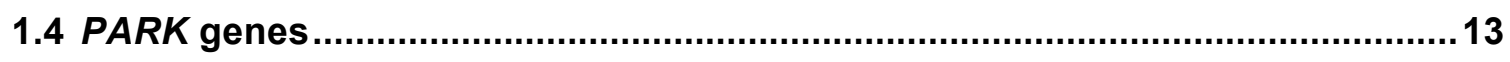

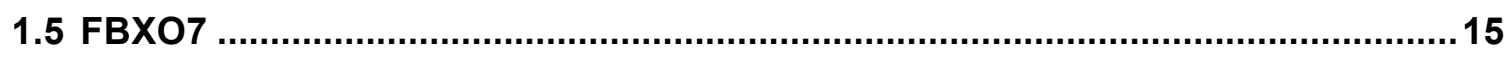

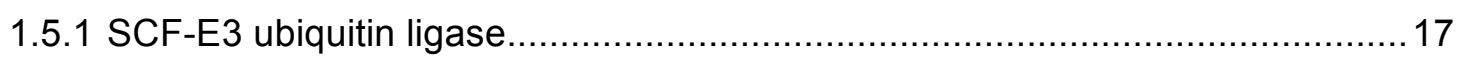

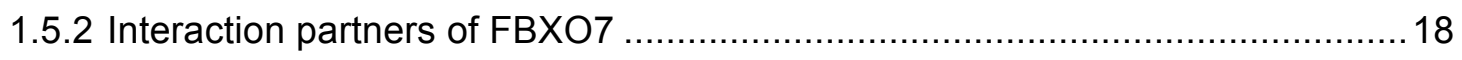

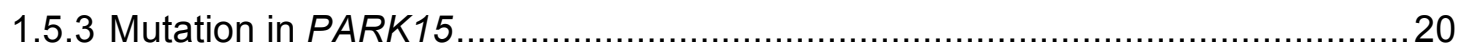

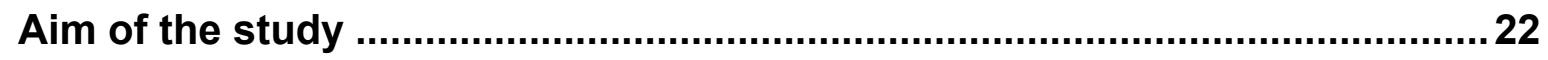

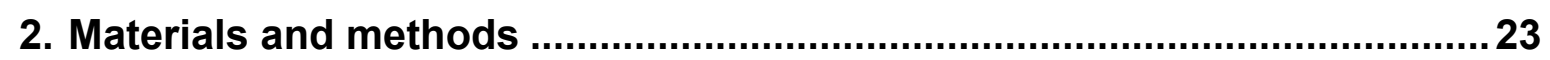

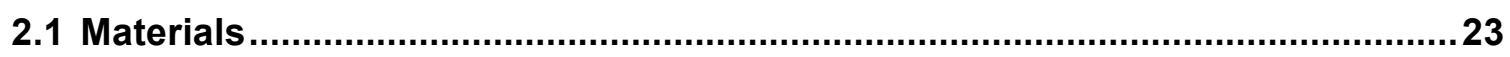

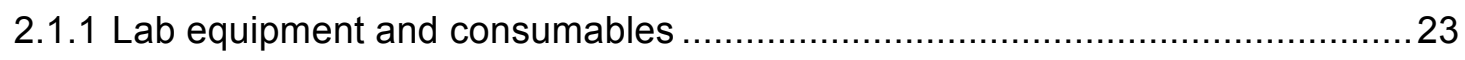

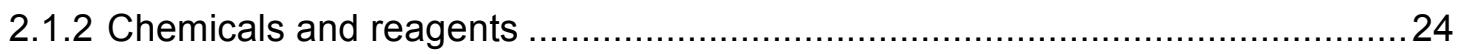

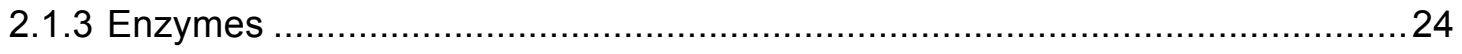

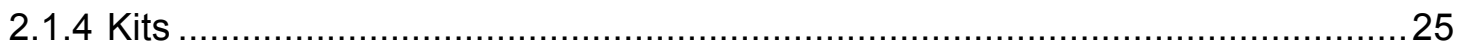

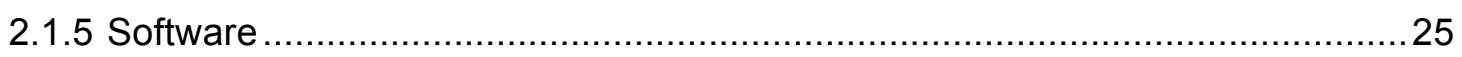

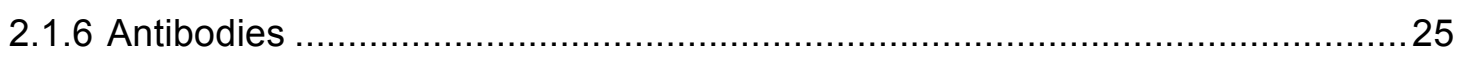

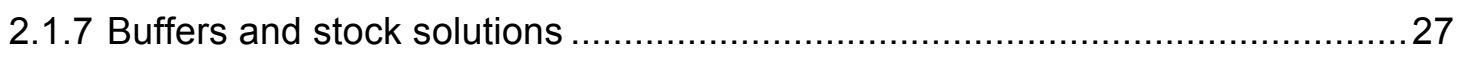




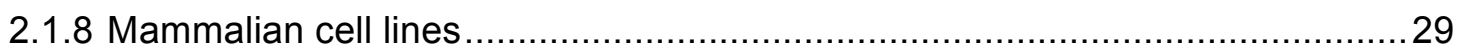

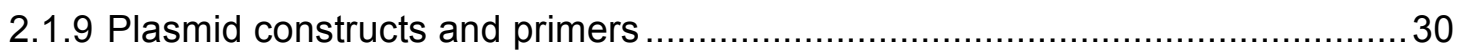

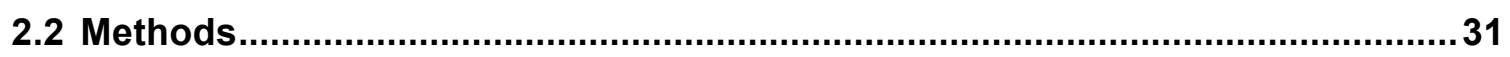

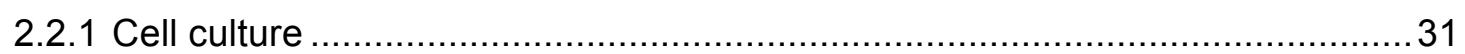

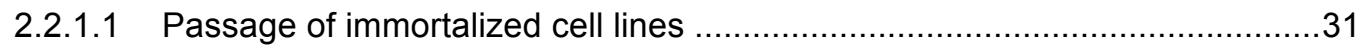

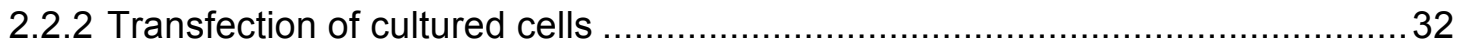

2.2.2.1 Calcium phosphate transfection ........................................................... 32

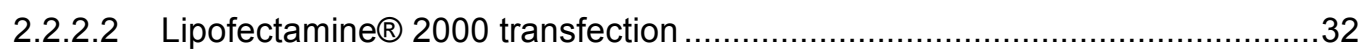

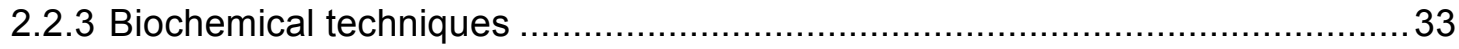

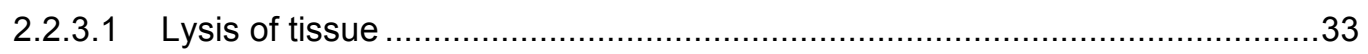

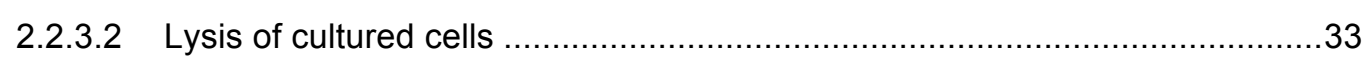

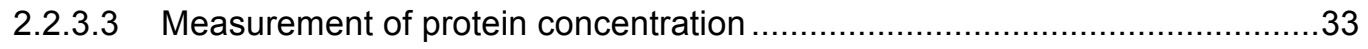

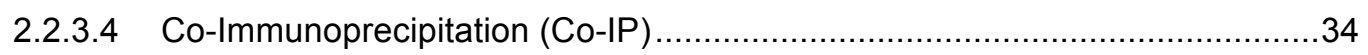

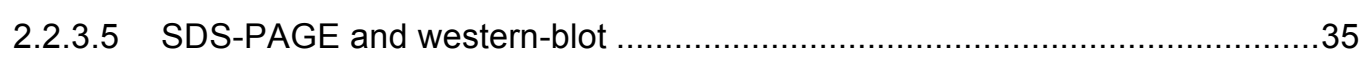

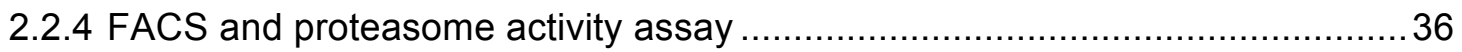

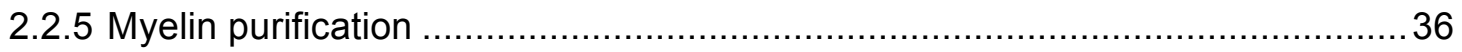

2.2.5.1 Silver staining of SDS-PAGE

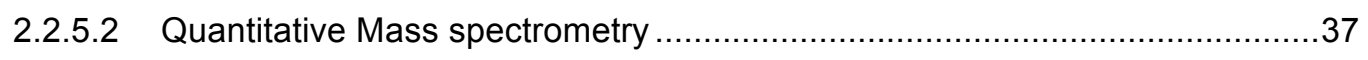

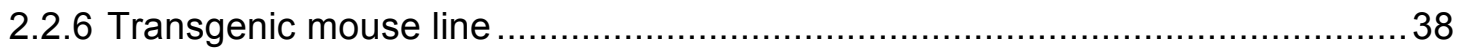

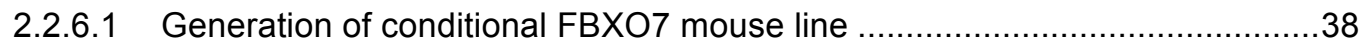

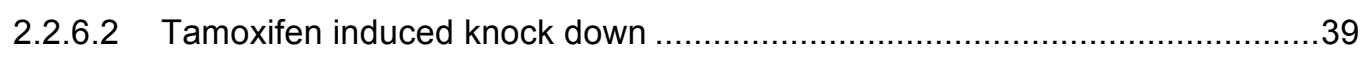

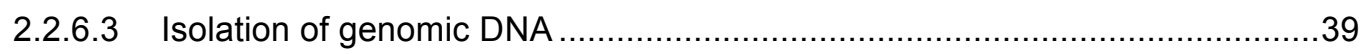

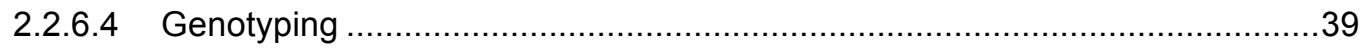

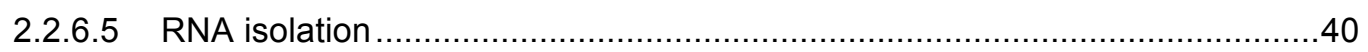

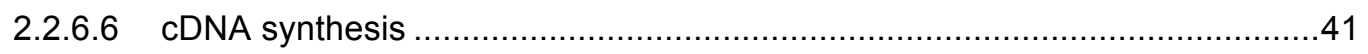

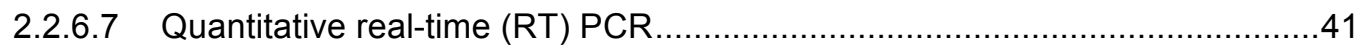

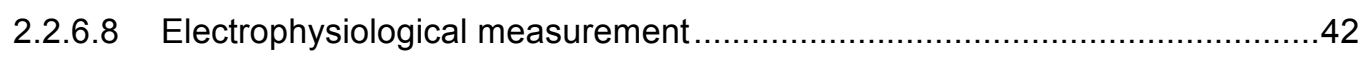

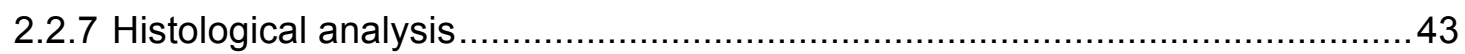

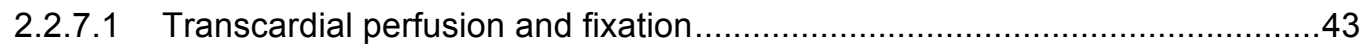

2.2.7.2 Immunohistochemistry on cryo-sections ................................................43

2.2.7.3 Immunohistochemistry on paraffin-sections .............................................4

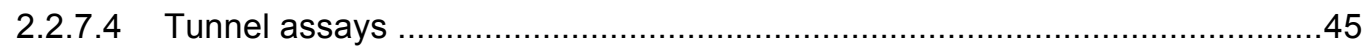

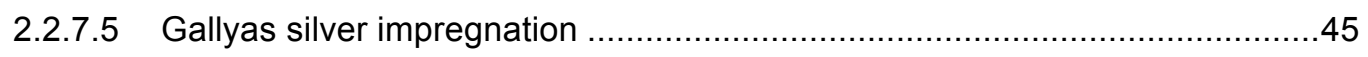

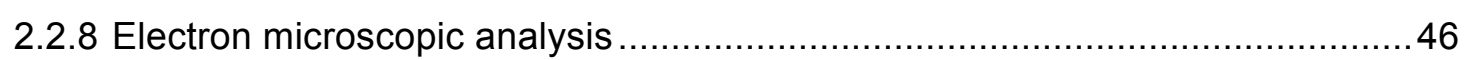

2.2.8.1 Tissue preparation and epon embedding ............................................... 46

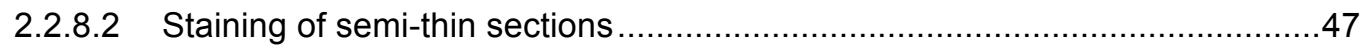

2.2.8.3 Contrasting of ultra-thin sections ...................................................... 47

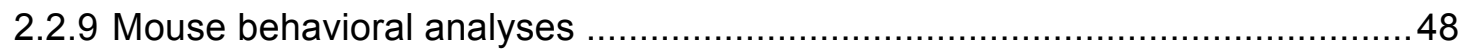

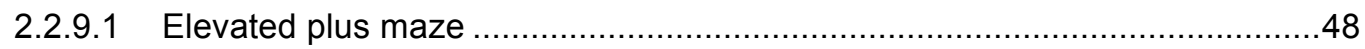




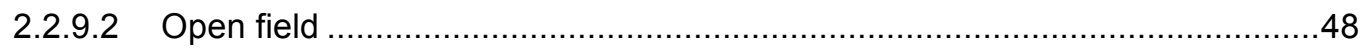

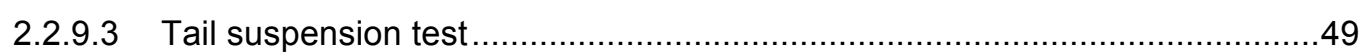

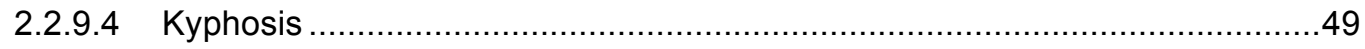

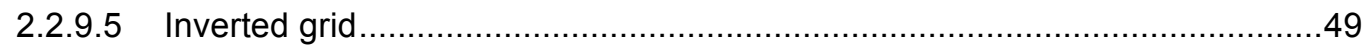

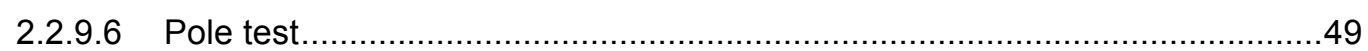

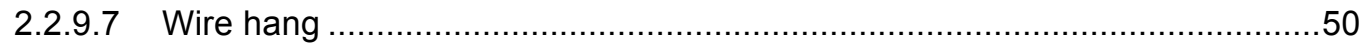

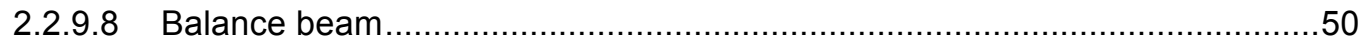

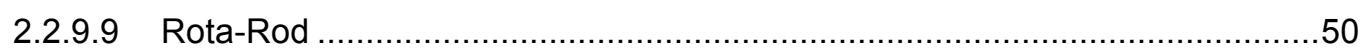

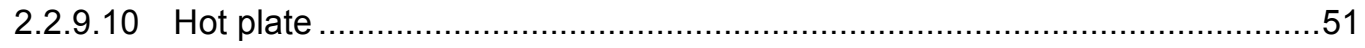

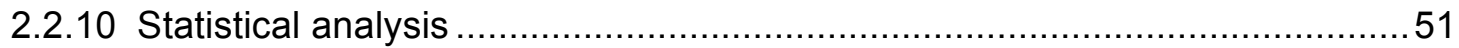

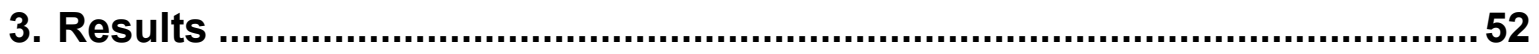

3.1 Systemic characterization of $\mathrm{Cnp}^{\mathrm{Cre} /+} ; \mathrm{Fbxo7}^{\mathrm{fl} / \mathrm{fl}}$ mice ..................................... 52

3.1.1 Deletion of Fbxo7 in myelinating cells by generating a conventional Cnp $1^{\text {Crel+ }} ; F b x O 7^{\text {fl/fl }}$ mouse line.

3.1.2 Cnp $1^{\mathrm{Cre} /+} ; \mathrm{FbxO} 7^{\mathrm{fl/fl}}$ mice display a distinct phenotype .................................... 53

3.1.3 $\mathrm{Cnp} 1^{\mathrm{Cre} /+} ; \mathrm{FbxO} 7^{\mathrm{fl/fl}}$ mice show paresis of the hind limbs caused by muscle

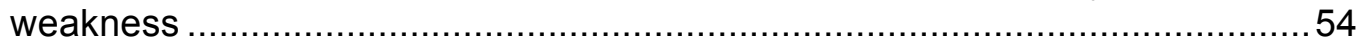

3.2 Cellular characterization of $\mathrm{Cnp1}^{\mathrm{Cre} /+} ; \mathrm{FbxO}^{\mathrm{fl} / \mathrm{fl}}$ mice .......................................56

3.2.1 Loss of Fbxo7 does not affect myelination but leads to a shift in axon caliber 56

3.2.2 $\mathrm{Cnp} 1^{\mathrm{Cre} /+} ; \mathrm{FbxO} 7^{\mathrm{fl/fl}}$ mice display prominent axonal degeneration in the periphery

3.2.3 Knockdown of $F b x o 7$ from myelinating cells leads to increased inflammation .72

3.3 Molecular characterization of $\mathrm{Cnp}^{\mathrm{Cre} /+} ; \mathrm{FbxO} 7^{\mathrm{fl} / \mathrm{fl}}$ mice .78

3.3.1 Fbxo7 deletion leads to an up-regulation of stress sensors and downregulation of cytoskeletal proteins in CNS myelin .....

3.3.2 Loss of Fbxo7 causes an immune response and down-regulation of cytoskeleton proteins in PNS myelin...

3.3.3 Increased myelin maintenance in the CNS and signs of peripheral neuropathy in $\mathrm{Cnp} 1^{\mathrm{Cre} /+} ; \mathrm{FbxO} 7^{\mathrm{fl} / \mathrm{fl}}$ mice.

3.3.4 $\mathrm{Cnp} 1^{\mathrm{Cre} /+} ; \mathrm{FbxO} 7^{\mathrm{fl/fl}}$ mice show unaltered development of oligodendrocytes regarding NG2 and CNP levels....

3.3.5 Knockdown of the E3-ubiquitin ligase $\mathrm{FBXO}$ decreases proteasome activity. 87

3.4 The post-developmental contribution of FBXO7 to the maintenance of the axon-glia interaction

3.4.1 Generation of the Plp $1^{\mathrm{CreERT} 2 /+} ;$ Fbxo $7^{\mathrm{fl/fl}}$ mouse line ....................................... 90

3.4.2 Plp $1^{\mathrm{CreERT} /++} ; \mathrm{FbxO} 7^{\mathrm{fl/fl}}$ mice show a moderate reduction of motor endurance and progressive muscle weakness

3.4.3 Post-developmental loss of $F b x o 7$ does not affect myelination, but induces a moderate axonal degeneration and immune response. 


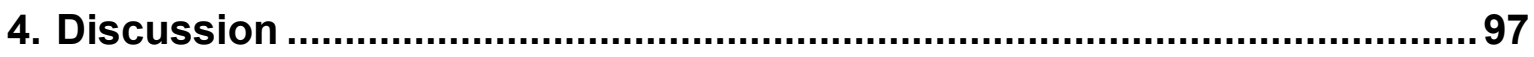

4.1 Deletion of $\mathrm{Fbxo7}$ in myelinating cells results in a strong motor phenotype in $\mathrm{Cnp}^{\mathrm{Cre} /+} ; \mathrm{FbxO} 7^{\mathrm{fl} / \mathrm{fl}}$ mice

4.2 Loss of Fbxo7 does not affect myelin integrity, but leads to degeneration of large-caliber axons in the PNS

4.3 Deletion of $\mathrm{Fbxo7}$ causes a shift in axon diameter without affecting myelination in the CNS 100

4.4 FBX07 remains relevant for the post-developmental maintenance of the axon-myelin interaction

4.5 Lack of Fbxo7 elicits a strong inflammatory response and an increase in

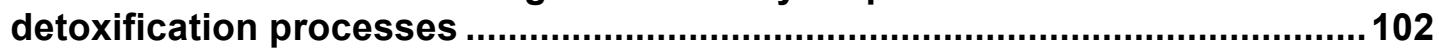

4.6 Mutation in the FBXO7 gene cause Parkinsonian-Pyramidal syndrome ........ 105

4.7 Molecular changes induced by loss of Fbxo7 ...............................................106

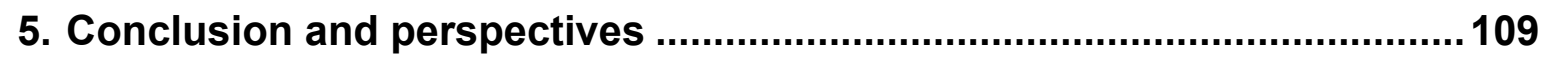

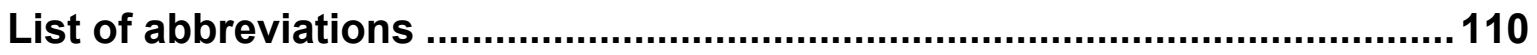

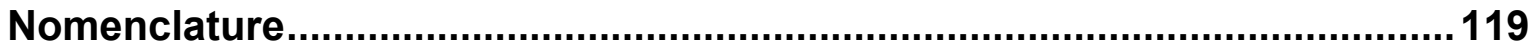

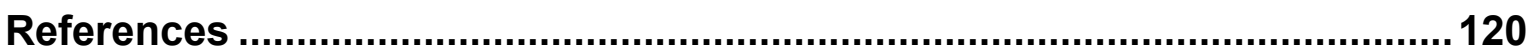




\section{List of figures}

1. Introduction

Figure 1.2.1 Different types of myelinating cells in the CNS and PNS.

Figure 1.2.2 Distribution of compact and non-compact myelin proteins at the axonglia junction in the CNS.

Figure 1.3.3 The cycle of protein ubiquitination.

Figure 1.3.4 The 26S/30S proteasome.

Figure 1.5.5 The Fbxo7 gene and protein structure ......................................... 17

Figure 1.5.6 The FBXO7 SCF-E3 ubiquitin ligase. .......................................... 17

3. Results 52

Figure 3.1.1 Validation of $\mathrm{Cnp} 1^{\mathrm{Cre} /+} ; \mathrm{Fbxo} 7^{\mathrm{fl} / \mathrm{fl}}$ knockout mouse line. 53

Figure 3.1.2 $\mathrm{Cnp} 1^{\mathrm{Cre} /+} ; \mathrm{Fbxo} 7^{\mathrm{fl} / \mathrm{fl}}$ mice display kyphosis, muscle and lung atrophy.......54

Figure 3.1.3 $\mathrm{Cnp} 1^{\mathrm{Cre} /+} ; \mathrm{FbxO} 7^{\mathrm{fl/fl}}$ mice show reduced motor performance, due to paresis of hind limbs and muscle weakness.

Figure 3.2.1 $\mathrm{Cnp}^{\mathrm{Cre} /+} ; \mathrm{FbxO} 7^{\mathrm{fl/fl}}$ mice present no histological changes in myelination.

Figure 3.2.2 $\mathrm{Cnp}^{\mathrm{Cre} / \mathrm{H}} ; \mathrm{FbxO} 7^{\mathrm{fl/fl}}$ mice do not display any major alterations in CNS myelination, but a shift in axon caliber.

Figure 3.2.3 $\mathrm{Cnp}^{\mathrm{Cre} /+} ; \mathrm{FbxO} 7^{\mathrm{fl} / \mathrm{fl}}$ mice show no severe changes in PNS myelination, but a shift in axon caliber.

Figure 3.2.4 $\mathrm{Cnp}^{\mathrm{Cre} /+}$; Fbxo $7^{\mathrm{fl} / \mathrm{fl}}$ mice display a normal abundance of oligodendrocyte, Schwann cell and Remak cell nuclei.

Figure 3.2.5 $\mathrm{Cnp}^{\mathrm{Cre} /+} ; \mathrm{FbxO} 7^{\mathrm{fl/fl}}$ mice show axonal damage in the PNS.

Figure 3.2.6 Loss of FBXO7 induces an increase in axon caliber in the CNS and a shift towards small caliber axons in the PNS of $\mathrm{Cnp}^{\mathrm{Crel+}} ; \mathrm{FbxO} 7^{\mathrm{flffl}}$ mice.

Figure 3.2.7 $\mathrm{Cnp}^{\mathrm{Cre} / \mathrm{+}} ; \mathrm{Fbxo} 7^{\mathrm{fl} / \mathrm{fl}}$ mice show no significant increase in the number of axons as well as degenerated axons in the optic nerve.

Figure 3.2.8 Loss of Fbxo7 leads to increased axonal degeneration within the sciatic nerve of $\mathrm{Cnp} 1^{\mathrm{Cre} /+} ; \mathrm{FbxO} 7^{\mathrm{fl/fl}}$ mice.

Figure 3.2.9 Severe axonal degeneration in the sciatic nerve of $\mathrm{Cnp} 1^{\mathrm{Cre} /+} ; \mathrm{Fbxo} 7^{\mathrm{fl/fl}}$ mice.

Figure 3.2.10 Increased inflammation in the white matter of cerebellum and spinal cord of $\mathrm{Cnp}^{\mathrm{Cre} /+} ; \mathrm{FbxO} 7^{\mathrm{flffl}}$ mice.

Figure 3.2.11 Levels of inflammatory markers show a trend of elevation in the cerebellum of $\mathrm{Cnp} 1^{\mathrm{Cre} /+} ; \mathrm{FbxO} 7^{\mathrm{fl/fl}}$ mice. 
Figure 3.2.12 Increased inflammatory response in sciatic nerve of Cnp $1^{\mathrm{Cre} /+} ; \mathrm{FbxO} 7^{\mathrm{fl/fl}}$ mice.

Figure 3.3.1 Up- and down-regulated proteins in CNS myelin upon deletion of Fbxo7.

Figure 3.3.2 Increased GSTா1 levels in the CNS due to Fbxo7 deletion.

Figure 3.3.3 Up- and down-regulated proteins in PNS myelin upon Fbxo7 deletion. . 83

Figure 3.3.4 Increased GSTח1 signal in sciatic nerve isolated from Cnp $1^{\mathrm{Cre} /+} ; \mathrm{FbxO} 7^{\mathrm{fl/fl}}$ mice.

Figure 3.3.5 Loss of Fbxo7 induces an increase in CNS myelin maintenance and affects proteins, which are associated with peripheral neuropathy in the PNS

Figure 3.3.6 Fbxo7 deletion does not influence the development of oligodendrocytes.

Figure 3.3.7 The FBXO7 F-box domain is crucial for the SCF-complex formation..... 88

Figure 3.3.8 Knockdown of FBXO7 in Schwann cells leads to decreased proteasome activity

Figure 3.4.1 Validation of Tamoxifen-inducible Plp $1^{\mathrm{CreERT} 2 /+} ;$ Fbxo $7^{\mathrm{fl/fl}}$ mouse line...... 91

Figure 3.4.2 $\mathrm{Plp}^{\mathrm{CreERT} 2 /+} ;$ Fbxo $7^{\mathrm{fl/fl}}$ mice show mild but progressive muscle weakness and reduced motor endurance...

Figure 3.4.3 Plp1 ${ }^{\mathrm{CreERT} 2 /+}$; Fbxo ${ }^{\mathrm{fl/fl}}$ mice display no alteration in PNS myelination and no significant but slight increase in axonal degeneration and inflammation. 


\section{List of tables}

2. Materials and methods Error! Bookmark not defined.

Table 2.1.1 List of enzymes used in the study. 24

Table 2.1.2 List of commercially available kits used in this study..... 25

Table 2.1.3 List of commercially available primary antibodies used in this study.......26

Table 2.1.4 List of commercially available secondary antibodies used in this study. . 26

Table 2.1.5 Immortalized cell lines used for experiments. 29

Table 2.1.6 Plasmid constructs and primers used in this study 30

Table 2.2.1 Recipe for SDS-PAGE gels of different acrylamide percentage. .35

Table 2.2.2 Recipe for PCR reaction. 40

Table 2.2.3 Set up of PCR program for genotyping. 40

Table 2.2.4 Protocol for cDNA synthesis I. 41

Table 2.2.5 Procedure for cDNA synthesis II. 41

Table 2.2.6 Protocol for RT-PCR. 42 


\section{Abstract}

The regulated turnover of proteins is an essential aspect of every cell. Cells must be able to respond to environmental changes or undergo different developmental stages, while still maintaining a balanced protein homeostasis. The ubiquitin-proteasome system (UPS) is a major intracellular regulator of the protein homeostasis and is responsible for protein degradation and quality control. Dysfunctions of the UPS have been linked to various neurodegenerative diseases and opened up a new perspective on the disease-causing mechanism in these disorders.

The E3-uniquitin ligase FBXO7 is part of the UPS and is expressed throughout the brain, predominantly in the cortex, hippocampus and substantia nigra, as well as in the white matter of the cerebellum and corpus callosum. Mutations of the Fbxo7 gene (PARK15) are known to cause an early-onset form of Parkinsonism with a broad spectrum of symptoms, which are collectively referred to as Parkinsonian-Pyramidal syndrome. So far, the role of FBXO7 in the nervous system is not fully understood and while recent studies focused on the function of $\mathrm{FBXO7}$ in neurons, its importance in myelinating cells has not been investigated. Although myelinating cells are as equally important to the function of the nervous system as neurons, little is known about the relevance of the UPS in myelinating cells.

In my project, I investigated the importance of FBXO7 for myelinating cells and its impact on the axon-myelin interaction. Therefore, we generated the $\mathrm{Cnp}_{1}^{\mathrm{Cre} /+} ; \mathrm{FbxO} 7^{\mathrm{fl} / \mathrm{fl}}$ mouse line, in which FBXO7 was deleted from myelinating cells. The phenotype of $\mathrm{Cnp}^{\mathrm{Cre} / \mathrm{+}} ; \mathrm{FbxO}^{\mathrm{fl} / \mathrm{fl}}$ mice displayed severe motor deficit and premature death. Interestingly, I showed that deletion of Fbxo7 did not induce significant changes in myelination, however severely affected the integrity of axons. Moreover, deletion of Fbxo7 from Schwann cells affected the survival of axons in the PNS to a greater extent, than the integrity of CNS axons, when deleted from oligodendrocytes. In order to elucidate the post-developmental contribution of FBXO7 to the maintenance of the axon-glia interaction, I further generated the Tamoxifen-inducible $P / p 1^{\mathrm{CreERT} 2 /+} ; F b x O 7^{\mathrm{fl} / \mathrm{fl}}$ mouse line, in which FBXO7 was deleted from myelinating cells once myelination was completed. I found FBXO7 to be less crucial, however still relevant for the function of myelinating cells regarding axonal support, once myelination was completed. Concluding from my results, I demonstrate the vital importance of $\mathrm{FBXO} 7$ for myelinating cells, particularly during development. Furthermore, I showed that FBXO7 is essential for the maintenance of the axon-myelin interaction, especially in the PNS. 


\section{Introduction}

\subsection{The nervous system}

The human nervous system is a remarkable structure, which has developed in the course of evolution to perform exceptional tasks. It computes information from inside and outside the body and generates an appropriate response, which enables us to interact with our environment, conduct higher cognitive activities and regulate almost all our body functions. In vertebrates, the two main parts of the nervous system are the central nervous system (CNS) and the peripheral nervous system (PNS). While the CNS consists of the brain and spinal cord, the PNS mainly comprises nerves, which connect the CNS to every part of the body. At a cellular level, the main constituents of the nervous system are neurons and glial cells. Neurons receive and process signals and relay this information to connected neurons of the network via electrical and chemical signals, known as action potentials (AP). Neurons that connect to each other form neuronal circuitries (Eric R. Kandel, 2000). Glial cells provide a functional scaffold for neurons and together these cells engage in a bi-directional dialogue that is essential for the functioning of neuronal networks. The detailed function of glial cells, however, has only just started to be unraveled.

\subsection{Glial cells}

Glial cells are typically subdivided into astrocytes, microglia and myelinating cells and are as abundant as neurons in the nervous system (Azevedo et al., 2009; Eric R. Kandel, 2000). The main function of astrocytes is to support the neuronal network by transferring nutrients, recycling neurotransmitter from the synaptic cleft and participating in the inflammatory response - to name a few functions (Carson et al., 2006; Eric R. Kandel, 2000; Helmut Kettenmann, 2013).

Microglia are brain-specific inflammatory cells, which are activated during an inflammatory event. Further on, they support the clearance of debris from apoptotic cells and synapses (Allen and Barres, 2009).

Myelinating cells insulate axons with a multilayered myelin sheath, by extending their cell membrane and wrapping it around long segments of axons (Nave, 2010a). Myelination increases the electrical resistance and lowers the capacitance of axons, which enables a fast and saltatory propagation of the action potential that is 50 to 100 fold faster compared to non-myelinated axons. In addition, myelinated axons consume less energy compared 
to non-myelinated axons, since they not require as much energy to maintain ion gradients along insulated axons (Nave, 2010b). Evolutionarily, these characteristics of myelinated axons were beneficial for developing fast and complex brain function.

\subsubsection{Myelinating cells}

There are two types of myelin-producing cells specific for each part of the nervous system: oligodendrocytes in the CNS and Schwann cells in the PNS. While oligodendrocytes are capable of myelinating multiple segments of different axons at the same time, Schwann cells only myelinate one axonal segment (Helmut Kettenmann, 2013; Jessen and Mirsky, 2005) (Figure 1.2.1). Another subclass of Schwann cells are the non-myelinating Remak cells that engulf small caliber $\mathrm{C}$-fibers axons and form the socalled Remak bundles (Feltri et al., 2016). In both CNS and PNS the axon-myelin interaction is comparable and accomplishes similar tasks, which are performed by overlapping, but not identical set of proteins (Nave, 2010a).

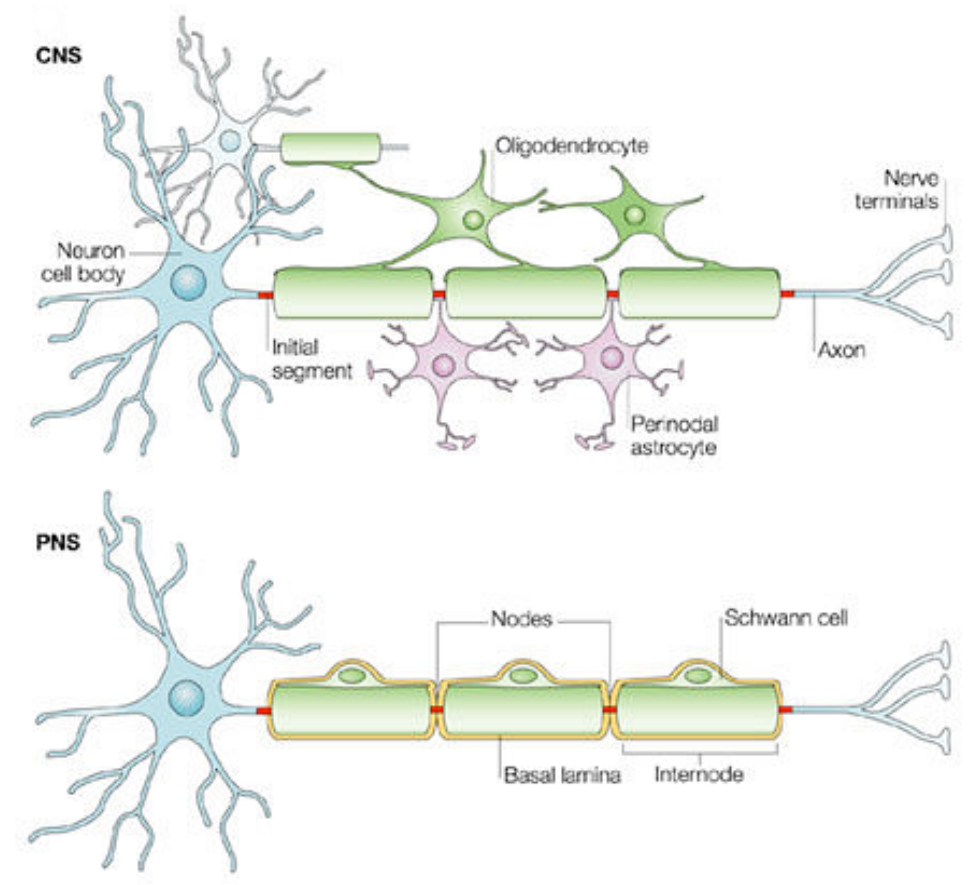

Figure 1.2.1 Different types of myelinating cells in the CNS and PNS.

Oligodendrocytes exclusively myelinate axons of the CNS, whereas axons of the PNS are myelinated by Schwann cells. While oligodendrocytes are able to myelinate multiple axonal segments, Schwann cells only wrap around one axonal segment. Both types of myelinating cells enable the saltatory propagation of action potentials. The figure was modified from: Poliak S, Peles E (2003) The local differentiation of myelinated axons at nodes of Ranvier. Nat Rev Neurosci 4:968-980, doi:10.1038/nrn1253. Reprinted by permission from Macmillan Publishers Ltd: Nat Rev Neurosci, copyright (2003). Nature publishing group license number 4151391176819. 


\subsubsection{Myelin}

Myelin is a specialized plasma membrane that consists of $80 \%$ lipids and approximately $20 \%$ of proteins (as per dry weight) (Norton and Autilio, 1965; Pfeiffer et al., 1993). This enrichment in lipids is the underlying reason for the insulating properties of myelin. Owing to the low density, the purifications of myelin via density gradient centrifugation is feasible (Norton and Poduslo, 1973a). The most abundant proteins within CNS myelin are proteolipid protein (PLP) and myelin basic protein (MBP), representing $17 \%$ and $8 \%$ of total myelin, respectively. In the PNS, myelin protein zero (MPZ or P0), periaxin and MBP constitute 21,16 and $8 \%$ of total myelin, respectively. Further, myelin proteins that are expressed in both systems include 2',3'-cyclic nucleotide 3'-phosphodiesterase (CNP), myelin-associated glycoprotein (MAG) and tetraspanin-29 (known as CD9) (Jahn et al., 2009; Patzig et al., 2011). Myelin can be divided in two distinct domains: compact and non-compact myelin (Poliak and Peles, 2003). Compact myelin defines the tightly packed layers of myelin, which are devoid of cytoplasm and contain proteins including MBP, PLP and MPZ (Dupouey et al., 1979; Martini et al., 1995). The cytoplasmic rich non-compact region represents a specific axon-glial contact zone, in which the myelinating cell interacts with the axonal side and the nodes of Ranvier. This region contains proteins like CNP and MAG and further harbors organelles, secretory vesicles and a cytoskeleton (Nave, 2010b; Zuchero and Barres, 2011).

The node of Ranvier describes the region between two segments of myelin. Here, the axon is not insulated by myelin and contains a high density of voltage-gated sodium channels as well as other channels, which enable the saltatory propagation of an AP from one node to the neighboring one (Bennett and Lambert, 1999; Eric R. Kandel, 2000). Next to the nodes of Ranvier is the non-compact paranodal region, which is adjacent to the juxtaparanodal region. Within these domains, myelin interacts with the axon, by means of adhesion proteins to maintain the axon-glial interface. The juxtaparanodal region further harbors potassium channels, which repolarize the axonal membrane during an AP (Eric R. Kandel, 2000; Poliak and Peles, 2003; Tait et al., 2000) (Figure 1.2.2). Myelin thickness is tightly regulated by axonal signals such as neuregulin 1 type III in the PNS (Michailov et al., 2004; Taveggia et al., 2005). A method to evaluate the thickness of myelin is to measure the g-ratio, which determines the ratio of inner axonal diameter divided by outer diameter of the myelinated axon (Rushton, 1951). The average g-ratio in the CNS is around 0.77 and in the PNS has an approximate value of 0.6 (Chomiak and Hu, 2009; Rushton, 1951). Variations in g-ratio indicate potential pathological changes in myelination. 


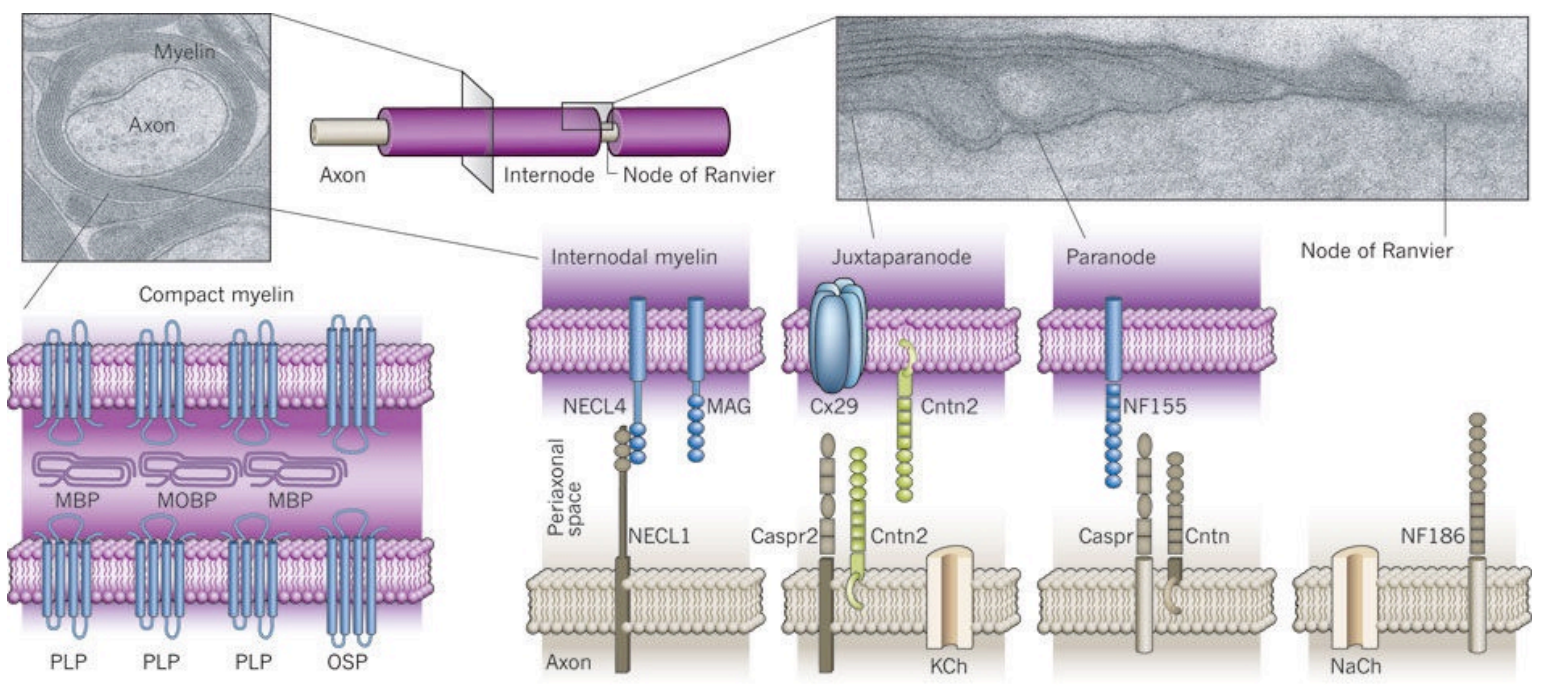

Figure 1.2.2 Distribution of compact and non-compact myelin proteins at the axon-glia junction in the CNS.

The illustration shows the distribution of myelin proteins at the axon-glia interface along different regions of myelin. The regions depicted include compact myelin, juxtaparanode, paranode and the node of Ranvier. The electron microscopic images show the ultrastructure of cross- and longitudinal-section of a myelinated axon from the CNS. Abbreviations: Caspr: contactin-associated protein; Cntn: contactin; Cx29: connexin 29 kDa; $\mathrm{KCh}$ : fast potassium channels; MAG: myelin-associated glycoprotein; MBP: myelin basic protein; MOBP: myelin oligodendrocyte basic protein; $\mathrm{NaCh}$ : voltage-gated sodium channels; NECL: nectin-like protein/synCAM; NF155/186: neurofascin 155 kDa/186 kDa; OSP: oligodendrocyte-specific protein; PLP: proteolipid protein. The figure was adapted from: Nave, K.A. (2010). Myelination and support of axonal integrity by glia. Nature 468, 244-252 10.1038/nature09614. Reprinted by permission from Macmillan Publishers Ltd: Nature, copyright (2010). Nature publishing group license number 4151350094282.

\subsubsection{Axon-glial interaction}

In addition to ensuring a fast and saltatory propagation of the AP, myelinating cells are crucial for the long-term integrity and survival of axons (Griffiths et al., 1998; Lappe-Siefke et al., 2003; Nave, 2010a; Yin et al., 1998). Previous studies showed that myelinating cells support the integrity of axons by providing neurotrophic factors, such as growth factors and cytokines (Nave, 2010a, b). Schwann cells secrete molecules like ciliary neurotrophic factor (CNTF) and erythropoietin to enhance axonal survival. Moreover, it has been shown that deletion of the gene encoding neuregulin1 receptor ErbB3 in Schwann cell induces severe neuropathy (Keswani et al., 2004; Riethmacher et al., 1997; Simon et al., 2010). Oligodendrocytes release factors including brain-derived neurotrophic factor (BDNF), neurotrophin3 (NT3), insulin-like growth factor 1 (IGF1) and glial cellderived neurotrophic factor (GDNF) to support axonal function (Dai et al., 2003; Du and Dreyfus, 2002; Wilkins et al., 2003). Additionally, myelinating cells supply axons with 
metabolic factors, as myelinated and thus insulated axons are deprived of metabolic access from the extracellular space (Nave, 2010b). Especially axons that have larger calibers have a higher energy demand and are highly dependent on the metabolic support of glial cells. Myelinating cells express the glial glucose transporter GLUT1 and are able to take up glucose from the blood vessels. They have also been reported to perform more glycolytic metabolism than oxidative metabolism, resulting in pyruvate and lactate as products (Lee et al., 2012b; Morland et al., 2007). Further studies show that oligodendrocyte-derived lactate is shuttled through the monocarboxylate transporter MCT1 via the axonal-specific MCT2 transporter into axons, where lactate is metabolized (Funfschilling et al., 2012; Lee et al., 2012b; Saab et al., 2013; Simons and Nave, 2015). These additional contributions of myelinating cells to the maintenance of axons are independent from their myelinating function and persist throughout the lifetime of an axonglia symbiosis (Nave, 2010a). The axon-glia axis is not a one-way street, but is rather based on a bi-directional communication and mutual support (Taveggia et al., 2005). Hence, axonal signals also control the survival, proliferation, differentiation and myelination of myelinating cell. Neuregulin1 type III (NRG1), which is expressed by axons, has been shown to control myelination by Schwann cells, as well as the cells' proliferation and survival (Michailov et al., 2004; Nave and Salzer, 2006). In the CNS, growth factors and cytokines like BDNF, CNTF, platelet derived growth factor (PDGF) and leukemia inhibitory factor (LIF) control proliferation and differentiation of oligodendrocytes (Nave, 2010a).

\subsubsection{Dysfunctions in myelinating cells induce axonal pathology}

Myelinating cells support and maintain axonal integrity, but when alterations occur within myelinating cells, this supportive function is disturbed. Abnormalities in myelinating cells can induce axonal degeneration and eventually cause different neurodegenerative diseases (Nave, 2010a). Studies, in which mouse models lack particular myelin proteins, demonstrated the relevance of a functional axon-glial interaction. Mutations of $M p z$ in Schwann cells or mutations of the Plp1 gene leading to a medium number of gene-copies in oligodendrocytes induce dysmyelination and eventually causes axonal loss (Clark et al., 2013; Griffiths et al., 1998; Klugmann et al., 1997; Suter and Scherer, 2003). These pathological changes are seen in neurological disorders such as Charcot-Marie-Tooth (CMT), an inherited peripheral neuropathy, in which MPZ is mutated (De Jonghe et al., 1999). Moreover, mutations in PLP1 are linked to Pelizaeus-Merzbacher disease, which is an inherited form of leukodystrophy (Garbern, 2007). Interestingly, myelinating cells can 
also cause axonal degeneration, without major impairments in myelin synthesis. Mouse models, in which Cnp1 is deleted, develop without motor symptoms until four months of age and display a normal compaction of the myelin sheaths. However at around six months of age, these mice exhibit altered paranodes, axonal swellings, defective axonal transport and axonal death, which reflects in a prominent motor phenotype in young adult mice (Edgar et al., 2009; Lappe-Siefke et al., 2003). Furthermore, in Plp $1^{-/}$mice, which undergo normal motor development in the first year, the overall myelination appears to be intact, but long spinal tracts show progressive degeneration (Garbern et al., 2002; Griffiths et al., 1998; Klugmann et al., 1997). Myelin of $P / p 1^{-/-}$mice only show abnormalities at an ultrastructural level (Rosenbluth et al., 2006). Mutations of the Plp1 gene have a dosedependent effect depending on the number of copies of the transgene (Griffiths et al., 1998). While high gene copies induce more severe symptoms, a prominent dysmyelination and early death, low gene copies or $\mathrm{Plp} 1^{-1-}$ mice only develop late onset neurodegenerations including axonal degeneration (Griffiths et al., 1998). Long-traveling axons appear to be most vulnerable to this lack of support by dysfunctional myelin cells, as it is seen in Plp1 $1^{-/-}$and Mpz mouse models (Garbern, 2007; Griffiths et al., 1998). Investigations on myelin function always pose an interdisciplinary challenge, due to its close axonal interaction. In the recent decades interesting and essential new functions of myelinating cells have been identified, however further studies are required to better understand the axon-glia axis and thereby elucidate the pathological changes occurring in neurological disorders.

\subsection{The ubiquitin-proteasome system (UPS)}

The proper function of a cell is based on a well-orchestrated interplay of fundamental cellular mechanisms. Such mechanisms including metabolism, energy production, molecular transport, cell division, cell growth and structural arrangement are constantly regulated. The ubiquitin-proteasome system (UPS) is a major intracellular regulator that is responsible for protein degradation and quality control (Hershko and Ciechanover, 1998). It therefore participates in essentially all processes involved in the precise spatial and temporal regulation of protein homeostasis. Target proteins of the UPS are modified with ubiquitin (Ub), a small $8.5 \mathrm{kDa}$ molecule that is covalently attached to lysine residues of the substrate (Hershko and Ciechanover, 1998; Schlesinger and Goldstein, 1975). Conjugation of ubiquitin to a substrate is accomplished via a three-step enzymatic cascade. Initially, Ub is activated in an ATP-depended manner by the ubiquitin-activating enzyme E1. It is then transferred to the ubiquitin-conjugating enzyme E2. From there, 
ubiquitin can either be directly coupled to a substrate that is specifically bound to an E3 ubiquitin ligase, or $\mathrm{Ub}$ is transferred onto an E3 ubiquitin ligase and then conjugated to a substrate recruited by this particular E3 ligase (Ciechanover and Schwartz, 2002; Pickart and Eddins, 2004). The modification of proteins by ubiquitin determines their fate, which is why ubiquitination can be viewed as a code. A substrate can either be monoubiquitinated, multimono-ubiquitinated or poly-ubiquitinated. Poly-ubiquitination occurs when additional $\mathrm{Ub}$ molecules are attached to one of the seven lysine $(\mathrm{K})$ residues of the preceding ubiquitin. Linkages of K48 Ub-chains are commonly associated with proteasomal degradation; whereas K63 linked chains are mainly considered to induce a non-proteolytic, functional modification of the target protein (Komander and Rape, 2012; Pickart and Fushman, 2004). Furthermore, protein degradation is also regulated by deubiquitinating enzymes (DUBs), which can reverse ubiquitination of mono- or polyubiquitinated proteins by removing Ub molecules. DUBs thereby are able to reverse the fate of modified proteins and additionally are able to recycle Ub molecules during protein degradation for further ubiquitination processes (Glickman and Ciechanover, 2002; Lilienbaum, 2013) (Figure 1.3.3). Proteins designated for degradation, are generally send to the 26S multi-catalytic proteasome. This complex consists of two compartments: the $20 S$ barrel-shaped core particle (CP) and the 195 regulatory particle (RP), which is attached to one or both ends of the CP. The core particle consists of two $\beta$-rings located at the center and two outer $\alpha$-rings (Bochtler et al., 1999). One $\alpha$-ring and one $\beta$-ring comprise seven $\alpha$-subunits and seven $\beta$-subunits, respectively. The $\alpha$-rings, provide structural stability to the proteasome holoenzyme, while the $\beta$-rings harbor catalytic activity. Prior to proteolysis, the RP recruits ubiquitinated proteins to the proteasome. The $\mathrm{RP}$ is bound to the $\alpha$-rings and harbors an ubiquitin-recognition motif for binding ubiquitinated proteins. Moreover, the RP unfolds and prepares the ubiquitinated substrate for degradation in the core (Dikic, 2017) (Figure 1.3.4). 


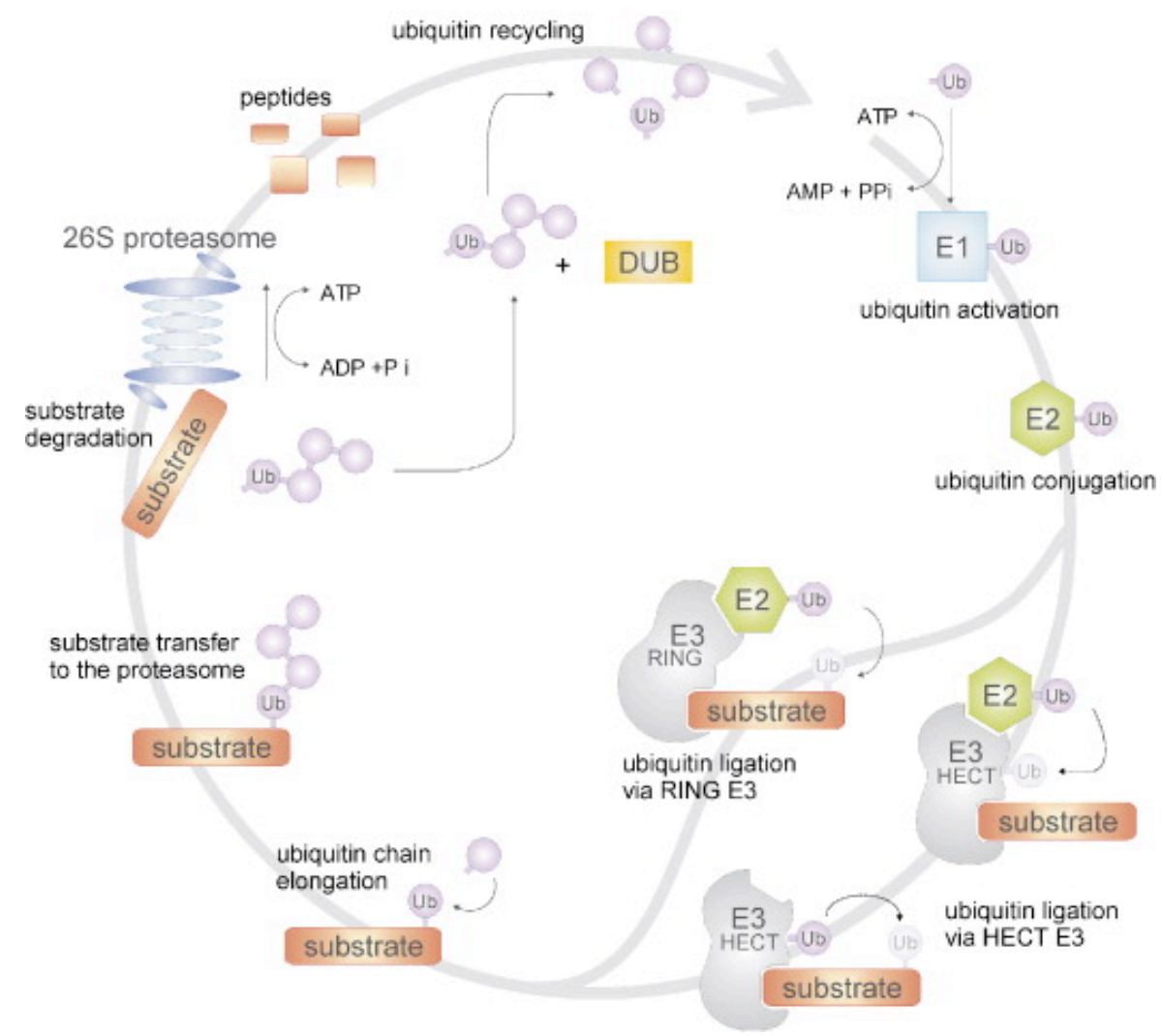

Figure 1.3.3 The cycle of protein ubiquitination.

The Ubiquitin-proteasome system starts with the activation of ubiquitin (Ub) by the E1-activating enzyme. Ub is then transferred on to the E2-conjugating enzyme. Proteins designated for ubiquitin-modification or degradation, interact with the E3-ubiquitin ligase, which mediated the ubiquitination of the target substrate. E3ubiquitin ligases are classified in RING or HECT-E3 enzymes. Substrates that are poly-ubiquitinated by K48 linkage of Ub generally bind to the $26 \mathrm{~S}$ proteasome and are degraded. Finally, Ub molecules are recycled by deubiquitinating enzymes (DUBs). The figure was adapted from: van Tijn, P., Hol, E.M., van Leeuwen, F.W., and Fischer, D.F. (2008). The neuronal ubiquitin-proteasome system: murine models and their neurological phenotype. Prog Neurobiol 85, 176-193. Reprinted by permission from Elsevier Ltd: Progress in Neurobiology, copyright (2008). Elsevier license number 4151791383353. 


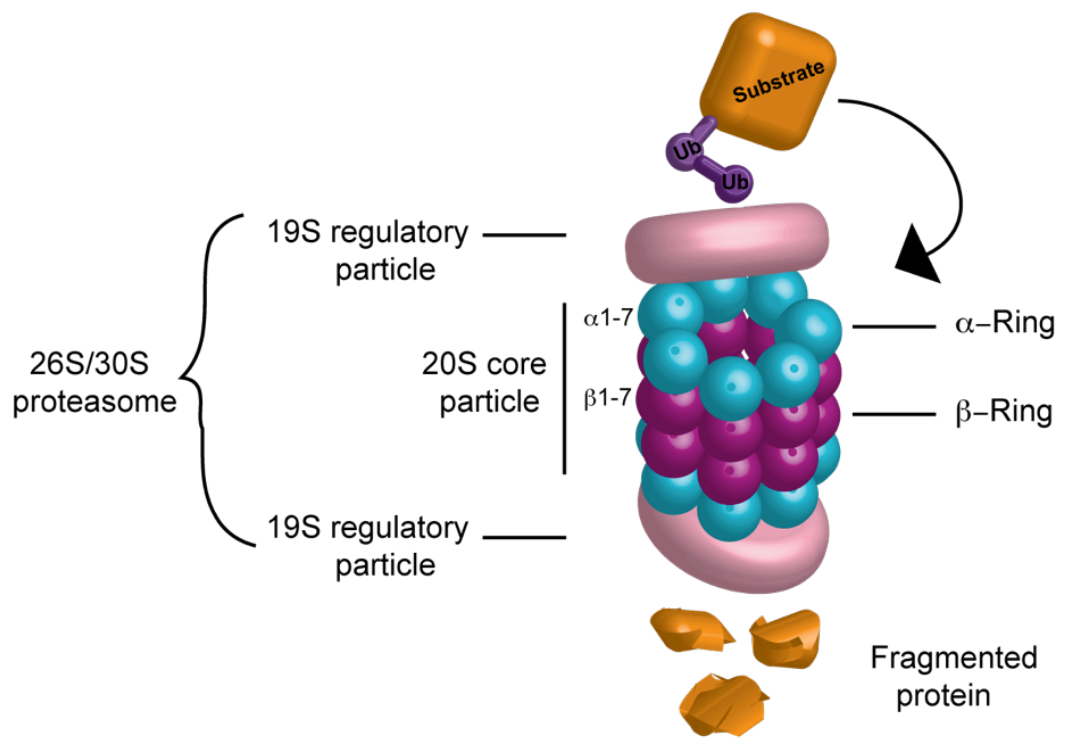

Figure 1.3.4 The $26 \mathrm{~S} / 30 \mathrm{~S}$ proteasome.

Schematic of the 26S/ 30 S proteasome, consisting of a 20 S core particle (CP) and one or two 195 regulatory particles (RP). The CP is constituted of two $\alpha$ - and two $\beta$-rings, each made up of seven respective subunits. Proteins designated for degradation bind to the RP and are degraded by the $\mathrm{CP}$.

\subsubsection{E3 ubiquitin ligases}

The degradation and post-translational modification of proteins by ubiquitination is a finetuned process that relies highly on its specificity for substrate recognition. It is therefore not surprising that the human genome encodes for over 600 different E3 ligases, which recognize substrates via unique protein-protein interactions (Deshaies and Joazeiro, 2009). In contrast, the human genome only encodes for two $E 1$ enzymes and approximately 35 E2 enzymes, pinpointing E3 ligases as the main determinants in the specific process of ubiquitination (Kawabe and Brose, 2011; Scheffner et al., 1995). An E3 ligase can have more than one interaction partner and in return substrates can be ubiquitinated by various E3 ligases. This adds another layer of complexity to the regulation of protein homeostasis and cellular function. Depending on the mode of ubiquitin transfer, E3 ligases can be classified as RING-type or HECT-type ligases. In 'really interesting new gene' (RING) ligases, the E3 enzyme functions as a scaffold binding the E2 conjugating enzyme as well as the target protein and bringing both in close proximity for a direct ubiquitination. RING-ligases can exist as monomeric or multimeric complexes and are more abundant than HECT-ligases (Pickart and Eddins, 2004; Pickart and Fushman, 2004). 'Homologous to E6AP C-terminus' (HECT) ligases have intrinsic enzymatic activity: the E2 ligase is recruited to the E3 ligase and transfers the ubiquitin 
molecule first onto the E3 enzyme before it is transferred onto the target substrate, which simultaneously binds to the E3 ligase (Komander and Rape, 2012) (Figure 1.3.3).

\subsubsection{UPS dysfunctions are associated with neurodegenerative diseases}

Like in any other cell type, the UPS plays a crucial role in neurons and glial cells. Dynamic changes or plasticity of the brain depend on the balance between synthesis and degeneration of proteins. Previous studies have shown that the UPS is essential for the functional and molecular reorganization of the postsynaptic density in rat hippocampal neurons in response to synaptic activity (Ehlers, 2003). Besides synaptic remodeling, axonal regeneration also relies on an efficient UPS. Interestingly, efficient UPS has been highlighted as part of the mechanism involved in new growth-cone formation after axonal injury (Verma et al., 2005). Glial cells are as essential to brain function as neurons and further contribute to its plasticity. When myelination hits its peak, myelinating cells produce myelin membrane at a daily rate that is equal to three times the weight of their soma (Jansen et al., 2014). Ensuring a stable homeostasis is therefore decisive for myelin integrity and involves the UPS. Studies from Goldbaum et al. show that inhibition of the proteasome by the inhibitor MG-132 induces apoptosis and mitochondrial dysfunction in cultured oligodendrocytes from rats (Goldbaum et al., 2006). In the PNS, the UPS was shown to participate in the response of Schwann cells to peripheral injuries. Inhibition of the UPS by MG-132 during the early phase of Wallerian degeneration of injured peripheral nerves induced a cell cycle arrest of Schwann cells and suppressed their dedifferentiation in vivo and in vitro (Lee et al., 2009). Further on, it has been reported for both rats and multiple myeloma patients, that treatment with the proteasome inhibitor Bortezomib caused a degeneration of Schwann cell myelin and peripheral neuropathy (Cavaletti et al., 2007; Filosto et al., 2007).

Proper protein turnover is not only vital during neurogenesis and gliogenesis, but the UPS provides also protection against age-associated changes in the adult brain. Disturbances in the UPS involving ubiquitination, deubiquitination or the proteasomal function are therefore associated with many different neurodegenerative diseases and forms of cancer. Hallmarks of major neurodegenerative diseases often include aggregates of protein within neurons and glial cells. Interestingly, these accumulations seen in tauopathies, synucleinopathies and polyglutamine diseases are thought to compromise the function of the overloaded UPS and contribute to the process of degradation (Bence 
et al., 2001; Dantuma and Bott, 2014; Lindsten et al., 2002). At the same time, inclusion bodies often consist of ubiquitinated proteins, UPS components and proteasome subunits (Dantuma and Salomons, 2016). Further studies in affected neurons suggest that ubiquitin in inclusions may reflect an attempt by the cell to clear these aggregates via proteolytic systems (Yamamoto et al., 2000). However, it is currently unclear whether ubiquitinated proteins within inclusion bodies are the result of a dysfunctional UPS or whether it indicates a protective mechanism of the cell to manage the toxic aggregates. Neurofibrillary tangles, consisting of hyper-phosphorylated tau molecules are a hallmark of Alzheimer's disease (AD) and are intensively ubiquitinated (Perry et al., 1987). In addition, amyloid $\beta$ peptide, the major constituent of amyloid plaques, another hallmark of $A D$, can interact with the proteasome and inhibit degradation of proteins (Gregori et al., 1995). Lewy bodies are a hallmark of Parkinson's disease (PD), which predominantly comprise $\alpha$-synuclein. It has been shown that $\alpha$-synuclein also binds to the proteasome and inhibits the UPS in vitro and in vivo (Chen et al., 2006; Snyder et al., 2003; Stefanis et al., 2001). In Huntington disease, ubiquitinated filamentous mutant huntingtin aggregates were found to selectively inhibit the peptidase activity of the $26 \mathrm{~S}$ proteasome in vitro (Diaz-Hernandez et al., 2006).

In diseases affecting the PNS, it was observed that proteasome impairment in Schwann cells induces misfolding and aggregations of proteins like SIMPLE (small integral membrane protein of lysosome/late endosome) and the myelin proteins PMP22 (peripheral myelin protein 22) and MPZ (Lee et al., 2012a). These pathologies are associated with the peripheral neuropathy of demyelinating Charcot-Marie-Tooth disease, which is characterized by motor and sensory weakness as well as muscle wasting (Lee et al., 2012a). Glial cells are similarly affected as neurons, however the disparity in inclusions occurring in neurons as compared to glial cells implies that the UPS is more efficient in clearing out toxic aggregates within glial cells. While glial cells may cope better with these protein aggregates, they still are affected and contribute to the general outcome. In multiple system atrophy, a-synuclein aggregates have been shown to be present in oligodendrocytes (Asi et al., 2014; Dickson, 2012; Stefanova et al., 2009). Inhibition of the UPS in oligodendrocytes expressing a-synuclein aggregates, leads to a severe motor phenotype and effects neuronal function and integrity (Stefanova et al., 2012).

Astrocytes are able to take up aggregates of $\alpha$-synuclein or amyloid $\beta$ and secrete proinflammatory markers, which activate microglia and subsequently help to clear out aggregates (Mandrekar et al., 2009; Mulder et al., 2014; Wyss-Coray et al., 2003). Proinflammatory markers such as interferon $y$ induce the formation of immunoproteasomes in 
glial cells that exhibit an exchange of $\beta$-subunits by immuno-subunits in the core particle of the proteasome. With this exchange, the catalytic activity in immunoproteasomes is increased and the cleavage pattern is altered, resulting in peptides that are subsequently presented to the MHC class-I molecule of the immune system (Basler et al., 2013; Sijts and Kloetzel, 2011). The inflammatory response of glial cells further leads to an upregulation of the NF-KB or JKN pathway, which are controlled by UPS components (Dalal et al., 2012; Stefanova et al., 2009). While it seems to be beneficial to up-regulate the inflammatory response and clear out toxic aggregates, it is unknown whether the induction of immunoproteasomes are beneficial or detrimental in neurodegenerative diseases in the long run, as chronic inflammation is known to contribute to the degeneration of neurons (Tansey et al., 2012).

\section{$1.4 \quad P A R K$ genes}

Neurodegenerative diseases often have an unknown origin, also referred to as idiopathic origin. Parkinson's disease (PD) for example, which is one of the most prevalent neurodegenerative conditions, is caused in $85-90 \%$ of the cases by a sporadic event, while approximately $10 \%$ are due to an environmental cause and $5-10 \%$ occur as a result of an inherited genetic mutation (de Lau and Breteler, 2006). Even though genetic mutations linked to PD only occur quite rarely, studying their cause will help to elucidate the mechanisms involved in sporadic PD cases. Cellular dysfunctions that had been identified in genetic forms of PD have also been found in idiopathic PD. For instance, the first gene that was associated with familial PD was SNCA, which encodes for a-synuclein (Polymeropoulos et al., 1997). Only later a-synuclein was identified as major constituent of Lewy bodies in sporadic PD patients (Spillantini et al., 1997). SNCA is also known as PARK 1 or 4 and belongs to the 20 identified PARK genes, which are linked to familial PD. Among these $P A R K$ genes with their various functions, 3 loci are related to the UPS: parkin, UCH-L1 and FBXO7.

Parkin (PARK2) encodes for an E3-ubiquitin ligase with multiple interaction partners. It is most prominently known to regulate mitochondrial function together with another PARK gene, PINK1 (PARK6). Upon mitochondrial damage, PINK1 accumulates at the outer membrane of the mitochondria and recruits parkin. Parkin then ubiquitinates outer membrane proteins and induces selective degradation of mitochondria (Pickrell and Youle, 2015). Mitochondrial impairment is shown in brains of sporadic PD patients in several studies before, however the critical pathway was previously unknown (Keeney et 
al., 2006; Parker et al., 1989; Schapira et al., 1989). This newly identified pathway, shed light on mitochondrial contribution in PD and identified an underlying mechanism, which is also relevant in sporadic forms of PD (Wang, 2017).

$U C H-L 1$ (PARK5) or ubiquitin carboxy-terminal hydrolase 1 is a deubiquitinating enzyme and part of the UPS. Its function lies in the recycling of monomeric ubiquitin molecules for new protein degradation and modification (Pickart, 2000). UCH-L1 is highly expressed in neurons and is required for axonal maintenance and integrity. Mutations in UCH-L1 lead to reduced intracellular ubiquitin levels, which restrain proper protein clearance and lead to an imbalanced protein turnover (McNaught et al., 2002; Osaka et al., 2003). Further on, $\mathrm{UCH}$-deficient mouse models have shown that lack of UCH-L1 will lead to inclusion bodies in axonal terminals as well as motor and sensory ataxia, hind limb paralysis and premature death (Bishop et al., 2016).

Another PARK gene that encodes for a component of the UPS is FBXO7 (PARK15). Since FBXO7 is the subject of my study, I will explain the function of FBXO7 in more detail in the following section.

Although the UPS provides a vital function in all different cell types, its role in myelinating cells is barely investigated. In oligodendrocytes it was reported that the SCF-E3 ubiquitin ligase FBXW7 limits the myelin-promoting activity of mTOR (Kearns et al., 2015). The mechanistic target of rapamycin (mTOR) serine/threonine kinase was previously shown to be a powerful driver of myelination, however factors that would regulate mTOR activity were only poorly elucidated (Guardiola-Diaz et al., 2012; Tyler et al., 2009; Wahl et al., 2014). The study by Kearns et al. identified mTOR as direct target of FBXW7 and showed in a mutant zebrafish model, in which Fbxw7 was deleted from oligodendrocytes, that mTOR signaling activity was elevated, resulting in hypermyelination. Hence, under physiological conditions FBXW7 limits myelination, while inhibiting mTOR activity and therefore acting as regulator of myelination during development (Kearns et al., 2015). Moreover FBXW7 was reported to decrease Notch signaling, which blocks neurogenesis and promotes gliogenesis. This identified FBXW7 as limiting factor of OPC-formation (Snyder et al., 2012). Another E3 ubiquitin ligase that regulates Notch signaling is called mind bomb-1 (MIB1). MIB1 promotes the endocytosis of Notch ligands and therefore the formation of progenitors designates for gliogenesis and was shown to suppress glial differentiation, when MIB1 was depleted (Kang et al., 2013).

In Schwann cells, mutations in the small integral membrane protein of lysosome/late endosome (SIMPLE) has been linked to CMT1C disease (Lee et al., 2012a). SIMPLE is involved in the UPS while interacting with the E3 ubiquitin ligase NEDD4 (Shirk et al., 
2005). Although its function is not fully understood, it is speculated that dysfunction of SIMPLE may lead to incorrect turnover of myelin proteins like PMP22, which have been found to be misfolded and aggregated in similar forms of CMT diseases (Kazunori Sango, 2014). Mutations in SIMPLE itself leads to aggregations and hence places a burden on the proteasome pathway (Kazunori Sango, 2014). Many mutations in PMP22 have been identified in mouse and human affected by CMT and have been shown to induce accumulations in the endoplasmic reticulum (ER) (D'Urso et al., 1990; Naef et al., 1997). A recent study showed that misfolded PMP22 at the site of ER is degraded by the E3ubiquitin ligase HRD1/SYVN1, which mediates ER-associated degradation (ERAD) (Hara et al., 2014).

Peripheral nerve injury results in axonal degeneration and phenotypic changes in Schwann cells, which are critical for potential nerve regeneration or degeneration. These changes in Schwann cells require an efficient turnover and modification of proteins within Schwann cells. The E3 ubiquitin ligase ZNRF1 has been reported to be deregulated in Schwann cells following a nerve injury, but its function remains to be further investigated (Araki et al., 2001).

Taken together, these examples illustrate the importance of the UPS for the cellular function and show that dysfunction of the UPS induces neurodegenerative diseases. Its crucial role in myelinating cells however is only poorly understood and requires further investigation.

\section{$1.5 \quad$ FBXO7}

The FBXO7 gene is located on chromosome $22 q 12-q 13$ and consists of nine exons (Figure 1.5.5a). There are three coding isoforms of the FBXO7 mRNA transcript known, with isoform 1 being most abundantly expressed in all different types of tissue. Isoform 2 and 3 are shorter and harbor alterations in the first couple of exons at the 5 prime-end (Nelson et al., 2013) (Figure 1.5.5b). When translated, FBXO7 comprises distinct functional domains, which enable FBXO7 to be involved in various cellular mechanisms. At its $\mathrm{N}$-terminus, FBXO7 contains an ubiquitin-related (UbR) domain, which is known to mediate its interaction with proteasome-linked proteins such as PSMA2 (Burchell et al., 2013; Cenciarelli et al., 1999; Kirk et al., 2008; Laman et al., 2005; Vingill et al., 2016). With its N-terminus, FBXO7 also interacts with parkin and together they regulate mitochondrial quality control (Burchell et al., 2013; Cenciarelli et al., 1999; Kirk et al., 2008; Laman et al., 2005; Vingill et al., 2016). The interaction of FBXO7 with the 
cyclinD/CDK6 complex via the cyclin-depended kinase 6 (CDK6) binding domain, mediates cell cycle regulation (Burchell et al., 2013; Cenciarelli et al., 1999; Kirk et al., 2008; Laman et al., 2005; Vingill et al., 2016). The FBXO7/PI31 (FP) domain is another prominent domain of $\mathrm{FBXO} 7$ that facilitates the interaction with the proteasomal inhibitor 31 (Burchell et al., 2013; Cenciarelli et al., 1999; Kirk et al., 2008; Laman et al., 2005; Vingill et al., 2016). The eponymous F-box domain, mediates the interaction to SKP1 and together with cullin1 and RBX1 forms the SCF-E3 ubiquitin ligase (Burchell et al., 2013; Cenciarelli et al., 1999; Kirk et al., 2008; Laman et al., 2005; Vingill et al., 2016). At its Cterminus, FBXO7 harbors a proline-rich repeat (PRR), which has been shown to be another site of interaction with cell cycle regulating molecules (Huang et al., 2003) (Figure 1.5.5c). All these specific domains facilitate the specific interaction of $\mathrm{FBXO} 7$ with its target substrates, as FBXO7 mainly acts as subunit of the cullin1-based SCF-E3 ubiquitin ligase (Cenciarelli et al., 1999; Winston et al., 1999; Zheng et al., 2002).

a

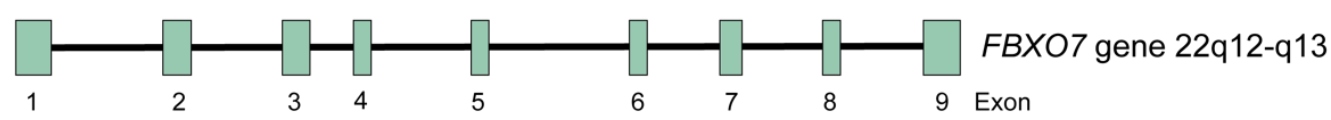

b

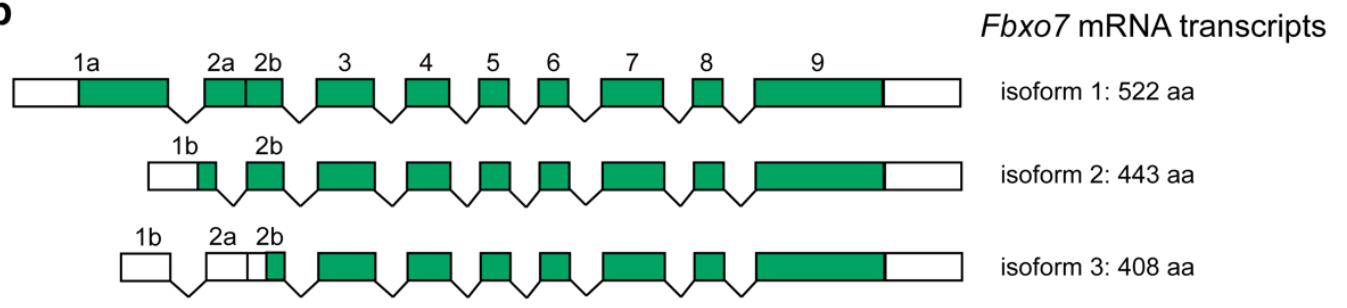

C

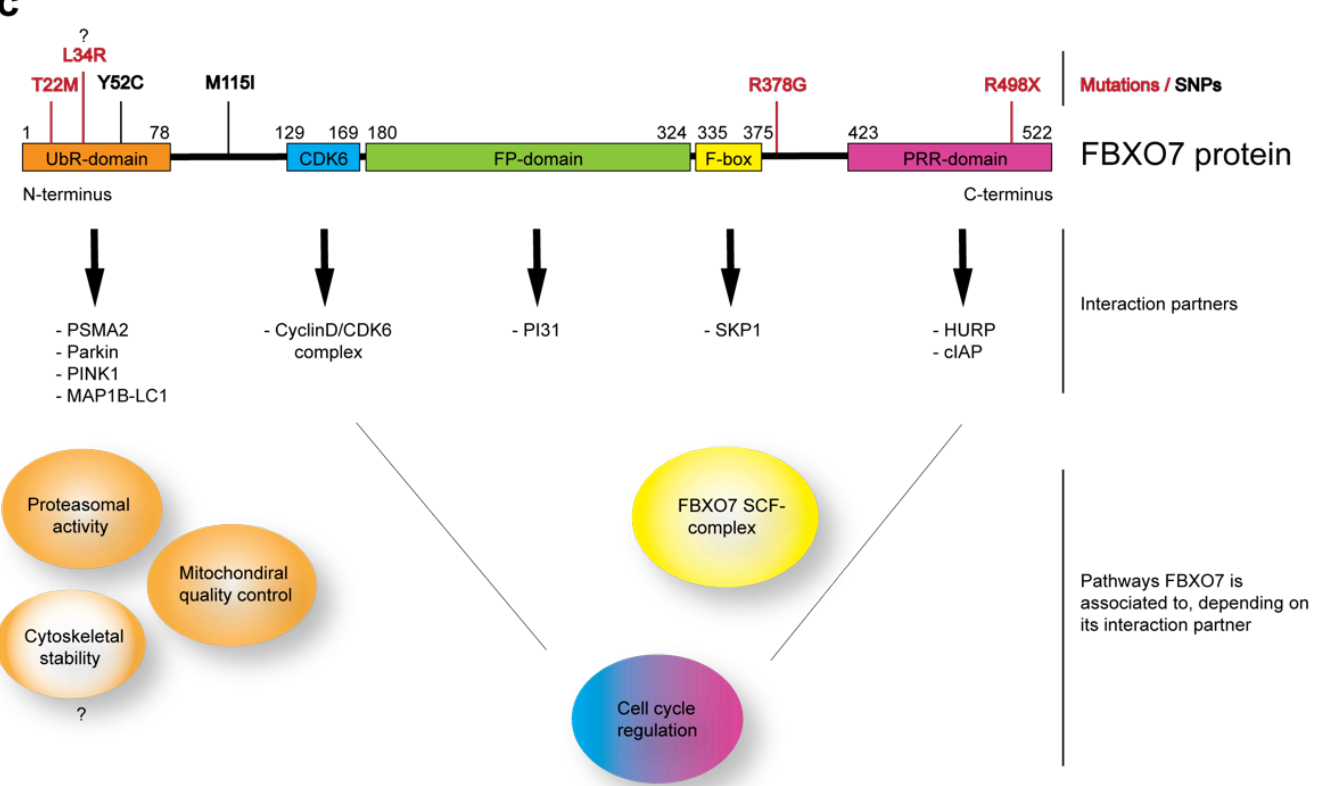


Figure 1.5.5 The Fbxo7 gene and protein structure.

(a) Schematic of the human FBXO7 gene, which is located at chromosome 22q12-q13 and harbors 9 exons. (b) Illustration of the 3 protein coding mRNA transcripts of $F B X O 7$ and the protein size of each isoform. (c) The protein construct of $F B X O 7$ isoform 1 and its distinctive domains. Pathogenic mutations of $\mathrm{FBXO7}$, which are linked to PPS are labeled in red, while SNPs are indicated in black. The pathways, in which FBXO7 is associated to, are sorted according to the domain, by which FBXO7 interacts with its substrates. UbR: ubiquitin-related domain; CDK6: cyclin-depended kinase 6 binding domain; FP: FBXO7/PI31 domain; PRR: prolin-rich-region. Modified from Nelson et al. (Nelson et al., 2013).

\subsubsection{SCF-E3 ubiquitin ligase}

Together with SKP1, cullin1 and RBX1, the adaptor molecule FBXO7 forms the multimeric SCF-complex. While CUL1, RBX1 and SKP1 constitute the core of the complex, FBXO7 is the substrate-recruiting subunit. As a result, FBXO7-SCF brings the E2 enzyme and substrate in close proximity for ubiquitin transfer. The SCF-E3 ubiquitin ligase is categorized as RING-type ligase. At a closer look, the subunit of the SCF-complex, cullin1 (CUL1) acts as scaffold protein. It binds the RING-box protein 1 (RBX1), which recruits the E2 conjugating enzyme and also binds the small adaptor protein S-phase kinaseassociated protein 1 (SKP1). SKP1 in turn binds the respective F-box protein (FBP), like F-box only protein 7 (FBXO7) (Cardozo and Pagano, 2004) (Figure 1.5.6).. Based on the structural motifs, FBPs are categorized as: FBXLs, which contain leucin rich repeats, FBXWs that harbor a specific WD40 domain and FBXOs with no or other structural motifs (Jin et al., 2004). FBPs are the subunits responsible for the decisive step of interaction and recruitment of target substrates, which are designated for ubiquitination.

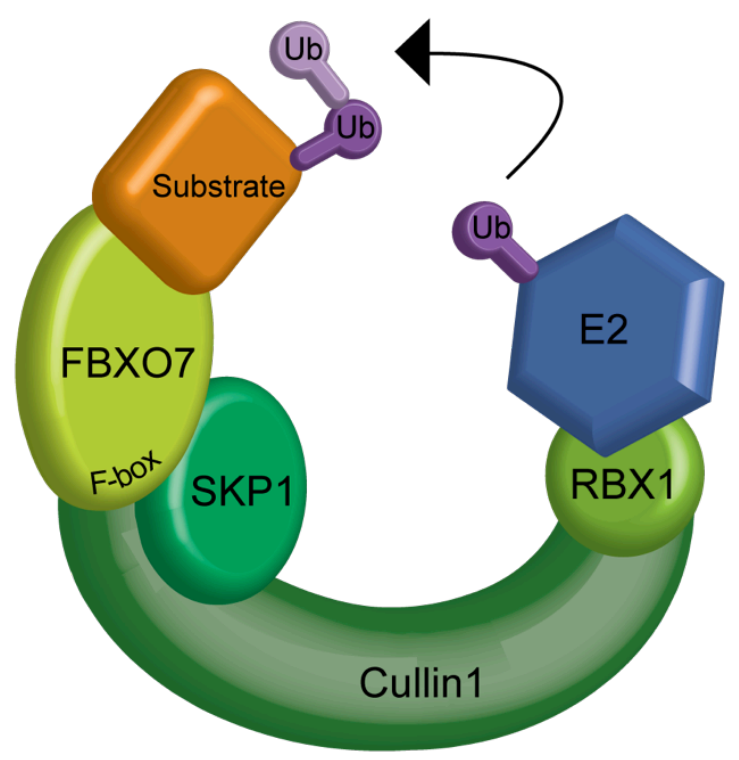

Figure 1.5.6 The FBXO7 SCF-E3 ubiquitin ligase.

Schematic representation of the SKP1-cullin1FBXO7 complex, which mediates the ubiquitination of a target substrate, while simultaneously binding the E2-conjugating enzyme and the substrate. The FBXO7 SCFligase belongs to the RING-type E3ubiquitinating ligases. Ub: ubiquitin; SKP1: Sphase kinase-associated protein1; RBX1: RINGbox1. 


\subsubsection{Interaction partners of FBXO7}

FBXO7 has multiple interaction partners and is involved in various pathways. It was first identified in a yeast two-hybrid analysis together with other F-box proteins, while using SKP1 as bait (Cenciarelli et al., 1999; Winston et al., 1999). After establishing its participation in the SCF-E3 ubiquitin ligase, different studies searched for the interactors and ubiquitination substrates of FBXO7. Soon after, the first interaction partner of FBXO7 and target of ubiquitination was found - HURP (Hsu et al., 2004). The hepatoma upregulated protein (HURP) is localized at the spindle poles during mitosis. Its abundance is tightly regulated during the cell cycle, with elevated levels of HURP during the $G_{2} / M$ phase (Chen et al., 2014b; Tsou et al., 2003). FBXO7 interacts with HURP via its C-terminal proline-rich repeat (PRR) and ubiquitinates HURP depending on its phosphorylation by the cyclin B/CDK1 complex (Huang et al., 2003).

FBXO7 was further shown to be involved in cell cycle regulation, when the cyclin D/CDK6 complex was identified as additional interaction partner of FBXO7 (Laman et al., 2005). Within the cyclinD/CDK6 complex, cyclin D activates the cyclin-dependent kinase 6 (CDK6) and converts growth signals into signals for cell cycle progression (Morgan, 1995; Sherr, 1996). It is anticipated that FBXO7 interacts with the cyclinD/CDK6 complex in a ligase-independent manner and promotes a positive regulation of the complex, since knockdown of FBXO7 reduces the levels of cyclinD/CDK6 assembly in immortalized fibroblasts (Laman et al., 2005). FBXO7 interacts with CDK6 by its CDK6-binding domain. Since FBXO7 was found to be present in colon and lung carcinomas but absent in healthy colon and lung tissue, FBXO7 is suggested to be a potential oncogene (Laman, 2006; Laman et al., 2005). This positive influence of $\mathrm{FBXO7}$ on the cell cycle regulation and proliferation is however only interesting for mitotic cells, rather than for the majority of post-mitotic cells found in the nervous system.

In contrast, FBXO7 has an anti-proliferative function in hematopoietic precursor cells where it promotes the maturation of precursor cells (Meziane el et al., 2011). The reduction of FBXO7 in a hypomorphic mouse model resulted in anemia (Randle et al., 2015).

Other proteins that have been reported to be directly ubiquitinated by FBXO7 are the cellular inhibitor of apoptosis 1 (CIAP1) and TNF receptor associated factor 2 (TRAF2) (Chang et al., 2006; Kuiken et al., 2012). Both proteins are involved in the NF-kB pathway, which is responsible for promoting cell survival by inhibition of apoptosis and initiates an 
immune response (Chen and Goeddel, 2002). By ubiquitinating ClAP1 and TRAF2, FBXO7 reduces their function as indirect NF-KB activators and therefore decreases the NF-KB signaling pathway (Kuiken et al., 2012). It is anticipated that the ubiquitination of TRAF2 by FBXO7 initiates protein degradation, however so far little is known about the consequences of ubiquitination by FBXO7 for clAP1 and TRAF2 (Chen et al., 2014a).

Recently, FBXO7 was also shown to be involved in mitochondrial quality control, while interacting with parkin and PINK1. FBXO7 mediates the recruitment of parkin to the depolarized mitochondrial membrane and acts as scaffold protein for the interaction of parkin and PINK1 (Burchell et al., 2013; Scarffe et al., 2014). Further studies show that mutant forms of FBXO7 aggregate in mitochondria and inhibit mitophagy, which eventually leads to increased generation of reactive oxygen species, depolarization of mitochondrial membrane and less ATP production (Delgado-Camprubi et al., 2017; Zhou et al., 2015). However, the exact role of FBXO7 in the mitochondrial maintenance and mitophagy still remains to be further elucidated.

As an E3-ubiquitin ligase, FBXO7 is part of the UPS, but in the past years its interaction with the proteasome could not be thoroughly proven. FBXO7 was first speculated to interact with the proteasome, since it harbors an ubiquitin-related (UbR) domain at its $\mathrm{N}$ terminus, which is commonly shared in proteins that regulate proteasomal function (Hartmann-Petersen and Gordon, 2004). Then, PI31 was discovered as interaction partner of FBXO7 and was shown to share a dimerization domain with FBXO7 - the FBX07-PI31 (FP) domain (Kirk et al., 2008). The proteasomal inhibitor 31 (PI31) regulates the formation of immunoproteasomes in vivo and inhibits the $20 \mathrm{~S}$ proteasome in vitro (McCutchen-Maloney et al., 2000; Zaiss et al., 2002). However its detailed functional relevance and interaction with FBXO7 remained unknown. Recently, our group introduced a novel interaction partner of FBXO7, which is part of the proteasome. With a yeast twohybrid screen, my colleges identified the proteasomal subunit a2 (PSMA2) as direct interactor and ubiquitination substrate of FBXO7. PSMA2 is a subunit of the $26 \mathrm{~S}$ core particle of the proteasome and like other a-subunits it is crucial for the structural stability and binding of the regulatory particle. In addition, it regulates the access to the proteolytic chamber of the proteasome (Finley, 2009). My colleagues showed that FBXO7 interacts with PSMA2 via its UbR domain and induces a K63-linked ubiquitination, which may lead to a functional modification of PSMA2. In vitro and in vivo experiments revealed that deletion of FBXO7 reduced proteasome activity. While searching for the cause of decreased activity, FBXO7 was reported to not interfere with the gating and proteolytic activity of the proteasome holoenzyme, but that loss of FBXO7 significantly increases the abundance of free core and regular particles in vivo and in vitro. Therefore our group 
could demonstrate that $\mathrm{FBXO7}$ is a proteasome-associated protein involved in proteasome assembly and activity (Vingill et al., 2016).

In the same yeast two-hybrid screening, my colleague Dr. David Brockelt could also identify the light chain1 of the microtubule-associated protein 1B (MAP1B-LC1), MAP1ALC2 and MAP1S as novel and potential interactor of FBXO7. MAPs are part of the cytoskeleton arrangement and stabilize microtubules (Mandelkow and Mandelkow, 1995). MAP1A and MAP1B are predominately expressed in neurons and are important for axonal growth, while MAP1S is ubiquitously expressed in different tissues (Noiges et al., 2002; Orban-Nemeth et al., 2005). Microtubules provide a structural network in neurons and form tracks for organelle transport, like mitochondrial transport (Jimenez-Mateos et al., 2006; Mandelkow and Mandelkow, 1995). In an additional mapping analysis Dr. Brockelt could demonstrate that the mitochondrial aggregation and genome destruction (MAGD) domain of MAPs is the specific region of interaction with FBXO7. While performing an ubiquitination assay, David showed that MAP1B-LC1 and MAP1A-LC2 are ubiquitinated by FBXO7 and hypothesized a potential K63 linage of ubiquitination. However further experiments in vitro and in vivo are required to elucidate the interaction of MAPs and FBXO7, as well as their function (Brockelt, 2015).

\subsubsection{Mutation in PARK15}

Autosomal-recessive mutations in the $\mathrm{FBXO7}$ gene were identified in genome-wide linkage analysis of Parkinsonian-Pyramidal Syndrome (PPS) affected family members and soon after FBXO7 was established as a parkinsonism-associated gene (PARK15) (Di Fonzo et al., 2009; Shojaee et al., 2008). Mutations in FBXO7 cause an early-onset form of parkinsonism, referred to as Parkinsonian-Pyramidal syndrome. Patients affected by PPS display a broad spectrum of disorders, ranging from only Parkinsonism signs, to only Pyramidal tract sings and a mixed form of Parkinsonism and Pyramidal signs, as it is seen in majority of the cases (Di Fonzo et al., 2009; Lohmann et al., 2015; Shojaee et al., 2008). Typical clinical symptoms of Parkinsonism include dyskinesia, rigidity, tremor and postural instability, while spasticity, impaired fine movement and Babinski sign characterize Pyramidal tract signs. Pyramidal tract lesions eventually affect the performance of muscles, which can react with stiffness but also show muscle weakness. PPS patients can have one or more of the listed symptoms and often show additional signs including dystonia, dysphagia, dysarthria, cortical atrophy and/or cognitive decline (Di Fonzo et al., 2009; Lohmann et al., 2015). PPS therefore represents a wide-ranged 
disease with a heterogenic pattern of symptoms and signs, but with a disease causing mutation in the FBXO7 gene that is common to all PPS cases. Different mutations of FBXO7 have been identified, which include the homozygous missense mutation Arg378Gly, a homozygous nonsense mutation Arg498X and the compound heterozygous mutation of a missense mutation Thr22Met, together with a mutation at the internal splice site (IVS7+1G/T) (Di Fonzo et al., 2009; Shojaee et al., 2008). Recently, new single nucleotide polymorphism (SNP) variants of Fbxo7 have been found at the side of Tyr52Cys and Met115lle (Chen et al., 2014a). Moreover, the additional homozygous missense mutation Leu34Arg has been found (Lohmann et al., 2015). However these new mutations remain to be validated, since the novel missense mutation was not further investigated and an association study of the two SNPs, regarding an increased risk of PD was not entirely conclusive (Figure 1.5.5c). 


\section{Aim of the study}

Studies on the role of the UPS in neurodegenerative diseases mainly focus on neurons, as these cell types appear to be affected the most. Lately however, an increasingly important role of glial cells is emerging in neurodegenerative disease. While some studies investigated UPS dysfunction in astrocytes and microglia, very little is known about its influence in myelinating cells. Alterations in the UPS may not only affect the protein homeostasis in myelinating cells, but also impact neuronal function, since both cell types engage in a close interaction, that provides mutual support. Thus, further investigations on the axon-glial interaction and influence of the UPS are crucial to understand the pathophysiological changes in neurodegenerative diseases.

In this study, I investigated the role of the E3-ubiquitin ligase FBXO7 in myelinating cells and its influence on the axon-glia axis. To pursue this goal, we generated a conditional mouse line, in which FBXO7 was deleted from myelinating cells, as FBXO7 is highly expressed in the white matter of cerebellum and corpus callosum. The analyses included the examination of myelinating cells of the CNS and PNS, and associated axons. With this study, I aimed at elucidating the importance of the UPS in myelinating cells and its influence on axonal support. By setting the focus on myelinating cells, it will give a new perspective on neurodegenerative diseases like Parkinsonian-Pyramidal syndrome and contribute to a further understanding and potential therapies for related diseases. 


\section{Materials and methods}

\subsection{Materials}

\subsubsection{Lab equipment and consumables}

The following lab equipment was used during the experiments: plastic ware was purchased from Eppendorf (Hamburg, Germany), Sarstedt AG (Nürnbrecht, Germany), Thermo Fisher Scientific (Waltham, USA), Falcon BD (Le Pont de Claix, France), Gilson (Middleton, USA), Corning (New York, USA) and Greiner Bio-One (Frickenhausen, Germany). Pipettes were bought from Gilson, centrifuges from Eppendorf and Thermo Fischer Scientific, heating blocks from Grant Instruments (Shepreth, UK), horizontal platform shakers from Heidolph instruments (Schwabach, Germany) and thermocyclers from Biometra (Göttingen, Germany). The spectrophotometer was obtained from GE Healthcare (New Jersey, USA), the microplate reader from Tecan (Männedorf, Switzerland) and the thermoshaker from Biometra as well as the gel documentation and UV transilluminator system. Power supplies together with all equipment needed for gel electrophoresis were purchased from Biometra or Bio-Rad (Herkules, USA). Microscopes used in this study included the dissection microscope SMZ645 from Nikon (Tokyo, Japan), the light microscope Axiophot from Carl Zeiss (Oberkochen, Germany), the inverted light microscope Eclipse TS 100 from Nikon, the fluorescent microscope BX51 from Olympus (Tokyo, Japan) as well as the Eclipse TI from Nikon. Glassware was used from Schott Duran (Wertheim, Germany), syringes and needles were bought from B. Braun (Melsungen, Germany) and the peristaltic pump drive 5001 was purchased from Heidolph instruments. The rotarod was acquired from Ugo Basile (Monvalle, Italy), all other tools used for mouse behavior analyses were custom-made by the fine mechanical workshop of Max-Planck Institute of Experimental Medicine. The tissue processor HMP 110 was from Microm and the microtome HM 430 from Thermo Fischer Scientific. The cryostat CM3050 S that was used, was from Leica Biosystems (Wetzlar, Germany) and the histo bath HIR-3 was bought from Kunz instruments (Stockholm, Sweden). For cell culture experiments a biological safety cabinet from HERAsafe $®$ by Kendro (Hanau, Germany) was used and the incubator Hera cell 150, was also purchased from Kendro. The water bath was obtained from Memmert (Schwabach, Germany). 


\subsubsection{Chemicals and reagents}

Unless mentioned otherwise, the chemicals used in this study were mainly obtained from Merck Millipore (Darmstadt, Germany), Macherey-Nagel (Dueren, Germany) Sigma-Aldrich (Munich, Germany), Roth (Karlsruhe, Germany), AppliChem (Darmstadt, Germany) Biomol (Hamburg, Germany), Serva Electrophoresis (Heidelberg, Germany), Invitrogen (Darmstadt, Germany), Becton Dickinson and Company (Heidelberg, Germany), Worthington (New Jersey, USA), DAKO (Carpinteria, USA), GE Healthcare, New England BioLabs (Frankfurt, Germany), Promega (Fitchburg, USA), Zytomed Systems (Berlin, Germany) or Th. Geyer (Erlangen, Germany).

Cell culture reagents that were used included Dulbecco's modified eagle's medium (DMEM), Hank's balanced salt solution (HBSS), basal medium eagle (BME), Opti-MEM reduced serum medium, GlutaMAX ${ }^{\mathrm{TM}}$, Pen-Strep-Glutamine (PSG), B27 supplement and 0.5\% Trypsin-EDTA, which were all purchased from Gibco by Life Technologies (Carlsbad, USA). Poly-L-Lysin (PLL) and goat serum (GS) were bought from Sigma-Aldrich, Trypsin from Worthington, fetal bovine serum (FBS) from Biochrom (Berlin, Germany), calf serum (CS) from Hyclone (Utah, USA), horse serum (HS) from PAA (Coelbe, Germany) and Lipofectamine 2000 from Invitrogen.

Further on DNA and protein ladders, as well as the ECL western blotting solutions were acquired from Thermo Fischer Scientific. Protein A-Sepharose beads were purchased from GE Healthcare, albumin fraction $\vee$ from AppliChem and Bio-Rad Protein Assay was from Bio-Rad. Xylazine also known as Rompun was bought from CP Pharma (Burgdorf, Germany) and Ketamine was from Medistar Arzneimittelvertrieb $\mathrm{GmbH}$ (Ascheberg, Germany).

\subsubsection{Enzymes}

A detailed list of used enzymes in this study is shown in Table 2.1.1.

Table 2.1.1 List of enzymes used in the study.

\begin{tabular}{lll}
\hline Enzyme & Application & Supplier \\
\hline Proteinase K & Protein digestion & AppliChem \\
GoTag® DNA polymerase & Polymerase chain reaction & Promega \\
Superscript III reverse transcriptase & RT-PCR & Invitrogen \\
\hline
\end{tabular}




\subsubsection{Kits}

Commercial kits that were used for experiments are listed in Table 2.1.2.

Table 2.1.2 List of commercially available kits used in this study.

\begin{tabular}{|c|c|c|}
\hline Kit & Application & Supplier \\
\hline Nucleobond® Xtra Midi EF Kit & DNA isolation & Macherey-Nagel \\
\hline $\begin{array}{l}\text { SuperScript }{ }^{\circledR} \text { III First strand } \\
\text { synthesis kit }\end{array}$ & cDNA synthesis & Invitrogen \\
\hline SYBER® green & RT-PCR & Thermo Fischer Scientific \\
\hline Pierce $^{\mathrm{TM}}$ Silver Stain Kit & Silver staining & Thermo Fischer Scientific \\
\hline $\mathrm{LSAB}_{2}$ & Immunohistochemistry & Dako \\
\hline DAB Zytomed kit & $\begin{array}{l}\text { Immunohistochemistry } \\
\text { (Veitenhansl et al.) }\end{array}$ & Zytomed Systems GmbH \\
\hline $\begin{array}{l}\text { DeadEnd }{ }^{\mathrm{TM}} \text { Fluorometric } \\
\text { TUNEL system }\end{array}$ & Immunohistochemical staining & Promega \\
\hline Bio-Rad Protein assay & Protein measurement (Bradford) & Bio-Rad \\
\hline Bio-Rad DC Protein assay & Protein measurement (Lowry) & Bio-Rad \\
\hline Pierce $^{\mathrm{TM}} \mathrm{ECL}$ substrate & Western blotting & Thermo Fischer Scientific \\
\hline
\end{tabular}

\subsubsection{Software}

In order to record and analyze the mouse behavioral open field and elevated plus maze test, the software Viewer from Biobserve (St. Augustin, Germany) was applied. Moreover immunohistochemical quantification was obtained using ImageJ and various plug-ins accordingly. Pictures were edited using Adobe Photoshop and Illustrator. For statistical analysis and plotting of acquired data, Microsoft Excel and GraphPad Prism were used in this study.

\subsubsection{Antibodies}

The following primary and secondary antibodies were used for experiments and are listed in Table 2.1.3 and Table 2.1.4. These were purchased from Biolegend (San Diego, USA), Merck Millipore (Darmstadt, Germany), Sigma-Aldrich (Munich, Germany), Santa Cruz Biotechnology (Dallas, USA), Leica Biosystems, Becton Dickinson and Company (Heidelberg, Germany), Wako Chemicals GmbH (Neuss, Germany), Cell Signaling Technology (Cambridge, UK) and Dianova (Hamburg, Germany). 
Table 2.1.3 List of commercially available primary antibodies used in this study.

IHC (Immunohistochemistry), WB (Western blot).

\begin{tabular}{|c|c|c|c|c|}
\hline Primary antibody & Host species & Application & Dilution & Supplier \\
\hline a-APP 6E10 & mouse monoclonal & $\mathrm{IHC}$ & $1: 200$ & Biolegend \\
\hline$\alpha-C N P a s e$ & mouse monoclonal & WB & $1: 500$ & Sigma-Aldrich \\
\hline a-Cullin1 & mouse monoclonal & WB & $1: 50$ & Santa Cruz Biotechnology \\
\hline a-FBX07 & mouse monoclonal & WB & $1: 50$ & Santa Cruz Biotechnology \\
\hline$\alpha$-Flag & mouse monoclonal & WB & $1: 1000$ & Sigma-Aldrich \\
\hline$\alpha$-GFAP & mouse monoclonal & $\mathrm{IHC}$ & $1: 200$ & Leica Biosystems \\
\hline \multirow[t]{2}{*}{ a-GSTח1 } & \multirow[t]{2}{*}{ mouse monoclonal } & WB & $1: 250$ & \multirow[t]{2}{*}{ BD Biosciences } \\
\hline & & $\mathrm{IHC}$ & $1: 200$ & \\
\hline a-lba1 & rabbit polyclonal & $\mathrm{IHC}$ & $1: 1000$ & Wako Chemicals GmbH \\
\hline a-Mac3 & mouse monoclonal & $\mathrm{IHC}$ & $1: 200$ & BD Biosciences \\
\hline$\alpha-M B P$ & rabbit monoclonal & $\mathrm{IHC}$ & $1: 200$ & Cell Signaling Technology \\
\hline a-Myc & mouse monoclonal & WB & $1: 1000$ & Santa Cruz Biotechnology \\
\hline$\alpha-N G 2$ & rat monoclonal & WB & $1: 200$ & Dr. Hauke Werners lab \\
\hline \multirow[t]{2}{*}{ a-PLP } & mouse monoclonal & WB & $1: 50$ & Prof. Dr. Mikael Simons lab \\
\hline & & $\mathrm{IHC}$ & $1: 200$ & \\
\hline a-PSMA2 & mouse monoclonal & WB & $1: 1000$ & Cell signaling \\
\hline$\alpha-y T u b u l i n$ & mouse monoclonal & WB & $1: 1000$ & Sigma-Aldrich \\
\hline
\end{tabular}

Table 2.1.4 List of commercially available secondary antibodies used in this study. IHC (Immunohistochemistry), WB (Western blot).

\begin{tabular}{|c|c|c|c|c|c|}
\hline Secondary antibody & Host species & $\begin{array}{l}\text { Conjugated } \\
\text { substrate/dye }\end{array}$ & Application & Dilution & Supplier \\
\hline$\alpha$-mouse IgG & goat & HRP & WB & $1: 10000$ & Dianova \\
\hline a-mouse IgG & goat & Cy2/Alexa 488 & $\mathrm{IHC}$ & 1:1000 & Dianova \\
\hline a-mouse IgG & goat & Сy3/Alexa 555 & $\mathrm{IHC}$ & 1:1000 & Dianova \\
\hline$\alpha$-rabbit lgG & goat & HRP & WB & 1:10000 & Dianova \\
\hline$\alpha$-rabbit lgG & goat & Cy2/Alexa 488 & $\mathrm{IHC}$ & 1:1000 & Dianova \\
\hline a-rabbit lgG & goat & Сy3/Alexa 555 & $\mathrm{IHC}$ & $1: 1000$ & Dianova \\
\hline
\end{tabular}




\subsubsection{Buffers and stock solutions}

Buffers and solutions that were used during the course of this study are listed below.

-Buffer for MSC80 cells

MSC80 medium: DMEM [+] 4.5g/l glucose [-] glutamine [-] pyruvate, $10 \%$ horse serum, $1 \%$ GlutaMAX ${ }^{\mathrm{TM}}$

- Buffers and media for HEK293T cells and transfection

HEK293T medium: DMEM [+] 4.5g/l glucose [-] glutamine [-] pyruvate, 10\% FBS, 1\% GlutaMAX ${ }^{\mathrm{TM}}$

2xHBSS: $50 \mathrm{mM}$ HEPES, $10 \mathrm{mM} \mathrm{KCl} 280 \mathrm{mM} \mathrm{NaCl}, 15 \mathrm{mM}$ glucose, $1.5 \mathrm{mM} \mathrm{Na}_{2} \mathrm{HPO}_{4}$ in sterile $\mathrm{H}_{2} \mathrm{O}, \mathrm{pH} 7.11$

\section{5 $\mathrm{M} \mathrm{CaCl}_{2}$}

Trypsin/EDTA: $10 \%$ HBSS(10x), 10\% Trypsin/EDTA(10x) in sterile $\mathrm{H}_{2} \mathrm{O}, \mathrm{pH} 7.0$

- Buffers and reagents necessary for biochemical techniques

Triton $₫ X-100$ lysis buffer: $1 \%$ Triton $® X-100,150 \mathrm{mM} \mathrm{NaCl}, 50 \mathrm{mM}$ Tris- $\mathrm{HCl} \mathrm{pH} 7.5$, $1 \mathrm{mM}$ EDTA in distilled $\mathrm{H}_{2} \mathrm{O}(1: 1600$ aprotinin, 1:1000 pepstatin, leupeptin, Dithiothreitol)*

Co-IP buffer: $1 \%$ Nonidet P40, $150 \mathrm{mM} \mathrm{NaCl}, 20 \mathrm{mM}$ Tris-HCl pH 7.5, $1 \mathrm{mM}$ EDTA, $10 \%$ glycerol in distilled $\mathrm{H}_{2} \mathrm{O}$

RIPA buffer: $0.1 \%$ SDS, $1 \%$ Nonidet $\mathrm{P} 40,0.5 \%$ sodium deoxycholate, $150 \mathrm{mM} \mathrm{NaCl}$, $50 \mathrm{mM}$ Tris- $\mathrm{HCl} \mathrm{pH} 8.0,5 \mathrm{mM}$ EDTA in distilled $\mathrm{H}_{2} \mathrm{O}$

SDS sample buffer (4x): 300mM Tris- $\mathrm{HCl} \mathrm{pH} 6.8,50 \%$ glycerol, $50 \%$ Upper buffer, $10 \%$ SDS, $25 \%$-Mercaptoethanol, $0.05 \%$ bromophenol blue in distilled $\mathrm{H}_{2} \mathrm{O}$

\section{- Buffers used for SDS-PAGE}

Lower buffer: $1.5 \mathrm{M}$ Tris, $0.4 \%$ SDS in distilled $\mathrm{H}_{2} \mathrm{O}$, pH 8.8

Upper buffer: $0.5 \mathrm{M}$ Tris, $0.4 \%$ SDS in distilled $\mathrm{H}_{2} \mathrm{O}, \mathrm{pH} 6.8$

Running buffer: $125 \mathrm{mM}$ Tris, $1.25 \mathrm{M}$ glycine, $0.5 \%$ SDS in distilled $\mathrm{H}_{2} \mathrm{O}$

Transfer buffer: $20 \mathrm{mM}$ Tris $153 \mathrm{mM}$ glycine $20 \%$ methanol in distilled $\mathrm{H}_{2} \mathrm{O}$

PBS: $137 \mathrm{mM} \mathrm{NaCl}, 10 \mathrm{mM} \mathrm{KCl}, 20 \mathrm{mM} \mathrm{Na}_{2} \mathrm{HPO}_{4}, 20 \mathrm{mM} \mathrm{KH}_{2} \mathrm{PO}_{4}$ in distilled $\mathrm{H}_{2} \mathrm{O}$, $\mathrm{pH} 7.4$

PBST: 1xPBS, $0.1 \%$ Tween-20

Blocking buffer: PBST, 4\% milk powder

Antibody solution: $3 \% \mathrm{BSA}, 0.02 \% \mathrm{NaN}_{3}$ in PBS 
- Buffers used for genotyping

Tail lysis buffer: $10 \mathrm{mM}$ Tris $\mathrm{pH} 8.0,10 \mathrm{mM}$ EDTA, $0.5 \%$ SDS, $200 \mathrm{mM} \mathrm{NaCl}{ }^{*}, 3 \mu \mathrm{g} / \mu \mathrm{l}$ Proteinase $\mathrm{K}^{*}$

2xTAE buffer: $80 \mathrm{mM}$ Tris-acetate, $2 \mathrm{mM}$ EDTA in distilled $\mathrm{H}_{2} \mathrm{O}$, $\mathrm{pH} 8.5$

- Buffers and reagents used for the proteasome activity assay

Proteasome lysis buffer: $50 \mathrm{mM}$ Tris- $\mathrm{HCl} \mathrm{pH} 7.5,250 \mathrm{mM}$ sucrose, $5 \mathrm{mM} \mathrm{MgCl}_{2}$, $0.5 \mathrm{mM}$ EDTA, 2mM ATP*, $1 \mathrm{mM} \mathrm{DTT}^{*}, 0.025 \%$ Digitonin* in distilled $\mathrm{H}_{2} \mathrm{O}$

Proteasome assay buffer: $50 \mathrm{mM}$ Tris- $\mathrm{HCl} \mathrm{pH} 7.5,40 \mathrm{mM} \mathrm{KCl}, 5 \mathrm{mM} \mathrm{MgCl}, 0.5 \mathrm{mM}$ ATP*, $1 \mathrm{mM} \mathrm{DTT}^{*}$ in distilled $\mathrm{H}_{2} \mathrm{O}$

-Buffers used for myelin preparation

TBS: $1370 \mathrm{mM} \mathrm{NaCl}, 200 \mathrm{mM}$ Tris- $\mathrm{HCl}$ in distilled $\mathrm{H}_{2} \mathrm{O}$, pH 7,4

- Buffers and reagents used for immunohistochemistry

Anesthetics

Ketamine/Xylazine: $10 \%$ Ketamine, 5\% Xylazine in sterile PBS

Perfusion

4\% PFA for perfusion: $40 \%$ of $0.2 \mathrm{M} \mathrm{NaH}_{2} \mathrm{PO}_{4}, 10 \%$ of $0.2 \mathrm{M} \mathrm{Na}_{2} \mathrm{HPO}_{4}, 50 \%$ of $4 \%$ Paraformaldehyde in sterile $\mathrm{H}_{2} \mathrm{O}\left(6 \mathrm{~g}\right.$ PFA in $\left.75 \mathrm{ml} \mathrm{H}_{2} \mathrm{O}\right)$, $\mathrm{pH} 7.4$

\section{Embedding of Tissue}

4\% PFA for tissue: $4 \mathrm{~g}$ Paraformaldehyde, $4 \mathrm{~g}$ sucrose in $100 \mathrm{ml}$ PBS

1\% PFA for tissue: $3 \mathrm{ml} 4 \%$ PFA for tissue, $1 \mathrm{ml}$ PBS

\section{Gallyas silver impregnation on paraffin sections}

Incubating solution: $12.5 \mathrm{mM} \mathrm{NH}_{4} \mathrm{NO}_{3}, 5.9 \mathrm{mM} \mathrm{AgNO}_{3}, 3 \mathrm{mM} \mathrm{NaOH}$ in distilled $\mathrm{H}_{2} \mathrm{O}$

Developing solution: $50 \%$ solution $A+35 \%$ solution $B+15 \%$ solution $C$

Solution A: $472 \mathrm{mM} \mathrm{Na}_{2} \mathrm{CO}_{3}$ in distilled $\mathrm{H}_{2} \mathrm{O}$

Solution B: $25 \mathrm{mM} \mathrm{NH}_{4} \mathrm{NO}_{3}, 11.8 \mathrm{mM} \mathrm{AgNO}_{3}, 3.5 \mathrm{mM}$ Silicotungstic acid in distilled $\mathrm{H}_{2} \mathrm{O}$

Solution C: $25 \mathrm{mM} \mathrm{NH}_{4} \mathrm{NO}_{3}, 11.8 \mathrm{mM} \mathrm{AgNO} 3,3.5 \mathrm{mM}$ Silicotungstic acid, $1.89 \%$ formaldehyde in distilled $\mathrm{H}_{2} \mathrm{O}$

\section{DAB staining on paraffin sections}

Citrate buffer: $1.8 \%$ solution $\mathrm{D}+8.2 \%$ solution $\mathrm{E}$ in distilled $\mathrm{H}_{2} \mathrm{O}, \mathrm{pH} 6.0$

Solution D: $0.1 \mathrm{M}$ citric acid in distilled $\mathrm{H}_{2} \mathrm{O}$

Solution E: $0.1 \mathrm{M}$ sodium citrate in distilled $\mathrm{H}_{2} \mathrm{O}$

Tris buffer: $15.5 \mathrm{mM} \mathrm{NaCl}, 50 \mathrm{mM}$ Tris- $\mathrm{HCl}$ in distilled $\mathrm{H}_{2} \mathrm{O}, \mathrm{pH} 7.6$

Tris buffer + Milk: $2 \%$ milk powder in Tris buffer

Blocking buffer: $20 \%$ goat serum in BSA/PBS

BSA/PBS: $1 \%$ BSA in PBS 
Immunofluorescence staining of cryo-sections and free floating sections

Solution to store free floating samples: $0.02 \% \mathrm{NaN}_{3}$ in PBS

Blocking solution: $10 \%$ goat serum, $2 \%$ BSA, $0.5 \%$ TX-100 in PBS

Antibody solutions: $10 \%$ goat serum, $2 \%$ BSA in PBS

\section{Mounting media}

Mowiol mounting media: $6 \mathrm{~g}$ glycerol (85\%), $2.4 \mathrm{~g}$ Mowiol 4-88, $6 \mathrm{ml} \mathrm{H}_{2} \mathrm{O}, 12 \mathrm{ml} 0.2 \mathrm{M}$ Tris- $\mathrm{HCl} \mathrm{pH} \mathrm{8.5,} \mathrm{25mg/ml} \mathrm{DABCO}$

Eukitt: [commercially available from Kindler (Freiburg, Germany)]

Aqua-poly/Mount: [commercially available from Polysciences (Eppelheim, Germany)]

\section{Electron microscopy stainings}

Karlsson and Schultz buffer: $0.36 \mathrm{~g} \mathrm{NaH} 2 \mathrm{PO} 4{ }^{*} \mathrm{H} 2 \mathrm{O}, 3.1 \mathrm{~g} \mathrm{Na} 2 \mathrm{HPO} 4{ }^{*} 2 \mathrm{H} 2 \mathrm{O}, 1 \mathrm{~g} \mathrm{NaCl}$ in $100 \mathrm{ml}$ distilled $\mathrm{H}_{2} \mathrm{O}, 25 \%(20 \mathrm{ml})$ glutaraldehyde, $16 \%(50 \mathrm{ml})$ formaldehyde, $30 \mathrm{ml}$ distilled $\mathrm{H}_{2} \mathrm{O}$

Epon: $21.4 \mathrm{~g}$ glycidether, $14.4 \mathrm{~g}$ Dodecenyl succinic anhydride (DDSA), $11.3 \mathrm{~g}$ methylacid anhydride (MNA) and 0.84ml DMP-30

Methylene blue: $1 \%$ sodium tetraborate and $1 \%$ methylene blue in $\mathrm{H}_{2} \mathrm{O}$

Azure II staining solution: $1 \%$ Azure II in $\mathrm{H}_{2} \mathrm{O}$

${ }^{*}=$ added freshly before use

\subsubsection{Mammalian cell lines}

In the course of this study different immortalized cell lines were used as listed in Table 2.1.5.

Table 2.1.5 Immortalized cell lines used for experiments.

\begin{tabular}{llll}
\hline Cell name & Tissue type & Tissue & Phenotype \\
\hline HEK-293T & Human & Kidney & Adherent \\
MSC80 & Mouse & Schwann cell & Adherent \\
\hline
\end{tabular}




\subsubsection{Plasmid constructs and primers}

For biochemical experiments different plasmid constructs and primers were used as shown in Table 2.1.6.

Table 2.1.6 Plasmid constructs and primers used in this study.

Fwd (forward), rev (reverse) and bp (base pair).

Plasmid constructs for transfection

\begin{tabular}{|c|c|}
\hline Vector plasmid & Constructed by \\
\hline p3xFLAG-CMV10-Fbxo7 wt & Siv Vingill \\
\hline p3xFLAG-CMV10-Fbxo7 $\Delta$ fbox & David Brockelt \\
\hline pCMV-myc-Skp1 & Judith Stegmüller \\
\hline pcDNA3-BCL ${ }^{X L}$ & Azad Bonni \\
\hline pSUPER- FBXO7 shRNA 1 & Siv Vingill \\
\hline pSUPER- FBXO7 shRNA 4 & Siv Vingill \\
\hline pSUPER- PSMA2 shRNA 1 & Siv Vingill \\
\hline pSUPER- PSMA2 shRNA 7 & Siv Vingill \\
\hline
\end{tabular}

Primers for genotyping

\begin{tabular}{lllc}
\hline Gene & Sequence & Size & Primer number \\
\hline floxed Fbxo7 (fwd) & 5'-tcagcatgggttgttaagcatctacta-3' & & 23988 \\
\hline floxed Fbxo7 (rev) & 5'-ggtctagatatctcgacataacttcgtata-3' & $600 \mathrm{bp}$ & 22243 \\
\hline wild type Fbxo7 (fwd) & 5'-gggctgtatgaaggaagtgctatt-3' & & 31214 \\
\hline wild type Fbxo7 (rev) & 5'-ccctgagagtgaagggtgctgttc-3' & 800bp & 31215 \\
\hline Cre (fwd) & 5'-cagggtgttataagcaatccc-3' & & 04193 \\
\hline Cre (rev) & 5'-cctggaaaatgcttctgtccg-3' & $250 \mathrm{bp}$ & 04192 \\
\hline
\end{tabular}

Primers for RT-PCR

\begin{tabular}{|c|c|c|}
\hline Gene & Sequence & Primer number \\
\hline IL-10 (fwd) & 5'-atgcaggactttaagggttacttg-3' & 33860 \\
\hline IL-10 (rev) & 5'-tagacaccttggtcttggagctta-3' & 33861 \\
\hline IL-1RA (fwd) & 5'-cagttccaccctgggaaggt-3' & 33858 \\
\hline IL-1RA (rev) & 5'-gagcggatgaaggtaaagcg-3' & 33859 \\
\hline$I L-1 \beta$ (fwd) & 5'-cctgcagctggagagtgtgga-3' & 33157 \\
\hline IL-1 $\beta$ (rev) & 5'-cccatcagaggcaaggaggaa-3' & 33158 \\
\hline IL-6 (fwd) & 5'-cggagaggagacttcacagagga-3' & 22936 \\
\hline IL-6 (rev) & 5'-ggagagcattggaaattgggg-3' & 22937 \\
\hline $\operatorname{Tnf-\alpha }(\mathrm{fwd})$ & 5'-gcggtgcctatgtctcagcc-3' & 22942 \\
\hline
\end{tabular}




\begin{tabular}{|c|c|c|}
\hline Tnf- $\alpha$ (rev) & 5'-tgaggagcacgtagtcgggg-3' & 22943 \\
\hline$I p-10$ (fwd) & 5'-ctgcctcatcctgctgggtctg-3' & 12127 \\
\hline Ip-10 (rev) & 5'-ataggctcgcagggatgatttcaagc-3' & 12128 \\
\hline Mcp1 (fwd) & 5'-ggtccctgtcatgcttctgggc-3' & 12125 \\
\hline Mcp1 (rev) & 5'-agcaggtgtcccaaagaagctgtagt- 3 ' & 12126 \\
\hline$\beta$-Actin (fwd) & 5 '-cgtgcgtgacatcaaagagaagctg -3 & 6956 \\
\hline$\beta$-Actin (rev) & 5'-ggatgccacaggattccatacccaag -3' & 6957 \\
\hline Fbxo7 (fwd) & 5'-tggaagtcaagtggtgtatac-3' & 31241 \\
\hline Fbxo7 (rev) & 5'-tactccagcagcaacgtagga-3' & 31242 \\
\hline Gapdh (fwd) & 5'-aggaacacggaaggccatg -3 ' & 4876 \\
\hline Gapdh (rev) & 5'-atggcccctctggaaagct -3' & 4877 \\
\hline
\end{tabular}

Target sequence of shRNA

\begin{tabular}{llll}
\hline shRNA & Functionality & Sequence & Target region (human) \\
\hline FBXO7 shRNA 1 & functional & 5'-gaagagaccttggcttcata-3' & $178-197 \mathrm{bp}$ \\
FBXO7 shRNA 4 & non-functional & 5'-gaaactacgcatcttccgac-3' & $1017-1037 \mathrm{bp}$ \\
PSMA2 shRNA 1 & non-functional & 5'-gctgactacattcagccc-3' $^{\prime}$ & $27-45 \mathrm{bp}$ \\
PSMA2 shRNA 7 & functional & 5'-ggattacttggctgccatagc-3' & $680-700 \mathrm{bp}$ \\
\hline
\end{tabular}

\subsection{Methods}

\subsubsection{Cell culture}

All experiments regarding cell culture were performed in a sterile hood under sterile conditions. The cells were kept for growth in a $37^{\circ} \mathrm{C}$ incubator, supplemented with $5 \%$ $\mathrm{CO}_{2}$

\subsubsection{Passage of immortalized cell lines}

Prior to splitting a respective cell line (HEK293T or MSC80), the according medium was pre-warmed at $37^{\circ} \mathrm{C}$ in a water bath. In addition sterile PBS and Trypsin/EDTA (TE) buffer were pre-warmed at $37^{\circ} \mathrm{C}$. The old medium was aspirated off a $10 \mathrm{~cm}$ cell culture dish and cells were washed with $10 \mathrm{ml}$ of sterile PBS. After aspirating off PBS, $2 \mathrm{ml}$ of TE was added and incubated for $2 \mathrm{~min}$ at $37^{\circ} \mathrm{C}$. $10 \mathrm{ml}$ of the respective medium (HEK293T medium or MSC80 medium) was added to the cells and were detached from the plate surface. The 
cell suspension was then transferred into a $15 \mathrm{ml}$ tube and centrifuged at $800 \mathrm{rpm}$ for $5 \mathrm{~min}$ at $4^{\circ} \mathrm{C}$. After centrifugation the supernatant was aspirated off and the cell pellet was resuspended in $5 \mathrm{ml}$ of appropriate medium. For the maintenance of the cell line, a 1:10 dilution of the cell suspension was plated into a new $10 \mathrm{~cm}$ cell culture dish, containing fresh medium. For experiments the cells were further plated in 6-well or 12-well plates. The cells were maintained at $37^{\circ} \mathrm{C}$ and $5 \% \mathrm{CO}_{2}$ until approximately $90 \%$ of confluency was reached. HEK293T cells had to be split every 3 days and MSC80 cells required splitting once a week. MSC80 cells were kindly provided by the group of PD Dr. Burkhard Gess.

\subsubsection{Transfection of cultured cells}

For the transfection of cultured cells with nucleic acids (DNA or RNA) two methods were used: HEK293T cells were transfected using the modified calcium phosphate method as previously described by Konishi et al. (Konishi et al., 2004), while MSC80 cells were transfected with the help of Lipofectamine ${ }^{\circledR} 2000$. HEK293T cells were split 24 hours prior to the transfection, whereas MSC80 cells were split two days in advance.

\subsubsection{Calcium phosphate transfection}

In order to transfect HEK293T cells in a 6-well plate, $0.5-2 \mu \mathrm{g}$ of plasmid DNA and $0.1 \mu \mathrm{g}$ of farnesylated-GFP (= transfection marker) were diluted in $90 \mu \mathrm{l}$ sterile $\mathrm{H}_{2} \mathrm{O}$ and were mixed with $10 \mu \mathrm{l}$ of $2.5 \mathrm{M} \mathrm{CaCl}_{2}$. $100 \mu \mathrm{l}$ of $2 x H B S S$ was added and mixed while introducing air bubbles to the solution. The mixture was incubated for $5 \mathrm{~min}$ at RT and $200 \mu \mathrm{l}$ of it was drop-wise added onto the cells. The transfected HEK293T cells were maintained for 3 days at $37^{\circ} \mathrm{C}$ and $5 \% \mathrm{CO}_{2}$ before lysis. The transfection efficiency was monitored, while detecting green fluorescent signals from the co-transfected GFP expression with a fluorescent microscope (Eclipse TS 100, Nikon).

\subsubsection{Lipofectamine ${ }^{\circledR} 2000$ transfection}

For the transfection of MSC80 cells in a $10 \mathrm{~cm}$ culture dish $6 \mu \mathrm{g}$ of plasmid DNA or shRNA together with $0.8 \mu \mathrm{g}$ of farnesylated-GFP (transfection marker and selection marker for FACS) and $0.6 \mu \mathrm{g}$ of the anti-apoptotic $\mathrm{Bcl}^{\mathrm{XL}}$ plasmid were co-transfected and diluted in $1.5 \mathrm{ml}$ of Opti-MEM. In an additional tube $15 \mu \mathrm{l}$ of Lipofectamine $\AA 2000$ was added to $1.5 \mathrm{ml}$ Opti-MEM. The two solutions were incubated for $5 \mathrm{~min}$ at RT prior to mixing. The mixture was incubated for $20 \mathrm{~min}$ at RT and then added drop-wise to the cells. About $20 \mathrm{~h}$ after 
transfection the medium was changed twice with fresh $15 \mathrm{ml}$ of culture medium. The cells were kept at $37^{\circ} \mathrm{C}$ and $5 \% \mathrm{CO}_{2}$ for 3 days before lysis or FACS sorting. Again, transfection efficiency was monitored while using the Eclipse TS 100 fluorescent microscope from Nikon.

\subsubsection{Biochemical techniques}

\subsubsection{Lysis of tissue}

For further biochemical experiments mice were scarified at the desired age and tissue or organs were immediately obtained. The fresh, non-fixated tissue was placed in a reagent tube, snap frozen in liquid nitrogen and stored at $-80^{\circ} \mathrm{C}$. In order to lyse, the tissue was added to a $2 \mathrm{ml}$ dounce or homogenizer containing ice-cold Triton $囚 X-100$ lysis buffer + proteinase inhibitors (freshly added). By mechanical force the sample was homogenized and incubated for $30 \mathrm{~min}$ on ice. Subsequently the lysate was centrifuged for $10 \mathrm{~min}$ at $11000 \mathrm{rpm}$ and $4^{\circ} \mathrm{C}$. The supernatant was collected in a new tube and the protein concentration was measured.

\subsubsection{Lysis of cultured cells}

Cultured cells were lysed for further biochemical experiments. Therefore proteinase inhibitors (aprotinin, DTT, leupeptin and pepstatin) were freshly added to the Triton $₫ X$ 100 lysis buffer or Co-IP buffer if a co-immunoprecipitation was followed. Throughout the lysis, cells and lysate were kept on ice. The culture medium was aspirated off and cells were once washed with cold PBS. After aspirating off PBS, 150 $\mu$ of the supplemented Triton®X-100 lysis buffer/Co-IP buffer was added to each well of a 6-well plate. Using a cell scraper attached cells were removed from the plate. The cell lysate was collected in a $1.5 \mathrm{ml}$ tube and incubated for $30 \mathrm{~min}$ on ice. Subsequently the lysate was centrifuged at $11000 \mathrm{rpm}$ for $10 \mathrm{~min}$ at $4^{\circ} \mathrm{C}$. The supernatant was transferred into a new tube and the pellet discarded. For further experiments the samples were kept on ice.

\subsubsection{Measurement of protein concentration}

To measure the protein concentration either a Bradford assay or a Lowry assay was performed.

For a Bradford assay (Bradford, 1976) the Bio-Rad Bradford reagent was used in a 1:5 dilution with PBS. In order to obtain a standard curve $2,4,6,8$, and $10 \mu \mathrm{g}$ of bovine 
serum albumin (Ip et al.) was diluted in $1 \mathrm{ml}$ of Bradford/PBS solution, including a blank. Further on $2 \mu \mathrm{l}$ of the desired sample (cell lysate or tissue lysate) was added to $1 \mathrm{ml}$ of Bradford/PBS solution. The protein concentration was measured with a spectrophotometer, detecting the shift in absorbance at $595 \mathrm{~nm}$ wavelength. This reflected the binding of protein to Coomassie Brilliant Blue G-250. The BSA measurement resulted in a standard curve, which was used to calculate the protein concentration of the samples of interest.

For a Lowry assay (Lowry et al., 1951) reagents from Bio-Rad were used. $0.5 \mu$ of protein assay reagent $S$ were added to $24.5 \mu \mathrm{l}$ of reagent $A$. The $25 \mu \mathrm{l}$ of solution mix was pipetted into a 96-well plate, further adding $5 \mu \mathrm{l}$ of the lysate of interest and $200 \mu$ l of reagent $B$. Additionally, a standard curve was generated using $0.2,0.5,0.8,1.0$ and $1.5 \mu \mathrm{g}$ of BSA as well as a blank. Afterwards the plate was inserted into the Tecan microplate reader, in which it was incubated for $15 \mathrm{~min}$ at $26^{\circ} \mathrm{C}$. Biuret and Folin-Ciocalteu reaction allowed for the measuring of absorption at $750 \mathrm{~nm}$ wavelength. Using the resulting standard protein curve, the concentration of the lysate of interest was determined. Excel from Microsoft Office was used for calculations.

\subsubsection{Co-Immunoprecipitation (Co-IP)}

In order to investigate the interaction of two proteins a co-immunoprecipitation assay was performed. Cells were transfected with plasmids expressing tagged proteins. Two days after the transfection, the cells were lysed with Co-IP buffer supplemented with protease inhibitors. As a control of expression $100 \mu \mathrm{g}$ of input from the cell lysate was mixed with SDS sample buffer $(4 x)$ and heated at $95^{\circ} \mathrm{C}$ for $5 \mathrm{~min}$. The sample was shortly spun down and either directly pipetted onto the SDS-PAGE or stored at $-20^{\circ} \mathrm{C}$ until usage. For the coimmunoprecipitation $1 \mathrm{mg}$ of cell lysate was incubated for $2-3 \mathrm{~h}$ with $0.6 \mu \mathrm{g}$ of either flag- or myc-antibody at $4^{\circ} \mathrm{C}$ on a rotator. In the meantime, protein A-sepharose beads, which bind to rabbit and mouse IgGs, were washed 3 times with Co-IP buffer and stored in equal amount of Co-IP buffer. Following, the sample was mixed with $15 \mu$ l of protein Asepharose beads and incubated for $1 \mathrm{~h}$ at $4^{\circ} \mathrm{C}$ on a rotator. The beads were then washed 2-3 times with lysis buffer while incubating for $5 \mathrm{~min}$ at $4^{\circ} \mathrm{C}$ and centrifuging in between for $1 \mathrm{~min}$ at $11000 \mathrm{rpm}$. The beads were then subjected to a quick wash with $500 \mu \mathrm{l}$ of RIPA buffer and centrifuged again. In the final wash step PBS was added and after centrifugation a small volume of PBS was left and mixed with $10 \mu \mathrm{l}$ of SDS samples buffer $(4 x)$. The sample was boiled at $95^{\circ} \mathrm{C}$ for $5 \mathrm{~min}$, shortly spun down and ran on an SDSPAGE for subsequent western-blot analysis. 


\subsubsection{SDS-PAGE and western-blot}

To separate proteins according their size an SDS-PAGE method was used as descripted previously (Weber and Osborn, 1969). The polyacrylamide gel, consisting of an upper gel for stacking (3.9\% of acrylamide) and a lower gel for separation $(10 \%$ or $12 \%$ of acrylamide), were prepared in a gel casting system from Bio-Rad. The gel was prepared according to the following scheme:

Table 2.2.1 Recipe for SDS-PAGE gels of different acrylamide percentage.

\begin{tabular}{lccc}
\hline & Stacking gel & \multicolumn{2}{c}{ Separating gel } \\
\% of acrylamide & $3.9 \%$ & $10 \%$ & $12 \%$ \\
\hline Acrylamide/bis-acrylamide & $0.65 \mathrm{ml}$ & $2.5 \mathrm{ml}$ & $3 \mathrm{ml}$ \\
Upper buffer & $1.25 \mathrm{ml}$ & - & - \\
Lower buffer & - & $1.875 \mathrm{ml}$ & $1.875 \mathrm{ml}$ \\
$\mathrm{H}_{2} \mathrm{O}$ & $3.05 \mathrm{ml}$ & $3.125 \mathrm{ml}$ & $2.625 \mathrm{ml}$ \\
Ammonium persulfate $\mathbf{( 1 0 \% )}$ & $30 \mu \mathrm{l}$ & $30 \mu \mathrm{l}$ & $30 \mu \mathrm{l}$ \\
Tetramethylethylenediamine & $3 \mu \mathrm{l}$ & $3 \mu \mathrm{l}$ & $3 \mu \mathrm{l}$ \\
\hline
\end{tabular}

The separating gel was cast first by pouring the gel mixture into the gel casting system. In addition a layer of isopropanol was added onto the separating gel. After polymerization the isopropanol was discarded and $\mathrm{H}_{2} \mathrm{O}$ was used for washing. Afterwards the stacking gel was loaded and a 10-well comb inserted. Once the complete polyacrylamide gel was polymerized the gel was inserted into the Trans-Blot $₫$ Cell (Bio-Rad) and running buffer was added. The previously boiled lysates as well as a protein ladder were loaded into the wells of the gel. Proteins were separated through electrophoresis at $35 \mathrm{~mA}$ per gel for $1 \mathrm{~h}$. Subsequently the proteins were transferred onto a nitrocellulose membrane, again using the Trans-Blot $₫$ Cell which contained transfer buffer. For the transfer $220 \mathrm{~mA}$ were applied for $2 \mathrm{~h}$ at ${ }^{\circ} 4 \mathrm{C}$. After transfer the nitrocellulose membrane was rinsed with PBST and then blocked in blocking buffer (4\% milk in PBST) for 20min at RT on a shaker. The membrane was then rinsed with PSBT and incubated in antibody solution containing the desired dilution of primary antibody for $3 \mathrm{~h}$ or over night at $4^{\circ} \mathrm{C}$ on a shaker. A 3 times washing step with PBST for 10min each on a shaker was followed. The secondary HRPconjugated antibody was diluted in blocking buffer and was incubated for $1 \mathrm{~h}$ at RT on a shaker. Followed by washing thrice with PBST, the membrane was incubated in enhanced chemoluminescent $(E C L)$, a horseradish peroxidase substrate by Thermo Fischer Scientific. Quickly after, the membrane was placed into a membrane developing system by Biometra, which recorded the luminescent signal and captured it as a digital picture. Western blot pictures were edited using Adobe Photoshop and Illustrator. 


\subsubsection{FACS and proteasome activity assay}

The proteasome activity assay was carried out according to a modified method by Kisselev and Goldberg et al. (Kisselev and Goldberg, 2005). The assay was performed with cell lysates of transfected MSC 80 cells. MSC 80 cells were transfected with shRNA and co-transfected with GFP. The cells were washed with PBS and detached from the $10 \mathrm{~cm}$ cell plate, while using a cell scraper. Afterwards the cells were centrifuged for $5 \mathrm{~min}$ at 200rpm. The cell pellet was resuspended in $1 \mathrm{ml}$ of cold PBS and sorted via FACS cytometer (FACS Calibur, BD). The sorted cells were lysed in proteasome lysis buffer, containing the mild detergent digitonin. $100 \mu \mathrm{g}$ BSA and $100 \mu \mathrm{M}$ of fluorogenic peptide substrate Suc-LLVY-AMC was pipetted in triplicates per sample into a 96-well plate containing proteasome assay buffer and was incubated for $10 \mathrm{~min}$ at $37^{\circ} \mathrm{C}$. Subsequently, $12 \mu \mathrm{g}$ of cell lysate was added per well (total volume $200 \mu \mathrm{l}$ ). The fluorescent signal was measured at 355nm excitation and 460nm emission every half an hour at $0,30,60,90$ and 120min using the Tecan mircoplate reader. In-between measurements the 96-well plate was incubated at $37^{\circ} \mathrm{C}$ and protected from light. In order to verify the knockdown induced by shRNA, one part of the cell lysate was subjected to western-blot analysis.

\subsubsection{Myelin purification}

Myelin was purified from brain samples by density centrifugation using a sucrose gradient. According to Norton and Poduslo's previously described method (Norton and Poduslo, 1973a, b), (Larocca and Norton, 2007) the samples were first homogenized in 0.32M sucrose containing protease inhibitors and using the ultraturrax. At all times samples were kept on ice or at $4^{\circ} \mathrm{C}$. $200 \mu \mathrm{l}$ of the homogenate was stored at $-80^{\circ} \mathrm{C}$ for later experiments. The remaining homogenate was carefully added onto $0.85 \mathrm{M}$ sucrose containing protease inhibitors in an Ultra-Clear Tube (Beckman no. 344060). Afterwards the sucrose gradient was centrifuged for $30 \mathrm{~min}$ at $75000 \mathrm{xg}$ in the Beckman XL-70 ultracentrifuge, using a swing out rotor (SW40Ti Beckman rotor, 24400rpm). The interphase was transferred into a new tube and washed by adding water. After centrifugation at $75000 x \mathrm{xg}$ for $15 \mathrm{~min}$, an osmotic shock was induced by resuspending the pellet in $\mathrm{H}_{2} \mathrm{O}$, incubated for $15 \mathrm{~min}$ and centrifuged at $12000 x$ for $15 \mathrm{~min}$ (SW40Ti Beckman rotor, 9700 rpm). This osmotic shock was repeated once more. Subsequently the pellet was resuspended in $0.32 \mathrm{M}$ sucrose. Layering the resuspended pellet over $0.85 \mathrm{M}$ sucrose generated a second sucrose gradient. After centrifugation for $30 \mathrm{~min}$ at $75000 \mathrm{xg}$, the interphase was collected in a new tube, $\mathrm{H}_{2} \mathrm{O}$ was added and centrifuged at $75000 \mathrm{xg}$ for $15 \mathrm{~min}$. This final pellet consisted of 
enriched myelin and was resuspended in $200 \mu$ l of TBS containing protease inhibitors and was sored at $-80^{\circ} \mathrm{C}$. Myelin purification from brain tissue was performed by Ramona Jung (Group of PD, Dr. Hauke Werner department of Prof. Dr. Klaus-Armin Nave, Max-Planck Institute of Experimental Medicine, Götttingen).

For myelin purification from the sciatic nerve, samples were homogenized in $0.29 \mathrm{M}$ sucrose containing protease inhibitors using an ultraturrax. For further experiments $100 \mu \mathrm{l}$ of lysate were stored at $-80^{\circ} \mathrm{C}$. Similar to the sucrose gradient described before, the lysate was add onto $0.85 \mathrm{M}$ sucrose in an Ultra-Clear Tube (Beckman no. 344062). The samples were centrifuged as well for 30min at 75000xg (26900rpm) but in a TH660 Beckman rotor. Again the interphase was washed with water as described before and only one osmotic shock was induced. The pellet was resuspended in $100 \mu$ l of TBS containing protease inhibitors and stored at $-80^{\circ} \mathrm{C}$. Myelin purification from sciatic nerves was conducted together with Katja Lüders (Group of PD, Dr. Hauke Werner department of Prof. Dr. KlausArmin Nave, Max-Planck Institute of Experimental Medicine, Göttingen).

\subsubsection{Silver staining of SDS-PAGE}

In order to detect robust changes in protein abundance of purified myelin within and between genotypes, samples were subjected to SDS-PAGE analyses. $12 \%$ gels were prepared as previously described and $0.5 \mu \mathrm{g}$ of purified CNS myelin or $5 \mu \mathrm{g}$ of PNS myelin was loaded onto the gels and ran for 1 hour at 200V. The gels were incubated in $40 \%$ ethanol $+10 \%$ acetic acid over night at $4^{\circ} \mathrm{C}$. On the next day a silver impregnation was performed according to the Pierce $®$ Silver staining kit. The gels were incubated twice $5 \mathrm{~min}$ in $10 \%$ ethanol and twice washed for $5 \mathrm{~min}$ in water. Next, the gels were incubated in sensitizer solution for $1 \mathrm{~min}$, washed twice for $1 \mathrm{~min}$ in $\mathrm{H}_{2} \mathrm{O}$ and then incubated for $30 \mathrm{~min}$ in working solution. After two quick washes in water for $20 \mathrm{sec}$, the developer solution was immediately added and incubated until bands appeared. The solution was replaced with stop solution ( $5 \%$ acetic acid), briefly washed, replaced with new stop solution and incubated for $10 \mathrm{~min}$. Finally the gels were washed with $\mathrm{H}_{2} \mathrm{O}$ and stored at $4{ }^{\circ} \mathrm{C}$.

\subsubsection{Quantitative Mass spectrometry}

The quantitative mass spectrometry was conducted by . Dr olaf Jahn from the proteomics department of the Max-Planck institute for Experimental Medicine. Here 10 $\mu$ g of purified myelin was lysed and processed according to a filter-aided sample preparation (FASP) protocol ((Wisniewski et al., 2009) and further modified as described by Distler et al 
(Distler et al., 2014; Distler et al., 2016). The samples were then subjected to LC-MS analysis, in which a nanoscale reversed-phase UPLC separation of tryptic peptides was performed. Therefore, a nanoAcquity UPLC system was used, equipped with a Symmetry C18 $5 \mu \mathrm{m}, 180 \mu \mathrm{m} \times 20 \mathrm{~mm}$ trap column and a HSS T3 C18 $1.8 \mu \mathrm{m}, 75 \mu \mathrm{m} \times 250 \mathrm{~mm}$ analytical column maintained at $45^{\circ} \mathrm{C}$. Injected peptides were trapped for $4 \mathrm{~min}$ at a flow rate of $8 \mu \mathrm{l} / \mathrm{min} 0.1 \%$ trifluoroacetic acid and then separated over $120 \mathrm{~min}$ at a flow rate of 300nl/min. The LC-MS data were analyzed while using Waters ProteinLynx Global Server version (Li et al., 2009). To identify proteins, a custom database was used and additionally the false discovery rate (FDR) that was set to $1 \%$ threshold was determined. The freely available software ISOQuant (http://www.isoquant.net) was used for post-identification analysis and the stringency of identified protein was increased by considering only peptides with a minimum length of six amino acids, which were identified with scores above or equal to 5.5 in at least two runs (Distler et al., 2014; Distler et al., 2016; Kuharev et al., 2015). The final analysis was done using Microsoft Excel and diagrams were prepared with GraphPad Prism.

\subsubsection{Transgenic mouse line}

All mice used for this study were kept and bred in the mouse facility of the Max-PlanckInstitute for Experimental Medicine in Göttingen or the mouse facility of the RWTH university hospital in Aachen. Experiments were performed according to the guidelines for German animal welfare and were approved by the "Verbraucherschutz und Lebensmittelsicherheit" of Lower Saxony, Germany (33.11.42502-04-11/0632). Mice were scarified either by cervical dislocation or by perfusion under anesthesia.

\subsubsection{Generation of conditional FBXO7 mouse line}

Homozygous conditional Fbxo $7^{f / / f l}$ mice (Vingill et al., 2016), in which exon 4 was flanked by loxP sites, were either mated with heterozygous $\mathrm{Cnp}^{\mathrm{Cre} /+}$ mice (Lappe-Siefke et al., 2003) or with heterozygous Tamoxifen-inducible Plp $1^{\text {CreERT2/+ }}$ mice (Leone et al., 2003). In these conditional knockout mice FBXO7 was deleted from myelinating cells.

Cnp- and well as Plp-driver line were provided by Prof $\mathrm{Dr}$ Klaus-Armin Nave (Neurogenetics department Max-Planck Institute of Experimental Medicine Göttingen). 


\subsubsection{Tamoxifen induced knock down}

Plp $1^{\text {CreERT2/+ }}$ mice were bred with $F b x O 7^{f / f l}$ mice to generate conditional Plp $1^{\mathrm{CreERT} 2 /+} ;$ FbXO $7^{\mathrm{fl/fl}}$ mice. In these inducible mice, Cre recombinase expression will only be activated upon Tamoxifen injection. Hence, $100 \mu \mathrm{l}$ of $20 \mathrm{mg} / \mathrm{ml}$ Tamoxifen dissolved in corn oil was intraperitoneally injected in mice for 5 consecutive days. The total amount of injected Tamoxifen was $10 \mathrm{mg}$. Injection of mice and thereby the induction of the conditional knock out of the Fbxo7 gene was performed at two months of age, when myelination was completed. Control mice lacking the Plp1-CreERT2 insertion were also injected with the same amount of Tamoxifen.

\subsubsection{Isolation of genomic DNA}

Tail biopsies from mice were used to isolate genomic DNA for subsequent genotyping analysis. The tissue was lysed in $200 \mu$ l of tail lysis buffer with freshly added $3 \mu \mathrm{g} / \mathrm{ml}$ Proteinase $\mathrm{K}$ and $0.2 \mathrm{M} \mathrm{NaCl}$ for minimum $2 \mathrm{~h}$ at $55^{\circ} \mathrm{C}$. Once the tail was completely lysed, the sample was centrifuged for $10 \mathrm{~min}$ at $14000 \mathrm{rpm}$ and RT. The supernatant was transferred into a new tube and mixed with $500 \mu$ of $100 \%$ ethanol and again centrifuged for $10 \mathrm{~min}$ at $14000 \mathrm{rpm}$ and RT. The supernatant was discarded and the pellet of precipitated DNA was washed with $300 \mu$ l of $70 \%$ ethanol. Again the sample was centrifuged for $3 \mathrm{~min}$ at $14000 \mathrm{rpm}$ and RT. After aspirating off the ethanol, the precipitated DNA pellet was air-dried at RT for $15 \mathrm{~min}$ and then dissolved in $200 \mu \mathrm{l}$ of sterile $\mathrm{H}_{2} \mathrm{O}$. The isolated genomic DNA was then used for genotyping and stored at $-20^{\circ} \mathrm{C}$.

\subsubsection{Genotyping}

For each sample 3 PCR reactions were set up. The PCR reaction was performed according to Kary Mullis first described and over the years modified protocol (Saiki et al., 1985). Using the Cre, wild type Fbxo7 as well as the floxed Fbxo7 primer pairs, the genotype of the conditional knockout mice was determined. For genotyping the GoTaq® DNA polymerase system was used and PCR samples were run on a $1 \%$ agarose gel (in 2xTAE buffer) containing 1:100000 of GelRed for visualization. Pictures were obtained with the UV transilluminator system from Biometra and edited using Image J, as well as Adobe lllustrator. 
The PCR reaction was pipette the following:

Table 2.2.2 Recipe for PCR reaction.

\begin{tabular}{ll}
\hline PCR reaction & \\
\hline $\mathbf{1 7 \mu \mathrm { l }}$ & $\mathrm{H}_{2} \mathrm{O}$ \\
$\mathbf{5} \boldsymbol{\mu l}$ & $5 \times$ GoTaq $\circledast$ buffer \\
$\mathbf{0 . 4} \boldsymbol{\mu l}$ & dNTPs $(2.5 \mathrm{mM})$ \\
$\mathbf{1} \boldsymbol{\mu l}$ & forward primer $(10 \mathrm{pmol} / \mu \mathrm{l})$ \\
$\mathbf{1} \boldsymbol{\mu l}$ & reverse primer $(10 \mathrm{pmol} / \mu \mathrm{l})$ \\
$\mathbf{0 . 1} \boldsymbol{\mu l}$ & GoTaq® DNA polymerase \\
$\mathbf{0 . 5 \mu \mathrm { l }}$ & genomic DNA \\
\hline
\end{tabular}

The PCR reaction was run according to the following program:

Table 2.2.3 Set up of PCR program for genotyping.

\begin{tabular}{llll}
\hline \multicolumn{4}{l}{ Fbxo7 PCR genotyping program } \\
\hline Denaturation & $95^{\circ} \mathrm{C}$ & $3 \mathrm{~min}$ & \\
Denaturation & $95^{\circ} \mathrm{C}$ & $30 \mathrm{sec}$ & $30 / 28^{*} \mathrm{Cycles}$ \\
Annealing & $55^{\circ} \mathrm{C} / 53^{\circ} \mathrm{C}^{*}$ & $45 \mathrm{sec} / 30 \mathrm{sec}^{*}$ & \\
Elongation & $72^{\circ} \mathrm{C}$ & $45 \mathrm{sec}$ & \\
Final elongation & $72^{\circ} \mathrm{C}$ & $5 \mathrm{~min}$ & \\
Final hold & $16^{\circ} \mathrm{C}$ & Pause & \\
\hline
\end{tabular}

${ }^{*}=$ specifically for the wild-type Fbxo7 primer pair

\subsubsection{RNA isolation}

Total RNA was isolated for further analysis of mRNA expression levels. Prior to RNA isolation, surface areas were thoroughly cleaned with ethanol and only filter pipette tips were used. Throughout isolation the samples were always kept on ice. $1 \mathrm{~mL}$ of Trizol@ Reagent was added to mouse tissue and homogenized in a $2 \mathrm{ml}$ glass dounce. $200 \mu \mathrm{l}(1 / 5$ of Trizol ${ }^{\circledR}$ Reagent volume) of chloroform was added and vortexed for $15 \mathrm{sec}$. Next, the sample was incubated for $15 \mathrm{~min}$ on ice and then centrifuged for $15 \mathrm{~min}$ at $14000 \mathrm{rpm}$ and $4^{\circ} \mathrm{C}$. The topmost layer after centrifugation containing isolated RNA was transferred into a new tube and mixed with equal volume of isopropanol followed by vortexing. The sample was incubated over night at $-80^{\circ} \mathrm{C}$ and on the consecutive day was centrifuged for $15 \mathrm{~min}$ at $14000 \mathrm{rpm}$ and $4^{\circ} \mathrm{C}$. The supernatant was discarded and the RNA pellet was washed with $100 \%$ ethanol, centrifuged and washed with $70 \%$ of ethanol. Next, ethanol was removed, the pellet air-dried and dissolved in $50 \mu \mathrm{l}$ of $10 \mathrm{mM}$ Tris/ $1 \mathrm{mM}$ EDTA, pH 7.5. The concentration of RNA was measured, while using a NanoQuant Tecan plate reader. 


\subsubsection{6 cDNA synthesis}

The previously isolated RNA was further used for cDNA synthesis. Therefore the SuperScript ${ }^{\circledR}$ III First strand synthesis kit was used according to the following scheme:

Table 2.2.4 Protocol for cDNA synthesis I.

\begin{tabular}{ll}
\hline \multicolumn{2}{l}{ cDNA synthesis I } \\
\hline $\mathbf{3 \mu \mathrm { g }}$ & isolated RNA \\
$\mathbf{1} \boldsymbol{\mu l}$ & $50 \mu \mathrm{M}$ Oligo dT \\
$\mathbf{1} \boldsymbol{\mu l}$ & $10 \mathrm{mM}$ dNTP \\
\hline $\mathbf{1 0 \mu \mathrm { I }}$ & $\mathrm{ddH}_{2} \mathrm{O}$ (fill up to final volume) \\
\hline
\end{tabular}

The mixture was incubated for $5 \mathrm{~min}$ at $65^{\circ} \mathrm{C}$ and $1 \mathrm{~min}$ on ice. In a second step, the reverse transcriptase mixture was prepared:

Table 2.2.5 Procedure for cDNA synthesis II.

\begin{tabular}{ll}
\hline \multicolumn{2}{l}{ cDNA synthesis II } \\
\hline $\mathbf{2} \boldsymbol{\mu l}$ & $10 \times$ reverse transcriptase buffer \\
$\mathbf{4} \boldsymbol{\mu l}$ & $25 \mathrm{mM} \mathrm{MgCl}_{2}$ \\
$\mathbf{2} \boldsymbol{\mu l}$ & $0.1 \mathrm{M} \mathrm{DTT}$ \\
$\mathbf{1} \boldsymbol{\mu l}$ & RNAse OUT \\
$\mathbf{1} \boldsymbol{\mu l}$ & SuperScript reverse transcriptase \\
$\mathbf{1 0} \boldsymbol{\mu l}$ & $\mathrm{ddH}_{2} \mathrm{O}$ (fill up to final volume) \\
\hline
\end{tabular}

Both mixtures were combined and incubated for $50 \mathrm{~min}$ at $50^{\circ} \mathrm{C}$. The reaction was stopped at $85^{\circ} \mathrm{C}$ for $5 \mathrm{~min}$ and followed by an incubation on ice and the addition of $1 \mu \mathrm{l}$ of RNAseH. The samples were incubated for $20 \mathrm{~min}$ at $37^{\circ} \mathrm{C}$ and stored at $-20^{\circ} \mathrm{C}$ until usage for RT-PCR.

\subsubsection{Quantitative real-time (RT) PCR}

To amplify target sequences and quantify the amount of template at the same time, a realtime PCR was conducted. Therefore the Power SYBR Green system was used and prepared as described in table 2.2.6. The primers used are listed in table 2.1.6. The quantitative RT-PCR was monitored via a PCR thermo cycler. For analysis of the obtained data, Microsoft Excel was used applying the Livak - delta delta $\mathrm{C}_{\mathrm{T}}$ method for quantification. $\beta$-Actin was used as a reference gene and the average of all control samples was also used as a reference. 
First the $\mathrm{C}_{\mathrm{T}}$ value of the target gene was normalized to the $\mathrm{C}_{\mathrm{T}}$ value of the reference gene: $\Delta \mathrm{C}_{\mathrm{T}}$ (control sample) $=\mathrm{C}_{\mathrm{T}}$ (ctrl sample, target gene) $-\mathrm{C}_{\mathrm{T}}$ (ctrl sample, ref gene)

$\Delta \mathrm{C}_{\mathrm{T}}$ (test sample) $=\mathrm{C}_{\mathrm{T}}$ (test sample, target gene) $-\mathrm{C}_{\mathrm{T}}$ (test sample, ref gene)

Then the $\Delta \mathrm{C}_{\mathrm{T}}$ of the test sample was normalized to the $\Delta \mathrm{C}_{\mathrm{T}}$ of the control sample:

$\Delta \Delta \mathrm{C}_{\mathrm{T}}=\Delta \mathrm{C}_{\mathrm{T}}$ (test sample) $-\Delta \mathrm{C}_{\mathrm{T}}$ (control sample)

Finally the fold difference in expression was calculated:

normalized expression ration $=2^{-\Delta \Delta C}{ }_{T}$

Further on GraphPad Prism was used for generating graphs and statistical analysis.

Table 2.2.6 Protocol for RT-PCR.

\begin{tabular}{ll}
\hline RT-PCR & \\
\hline $\mathbf{5 \mu l}$ & 2x SYBR Green \\
$\mathbf{0 . 1} \boldsymbol{\mu l}$ & $1 \mathrm{pmol}$ forward primer \\
$\mathbf{0 . 1} \boldsymbol{\mu l}$ & $1 \mathrm{pmol}$ reverse primer \\
$\mathbf{0 . 1 4} \boldsymbol{\mu l}$ & $\mathrm{cDNA}$ \\
\hline $\mathbf{1 0 \mu l}$ & $\mathrm{ddH}_{2} \mathrm{O}$ (fill up to final volume) \\
\hline
\end{tabular}

\subsubsection{Electrophysiological measurement}

In order to investigate the propagation of action potentials along nerve fibers on anesthetized animals, electrophysiological recordings were conducted. The analysis was performed by stimulation of the nervus ischiadicus and the nervus tibialis posterior at the proximal site of the foramen ischiadicum. At the distal area of the knee, a needle electrode was injected and the nerves were stimulated for $0.1 \mathrm{~ms}$. By doing so, the delay between initiating an action potential and the response of the muscles was measured. The nerve conductance velocity (NCV) was calculated, by measuring the time between proximal stimulation and distal recording of a given distance. Another measurement is the compound muscle action potential (CMAP), which was calculated from the amplitude of the highest and lowest value. Further on the distal motor latency (DML) was measured from the delay between initiating a stimulus and the evoked potential. Data retrieved were analyzed using Microsoft Excel and GraphPad Prism. This experiment was performed by Dr. Robert Fledrich (Group of Prof. Dr. Michael W. Sereda Max-Planck Institute of Experimental Medicine, Göttingen): 


\subsubsection{Histological analysis}

\subsubsection{Transcardial perfusion and fixation}

Mice were anesthetized by intraperitoneal injection of 10\% Ketamine (CP Pharma) and $5 \%$ Xylazine (Medistar Arzneimittelvertrieb $\mathrm{GmbH}$ ), using $100 \mu \mathrm{l}$ per $10 \mathrm{~g}$ of weight. Reflexes were tested at all four paws. Once all signs of reflexes were suppressed, the thorax was opened by a long insecure along the diaphragm and sternum, exposing the heart. A small G21 butterfly canula, which was connected to a peristaltic pump (rate set to $12 \mathrm{rpm}$ ), was inserted into the left ventricle of the heart and simultaneously the right atrium was cut. First $10 \mathrm{ml}$ sterile PBS was pumped into the vascular system to clear blood from body. Subsequently, the tissue was fixed with $10 \mathrm{ml}$ of $4 \%$ PFA for perfusion or with Karlsson and Schultz buffer, if the tissue was subjected to electron microscopic analysis. Organs were dissected and incubated in $4 \%$ PFA for tissue over night at $4^{\circ} \mathrm{C}$ and then further post-fixed, depending on the experimental procedure.

\subsubsection{Immunohistochemistry on cryo-sections}

The previously dissected and PFA-fixed sample was incubated in 30\% sucrose/PBS over night at $4^{\circ} \mathrm{C}$, embedded it OCT (Tissue Tek, Sakura, Torrance, USA) and stored at $-80^{\circ} \mathrm{C}$. For sectioning, the samples were cut into $10 \mu \mathrm{m}$ thin sagittal or coronal sections, as per experimental design, using a cryostat (CM3050 S, Leica). The sections were either mounted onto glass slides or stored in PBS $+0.02 \%$ of $\mathrm{NaN}_{3}$ as free-floating sections at $4^{\circ} \mathrm{C}$.For fluorescent staining, cryo-sections were washed twice $5 \mathrm{~min}$ with PBST on a shaker at RT, permeabilized with $0.5 \%$ Triton $® X-100$ in PBS for $30 \mathrm{~min}$ and then blocked for $1 \mathrm{~h}$ in blocking solution. After a $5 \mathrm{~min}$ wash in PBST the samples were incubated over night at $4^{\circ} \mathrm{C}$ in antibody solution containing the respective dilution of primary antibody. Next, the samples were washed thrice for $10 \mathrm{~min}$ in PBST and further incubated for $1 \mathrm{~h}$ at RT in a secondary antibody conjugated to a fluorescent dye, diluted in antibody solution and nuclei staining dye DAPI (1:8000). The samples were washed three times for $5 \mathrm{~min}$ in PBST at RT. In case of free-floating sections, the samples were mounted on a glass slide and shortly dried at $37^{\circ} \mathrm{C}$ for $15 \mathrm{~min}$. Cryo-sections were mounted using Mowiol mounting medium and stored at $4^{\circ} \mathrm{C}$. Pictures were taken using the fluorescent microscope BX51 from Olympus and for quantification ImageJ was used. In case of a double staining, nonspecific background staining was removed by using the SpectralUnmixing plugin generated by Joachim Walter. Pictures were further stitched by applying the plugin from Preibisch et al. (Preibisch et al., 2009) and quantified using a customized macro written by Dr. Miso Mitkovski. This customized macro quantified the area that is stained in pixel, as 
well as the total area of the sample, in order to calculate the percentage of area stained. Statistical analysis and graphs were performed using GraphPad Prism.

\subsubsection{Immunohistochemistry on paraffin-sections}

Post-fixation of mice tissue that was destined for paraffin embedding, was incubated over night in $4 \%$ PFA for tissue at $4^{\circ} \mathrm{C}$ after perfusion. The samples were then embedded in paraffin using an automated embedding machine (HMP110, MICROM) and following the protocol was applied:

$\begin{array}{cc}\text { Reagent } & \text { Duration } \\ 50 \% \text { ethanol } & 1 \mathrm{~h} \\ 70 \% \text { ethanol } & 2 \times 2 \mathrm{~h} \\ 96 \% \text { ethanol } & 2 \times 1 \mathrm{~h} \\ 100 \% \text { ethanol } & 2 \times 1 \mathrm{~h} \\ \text { isopropanol } & 1 \mathrm{~h} \\ \text { xylene } & 2 \times 2 \mathrm{~h} \\ \text { paraffin } & 2 \times 2 \mathrm{~h}\end{array}$

The tissue embedded in paraffin, was cut into $5 \mu \mathrm{m}$ sagittal sections using a microtome (HM 430, Thermo Fischer Scientific), mounted on glass slides and air-dried at RT. Paraffin-sections were stained using the $\mathrm{LSAB}_{2}$ detection system. Here, sections were deparaffinized by heating for $10 \mathrm{~min}$ at $60^{\circ} \mathrm{C}$, followed by $2 \times 10 \mathrm{~min}$ incubation in xylene and $10 \mathrm{~min}$ in a xylene/isopropanol mixture (1:2). The samples were further incubated in $100 \%$, $90 \%, 70 \%$ and finally $50 \%$ of ethanol for $5 \mathrm{~min}$, respectively. Lastly, tissue was hydrated in $\mathrm{ddH}_{2} \mathrm{O}$ for $5 \mathrm{~min}$. For DAB staining, the sections were incubated in citrate buffer for $5 \mathrm{~min}$ at RT and further boiled in citrate buffer for $10 \mathrm{~min}$ in a microwave oven to un-mask the antigen and permeabilize the tissue. The samples were given $20 \mathrm{~min}$ at RT to cool down, followed by incubation in Tris buffer $+2 \%$ milk for $5 \mathrm{~min}$. Afterwards the slides were placed into a Shandon cover plate by Thermo Fischer Scientific, allowing an even distribution of solution on the slide. Since the secondary antibody was conjugated with HRP (horseradish peroxidase), the slides were incubated for 5 min with $3 \% \mathrm{H}_{2} \mathrm{O}_{2}$ to inactivate endogenous peroxidase. The samples were rinsed with Tris-buffer + milk and then blocked in $100 \mu \mathrm{l}$ blocking buffer for $10 \mathrm{~min}$ at RT. Subsequently, the samples were incubated in primary antibody diluted in BSA/PBS at $4^{\circ} \mathrm{C}$ over night. The next day, the slides were rinsed with Tris buffer + milk and incubated for $10 \mathrm{~min}$ at RT in $100 \mu$ of a bridging, biotinylated antibody of the $\mathrm{LSAB}_{2}$ kit (Dako). Again, the slides were washed with Tris buffer + milk and then incubated in $100 \mu$ of horseradish peroxidase streptavidin 
complex for $10 \mathrm{~min}$ at RT (LSAB 2 kit). The slides were washed with Tris buffer, disassembled from the Shandon cover plate and placed in Tris buffer. Diaminobenzidine (Veitenhansl et al.), the substrate of HRP, was applied onto the slides using a DAB kit and incubated for 5-10 min. The sections were washed twice with $\mathrm{H}_{2} \mathrm{O}$ for each $5 \mathrm{~min}$ and then counter-stained in hemalaun for 30 seconds. The sections were washed with distilled $\mathrm{H}_{2} \mathrm{O}$, shortly incubated in $\mathrm{HCL} /$ ethanol and again rinsed with $\mathrm{H}_{2} \mathrm{O}$. After 5 min incubation in Scott's solution and a wash step in water, the sections were subjected to increasing ethanol dehydration in $50 \%, 70 \%, 90 \%$ and $100 \%$ ethanol for each $5 \mathrm{~min}$ at RT. Subsequently, the sections were immersed in isopropanol/xylene for $10 \mathrm{~min}$ and twice for 10 min in xylene. Finally, a coverslip was mounted onto the slides using Eukitt mounting medium. The light microscope Axiophot from Zeiss was used for imaging. The resulting pictures were then further analyzed with ImageJ. Graphs and statistical analyses were done using GraphPad Prism.

\subsubsection{Tunnel assays}

Staining of apoptotic cells was performed by using the DeadEnd ${ }^{\mathrm{TM}}$ Colorimetric TUNEL System kit. Once the paraffin-embedded $5 \mu \mathrm{m}$ tissue was deparaffinized as previously described, a TUNEL (TdT-mediated dUTP Nick-End Labeling) assay was performed according to the instruction from the kit. Terminal deoxynucleotidly transferase (TdT) mediates the binding of biotinylated nucleotids at the 3'-OH of fragmented DNA sites, which will be detected by streptavidin-HRP. Finally, the peroxidase substrate DAB binds to the complex and precipitates as brown staining. The sections were mounted with coverslips using Aqua-Poly/Mount mounting medium. Quantification and statistical analyses were conducted as described in "immunohistochemistry on paraffin-sections".

\subsubsection{Gallyas silver impregnation}

Myelin fibers were stained using the protocol developed by Gallyas (Gallyas, 1979), in which colloidal sliver particles bind to myelin. $5 \mu \mathrm{m}$ sections of tissue embedded in paraffin were de-paraffinized as described before and incubated in a 2:1 mixture of pyridine and acetic anhydride for 30 min at RT, preventing staining of any other tissue but myelin. The samples were rinsed three times with water for $10 \mathrm{~min}$ and then incubated in warm incubating solution for $10 \mathrm{~min}$ at RT. Afterwards the slides were washed three times with $0.5 \%$ acetic acid for $5 \mathrm{~min}$ and incubated in developing solution for $3-15 \mathrm{~min}$ until the desired intensity of staining was reached. The reaction was stopped by applying $1 \%$ acetic acid three times for $5 \mathrm{~min}$. The samples were washed twice for $3 \mathrm{~min}$ with $\mathrm{H}_{2} \mathrm{O}$ and incubated in $2 \%$ sodium thiosulfate solution for $5 \mathrm{~min}$, stabilizing the silver staining. After 
rinsing twice with water for $5 \mathrm{~min}$, the samples were dehydrated using an ethanol gradient $(50 \%, 70 \%, 90 \%$ and $100 \%$ of ethanol for $5 \mathrm{~min}$ each) and incubated for $10 \mathrm{~min}$ in isopropanol/xylene (1:1) and twice in xylene. The slides were mounted using Eukitt mounting medium. Quantification and statistical analyses were conducted as described in "immunohistochemistry on paraffin-sections".

\subsubsection{Electron microscopic analysis}

\subsubsection{Tissue preparation and epon embedding}

Mouse tissues were dissected from animals, which were perfused with Karlsson and Schultz buffer and post-fixed in Karlsson-Schulz fixative. The tissue was rinsed once in 0.1M PBS and embedded in epon according to a modified method described by Luft et al. (Luft, 1961). Using an automated embedding machine (EMTP, Leica), the following protocol was applied:

$\begin{array}{ccc}\text { Solution } & \text { Duration } & \text { Temperatu } \\ \text { phosphate buffer } & 3 \times 10 \mathrm{~min} & 4^{\circ} \mathrm{C} \\ 2 \% \mathrm{OsO}_{4} & 4 \mathrm{~h} & 4^{\circ} \mathrm{C} \\ \mathrm{ddH}_{2} \mathrm{O} & 3 \times 10 \mathrm{~min} & 4^{\circ} \mathrm{C} \\ 30 \% \text { ethanol } & 20 \mathrm{~min} & 4^{\circ} \mathrm{C} \\ 50 \% \text { ethanol } & 20 \mathrm{~min} & 4^{\circ} \mathrm{C} \\ 70 \% \text { ethanol } & 20 \mathrm{~min} & 4^{\circ} \mathrm{C} \\ 90 \% \text { ethanol } & 20 \mathrm{~min} & 4^{\circ} \mathrm{C} \\ 100 \% \text { ethanol } & 4 \times 10 \mathrm{~min} & 4^{\circ} \mathrm{C} \\ \text { propylenoxid } & 3 \times 10 \mathrm{~min} & \mathrm{RT} \\ \text { propylenoxid/ epon }(2: 1) & 2 \mathrm{~h} & \mathrm{RT} \\ \text { propylenoxid/ epon }(1: 1) & 2 \mathrm{~h} & \mathrm{RT} \\ \text { propylenoxid/ epon }(1: 2) & 4 \mathrm{~h} & \mathrm{RT} \\ \text { epon } & 4 \mathrm{~h} & \mathrm{RT}\end{array}$

The tissue was embedded further in an epon-filled mold and kept over night at $60^{\circ} \mathrm{C}$ for polymerization. 


\subsubsection{Staining of semi-thin sections}

The embedded samples were sectioned using a microtome (Ultracut S, Leica), while cutting with a diamond knife (Diatome Ultra $45^{\circ}$ ) semi-thin section of $500 \mathrm{~nm}$ thickness. The samples were placed onto a glass slide and dried on a $60^{\circ} \mathrm{C}$ hot plate. For staining of semi-thin sections, methylene blue and Azure // staining solution were freshly mixed 1:1 and applied onto the sections (Richardson et al., 1960). The sections were incubated for 1 min on a $60^{\circ} \mathrm{C}$ hot plate, thoroughly rinsed with $\mathrm{ddH}_{2} \mathrm{O}$, dried and mounted with Eukitt. Semi-thin sections were observed under a light microscope, in order to judge the position within a sample.

\subsubsection{Contrasting of ultra-thin sections}

Ultra-thin sections were cut similarly to semi-thin section, but of $50 \mathrm{~nm}$ thickness. The samples were placed onto formvar-polyvinyl coated cupper grids $(2 \mathrm{~mm}-1 \mathrm{~mm}$, AGRA scientific) and dried at RT. For contrasting, the grids were placed upside-down onto drops of uranyl acetate for $30 \mathrm{~min}$ at RT and covered from light. Then, the grids were washed three times with $\mathrm{dd}_{2} \mathrm{O}$ for $1 \mathrm{~min}$, incubated for $6 \mathrm{~min}$ onto drops of Reynolds lead citrate (Reynolds, 1963) and finally washed four times $1 \mathrm{~min}$ with $\mathrm{ddH}_{2} \mathrm{O}$. The grids were dried by placing them on filter paper. Electron micrographs of the ultra-thin sections were obtained by using the electron microscope EM900 from Zeiss combined with a wide-angle dual speed 2K-CCD camera from TRS. Afterwards, images were analyzed by measuring the gratio and by assessing distinctive histological features. ImageJ, Microsoft Excel and GraphPad Prism were used for further analyses.

For g-ratio measurement, 10 randomly chosen images of a section (3000x magnification) were taken. Of those, 100 axons per section were quantified. By this measurement the thickness of myelinated fibers was calculated. The outer circumference of the myelin sheath, as well as the inner circumference was calculated with ImageJ. The ratio of inner circumference divided by the circumference of the outer myelin sheath equals the g-ratio. A baseline g-ratio value is approximately 0.77 in the central nervous system and 0.6 in the peripheral nervous system. Values higher indicate a hypomyelination, whereas smaller values indicate hypermyelination.

$C n p 1^{\mathrm{Cre} /+} ; F b x O 7^{\mathrm{fl} / \mathrm{fl}}$ mice: embedding and sectioning of samples, as well as obtaining electron microscopic pictures were done with the help of Torben Ruhwedel and Boguscha

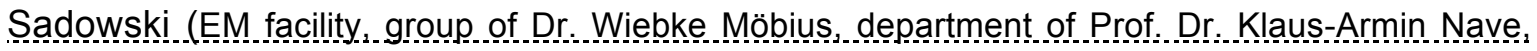
Max-Planck Institute of Experimental Medicine Göttingen). Siv Vingill measured the g-ratio of optic nerve samples. 
Plp $^{\text {CreERT2/+} ; ~ F b x o 7^{f / / f l}}$ mice: preparation of samples and acquisition of electron microscopic images were obtained with the support of Claudia Krude, Hannelore Mader and Dr. Istvan Katona (EM facility department of Prof Dr. Joachim Weis, RWTH University Aachen). Quantifications of the g-ratio of sciatic nerve samples were done together with Yuhao Huang.

\subsubsection{Mouse behavioral analyses}

Transgenic mice underwent behavioral analyses at different time points to assess motor and sensory phenotypes. All tests were conducted under standardizes conditions, at fixed light intensity of 90 lux and protected from disturbance. Male mice were used throughout the study for behavior analyses. Prior to each session, mice were allowed to acclimate for $30 \mathrm{~min}$ in the test room. Afterwards the weight of the mice was determined and the behavioral tests were performed in a distinct order: first elevated plus maze for assessing anxiety, then open filed test for ambulation and exploratory behavior, followed by tail suspension test, inverted grid, pole test, wire hang, balance beam and Rotarod for motor endurance and coordination. For sensory assessment the hot plate test was performed. In-between each mouse to be tested, the equipment was cleaned with water and $70 \%$ ethanol. The animals were monitored using the software Viewer from Biobserve. Further on obtained data were analyzed using Microsoft Excel and GraphPad Prism.

\subsubsection{Elevated plus maze}

In order to evaluate the anxiety of mice, an elevated plus maze test was conducted according to published protocol (Pellow et al., 1985). The apparatus is comprised of 4 arms, all measuring $5 \times 30 \mathrm{~cm}$. Two arms are open, whereas a $15 \mathrm{~cm}$ high wall encloses the other two arms. The maze is elevated $40 \mathrm{~cm}$ from the ground. Mice were placed in the center of the plus maze, facing an open arm, and both activity and exploratory behavior were recorded for $5 \mathrm{~min}$ with the Viewer software. The time spent in open and closed arms was analyzed, since intensive time spent in an open arm indicates reduced anxiety.

\subsubsection{Open field}

General locomotion and exploratory behavior was measured in an open filed test, as previously demonstrated (Hall, 1932). The round arena had a diameter $060 \mathrm{~cm}$ and was surrounded by a $20 \mathrm{~cm}$ high wall. Further on the open field was subdivided into 3 zones, the central circle of $20 \mathrm{~cm}$ in diameter, an intermediate zone of $40 \mathrm{~cm}$ in diameter and the 
peripheral zone of $60 \mathrm{~cm}$ in diameter. The mice were placed in the center and movement was monitored for $7 \mathrm{~min}$ with the Viewer animal tracking system. The travelled distance, velocity and time spent in different zones were analysed.

\subsubsection{Tail suspension test}

To assess signs of neurological deficits and neurodegenerative disease progression, a modified form of the tail suspension test described by Steru et al. (Steru et al., 1985) was performed. Mice were lifted by their tail and hold closely over their cage for 10 seconds. The position of the hind limbs were scored from $0-3$, with 0 representing normal, splayed hind limbs and 3 indicating strong clasping of the hind paws. An average out of three repetitive measurements was considered as final score. In-between repeated measurements a $30 \mathrm{sec}$ pause was given.

\subsubsection{Kyphosis}

The determination of kyphosis was conducted as previously described (Guyenet et al., 2010). Mice were observed while walking and the curvature of the spin was scored from $0-3$. A score of 0 implied no signs of kyphosis, were as 1 indicated an arched spin while sitting, but not while walking. A score of 2 was given when the back was curved while sitting and mildly during movement and a score of 3 marked a severe kyphosis during sitting and walking.

\subsubsection{Inverted grid}

Muscle strength was assessed by the inverted grid test. Therefore mice were placed onto the grid of their home cage and the gird was inverted, holding it above the cage. The time mice could hold on to the grid, while being upside down, was measured with a cut-off time at $60 \mathrm{sec}$. Three repeated measurements were done with a break of $1 \mathrm{~min}$ in-between and the average of all measurements were calculated (Kondziela, 1964).

\subsubsection{Pole test}

The pole test has been previously described as an assessment for basal ganglia related motor function (Matsuura et al., 1997), (Ogawa et al., 1985). Mice were placed onto a vertical $50 \mathrm{~cm}$ long pole facing upwards and had to turn in order to walk down the pole. The pole was placed in the home cage of the mice and the time needed to reach the bottom of the pole was taken. The animals were trained 2 days before testing, where 
three consecutive measurements were done, with an interval of 1 min. Finally, the average of all measurements were calculated.

\subsubsection{Wire hang}

Another test for muscle strength is the wire hang test, as previously described (AartsmaRus and van Putten, 2014). The wire apparatus consists of an $80 \mathrm{~cm}$ long steel wire, which was affixed at $30 \mathrm{~cm}$ to poles. The ground was covered with soft tissue and the mice were suspended in the middle of the wire with their front paws. Then the time was measured that the mice needed to reach one of the poles. Three repeats were performed with an interval of $1 \mathrm{~min}$ and the average time was calculated.

\subsubsection{Balance beam}

For testing balance and coordination, a balance beam test was conducted as previously described (Luong et al., 2011). The apparatus consists of either a $6 \mathrm{~mm}$ or a $12 \mathrm{~mm}$ wide and $80 \mathrm{~cm}$ long beam, which is attached to a black box $(15 \times 15 \times 15 \mathrm{~cm})$. The beam is elevated $50 \mathrm{~cm}$ from the ground, with a safety net placed underneath. Prior to testing the mice, the animals were acclimated for $1 \mathrm{~min}$ inside the back box containing food pellets. Afterwards, the mice were placed on the opposite end of the beam and time, as well as numbers of slips were counted until the black box was reached. The training was performed on two consecutive days and on the third days the animals were tested. For each beam, three repetitions were done, with a 1 min break in-between repetitions and 10 min resting time in-between the beams. The average of time required to cross the beam, as well as numbers of slips was calculated.

\subsubsection{Rota-Rod}

While subjecting the mice to the Rotarod test, the motor coordination and endurance was tested. The program of the Rotarod was set for an increase of acceleration every 5 seconds starting with $4 \mathrm{rpm}$ and reaching $40 \mathrm{rpm}$ after $3 \mathrm{~min}$. The average time spent on the moving rod was measured and each mouse was tested three times, with a $10 \mathrm{~min}$ break in-between. The cut-off time was set for $5 \mathrm{~min}$. Furthermore a learning curve was established by performing tests at $0 \mathrm{~h}, 3 \mathrm{~h}$ and $24 \mathrm{~h}$. 


\subsubsection{Hot plate}

To assess sensory deficits, especially pain, a hot plate test was conducted. (Eddy and Leimbach, 1953) Mice were placed in a $1000 \mathrm{ml}$ round glass beaker on a $55^{\circ} \mathrm{C}$ metal plate. The time was stopped when mice showed any sign of irritation due to the heat, indicated in paws licking or jumping. The animals were immediately removed from the plate once showing signs of irritation. Further on a cut-off time of $30 \mathrm{sec}$ was set. Three repeated measurements were taken with a $10 \mathrm{~min}$ break in-between. The average time was calculated.

Behavioral analyses of the Cnp $1^{\mathrm{Cre} /+} ; F b x o 7^{\mathrm{fl/fl}}$ mice was performed by Siv Vingill.

\subsubsection{Statistical analysis}

All data obtained were further analyzed using Microsoft Excel. For statistical analysis GraphPad Prism was used. Normally distributed data of two groups were compared using the student T-test. For the analysis of data from more than two groups a one-way ANOVA were used. In case of two different independent variables, the influence on the depended variable was calculated by using a two-way ANOVA. Statistical differences were considered as significant if $P<0.05\left({ }^{*} P<0.05,{ }^{* *} P<0.01,{ }^{* * *} P<0.001\right)$. All data are displayed as standard error of the mean (s.e.m.), unless otherwise stated.

Fluorescent images were analyzed using a customized macro designed by Dr Miso Mitkovski (Light microscopy facility s.Max-Planck Institute of Experimental Medicine, Göttingen). 


\section{Results}

\subsection{Systemic characterization of $\mathrm{Cnp} 1^{\mathrm{Cre} /+} ; \mathrm{FbxO}{ }^{\mathrm{fl} / \mathrm{fl}}$ mice}

The proper functioning of the UPS is essential to CNS and PNS integrity. FBXO7, which is part of the UPS, was shown to have crucial functions within neurons, since analyses of mice with conditional deletions of $\mathrm{FbxO} 7$ display severe motor deficits. While recent studies focused on the importance of FBXO7 in neurons, its impact on myelinating cells remains unknown. Owing to FBXO7's strong expression in myelinating cells and the intimate interaction of myelinating cells and neurons, I investigated if $\mathrm{FBXO} 7$ is equally essential for myelinating cells and the axonal integrity in the $\mathrm{Cnp} 1^{\mathrm{Cre} /+} ; \mathrm{FbxO} 7^{\mathrm{fl/fl}}$ mouse line. Investigating the role of the UPS in myelinating cells, will elucidate its importance for the axon-glia interaction and opens a new perspective on the underlying and contributing mechanisms in neurodegenerative diseases.

\subsubsection{Deletion of Fbxo7 in myelinating cells by generating a conventional Cnp1 ${ }^{\mathrm{Cre} /+} ; \mathrm{FbxO} 7^{\mathrm{fllfl}}$ mouse line}

FBXO7 is ubiquitously expressed in various tissues of mice and men (llyin et al., 2000; Winston et al., 1999). The widespread expression of FBXO7 in the murine brain was shown by my colleague Dr. David Brockelt, who performed a $\beta$-galactosidase staining of brain sections from conventional Fbxo7 knockout mice, in which the lacZ expression cassette was under the control of the endogenous Fbxo7 promoter (Brockelt, 2015). The staining revealed that $\mathrm{FBXO} 7$ is predominantly expressed in the cortex, hippocampus and substantia nigra, as well as in the white matter of the cerebellum and corpus callosum. While my colleagues investigated the importance of FBXO7 in neurons, I investigated its function in myelinating cells. In collaboration with the department of Prof. Dr. Klaus-Armin Nave, we generated the $\mathrm{Cnp} 1^{\mathrm{Cre} /+} ; \mathrm{FbxO} 7^{\text {fl/fl }}$ conditional knockout (cKO) mouse, by breeding the Fbxo ${ }^{\mathrm{fl/fl}}$ line (Vingill et al., 2016) with the Cnp $1^{\mathrm{Cre} /+}$ driver line (Lappe-Siefke et al., 2003) (Figure 3.1.1a). Cnp1 encodes for CNPase (2',3'-cyclic-nucleotide 3'phosphodiesterase), a myelin-associated enzyme, which is present in myelin of the central- (CNS) and peripheral nervous system (PNS) (Sprinkle et al., 1985). The Cnp1Cre mice were kept heterozygous, whereas the Fbxo7 floxed line was bred to homozygosity. Throughout this study $\mathrm{FbxO} 7^{\mathrm{fl} / \mathrm{fl}}$ and $\mathrm{Cnp} 1^{\mathrm{Cre} / \mathrm{t}}$ mice were used as controls for the $\mathrm{Cnp}^{\mathrm{Cre} / \mathrm{H}} ; \mathrm{FbxO} 7^{\mathrm{fl} / \mathrm{fl}}$ knockout mice. The correct breeding was confirmed and monitored, while genotyping of the Cre, floxed $\mathrm{Fbxo7}$ and wild type $\mathrm{Fbxo} 7$ allele (Figure 
3.1.1b). Further on, the deletion of Fbxo7 from myelinating cells was validated at the mRNA level. Therefore, a RT-PCR was performed on cerebellum samples from 2-monthold $\mathrm{FbxO} 7^{\mathrm{fl/fl}}$ and $\mathrm{Cnp} 1^{\mathrm{Cre} /+} ; \mathrm{FbxO} 7^{\mathrm{fl/fl}}$ mice. The Fbxo7 mRNA was reduced by about $73 \%$ in the cKO samples as compared to control confirming the knockout of $F b x O 7$ in myelinating cells (Figure 3.1.1c). These findings confirm the deletion of Fbxo7 from myelinating cells in the $\mathrm{Cnp} 1^{\mathrm{Cre} /+} ; \mathrm{FbxO} 7^{\mathrm{fl/fl}}$ mouse line.

.

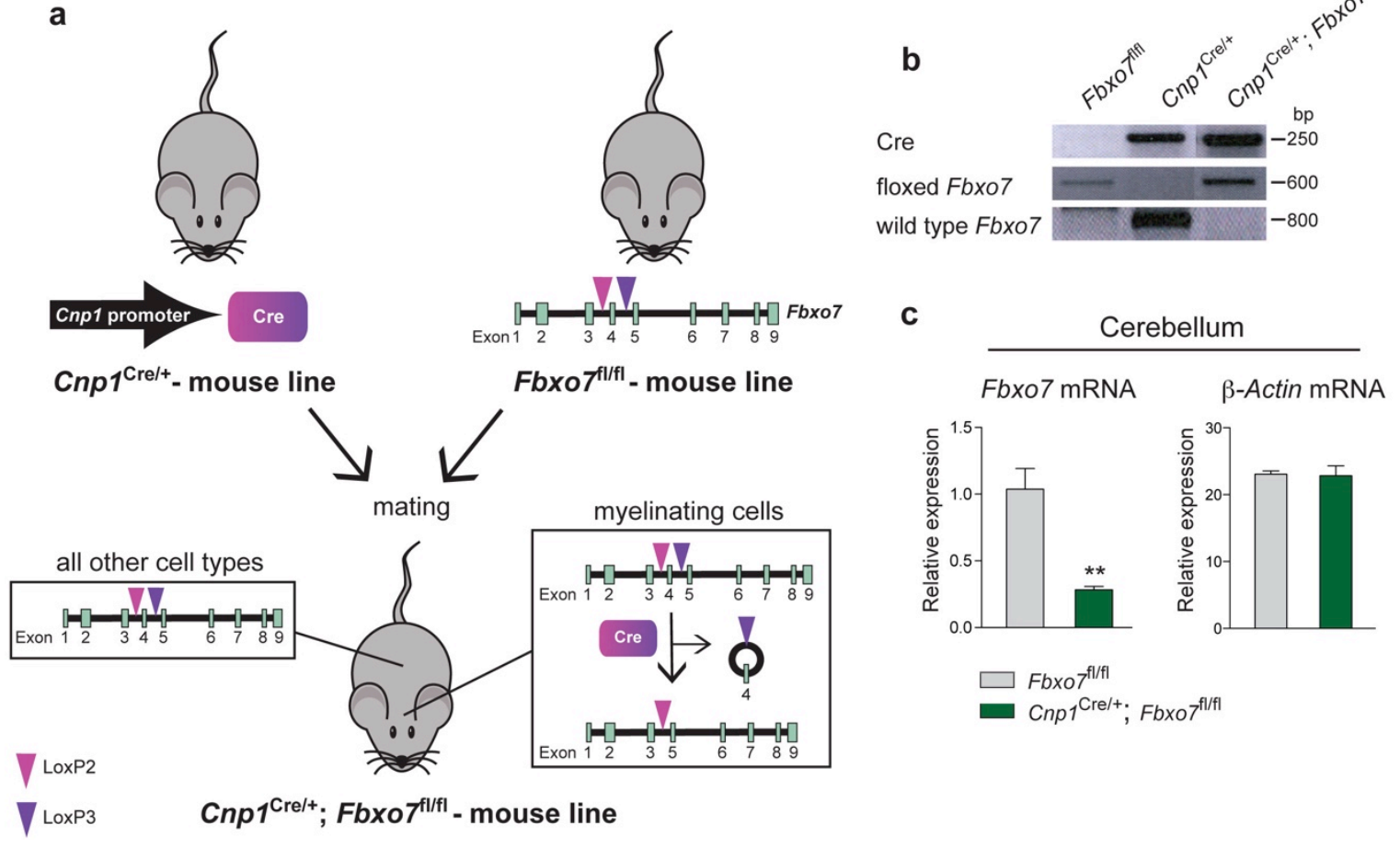

Figure 3.1.1 Validation of $\mathrm{Cnp} 1^{\mathrm{Cre} /+} ; \mathrm{FbxO} 7^{\mathrm{fl/fl}}$ knockout mouse line.

(a) Schematic representation of $\mathrm{Cnp}_{1}{ }^{\mathrm{Cre} / \mathrm{t}} ; \mathrm{FbxO}^{\mathrm{fl/f/1}}$ breeding including schematic of floxed $\mathrm{FbxO} 7$ gene. Modified from Erdmann et al. (Erdmann et al., 2008). Fbxo $7^{\text {fl/fl }}$ mice were generated by Nicola SchwedhelmDomeyer. (b) Genotyping PCR of $\mathrm{FbxO} 7^{\mathrm{fl/fl}}, \mathrm{Cnp} 1^{\mathrm{Crel+}+}$ and $\mathrm{Cnp} 1^{\mathrm{Crel}+} ; \mathrm{FbxO} 7^{\mathrm{fl/fl}}$ mice using primers for Cre, floxed

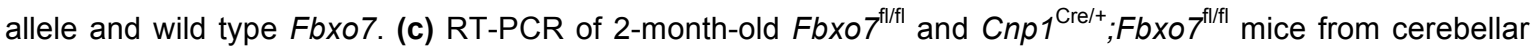
cDNA. Primers for $F b x o 7$ and $\beta$-Actin (reference) were used. $\mathrm{n}=4$ for both groups (unpaired t-test, ${ }^{* *} \mathrm{P}<0.01$, mean \pm s.e.m.).

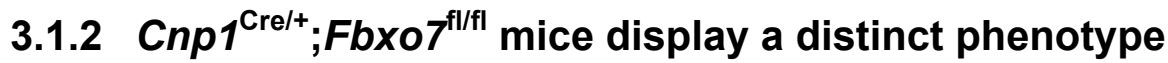

At 6 weeks of age, the phenotype of $\mathrm{Cnp}^{\mathrm{Cre} /+} ; \mathrm{FbxO} 7^{\mathrm{fl} / \mathrm{fll}}$ mice was clearly distinguishable from control mice. When examining $\mathrm{Cnp} 1^{\mathrm{Cre} /+} ; \mathrm{FbxO} 7^{\mathrm{fl} / \mathrm{fl}}$ and control mice at 3 months of age, I found cKO mice to be smaller in size and harboring a prominent kyphosis (Figure 3.1.2a). Moreover, $\mathrm{Cnp} 1^{\mathrm{Cre} /+} ; \mathrm{FbxO} 7^{\mathrm{fl} / \mathrm{fl}}$ mice died very early, already around 4 months of age. Therefore analyses in this study were performed latest at 3 months of age. To 
3.1 Systemic characterization of Cnp1Cre/+;Fbxo7fl/fl mice

determine the cause of the premature death, I examined the mice for pathological changes. I found that the cKO mice displayed a severe muscle atrophy of the musculoskeletal system (Figure 3.1.2b), as well as atrophic lungs (Figure 3.1.2c). Further on the animals showed a severe paresis of the hind limbs and a loss of tail tip tone. These preliminary observations indicate that FBXO7 is essential in myelinating cells.
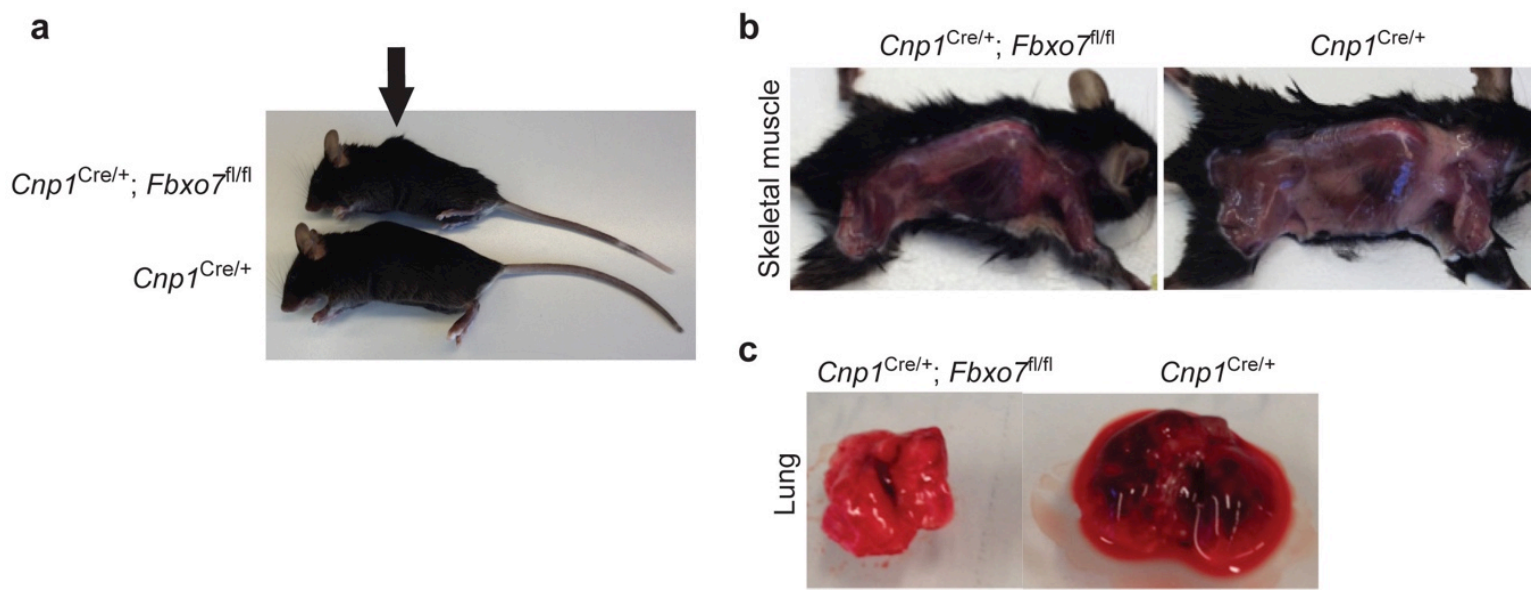

Figure 3.1.2 $\mathrm{Cnp} 1^{\mathrm{Cre} /+} ; \mathrm{FbxO} 7^{\mathrm{fl/fl}}$ mice display kyphosis, muscle and lung atrophy.

(a)-(c) Representative images of a 3-month-old $\mathrm{Cnp}{ }^{\mathrm{Cre} / \mathrm{t}} ; \mathrm{Fb} \times \mathrm{O}^{\mathrm{fl/fl}}$ and an age-matched $\mathrm{Cnp}^{\mathrm{Cre} / \mathrm{t}}$ mouse show (a) kyphosis, indicated by arrow, (b) atrophy of skeletal muscle and (c) atrophic lungs.

\subsubsection{Cnp $1^{\mathrm{Cre} /+} ; \mathrm{Fb} \times 07^{\mathrm{fl} / \mathrm{fl}}$ mice show paresis of the hind limbs caused by muscle weakness}

To examine the motor performance of $\mathrm{Cnp} 1^{\mathrm{Cre} /+} ; \mathrm{FbxO} 7^{\mathrm{fl/fl}}$ mice, my colleague Dr. Siv Vingill performed a battery of behavioral tests. 6 week-old $\mathrm{Cnp} 1^{\mathrm{Cre} /+} ; \mathrm{FbxO} 7^{\mathrm{fl/fl}}$ mice were tested together with $\mathrm{Cnp1}^{\mathrm{Cre} /+}$ and $\mathrm{Fbxo7^{ \textrm {fl } / \mathrm { fl } }}$ mice as control. Dr. Siv Vingill has previously demonstrated that $F b x o 7^{\text {fl/fl }}$ mice show normal behavior up to 12 months of age (Vingill, 2016). Further on, the study by Hagemeyer et al., showed that up to 24 months of age, Cnp $1^{\mathrm{Cre} /+}$ mice display normal motor activity, coordination and strength (Hagemeyer et al., 2012). The behavioral analyses revealed a significantly reduced bodyweight of $\mathrm{Cnp}^{\mathrm{Cre} / \mathrm{H}} ; \mathrm{FbxO} 7^{\mathrm{fl} / \mathrm{fl}}$ mice as compared to controls, likely due to the aforementioned muscle atrophy (Figure 3.1.3a). While analyzing hind limb clasping, $\mathrm{Cnp} 1^{\mathrm{Cre} /+} ; \mathrm{FbxO} 7^{\mathrm{flfl} l \mathrm{l}}$ mice scored significantly worse than control mice. However, cKO mice displayed rather a weakness of the hind limbs, than a clasping phenotype (Figure 3.1.3b). In addition, Cnp ${ }^{\mathrm{Cre} /+} ; \mathrm{FbxO}^{\mathrm{fl} / \mathrm{fl}}$ mice demonstrated muscle weakness, as their ability to hold on to the inverted grid was significantly reduced (Figure 3.1.3c). In order to assess motor coordination, mice performed the rotarod test. The procedure was repeated 3 and 24 
hours after the initial examination. The endurance of cKO mice was decreased, as mice fell off the rotating rod much faster than control mice. Moreover, the performance of $\mathrm{Cnp}^{\mathrm{Cre} / \mathrm{+}} ; \mathrm{FbxO} 7^{\mathrm{fl} / \mathrm{fl}}$ mice on the rotarod did not improve, since their learning curve did not increased over time (Figure 3.1.3d). To further examine motor coordination, a balance beam test was performed. While running across a $12 \mathrm{~mm}$ and $6 \mathrm{~mm}$ beam, the cKO mice required more time and showed a lower coordination score on the $6 \mathrm{~mm}$ beam than control mice, due to more frequent slips (Figure 3.1.3e). Anxiety and locomotion was tested by performing an open field test. $\mathrm{Cnp} 1^{\mathrm{Cre} /+} ; \mathrm{FbxO} 7^{\text {fl/fl }}$ mice did not show any signs of anxiety, but the distance they travelled was significantly shorter than of controls (Figure 3.1.3f). Taken together, these results provide strong evidence that loss of Fbxo7 in myelinating cells leads to decreased mobility, paresis of the hind limbs, resulting from muscle weakness and an overall reduced motor performance.
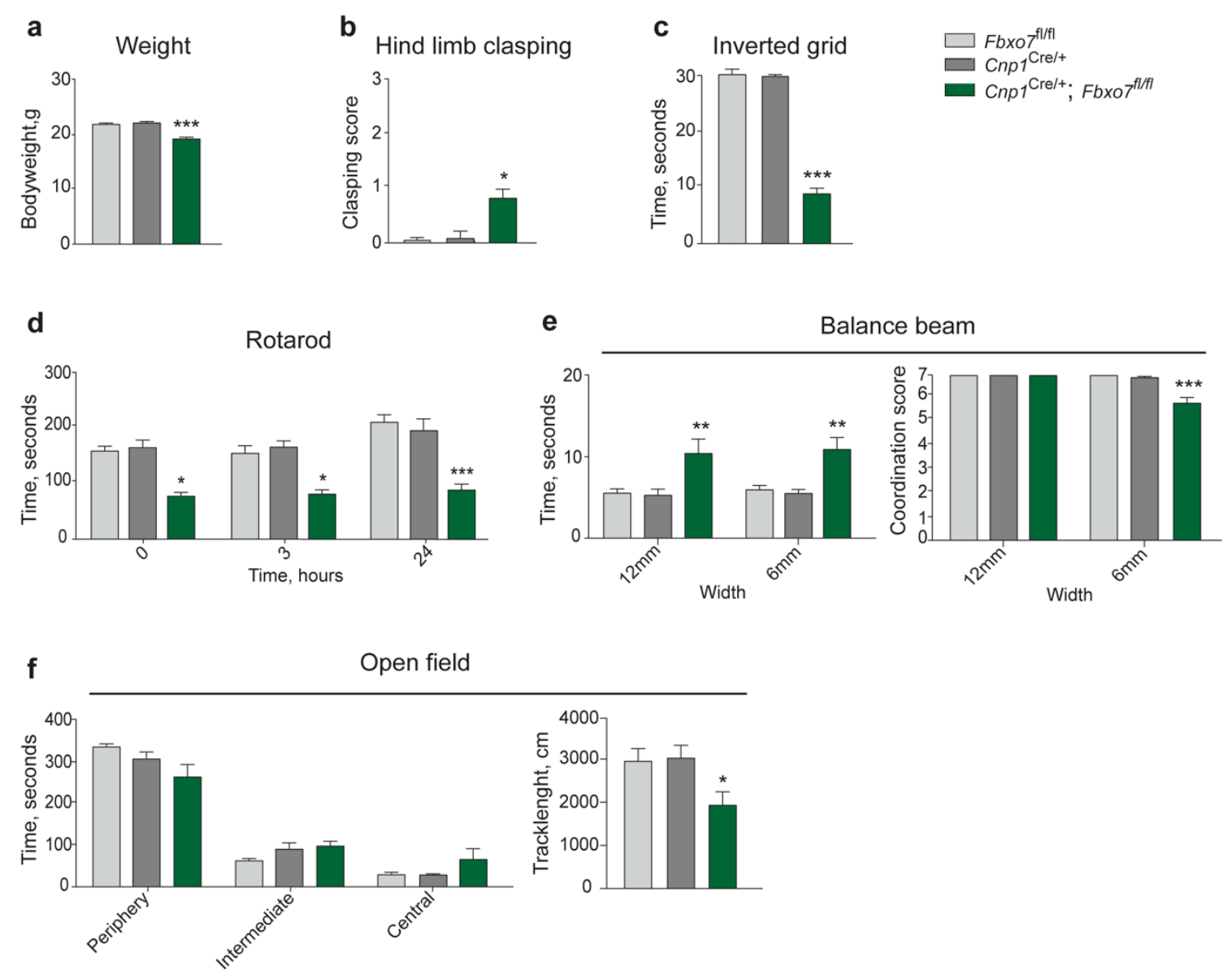

Figure 3.1.3 $\mathrm{Cnp1}^{\mathrm{Cre} / \mathrm{H}} ; \mathrm{FbxO} 7^{\mathrm{fl} / \mathrm{fl}}$ mice show reduced motor performance, due to paresis of hind limbs and muscle weakness.

(a)-(f) 6 week-old Fbxo $7^{\text {fl/fil }}(\mathrm{n}=8), \mathrm{Cnp}^{\mathrm{Cre} /+}(\mathrm{n}=9)$ and $\mathrm{Cnp} 1^{\mathrm{Cre} /+} ; \mathrm{FbxO} 7^{\mathrm{fl/fl}}(\mathrm{n}=10)$ mice were subjected to the following tests: (a) body weight, (b) tail suspension test $(0=$ normal, $3=$ strong hind limb clasping) and (c) time spent on inverted grid. Further on, a (d) rotarod test at 0,3 and $24 \mathrm{~h}$ was performed, as well as a (e) balance beam test with a beam of $6 \mathrm{~mm}$ or $12 \mathrm{~mm}$ width, respectively. Here, the time to cross the beam and a 
coordination score were measured $(0=$ unable to cross beam, $7=$ normal $)$. Finally an (f) open field test was conducted and the track lengths as well as the time spent in a specific area were monitored. (One-way ANOVA or two-way ANOVA, including Bonferroni post-test, ${ }^{*} \mathrm{P}<0.05$, ${ }^{\star \star} \mathrm{P}<0.01,{ }^{* \star *} \mathrm{P}<0.001$, mean \pm s.e.m.). These analyses were performed by Dr. Siv Vingill.

\subsection{Cellular characterization of $\mathrm{Cnp1} 1^{\mathrm{Cre} /+} ; \mathrm{FbxO} 7^{\mathrm{fl/fl}}$ mice}

In our lab, we investigated the impact of $\mathrm{Fbxo7}$ deletion on different cell types of the nervous system, dissecting its functions at the cellular level. Conditional knockout mice, in which Fbxo7 was deleted from the forebrain, did not exhibit neuronal loss in the cortex, however demonstrated astrogliosis and microgliosis (Vingill et al., 2016). In addition, deletion of $\mathrm{Fbxo7}$ from dopaminergic neurons did not induce neuronal cell death in the substantial nigra, but led to an increase in astrogliosis in the midbrain. The conventional Fbxo7 knockout mice, which died prematurely at P21, also showed astrogliosis and only a minimal increase in apoptosis in the cortex (Brockelt, 2015; Vingill, 2016). In the following experiments, I analyzed the effect of Fbxo7 deletion on myelinating cells, the axon-glia interaction and their environment.

\subsubsection{Loss of Fbxo7 does not affect myelination but leads to a shift in axon caliber}

To characterize the presented phenotype at the neuropathological level, I carried out histological analyses and determined if deletion of $\mathrm{Fbxo7}$ led to structural changes within myelinating cells. Therefore, I stained myelinated fiber tracts on sagittal brain sections of 3-month-old Fbxo $7^{\mathrm{fl/fl}}, \mathrm{Cnp} 1^{\mathrm{Cre} /+}$ and $\mathrm{Cnp} 1^{\mathrm{Cre} /+} ; \mathrm{FbxO} 7^{\mathrm{fl/fl}}$ mice according to the Gallya's silver impregnation protocol, but found no obvious difference between genotypes. There was no sign of increased or decreased thickness of myelinated fiber tracts that would indicate abnormalities in myelinated axons (Figure 3.2.1a).

Furthermore, I performed immunohistological stainings of spinal cord cross-sections of 3month-old $\mathrm{Cnp} 1^{\mathrm{Cre} /+} ; \mathrm{FbxO} 7^{\mathrm{fl} /+}$ and $\mathrm{Cnp} 1^{\mathrm{Cre} /+} ; \mathrm{FbxO} 7^{\mathrm{fl/fl}}$ mice and used myelin proteolipid protein (PLP) as marker. Quantification of $\mathrm{PLP}^{+}$area showed no difference in myelinated tracts of the CNS between cKO and control mice (Figure 3.2.1b).

To investigate changes in myelination in the PNS, I stained longitudinal sections of sciatic nerve from 3-month-old $\mathrm{FbxO} 7^{\mathrm{fl/fl}}$ and $\mathrm{Cnp}^{\mathrm{Cre} /+} ; \mathrm{FbxO}^{\mathrm{fl} / \mathrm{fl}}$ mice, with an antibody against myelin basic protein (MBP). Since PLP is of lower abundance in Schwann cells, but only of very low abundance in Schwann cell myelin, a staining with MBP was preferred 
(Kamholz et al., 1992). The analysis of $\mathrm{MBP}^{+}$area did not reveal any change in MBP levels in the PNS between cKO and control mice (Figure 3.2.1c). I analyzed and quantified fluorescent images, using a customized macro designed by Dr. Miso Mitkovski. Taken together, I did not detect any structural changes in myelination in the CNS or PNS.

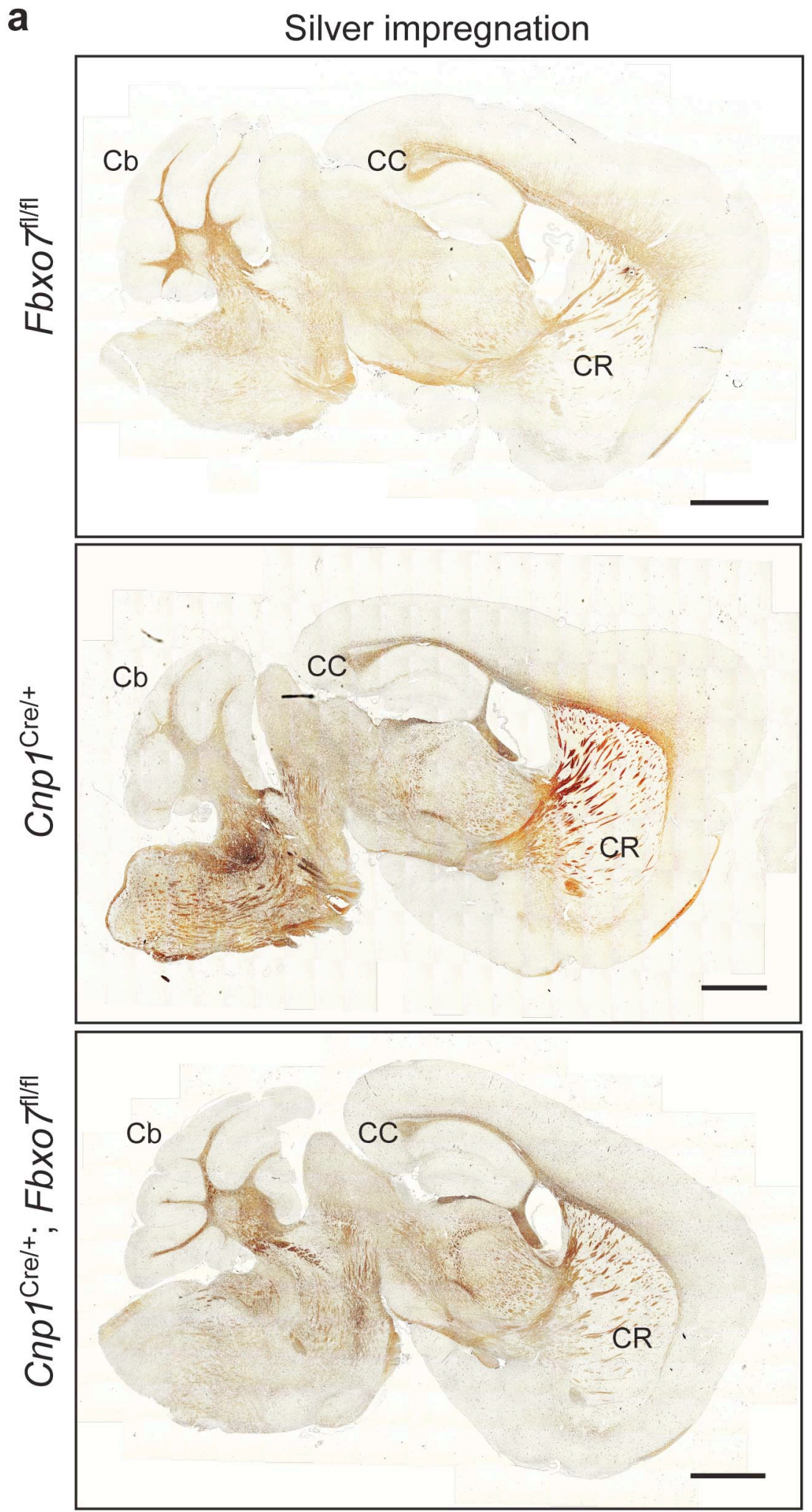


b
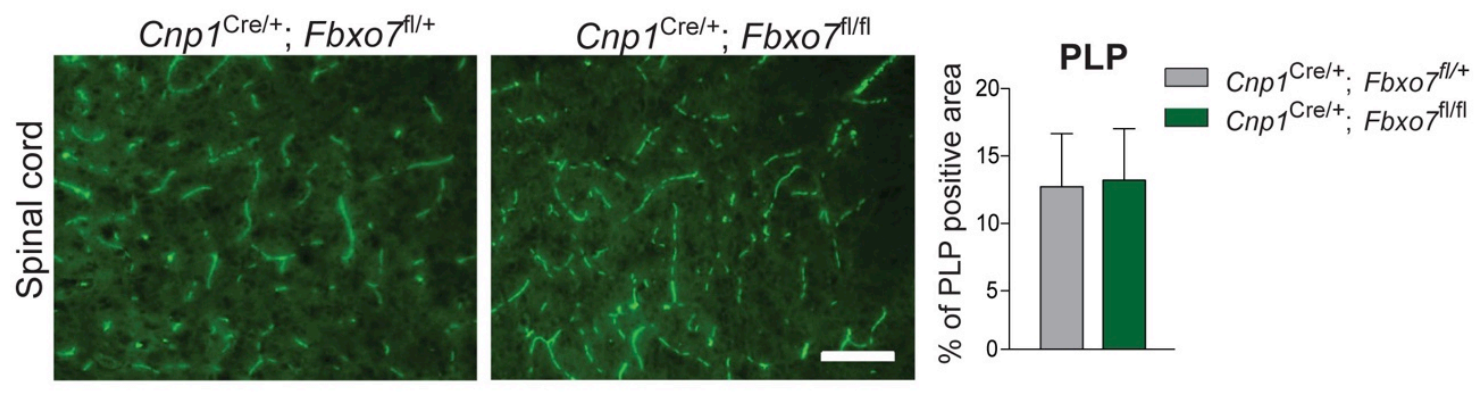

C
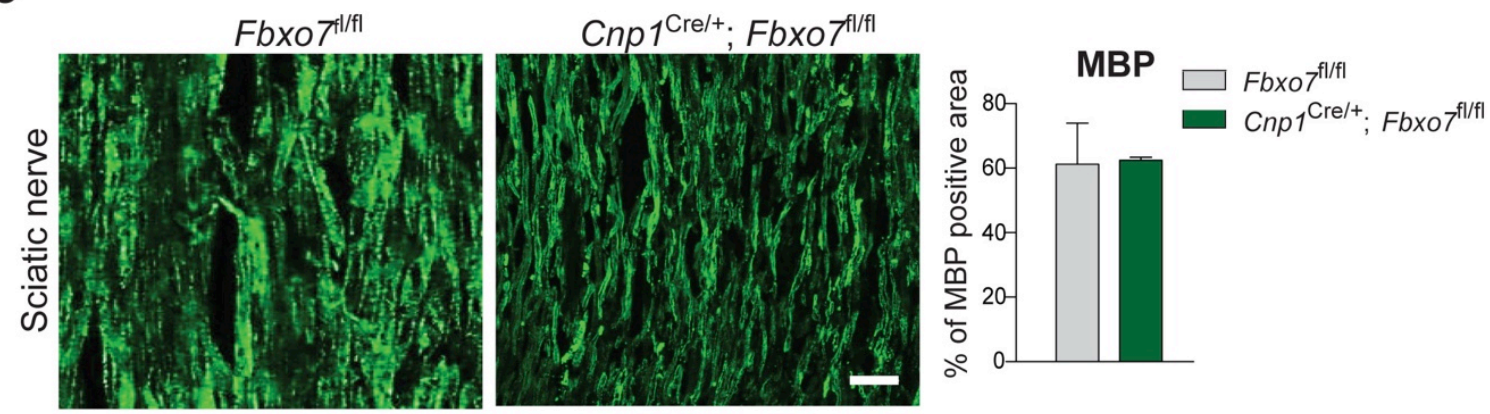

Figure 3.2.1 $\mathrm{Cnp}^{\mathrm{Cre} / \mathrm{t}} ; \mathrm{FbxO} 7^{\mathrm{fll} / \mathrm{fl}}$ mice present no histological changes in myelination.

(a) Gallyas staining of 3-month-old $F b x o 7^{f / / f l}, C n p 1^{\mathrm{Cre} /+}$ and $\mathrm{Cnp} 1^{\mathrm{Cre} /+} ; \mathrm{FbxO} 7^{\text {fl/fl }}$ sagittal brain sections. $\mathrm{Cb}=$ cerebellum, $\mathrm{CC}=$ corpus callosum, $\mathrm{CR}=$ corona radiata. $\mathrm{Scale}$ bar $=0.5 \mathrm{~mm}$. (b) Cryo-cross-sections of spinal cords from 3-month-old $\mathrm{Cnp}_{1}^{\mathrm{Crel+} ;} ; \mathrm{FbxO} 7^{\mathrm{fl} /+}$ and $\mathrm{Cnp} 1^{\mathrm{Cre} /+} ; \mathrm{FbxO} 7^{\mathrm{fl/ll}}$ mice were subjected to immunohistochemistry using PLP antibody. Sections were taken from lumbar segment 1-3 of the spinal cord. Three mice per genotype and two technical repeats per animal were included in the analyses. The percentage of area stained was quantified using a customized macro (unpaired t-test, mean \pm s.e.m.). Scale bar $=50 \mu \mathrm{m}$. (c) Representative images of longitudinal cryo-sections of sciatic nerves from 3-month-old Fbxo $7^{f / f l}$ and $\mathrm{Cnp}^{\mathrm{Crel}+} ; \mathrm{FbxO} 7^{\mathrm{fl/fl}}$ mice that were subjected to immunohistochemistry with an MBP antibody. Three biological and two technical repeats per genotype were included in the analyses. The percentage of area stained was quantified using a customized macro (unpaired t-test, mean \pm s.e.m.). Scale bar $=50 \mu \mathrm{m}$.

To investigate ultrastructural changes and the compaction of myelin layers, I decided to take advantage of electron microscopy. In collaboration with Dr. Wiebke Möbius, I subjected optic nerve and sciatic nerve samples of 3 -month-old $\mathrm{Cnp} 1^{\mathrm{Cre} /+}$ and Cnp ${ }^{\mathrm{Cre} /+} ; F b x O 7^{\mathrm{fl} / \mathrm{fl}}$ mice to electron microscopic analyses. Both, embedding of samples and acquisition of pictures were done with the support from Boguscha Sadowski and Torben Ruhweden. Cross-sections were quantified by calculating the g-ratio, which serves as benchmark for myelin thickness. The analysis of optic nerve was performed by Dr. Siv Vingill and showed an equal distribution of g-ratio values for cKO and control mice, indicating no change in myelination in the CNS of $\mathrm{Cnp}_{1}{ }^{\mathrm{Cre} /+} ; \mathrm{FbxO} 7^{\mathrm{fl/fl}}$ mice (Figure 3.2.2a). The average g-ratio for myelinated axons in the CNS is approximately 0.77 according to 
literature, however the quantification of our measurements revealed an average value of 0.7 for both cKO and control (Chomiak and Hu, 2009) (Figure 3.2.2b). To detect more subtle changes, which might only be appreciated within smaller subpopulations, I grouped the measured g-ratio values as following: Values from $0-0.64$ represented hypermyelination, values between $0.65-0.75$ reflected normal myelination and g-ratios from $0.76-0.90$ identified hypomyelination. The data showed that the majority of measured axons $(76 \%$ in cKO, $65 \%$ in control mice) displayed a normal myelination. The percentage of axons that displayed hyper- or hypomyelination was negligibly small (hypermyelination: $7 \%$ in cKO, $10 \%$ in control mice; hypomyelination: $17 \%$ in cKO, $25 \%$ in control mice) and only represented the edges of a Gaussian distribution. Interestingly, axons of $\mathrm{Cnp} 1^{\mathrm{Cre} /+} ; \mathrm{FbxO} 7^{\mathrm{fl} / \mathrm{fl}}$ mice presented a significant shift towards large-caliber axons throughout all groups as compared to control (Figure 3.2.2c). With these results, I show that loss of $\mathrm{FbxO} 7$ in oligodendrocytes does not severely influence myelination in the CNS. However deletion of Fbxo7 triggers a shift in axon caliber in the optic nerve of Cnp ${ }^{\mathrm{Cre} /+} ; \mathrm{FbxO}^{\mathrm{fl/fl}}$ mice. 
a
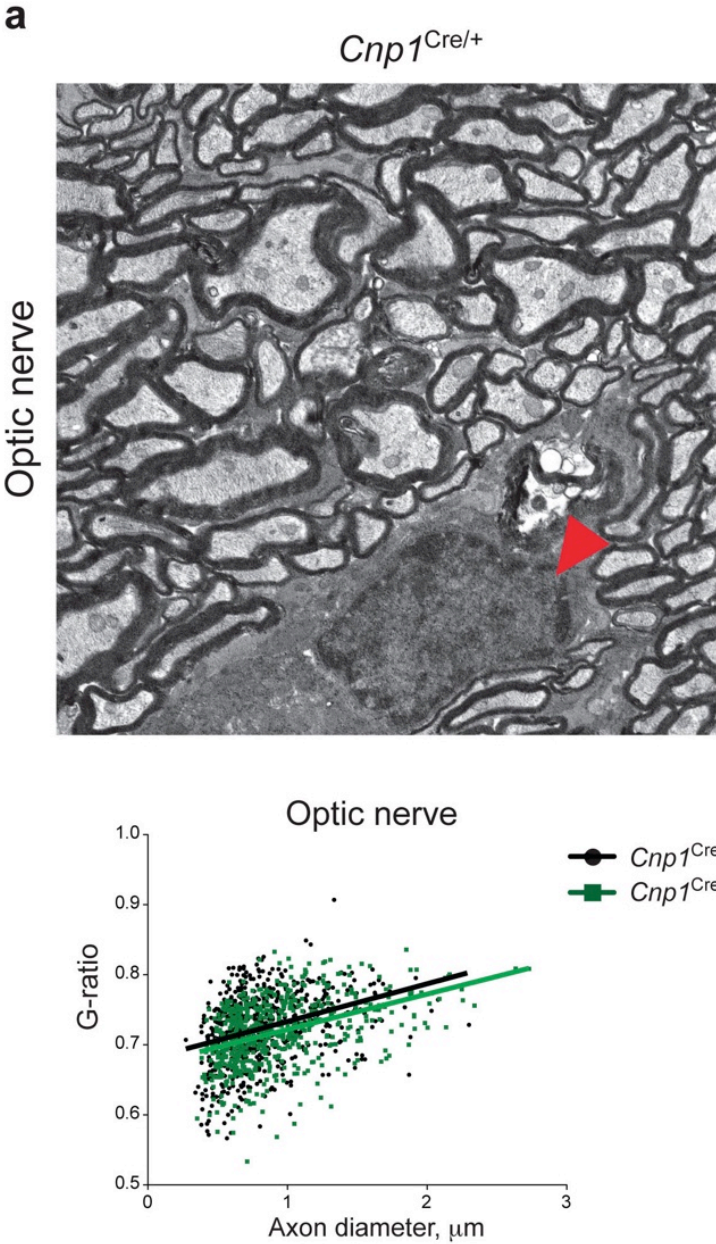

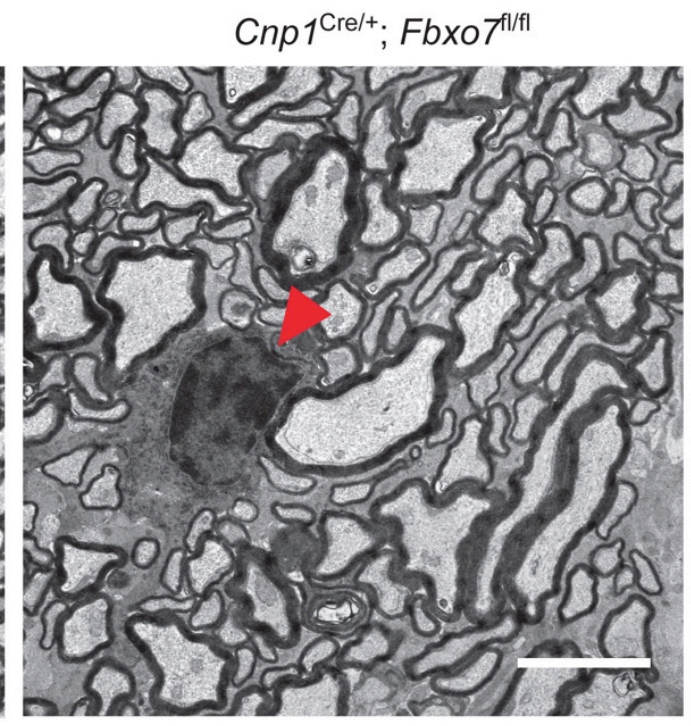

b Optic nerve

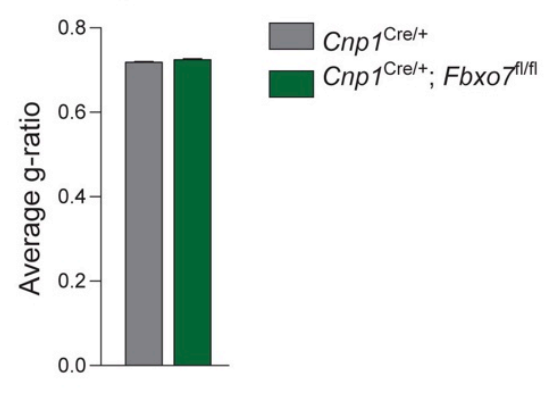

C

$0.0-0.64$ g-ratio

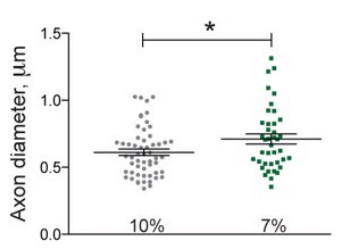

$0.65-0.75$ g-ratio

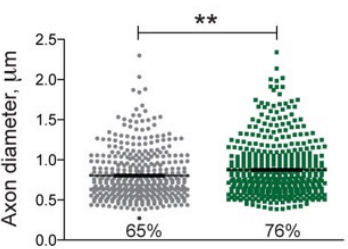

$0.76-0.90$ g-ratio

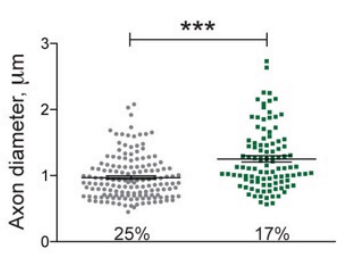

Distribution of g-ratio

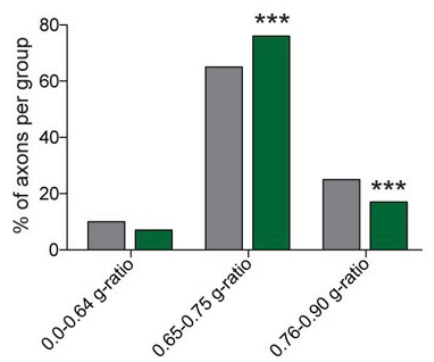

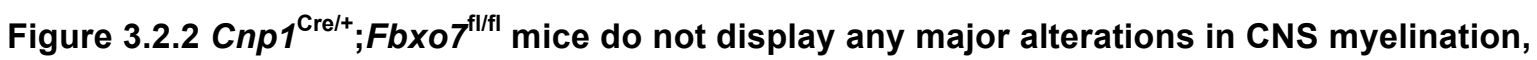
but a shift in axon caliber.

(a) Cross-sections of optic nerve from 3-month-old $\mathrm{Cnp} 1^{\mathrm{Cre} /+}$ and $\mathrm{Cnp} 1^{\mathrm{Cre} /+} ; \mathrm{FbxO} 7^{\mathrm{fl} / \mathrm{fl}}$ mice were obtained by electron microscopy. G-ratio was measured from three mice per genotype and displayed as scatter plot. 600 axons per genotype were quantified. Arrowheads indicate oligodendrocyte nuclei. Scale bar $=3 \mu \mathrm{m}$. Analysis was performed by Dr. Siv Vingill. (b) Average g-ratio of all measured axons from Cnp $1^{\mathrm{Cre} /+}$ and Cnp $1^{\mathrm{Cre} /+} ; \mathrm{Fbxo} 7^{\mathrm{fllfl}}$ mice (unpaired t-test, mean \pm s.e.m.). (c) Data obtained in (a) were sorted into 3 groups. Gratio values $0-0.64=$ hypermyelination, $0.65-0.75=$ normal myelination and $0.76-0.90=$ hypomyelination (unpaired t-test, ${ }^{*} \mathrm{P}<0.05,{ }^{* *} \mathrm{P}<0.01$, ${ }^{\star * *} \mathrm{P}<0.001$, mean \pm s.e.m.). The quantity of axons per group was analyzed and displayed as percentage (Chi-squared test, ${ }^{* * *} \mathrm{P}<0.001$ ). 
Analogously to the CNS, I examined myelination in the PNS. I measured the g-ratio of sciatic nerve cross-sections from $\mathrm{Cnp}^{\mathrm{Cre} /+} ; \mathrm{FbxO} 7^{\mathrm{fl} / \mathrm{fl}}$ and control mice, and found that the distribution of values of cKO and control mice was comparable. However, I observed that while the majority of data from both groups were similarly scattered, a small but noticeable fractions seemed to differ: a small population of axons in the cKO group indicated greater g-ratios (i) and in addition a second population of axons in the control group displayed larger diameter (ii) (Figure 3.2.3a). According to literature, the average g-ratio in the PNS equals approximately 0.6 (Rushton, 1951), however both our cKO and control mice revealed an average g-ratio of approximately 0.53 (Figure 3.2.3b). To flesh out the differences (i) in more detail, I subdivided the g-ratio measurements into classes. I chose values from $0-0.40$ to represent hypermyelination, values from $0.41-0.62$ should indicating normal myelination and g-ratios between $0.63-1$ reflected hypomyelination. The results showed that majority of axons from cKO and control mice displayed a normal myelination $(69 \%$ in $\mathrm{cKO}, 79 \%$ in control mice). Although the percentage of hypermyelinated and hypomyelinated axons in both genotypes were negligibly small (hypermyelination: $4 \%$ in $\mathrm{cKO}, 6 \%$ in control mice), cKO mice presented surprisingly more significant axons, which were hypomyelinated as compared to control $(27 \%$ in cKO, $15 \%$ in control mice). However, this small population of hypermyelinated axons in cKO and control mice only displays a small percentage of measured axons in the PNS. Regarding axon caliber (ii), cKO mice displayed significantly smaller axons and a lack of large caliber axons as compared to control. (Figure 3.2.3c). With these results I show that Fbxo7 deletion in Schwann cells did not cause major structural changes in myelin, however $12 \%$ more axons of cKO mice displayed increased hypomyelination than in control mice. Moreover the sciatic nerve of $\mathrm{Cnp} 1^{\mathrm{Cre} /+} ; \mathrm{FbxO} 7^{\mathrm{fl/fl}}$ mice contained significantly smaller axons, indicating a change in axon caliber upon loss of $F b x o 7$ from Schwann cells. 
a

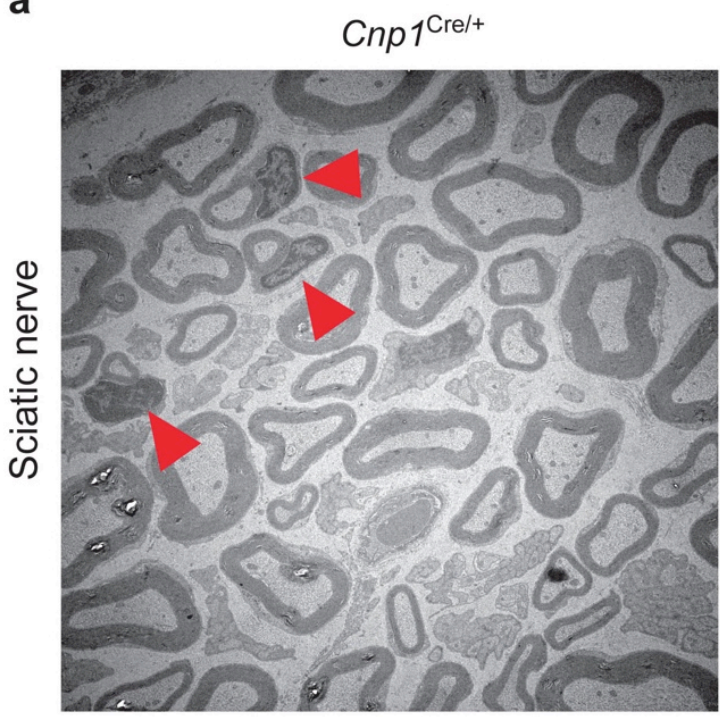

Cnp1 $1^{\mathrm{Cre} /+} ;$ Fbxo $7^{\mathrm{fl} / \mathrm{fl}}$

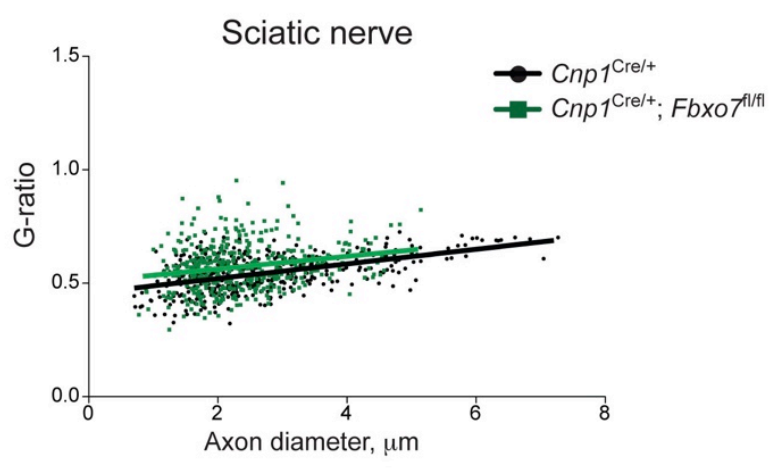

b Sciatic nerve
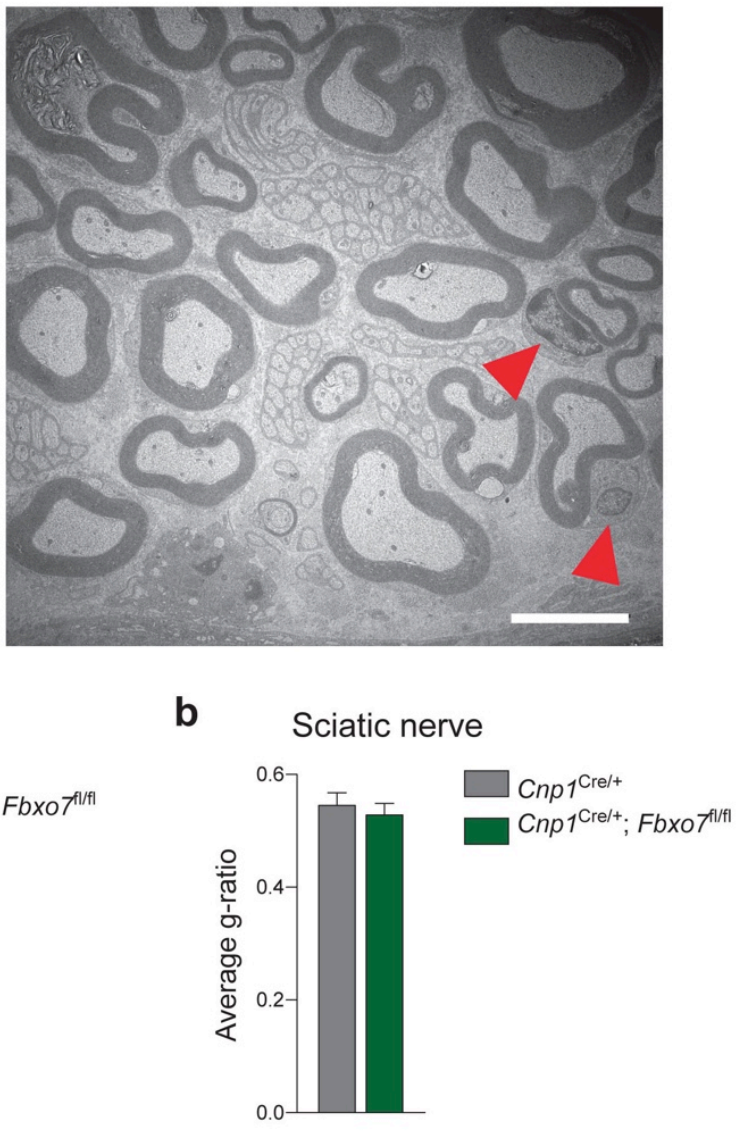

C
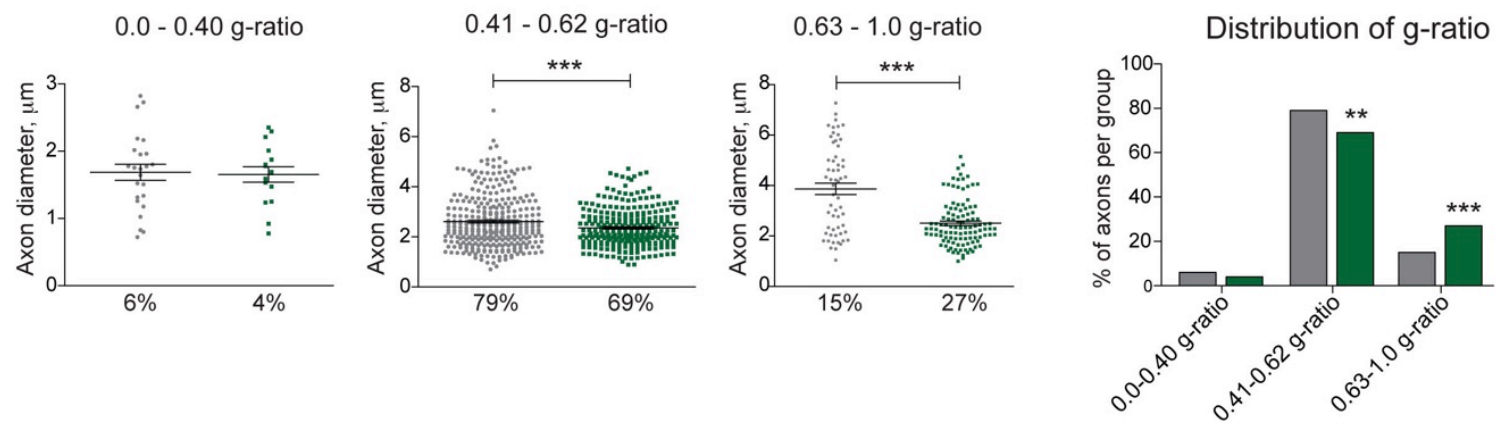

Figure 3.2.3 $\mathrm{Cnp1}^{\mathrm{Cre} /+} ; \mathrm{FbxO} 7^{\mathrm{fl} / \mathrm{fl}}$ mice show no severe changes in PNS myelination, but a shift in axon caliber.

(a) Representative images of sciatic nerve cross-sections from 3 -month-old $\mathrm{Cnp} 1^{\mathrm{Cre} /+}$ and $\mathrm{Cnp} 1^{\mathrm{Cre} /+} ; \mathrm{FbxO} 7^{\mathrm{fl} / \mathrm{fl}}$ mice. Images were obtained by electron microscopy and g-ratio was measured from four mice per genotype. Scatter plot presents 400 axons per genotype. Arrowheads indicate Schwann cell nuclei of myelinated axons. Scale bar $=3 \mu \mathrm{m}$. (b) Average g-ratio of all measured axons from $\mathrm{Cnp} 1^{\mathrm{Cre} /+}$ and $\mathrm{Cnp} 1^{\mathrm{Cre} /+} ; \mathrm{FbxO} 7^{\mathrm{fl} / / \mathrm{ll}}$ mice (unpaired t-test, mean \pm s.e.m.). (c) Analysis of (a) was grouped into 3 classes: g-ratio of $0-0.40=$ hypermyelination, $0.41-0.62=$ normal myelination group and $0.63-1=$ hypomyelination (unpaired $\mathrm{t}$-test, ${ }^{* * *} \mathrm{P}<0.001$, mean \pm s.e.m.). Percentage of axons per group was analyzed $\left(\mathrm{N}-1\right.$ Chi-squared test, ${ }^{*} \mathrm{P}<0.05$, $\left.{ }^{* * *} P<0.001\right)$. 
To examine if knockout of $\mathrm{Fbxo7}$ might influence the abundance of myelinating cells, I counted oligodendrocyte and Schwann cell nuclei in optic and sciatic nerve, respectively. Nuclei were counted from the same electron microscopic images that were used for $g$ ratio measurement. The results showed no significant change in the quantity of oligodendrocyte nuclei (Figure 3.2.4a) or Schwann cell nuclei. However a trend of slightly less Schwann cell nuclei was seen in $\mathrm{Cnp} 1^{\mathrm{Cre} /+} ; \mathrm{FbxO} 7^{\mathrm{fl} / \mathrm{fl}}$ mice as compared to control (Figure 3.2.4b).

While evaluating morphological changes within the sciatic nerve, I primarily focused on myelinated axons. However, non-myelinated small diameter axons, so-called $C$ fibers, are also found in the sciatic nerve. $C$ fibers are grouped together and form so-called Remak bundles, in which Remak cells engulf the fibers and cluster them together. To analyze the effect of Fbxo7 deletion on Remak bundles, I counted the nuclei of Remak cells. As depicted in Figure 3.2.4c, the number of Remak cells was not altered.

Moreover, I performed a TUNEL assay on 3-month-old sagittal brain sections from Fbxo $7^{\mathrm{fl/fl}}, \mathrm{Cnp} 1^{\mathrm{Cre} /+}$ and $\mathrm{Cnp} 1^{\mathrm{Cre} /+} ; \mathrm{FbxO} 7^{\mathrm{fl/fl}}$ mice, to determine cell death within white matter of the CNS. There were slightly more apoptotic cells present in the white matter of cerebellum of cKO mice than compared to controls, but this reached not significance. Further on, there was no significant increase in apoptotic cells in corpus callosum in cKO mice when compared to control mice (Figure 3.2.4d). 
a

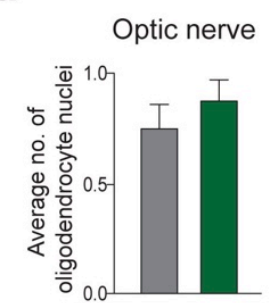

b

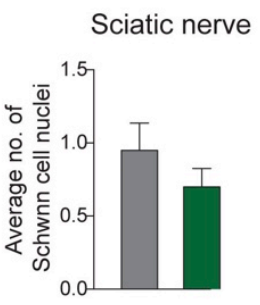

C
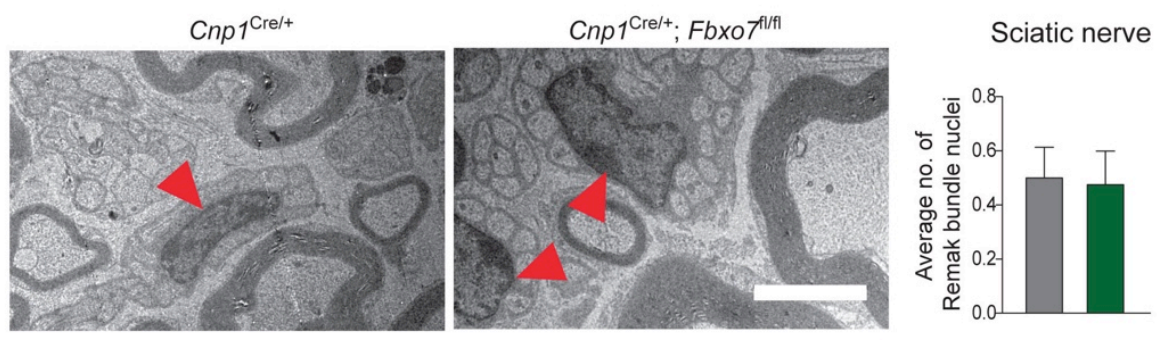

$\square \mathrm{Cnp} 1^{\mathrm{Cre} /+}$

- $\mathrm{Cnp}^{\mathrm{Cre} /+} ; \mathrm{Fbxo} 7^{\mathrm{fl} / \mathrm{ll}}$

d

Fbxo7 $7^{\text {1/n }}$

Cnp $1^{\text {Crel+ }}$

Cnp1 ${ }^{\mathrm{Crel}+} ; \mathrm{FbxO} 7^{\mathrm{n} / \mathrm{fl}}$

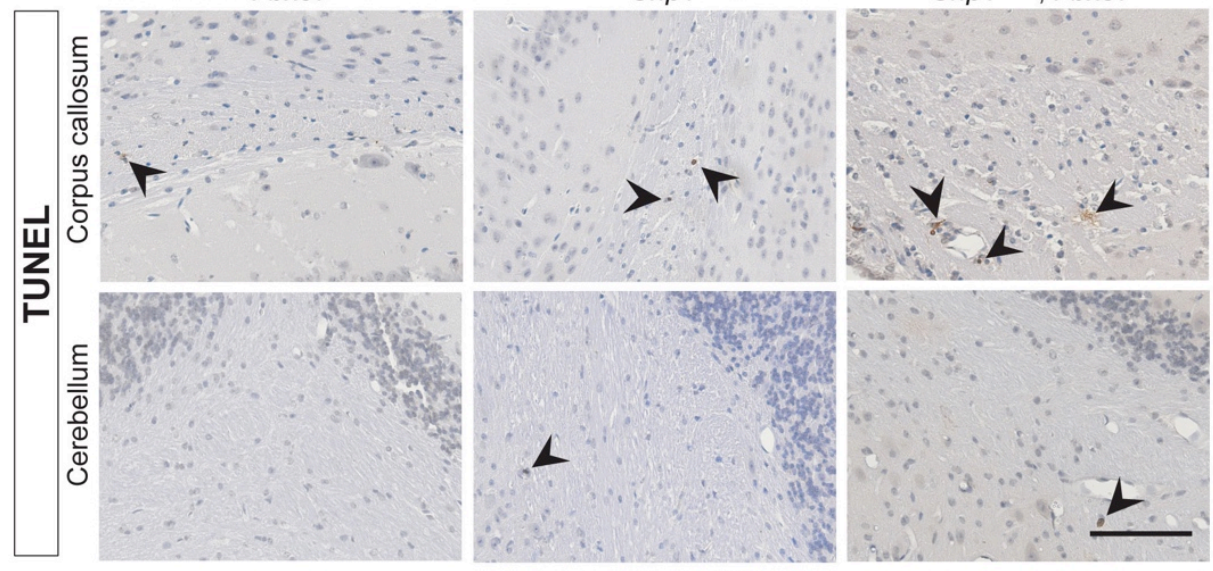

TUNEL

Corpus callosum
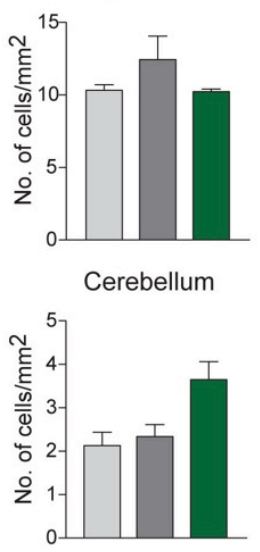

$$
\begin{aligned}
& \square \text { Fbxo } 7^{\mathrm{fl} / \mathrm{fl}} \\
& \text { - Cnp1 } 1^{\mathrm{Cre} /+} \\
& \text { - } \mathrm{Cnp}^{\mathrm{Cre} /+} ; \mathrm{FbxO}^{\mathrm{fl} / \mathrm{fl}}
\end{aligned}
$$

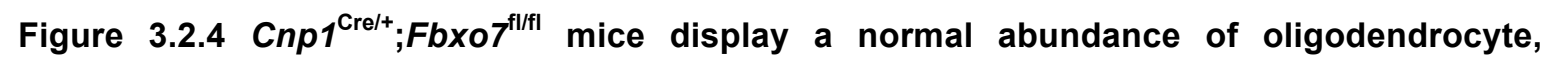
Schwann cell and Remak cell nuclei.

(a) Number of oligodendrocyte nuclei in optic nerve cross-section of 3-month-old Cnp1 ${ }^{\text {Cre/+ }}$ and Cnp $1^{\mathrm{Cre} /+} ; \mathrm{FbxO}{ }^{\mathrm{fl/fl}}$ mice. Nuclei were counted in the same images as described in 3.2.1.2a. (unpaired t-test, mean \pm s.e.m.). (b) Analysis of Schwann cell nuclei in cross-sections of sciatic nerve from 3-month-old $\mathrm{Cnp} 1^{\mathrm{Cre} /+}$ and $\mathrm{Cnp} 1^{\mathrm{Cre} /+} ; \mathrm{FbxO} 7^{\mathrm{fl} / \mathrm{fl}}$ mice (same images as described in 3.2.1.3a) (unpaired t-test, mean \pm s.e.m.). (c) Electron microscopy images of sciatic never cross-sections from $\mathrm{Cnp} 1^{\mathrm{Cre} /+}$ and $\mathrm{Cnp} 1^{\mathrm{Cre} /+} ; \mathrm{FbxO} 7^{\mathrm{fl} / \mathrm{fl}}$ mice were analyzed counting Remak bundle nuclei (unpaired t-test, mean \pm s.e.m.). Arrowheads indicate Remak bundle nuclei. Scale bar $=1.5 \mu \mathrm{m}$. (d) TUNEL assay was performed on sagittal paraffin sections of brains from 3-month-old Fbxo $7^{\mathrm{fl} / \mathrm{fl}}, \mathrm{Cnp}^{\mathrm{Cre} /+}$ and $\mathrm{Cnp} 1^{\mathrm{Cre} /+} ; \mathrm{FbxO} 7^{\mathrm{fl} / \mathrm{fl}}$ mice. Three independent animals per group and two technical replicates were analyzed. TUNEL positive cells were counted in corpus callosum and white matter of cerebellum (One-way ANOVA, including Bonferroni post-test, mean \pm s.e.m). Arrowheads indicate $\mathrm{TUNEL}^{+}$cells. Scale bar $=100 \mu \mathrm{m}$. 


\subsubsection{Cnp $1^{\mathrm{Cre} /+} ; \mathrm{Fb} \times 07^{\mathrm{fl} / \mathrm{fl}}$ mice display prominent axonal degeneration in the periphery}

Although $\mathrm{Fbxo7}$ was deleted from myelinating cells, my investigations showed no striking impact on myelination in the CNS or PNS. The interaction between myelinating cells and axons is essential for fast propagation of the action potential but also to ensure mutual support and stabilization. Owing to this strong cooperation and growing evidence that bolsters a critical trophic support for axons by myelinating cells (Corfas et al., 2004; Nave, 2010a; Simons and Nave, 2015), I investigated the effects of Fbxo7 deletion on axonal integrity. I subjected sagittal brain sections of 3-months-old Fbxo7 fl/fl and $\mathrm{Cnp}^{\mathrm{Cre} / \mathrm{H}} ; \mathrm{FbxO} 7^{\mathrm{fl} / \mathrm{fl}}$ mice to immunohistochemistry using an antibody against amyloid precursor protein (APP). APP is anticipated to accumulate as a result of axonal damage (An et al., 1997). However, I did not observe any change in APP distribution in cKO as compared to control mice, indicating no difference in axonal integrity within corpus callosum and white matter of cerebellum (Figure 3.2.5a). While there was no APP accumulation present in the CNS, quantifications of APP staining on longitudinal sciatic nerve sections from 3-month-old $\mathrm{FbxO} 7^{\mathrm{fl/fl}}, \mathrm{Cnp} 1^{\mathrm{Cre} /+}$ and $\mathrm{Cnp} 1^{\mathrm{Cre} /+} ; \mathrm{FbxO} 7^{\mathrm{fl/fl}}$ mice showed significant accumulation of APP in CKO tissue (Figure 3.2.5b). Collectively, my findings demonstrate that loss of $\mathrm{Fbxo7}$ results in axonal damage in the sciatic but not optic nerve and thus suggests a greater vulnerability in Schwann cells. 
a

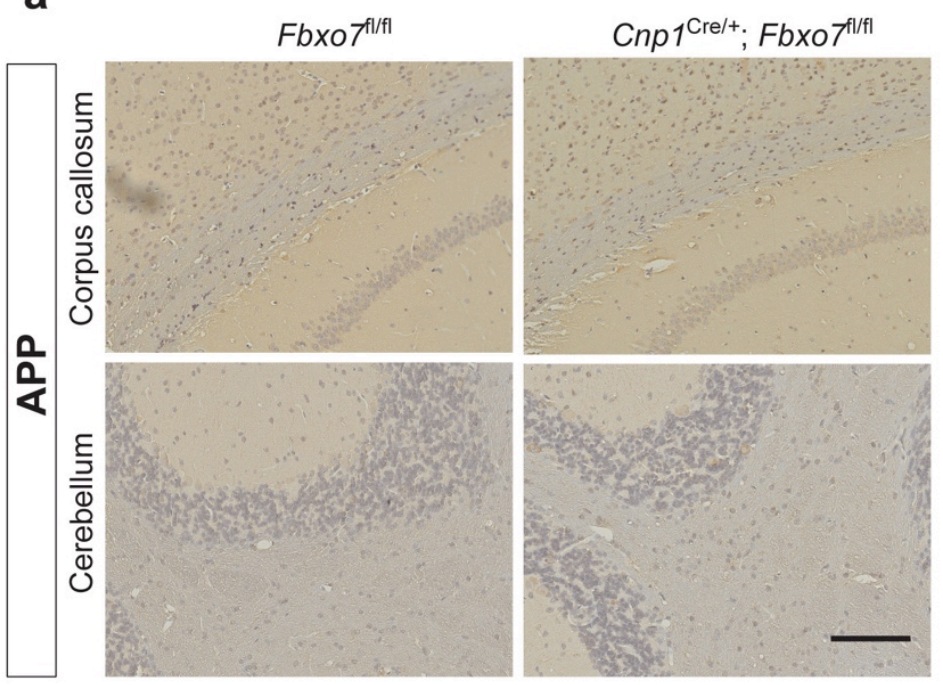

b

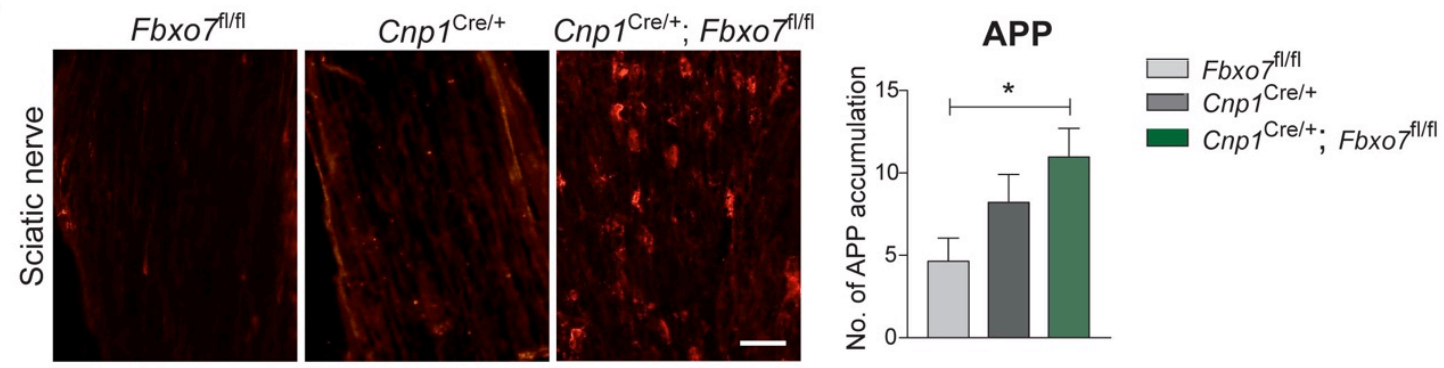

Figure 3.2.5 $\mathrm{Cnp}^{\mathrm{Cre} / \mathrm{+}}$; $\mathrm{FbxO}^{\mathrm{fl/fl}}$ mice show axonal damage in the PNS.

(a) Representative images of sagittal paraffin brain sections of 3-month-old $\mathrm{FbxO} 7^{\mathrm{fl/fl}}$ and $\mathrm{Cnp} 1^{\mathrm{Cre} /+} ; \mathrm{FbxO} 7^{\mathrm{fl/fl}}$ mice, which were immunostained with an APP antibody. Images depict white matter of cerebellum and corpus callosum. Scale bar $=100 \mu \mathrm{m}$. (b) Longitudinal cryo-section of sciatic nerves from 3-month-old Fbxo $7^{\mathrm{f} / \mathrm{fl}}$, $\mathrm{Cnp}_{1}{ }^{\mathrm{Crel}+}$ and $\mathrm{Cnp}_{1}{ }^{\mathrm{Crel}+} ; \mathrm{FbxO} 7^{\mathrm{fl/ft}}$ mice were subjected to immunohistochemistry using an antibody against APP. Three independent mice per genotype and three sections from each animal were analyzed. (one-way ANOVA, including Bonferroni post-test, ${ }^{*} P<0.05$, mean \pm s.e.m). The images were analyzed by applying a customized macro designed by Dr. Miso Mitkovski and further the numbers of APP accumulations were counted. Scale bar $=40 \mu \mathrm{m}$.

Owing to the observed axonal damage, I decided to analyze any changes in axon morphology and abundance using electron microscopic images of 3-month-old Cnp ${ }^{\text {Cre/ }}{ }^{-+}$ and $\mathrm{Cnp} 1^{\mathrm{Cre} /+} ; \mathrm{FbxO} 7^{\mathrm{fl/fl}}$ mice. Similar to previous analyses, g-ratio measurements of optic nerve samples were grouped but this time according to axon diameter. The groups included axons of either $<1 \mu \mathrm{m}$ or $>1 \mu \mathrm{m}$ in diameter. The results showed that the majority of axons from control and cKO mice displayed a diameter of $<1 \mu \mathrm{m}(75 \%$ in control, $66 \%$ in CKO). Interestingly, the distribution of axon sizes further revealed that $\mathrm{Cnp} 1^{\mathrm{Cre} /+} ; \mathrm{FbxO} 7^{\mathrm{fl} / \mathrm{fl}}$ mice harbored significantly more axons with a diameter greater than $1 \mu \mathrm{m}$ as compared to control ( $25 \%$ in control, $34 \%$ in $\mathrm{cKO})$. This indicates that loss of $\mathrm{FbxO} 7$ in oligodendrocytes 
leads to a mild shift towards large caliber axons in the optic nerve. Moreover, the analysis showed no difference in g-ratio between cKO and control mice, which matched my previous result (Figure 3.2.6a).

For the quantification of PNS axon calibers, g-ratio values from sciatic nerve were grouped as follows: axon diameter from $0-1 \mu \mathrm{m}, 2-3 \mu \mathrm{m}$ and $>4 \mu \mathrm{m}$. The results showed that the majority of axons of $\mathrm{Cnp} 1^{\mathrm{Cre} /+} ; \mathrm{FbxO} 7^{\mathrm{fl/fl}}$ and $\mathrm{Cnp} 1^{\mathrm{Cre} /+}$ mice had a diameter in the range of $2-3 \mu \mathrm{m}\left(57 \%\right.$ in $\mathrm{cKO}, 50 \%$ in control). Interestingly, Cnp $1^{\mathrm{Cre} /+} ; \mathrm{FbxO} 7^{\mathrm{fl/fl}}$ mice revealed a shift in axon caliber within the sciatic nerve: while axons larger than $4 \mu \mathrm{m}$ were significantly less abundant in cKO mice ( $5 \%$ in cKO and $17 \%$ in control), the number of small caliber axons that were $<4 \mu \mathrm{m}$ in diameter were increased in $\mathrm{Cnp}^{\mathrm{Cre} /+} ; \mathrm{FbxO} 7^{\mathrm{fl/fl}}$ mice as compared to controls (summarized from both groups: $95 \%$ in cKO, $83 \%$ in control). Additionally, the analysis confirmed my previous result and showed that sciatic nerve axons of cKO mice were rather hypomyelinated than axons of controls (Figure 3.2.6b). In conclusion, Fbxo7 deletion within oligodendrocytes leads to an increase in axon diameter, without significant changes in myelination, whereas in Schwann cells loss of Fbxo7 leads to a reduction in large caliber axons. Supporting my previous assumption, this analysis further indicated a moderate hypomyelination of PNS axons.

a

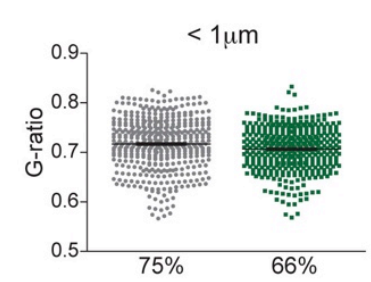

Distribution of axon diameter in optic nerve

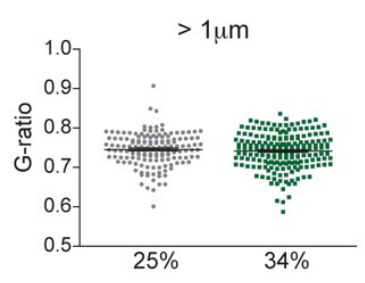

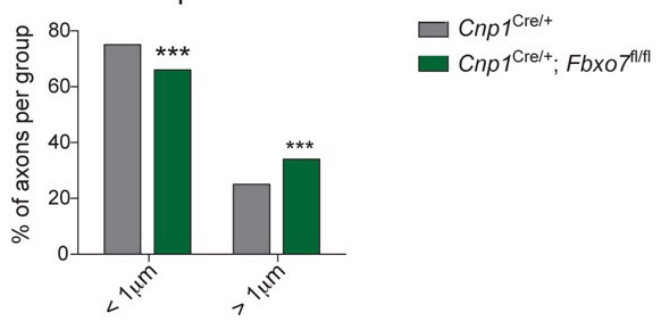

b
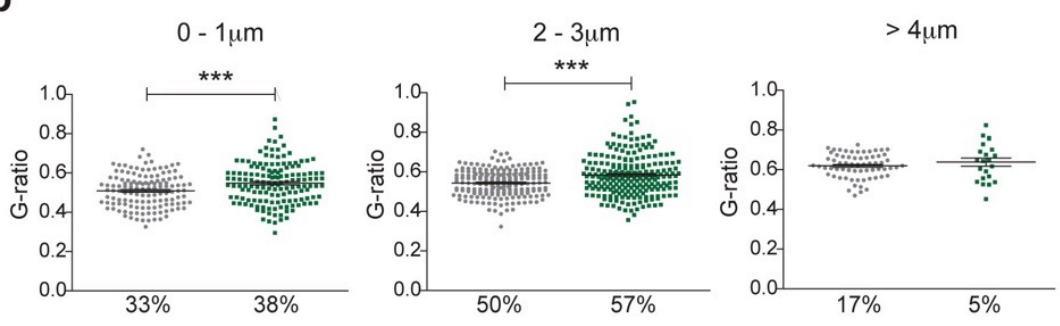

Distribution of axon diameter in sciatic nerve

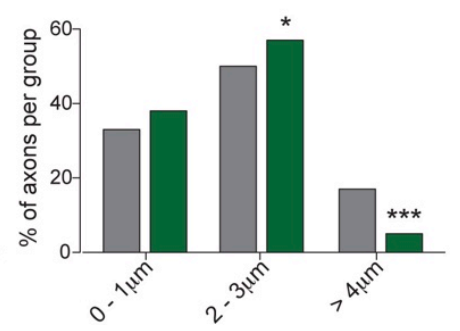

Figure 3.2.6 Loss of FBXO7 induces an increase in axon caliber in the CNS and a shift towards small caliber axons in the PNS of $\mathrm{Cnp}^{\mathrm{Cre/+}} ; \mathrm{FbxO}^{\mathrm{fl/fl}}$ mice.

(a) G-ratio measurement from optic nerve cross-sections of 3 -month-old $\mathrm{Cnp} 1^{\mathrm{Cre} /+}$ and $\mathrm{Cnp} 1^{\mathrm{Cre} /+} ; \mathrm{FbxO} 7^{\mathrm{fl/fl}}$ mice were grouped according to axonal diameter $(<1 \mu \mathrm{m},>1 \mu \mathrm{m})$. Three independent mice per genotype were included and 600 axons per condition analyzed (unpaired t-test, mean \pm s.e.m.). The percentage of axons per group was analyzed $\left(\mathrm{N}-1\right.$ Chi-squared test, $\left.{ }^{* * *} \mathrm{P}<0.001\right)$. (b) Measured g-ratios from sciatic nerve cross- 
sections of 3 -month-old $\mathrm{Cnp} 1^{\mathrm{Cre} /+}$ and $\mathrm{Cnp} 1^{\mathrm{Cre} /+} ; \mathrm{FbxO} 7^{\mathrm{fl} / \mathrm{fl}}$ mice were classified according to the axonal diameter $(0-1 \mu \mathrm{m}, 2-3 \mu \mathrm{m},>4 \mu \mathrm{m})$. Four independent animals were analyzed per genotype and 400 axons per condition measured (unpaired t-test, ${ }^{* *} \mathrm{P}<0.001$, mean \pm s.e.m.). The percentage of axons per group was analyzed ( $\mathrm{N}-1$ Chi-squared test, $\left.{ }^{*} \mathrm{P}<0.05,{ }^{* * *} \mathrm{P}<0.001\right)$.

Deletion of Fbxo7 induced a shift in axon diameter within the optic nerve and sciatic nerve. To investigate whether or not this shift in axon caliber correlates with changes in axon number, I counted myelinated axons. I analyzed axons on electron microscopic images from optic nerve sections of 3 -month-old $\mathrm{Cnp} 1^{\mathrm{Cre} /+}$ and $\mathrm{Cnp} 1^{\mathrm{Cre} /{ }_{+}} ; \mathrm{FbxO} 7^{\mathrm{fl/fl}}$ mice, but found no difference in the number of axons within the optic nerve of cKO and control mice (Figure 3.2.7a). In addition, I assessed the number of degenerated axons in the optic nerve. Here, $\mathrm{Cnp}^{\mathrm{Cre} /+} ; \mathrm{FbxO} 7^{\mathrm{fl/fl}}$ mice displayed a slight but not significant increase in degenerated axons (Figure 3.2.7b).
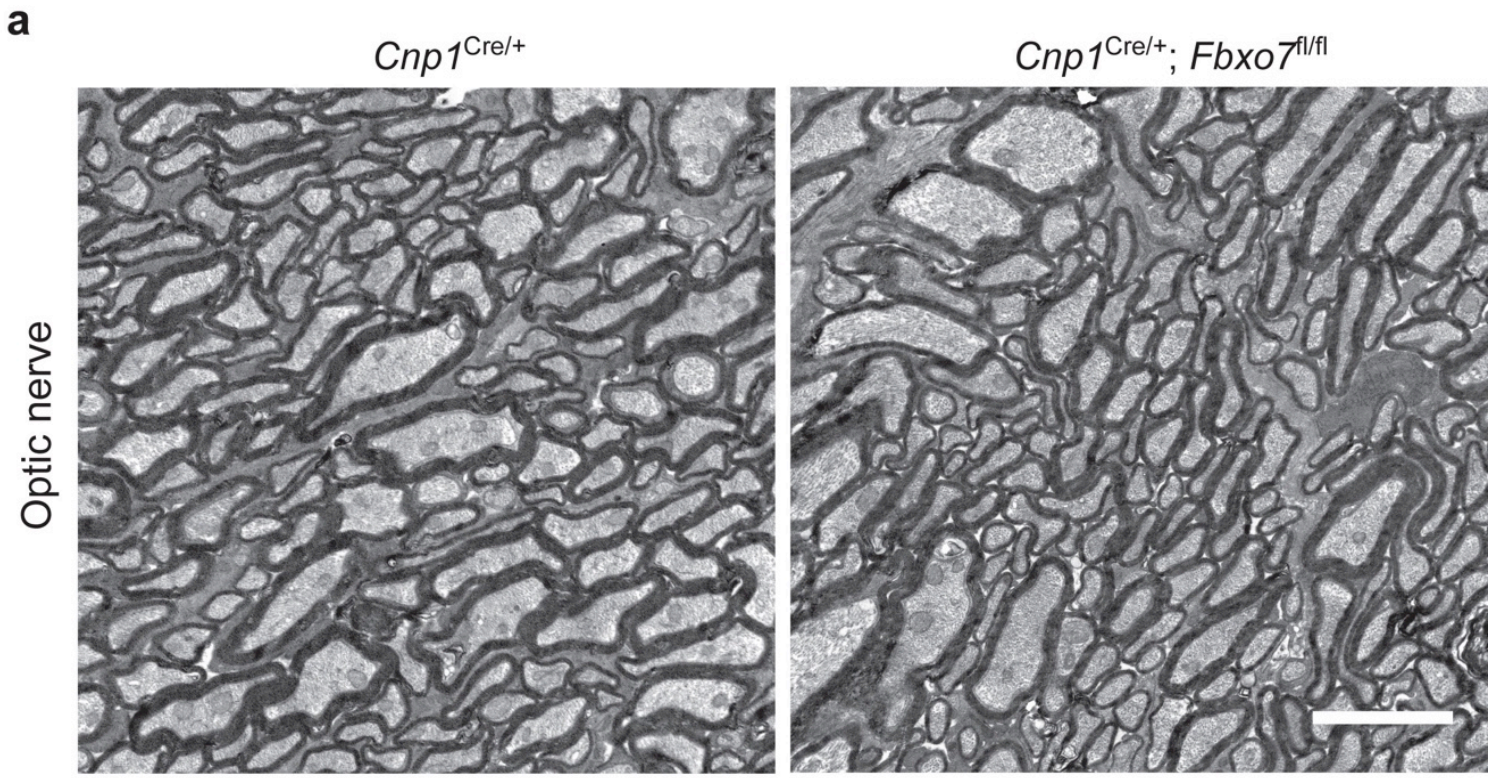

Optic nerve

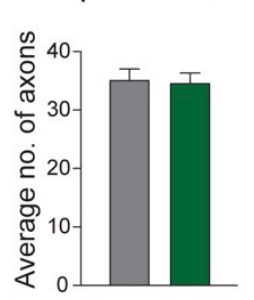

b

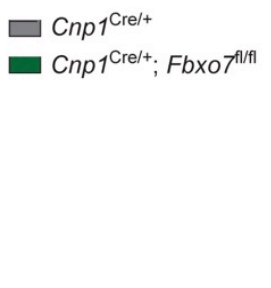

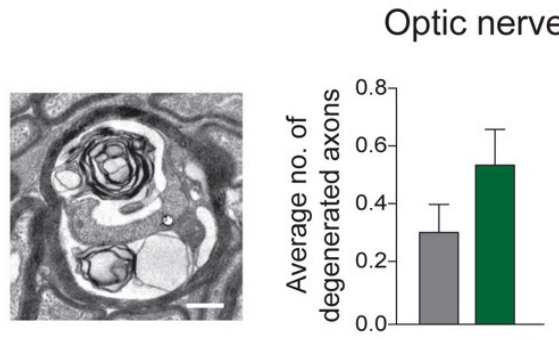

Figure 3.2.7 $\mathrm{Cnp1}^{\mathrm{Cre} /+} ; \mathrm{FbxO} 7^{\mathrm{fl} / \mathrm{fl}}$ mice show no significant increase in the number of axons as well as degenerated axons in the optic nerve.

(a) Average number of axons within optic nerve of 3-month-old $\mathrm{Cnp} 1^{\mathrm{Cre} /+}$ and $\mathrm{Cnp} 1^{\mathrm{Cre} /+} ; \mathrm{FbxO} 7^{\mathrm{fl} / \mathrm{fl}}$ mice. Three mice per condition and 10 images per mouse were analyzed (unpaired t-test, mean \pm s.e.m.). Images depict 
cross-sections of optic nerve. Scale bar $=3 \mu \mathrm{m}$. (b) Representative image of degenerated axon from optic nerve of 3-month-old $\mathrm{Cnp}^{\mathrm{Cre/+}} ; \mathrm{FbxO}^{\mathrm{nt/fl}}$ mouse. Images described in (a) were used to count the average number of degenerated axons from three mice per genotype and within 10 images per mouse (unpaired t-test, mean \pm s.e.m.). Scale bar $=0.5 \mu \mathrm{m}$.

I further quantified the abundance of myelinated axons and axonal degeneration depicted on electron microscopic images from sciatic nerve sections of 3-month-old $\mathrm{Cnp} 1^{\mathrm{Cre} /+}$ and Cnp $1^{\mathrm{Cre} /+} ; F b x O 7^{\mathrm{fl} / f l}$ mice. The results showed a significant loss of myelinated axons in cKO mice as compared to control (Figure 3.2.8a). Moreover, $C n p 1^{\mathrm{Cre} /+} ; \mathrm{FbxO} 7^{\mathrm{fl} / \mathrm{fl}}$ mice revealed a significant increase in degenerated axons within the sciatic nerve (Figure 3.2.8b). Furthermore, I counted the number of Remak bundles in the sciatic nerve, but saw no difference between $\mathrm{Cnp} 1^{\mathrm{Cre} /+} ; \mathrm{FbxO} 7^{\mathrm{fl/fl}}$ and control mice (Figure 3.2.8c). The number of degenerated Remak bundles was slightly but not significantly higher in cKO mice than in controls (Figure 3.2.8d). Overall, loss of Fbxo7 in myelinating cells leads to axonal degeneration in the optic and sciatic nerve. However, knockout of Fbxo7 appears to be more detrimental for large caliber axons in the PNS as compared to axons in the CNS, since the PNS shows a greater axonal loss. 
a
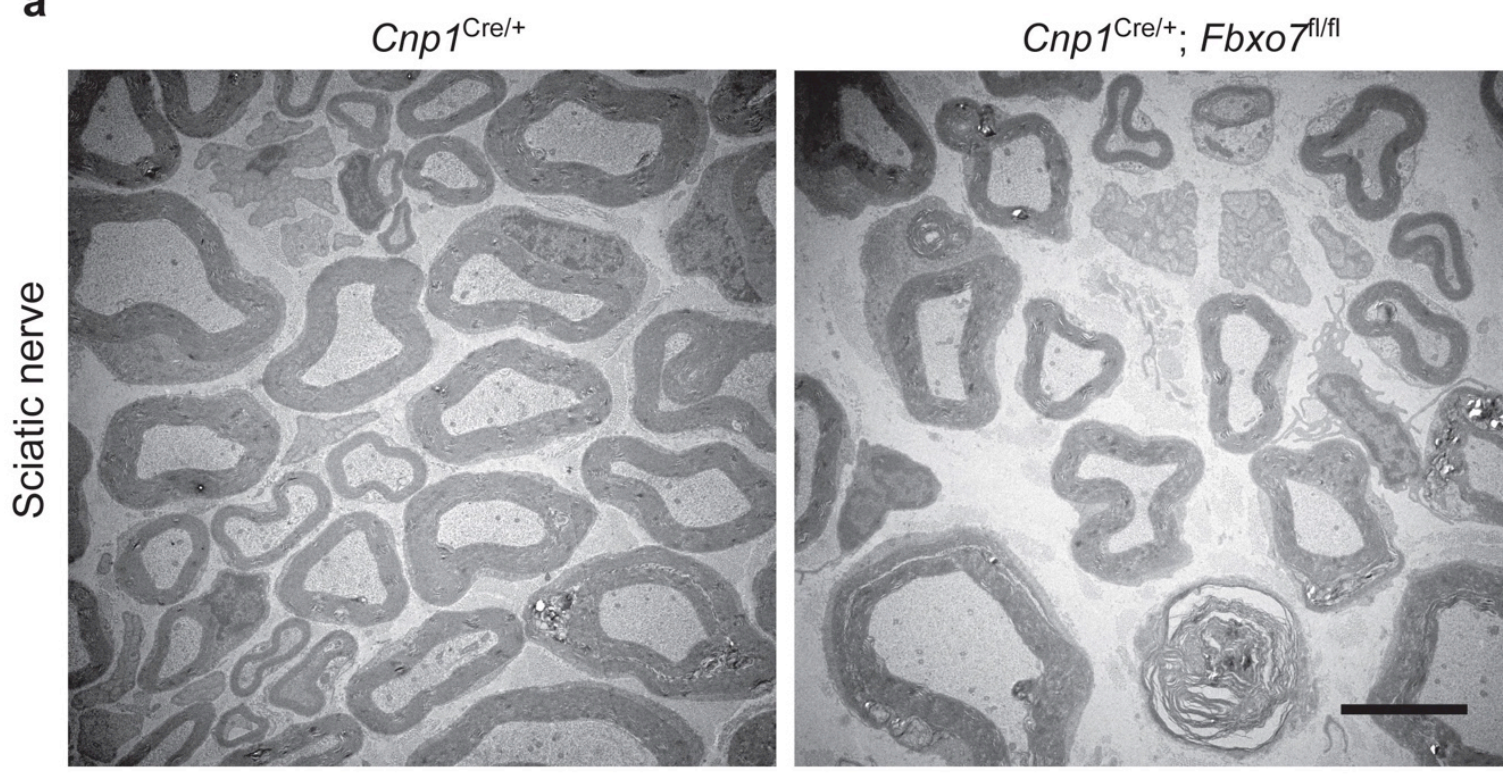

Sciatic nerve

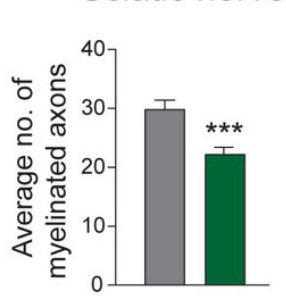

C

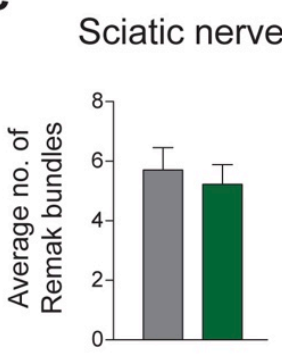

b

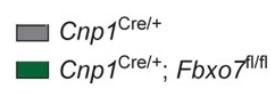

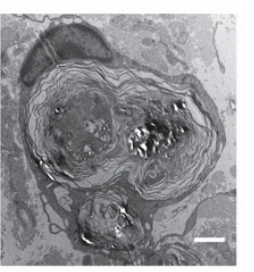

Sciatic nerve

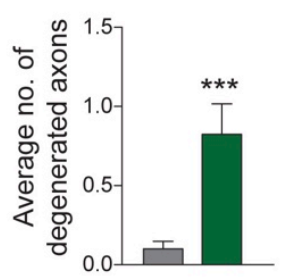

d

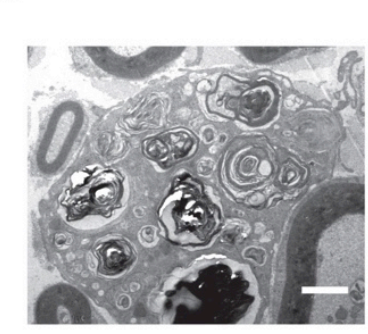

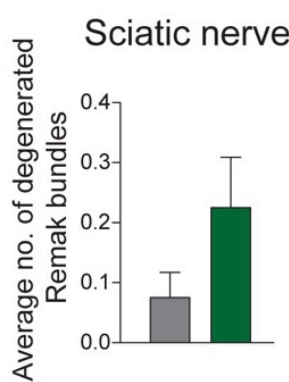

Figure 3.2.8 Loss of Fbxo7 leads to increased axonal degeneration within the sciatic nerve of $\mathrm{Cnp} 1^{\mathrm{Cre} /+} ; \mathrm{Fbxo} 7^{\mathrm{fl/f1}}$ mice.

(a)-(d) Sciatic nerve cross-sections of 3-month-old $\mathrm{Cnp} 1^{\mathrm{Cre} / \mathrm{+}}$ and $\mathrm{Cnp} 1^{\mathrm{Cre} /+} ; \mathrm{FbxO} 7^{\mathrm{HI/fl}}$ mice were analyzed. Four independent animals per condition and 10 images per mouse were included in the analyses (unpaired t-test, ${ }^{* * *} P<0.001$, mean \pm s.e.m.). (a) Representative electron microscopic images of cross-sections from sciatic nerve. The average number of myelinated axons was counted. Scale bar $=3 \mu \mathrm{m}$. (b) Further on, the average number of degenerated axons was counted. Electron microscopic image from sciatic nerve represents axonal degeneration. Scale bar $=1 \mu \mathrm{m}$. (c) The number of Remak bundles was assessed. (d) Analysis of degenerated Remak bundles. Electron microscopic image represents degenerated Remak bundles in sciatic nerve of 3-month-old $\mathrm{Cnp}^{\mathrm{Cre} /+} ; \mathrm{Fbxo} 7^{\mathrm{fl/t} / \mathrm{m}}$ mouse. Scale bar $=1 \mu \mathrm{m}$. 
In order to further understand the underlying pathophysiology of $\mathrm{Cnp}^{\mathrm{Cre} /+} ; \mathrm{FbxO} 7^{\mathrm{fl} / \mathrm{fl}}$ mice, we performed electrophysiological recordings. The pathology of knockout mice was predominantly located in the periphery and $\mathrm{FbxO} 7$ deletion led to a greater deterioration of PNS than of CNS axons. Thus, we decided to examine electrophysiological changes of the sciatic nerve. Electrophysiological recordings were performed by Dr. Robert Fledrich, who analyzed 2-month-old $\mathrm{Cnp} 1^{\mathrm{Cre} /+} ; \mathrm{FbxO} 7^{\mathrm{fl} /+}$ and $\mathrm{Cnp} 1^{\mathrm{Cre} /+} ; \mathrm{FbxO} 7^{\mathrm{fl} / \mathrm{ll}}$ mice. The key parameters for quantification of peripheral nerve function included the compound muscle action potential (CMAP), nerve conduction velocity (NCV) and distal motor latency (DML). The CMAP is an indicator for the quantity of functional axons. Analysis of Cnp ${ }^{\mathrm{Cre} / \mathrm{H}} ; \mathrm{FbxO}^{\mathrm{fl} / \mathrm{fl}}$ mice showed significant decrease in CMAP at distal and proximal position, thus demonstrating loss of axons in the sciatic nerve (Figure 3.2.9a). In addition, Cnp ${ }^{\mathrm{Cre} /+} ; \mathrm{FbxO}^{\mathrm{fl} / \mathrm{fl}}$ mice exhibited a significant reduction in $\mathrm{NCV}$, further indicating axonal loss. However, a significant decrease in NCV could also imply segmental demyelination (Somlai, 2016) (Figure 3.2.9b). These potential changes in myelination can further be elucidated by measuring the DML as demyelination would lead to a prolonged DML. The measurements of the DML did not show any difference between cKO and control mice, suggesting no significant alteration of myelination (Figure 3.2.9c). These analyses supported my previous results and showed that ablation of $\mathrm{Fbxo7}$ from myelinating cells leads to severe axonal loss without significantly affecting myelination in the sciatic nerve.

a

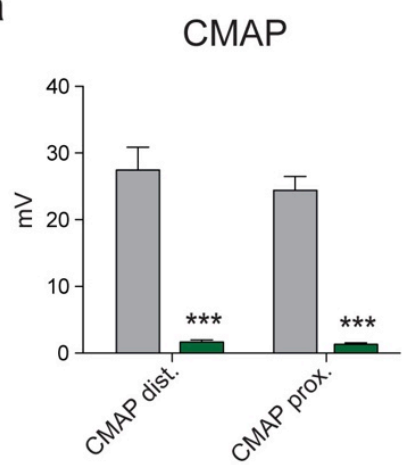

b

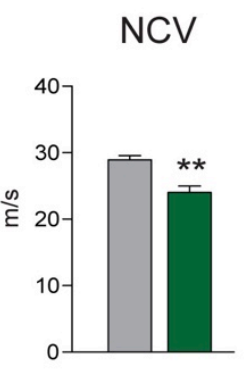

C

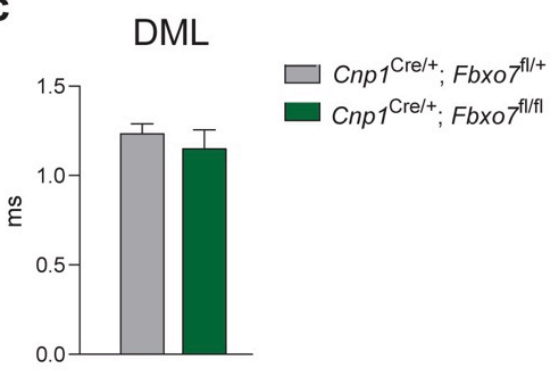

Figure 3.2.9 Severe axonal degeneration in the sciatic nerve of $\mathrm{Cnp} 1^{\mathrm{Cre} /+} ; \mathrm{FbxO} 7^{\mathrm{fl/fl}}$ mice.

(a)-(c) Electrophysiological recordings were measured from sciatic nerve of 2 -month-old $\mathrm{Cnp} 1^{\mathrm{Crel} /+} ; \mathrm{FbxO} 7^{\mathrm{fll+}}$ and $\mathrm{Cnp}_{1}{ }^{\mathrm{Cr} / \mathrm{f}} ; \mathrm{Fbxo} 7^{\mathrm{fl/fl}}$ mice. (a) Compound muscle action potential (CMAP). (b) Nerve conduction velocity (NCV). (c) Distal motor latency (DML). Analyses were performed on 6 independent mice per condition (unpaired t-test, ${ }^{* * P}<0.01,{ }^{* * *} P<0.001$, mean \pm s.e.m.). Electrophysiological recordings were performed by Dr. Robert Fledrich. 


\subsubsection{Knockdown of Fbxo7 from myelinating cells leads to increased inflammation}

The degeneration of cells and overall damage of tissue often evokes an immune response and as seen in many neurodegenerative diseases can induce neuroinflammation (Damier et al., 1993; Wyss-Coray and Mucke, 2002). Since $C n p 1^{\mathrm{Cre} /+} ; F b x O 7^{\mathrm{fl/fl}}$ mice featured increased axonal loss in both CNS and PNS, I searched for inflammatory events that would accompany the degenerative event in corpus callosum and white matter of cerebellum. Hence, I subjected 3-month-old sagittal brain sections from Fbxo $7^{\mathrm{fl} / \mathrm{fl}}, \mathrm{Cnp} 1^{\mathrm{Cre} /+}$ and $\mathrm{Cnp} 1^{\mathrm{Cre} /+} ; \mathrm{FbxO} 7^{\mathrm{fl/fl}}$ mice to immunohistochemical analysis using an antibody against the ionized calcium-binding adapter molecule 1 (Iba1), which acts as an indicator for inflammation. The quantifications of Iba1-positive cells within the corpus callosum did not show a difference between groups. However, analysis of the white matter of cerebellum showed a significant increase in the occurrence of microglia in cKO mice as compared to control (Figure 3.2.10a). To further investigate inflammation, I stained the aforementioned brain sections with an antibody against macrophage antigen 3 (Mac3), marker for reactivated microglia. The number of activated microglia resulted in a slight increase in the corpus callosum and white matter of cerebellum of $\mathrm{Cnp} 1^{\mathrm{Cre} /+} ; \mathrm{FbxO} 7^{\mathrm{fl/fl}}$ mice (Figure 3.2.10b). In addition, I examined whether loss of Fbxo7 leads to an increase in astrogliosis, since astrocytes extensively interact with microglia during an inflammatory response. Therefore, I immunostained brain sections with an antibody against glial fibrillary acidic protein (GFAP), a marker for astrocytes. The analysis showed a significant increase in GFAP signal in the white matter of cerebellum of $\mathrm{Cnp} 1^{\mathrm{Cre} /+} ; \mathrm{FbxO} 7^{\mathrm{fl/fl}}$ mice, but no difference in GFAP levels within the corpus callosum of all three groups (Figure 3.2.10c). To examine the inflammatory response upon $\mathrm{Fbxo7}$ deletion on long-traveling axons of the CNS, I further performed immunohistological staining on cross-sections of spinal cord from 3-months-old Fbxo $7^{\mathrm{fl} / \mathrm{fl}}, \mathrm{Cnp} 1^{\mathrm{Cre} /+}$ and $\mathrm{Cnp} 1^{\mathrm{Cre} /+} ; \mathrm{FbxO} 7^{\mathrm{fl} / \mathrm{fl}}$ mice. The analysis of lba1 stainings revealed a significant increase in microglia levels in Cnp ${ }^{\mathrm{Cre} / \mathrm{H}} ; \mathrm{FbxO} 7^{\mathrm{fl} / \mathrm{fl}}$ mice (Figure 3.2.10d). Moreover, GFAP stainings showed significantly more astrogliosis in cKO mice as compared to control (Figure 3.2.10e). Collectively, I found a significant increase in inflammation and astrogliosis predominantly in the white

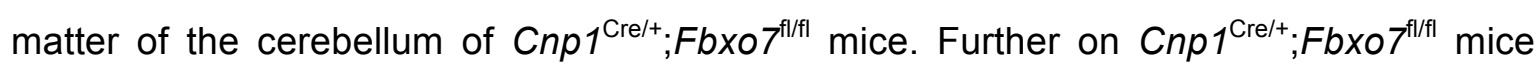
displayed significant inflammation and astrogliosis within the spinal cord. 


$$
\begin{aligned}
& \square \text { Fbxo } 7^{\mathrm{fl/fl}} \\
& \mathrm{Cnnp}^{\mathrm{Cre} /+} \\
& \mathrm{Cnnp}^{\mathrm{Cre} /+} ; \mathrm{Fbxo} 7^{\mathrm{fl/fl}}
\end{aligned}
$$

a

Fbxo7 7/fi

Cnp1 $1^{\mathrm{Cre} / \mathrm{t}}$

Cnp1 $1^{\mathrm{Cre} /+} ; \mathrm{FbxO} 7^{\text {1/fil }}$
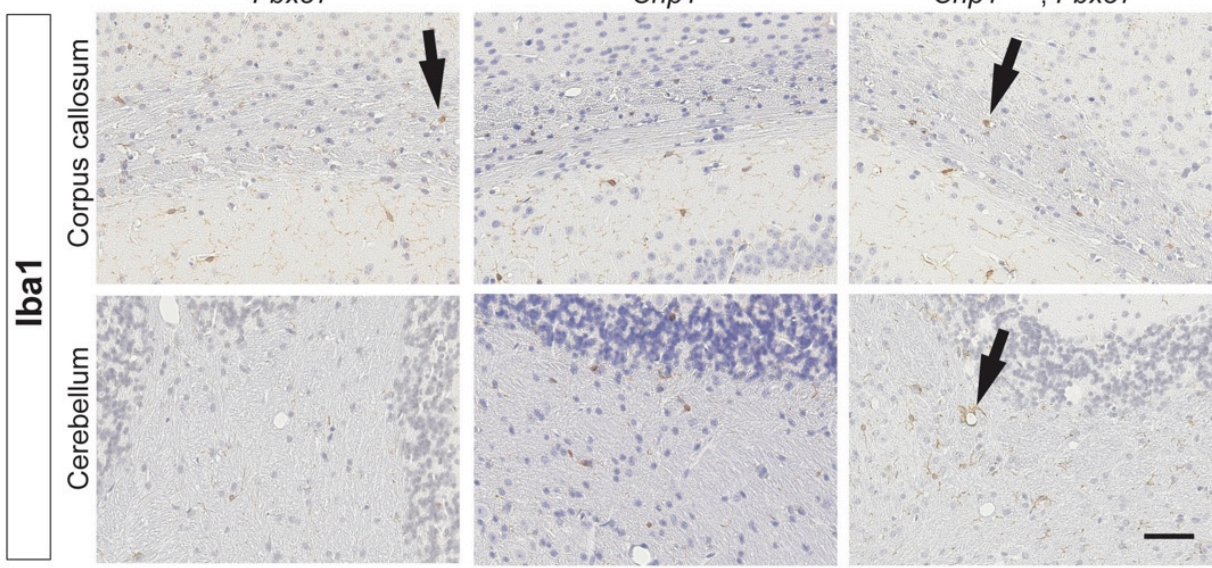

b
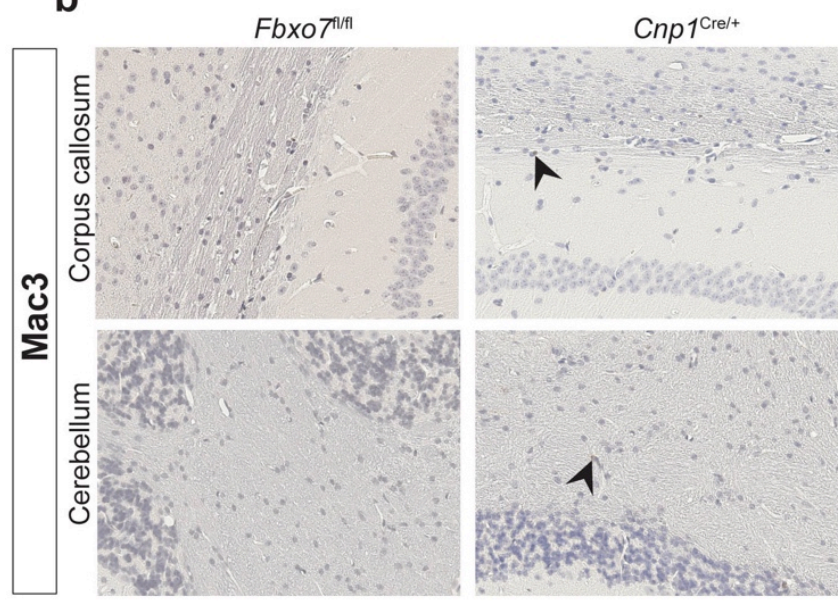

Cnp1 ${ }^{\mathrm{Cre} /+} ;$ Fbxo7 ${ }^{\mathrm{H} / \mathrm{fl}}$

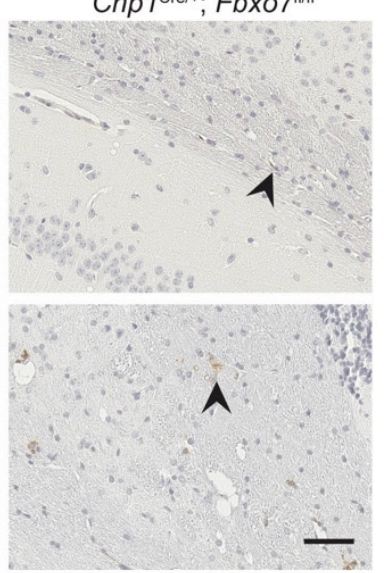

C

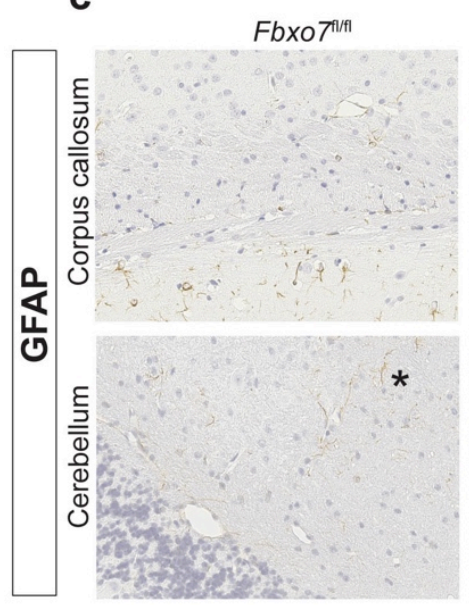

Cnp1 $1^{\text {Crel+ }}$

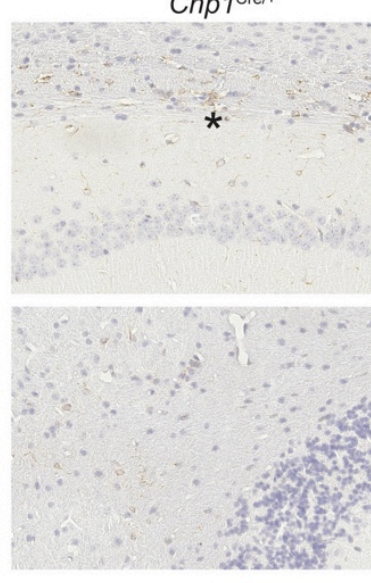

Cnp1 $1^{\mathrm{Crel}+} ; \mathrm{FbxO} 7^{\mathrm{H} / \mathrm{flf}}$
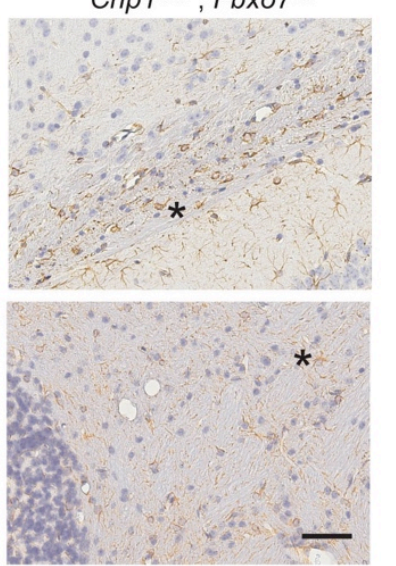

Iba1

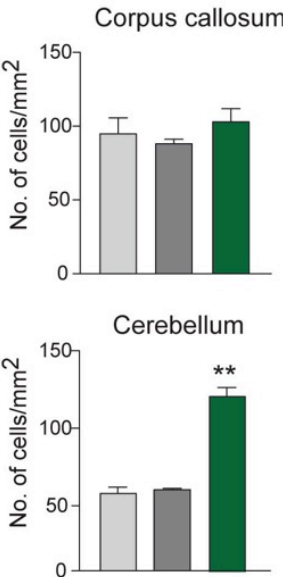

Mac3

Corpus callosum
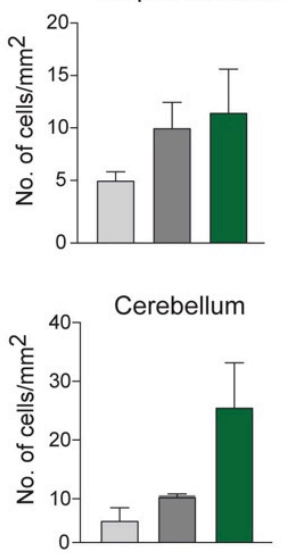

GFAP

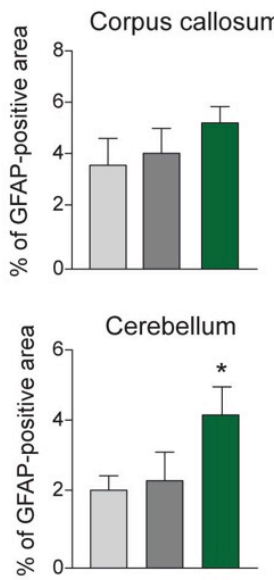


d

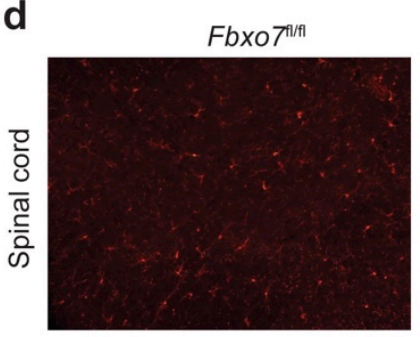

e

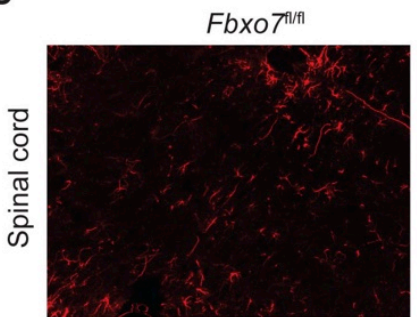

Cnp1 $1^{\mathrm{Cre} / \mathrm{t}}$

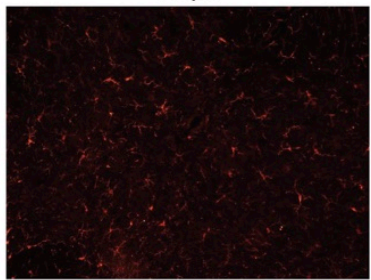

Cnp $1^{\text {Cre/+ }}$

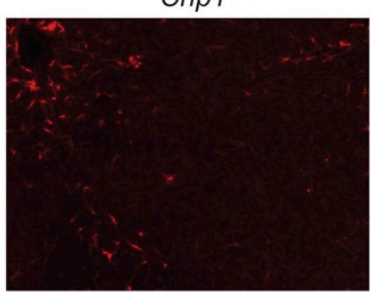

Cnp1 $1^{\mathrm{Cre} /+} ;$ Fbxo $7^{\mathrm{fl} / \mathrm{l}}$

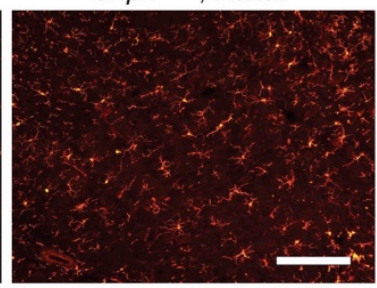

Cnp1 $1^{\mathrm{Cre} /+} ;$ Fbxo $7^{\text {fl/fl }}$

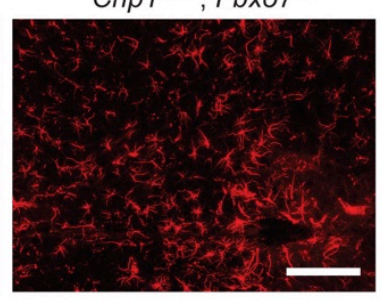

Iba1

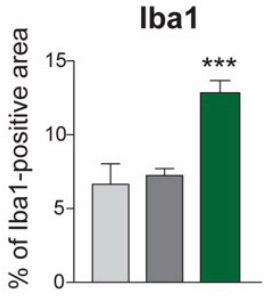

GFAP

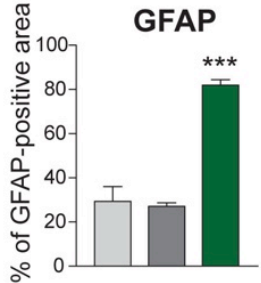

Figure 3.2.10 Increased inflammation in the white matter of cerebellum and spinal cord of Cnp1 ${ }^{\mathrm{Cre} /+} ; \mathrm{FbxO}^{\mathrm{fl/fl}}$ mice.

(a)-(c) Sagittal paraffin brain sections from 3-month-old $\mathrm{FbxO} 7^{\mathrm{fl/ft}}, \mathrm{Cnp} 1^{\mathrm{Crel}+\mathrm{t}}$ and $\mathrm{Cnp} 1^{\mathrm{Crel}+} ; \mathrm{FbxO} 7^{\mathrm{fl/fl}}$ mice were immunostained with (a) Iba1 (b) Mac3 and (c) GFAP antibodies. Three independent biological repeats per group and two technical repeats per animal were analyzed. Quantifications were performed within corpus callosum and white matter of cerebellum (one-way ANOVA, including Bonferroni post-test, ${ }^{*} P<0.05$, ${ }^{* *} P<$ 0.01 , mean \pm s.e.m). Arrows indicate microglia, arrowheads show reactivated microglia and asterisk point at astrocytes. Scale bar $=50 \mu \mathrm{m}$. (d) - (e) Representative images of spinal cord cross-sections from 3-month-old

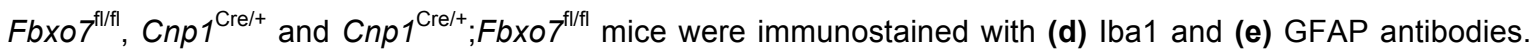
Sections were taken from lumbar segment 1-3 of the spinal cord and three mice per condition, as well as three samples per mouse were analyzed (one-way ANOVA, including Bonferroni post-test, ${ }^{* * *} P<0.001$, mean \pm s.e.m). The percentage of area stained by the respective antibody was analyzed, using a customized macro designed by Dr. Miso Mitkovski. Scale bar $=50 \mu \mathrm{m}$. 
Having determined that inflammation is significantly higher in cerebellar white matter of Cnp ${ }^{\mathrm{Cre} / \mathrm{+}} ; \mathrm{FbxO} 7^{\mathrm{fl} / \mathrm{fl}}$ mice, I further investigated inflammatory events by RT-PCR analysis. cDNA was synthesized from cerebellar tissue from 2-month-old Fbxo $7^{\text {fl/fl }}$ and Cnp ${ }^{\mathrm{Cre} /+} ; \mathrm{FbxO}^{\mathrm{fl} / \mathrm{fl} l}$ mice and mRNA levels of different anti- and pro-inflammatory markers were tested. The analyses of anti-inflammatory markers including interleukin 10 (IL-10), interleukin 1 receptor antagonist (IL-1ra) and Interleukin 6 (IL-6), showed no significant but a trend of increased expression in $\mathrm{Cnp} 1^{\mathrm{Cre} /+} ; \mathrm{FbxO} 7^{\mathrm{fl/fl} / \mathrm{l}}$ mice when compared to control mice (Figure 3.2.11a). Pro-inflammatory markers, such as tumor necrosis factor a (Tnfa), interleukin $1 \beta \quad(I L-1 \beta)$, interferon $\gamma$-induced protein $10 \quad(I p-10)$ and monocyte chemoattractant protein 1 (Mcp-1) showed higher levels of expression in cKO mice, indicating an elevated inflammatory response in $\mathrm{Cnp}^{\mathrm{Cre} /+} ; \mathrm{FbxO} 7^{\mathrm{fl/fl}}$ mice. However of those pro-inflammatory markers only Ip-10 was significantly increased (Figure 3.2.11b).

a

anti-inflammatory markers

Cerebellum
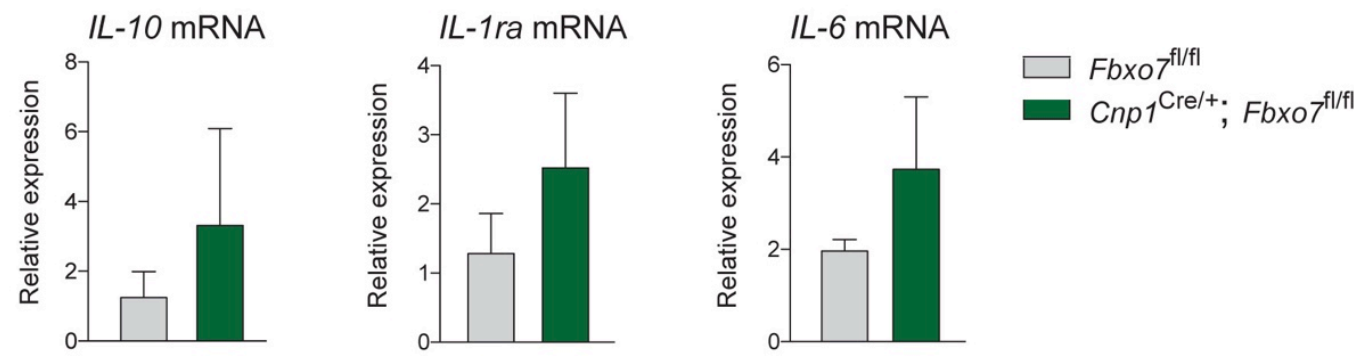

b

pro-inflammatory markers

\section{Cerebellum}
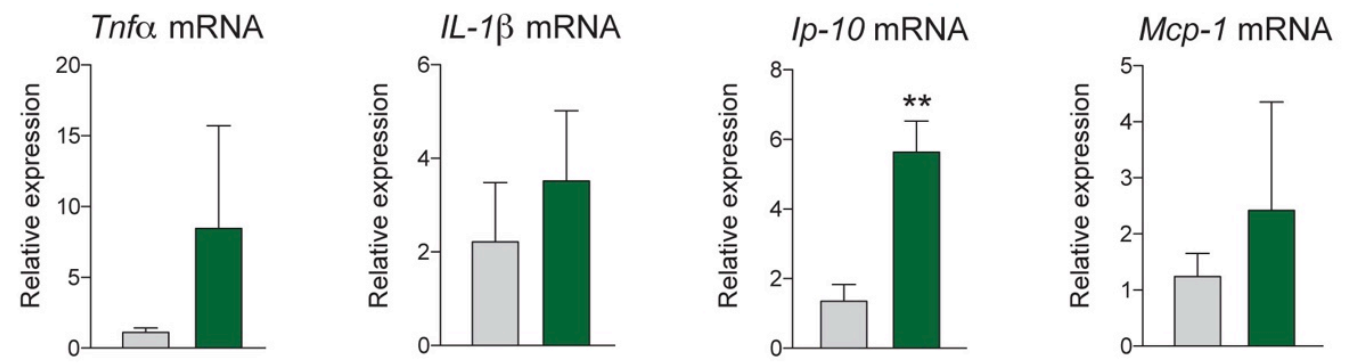

Figure 3.2.11 Levels of inflammatory markers show a trend of elevation in the cerebellum of Cnp1 ${ }^{\mathrm{Cre} /+} ; \mathrm{FbxO}^{\mathrm{fl} / \mathrm{fl}}$ mice.

(a)-(b) RT-PCR analysis of RNA isolated from cerebella of 2-month-old $F b x o 7^{\mathrm{flfl} / \mathrm{l}}$ and $\mathrm{Cnp} 1^{\mathrm{Crel} / \mathrm{t}} ; \mathrm{Fbxo} 7^{\mathrm{fl/fl}}$ mice. Primers were used for (a) anti-inflammatory markers including interleukin 10 (IL-10), interleukin 1 receptor antagonist (IL-1ra), Interleukin $6(I L-6)$ and (b) pro-inflammatory markers including tumor necrosis factor a $(T n f \alpha)$, interleukin $1 \beta(I L-1 \beta)$, interferon $\gamma$-induced protein $10(I p-10)$ and monocyte chemo attractant protein 1 $(M c p-1)$. Four independent animals per genotype were analyzed and three replicates per animal were included (unpaired t-test, ${ }^{* *} P<0.01$, mean \pm s.e.m). 
To assess inflammation in the PNS of $\mathrm{Cnp} 1^{\mathrm{Cre} /+} ; \mathrm{FbxO} 7^{\mathrm{fl/fl}}$ mice, I subjected longitudinal sections of sciatic nerve from 3-month-old Fbxo $7^{\mathrm{fl/fl}}, \mathrm{Cnp} 1^{\mathrm{Cre} /+}$ and $\mathrm{Cnp} 1^{\mathrm{Cre} /+} ; \mathrm{FbxO} 7^{\mathrm{fl/fl}}$ mice to immunohistochemical analysis using an antibody against Iba1 and GFAP. I found a significant increase in both Iba1-positive and GFAP-positive cells in cKO mice as compared to control (Figure 3.2.12a,b). Screening at a higher resolution for signs of inflammation, I analyzed electron microscopic images from sciatic nerve cross-sections of $\mathrm{Cnp} 1^{\mathrm{Cre} /+}$ and $\mathrm{Cnp} 1^{\mathrm{Cre} /+} ; \mathrm{FbxO} 7^{\mathrm{fl/fl}}$ mice. Interestingly, $\mathrm{Cnp} 1^{\mathrm{Cre} /+} ; \mathrm{FbxO} 7^{\mathrm{fl/fl}}$ mice harbored a striking number of macrophages engulfing and digesting dead myelinated axons, whereas macrophages were absent in control samples. Macrophages can be characterized by their thin, long processes, so-called pseudopodia, which they extend to engulf cellular debris, designated for phagocytosis and degradation. Additionally, large cytoplasmic granules are a feature of macrophages. These typical signs of microphages I observed in great abundance in almost all of the 40 electron microscopic images of cKO mice, but not in the 40 images of section of control sciatic nerve (Figure 3.2.12c). The data illustrate the increased infiltration of the sciatic nerve by macrophages and underscores a strong inflammatory response in $\mathrm{Cnp}^{\mathrm{Cre} /+} ; \mathrm{FbxO}^{\mathrm{fl} / \mathrm{lll}}$ mice upon $\mathrm{FbxO} 7$ deletion in the PNS. 
a

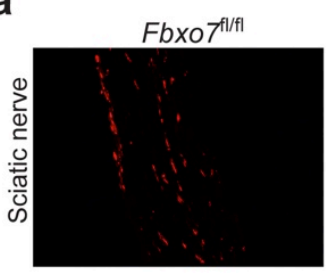

b
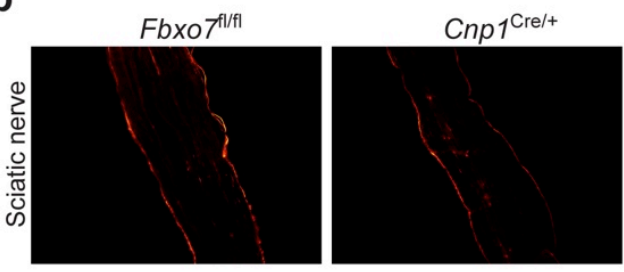

C

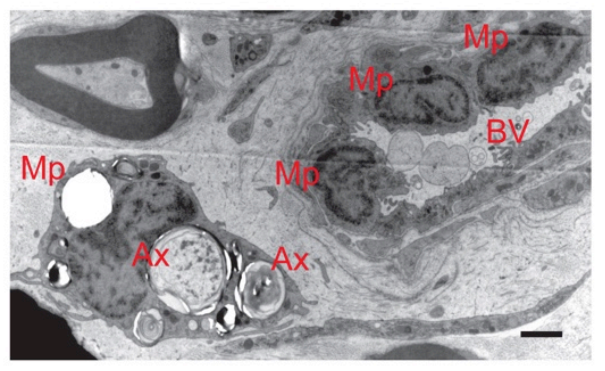

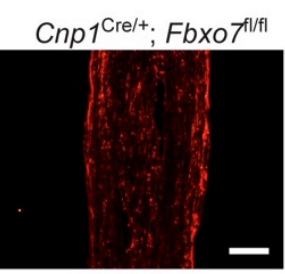
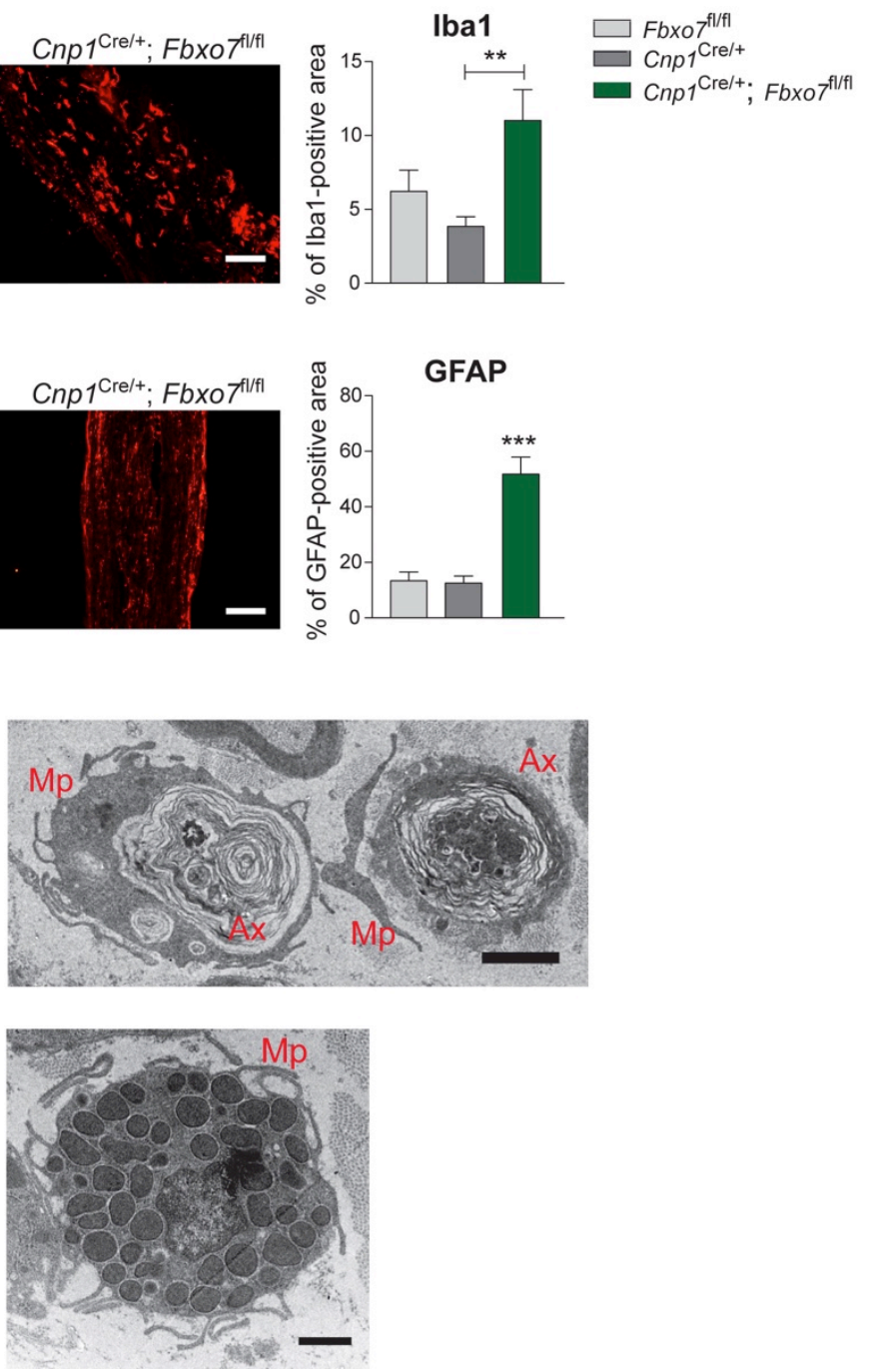

Figure 3.2.12 Increased inflammatory response in sciatic nerve of $\mathrm{Cnp} 1^{\mathrm{Crel+}} ; \mathrm{FbxO} 7^{\mathrm{fl/fl}}$ mice.

(a)-(b) Longitudinal cryo-section from sciatic nerves of 3-month-old $\mathrm{FbxO} 7^{\mathrm{fl} / \mathrm{fl}}, \mathrm{Cnp} 1^{\mathrm{Cre} /+}$ and $\mathrm{Cnp} 1^{\mathrm{Cre} /+} ; \mathrm{FbxO} 7^{\mathrm{fl} / \mathrm{fl}}$ mice were subjected to immunohistochemistry using an antibody against (a) lba1 or (b) GFAP. Three independent mice per genotype and three samples per mouse were analyzed (one-way ANOVA, including Bonferroni post-test, ${ }^{* *} \mathrm{P}<0.01,{ }^{* *} \mathrm{P}<0.001$, mean \pm s.e.m). The images were analyzed using a customized macro designed by Dr. Miso Mitkovski. Scale bar $=100 \mu \mathrm{m}$. (c) Representative images of electron microscopic cross-sections from sciatic nerve of 3 -month-old $\mathrm{Cnp1}{ }^{\mathrm{Cre} /+} ; \mathrm{FbxO} 7^{\mathrm{fl/fl}}$ mice. Images illustrate increased infiltration of sciatic nerve by macrophages engulfing dead, myelinated axons and migrating in from blood vessels. $\mathrm{Mp}=$ macrophage, $\mathrm{Ax}=$ axon, $\mathrm{BV}=$ blood vessel. Scale bar $=1 \mu \mathrm{m}$. 


\subsection{Molecular characterization of $\mathrm{Cnp} 1^{\mathrm{Cre} /+} ; \mathrm{FbxO} 7^{\mathrm{fl} / \mathrm{fl}}$ mice}

Owing to its function as E3 ubiquitin ligase, FBXO7 interacts with different proteins and thus affects different molecular pathways. Previous studies have shown that FBXO7 interacts with $p 27$, cyclin D/CDK6 complex and HURP, proteins which all are linked to cell cycle regulation (Hsu et al., 2004; Laman et al., 2005). Further on, FBXO7 was shown to interact with parkin and PINK, which both are essential for the mitochondrial quality control (Burchell et al., 2013). In our lab, Dr. David Brockelt identified FBXO7 to be a proteasome-associated protein, that binds to and ubiquitinates the proteasome subunit PSMA2 - a novel interaction partner. My colleagues demonstrated the vital role of FBXO7 in neurons and its regulatory function in proteasome assembly (Vingill et al., 2016). In the following experiments, I investigated the molecular changes in myelinating cells upon Fbxo7 deletion and examined the proteasomal activity in Fbxo7-depleted Schwann cells.

\subsubsection{Fbxo7 deletion leads to an up-regulation of stress sensors and down-regulation of cytoskeletal proteins in CNS myelin}

Myelinating cells not only insulate axons for fast and saltatory propagation of action potentials, they are also essential for the metabolic and trophic support of axons, ensuring their integrity and long term survival (Nave, 2010b). Hence, a balanced protein homeostasis within myelinating cells is crucial for the axon-glia interaction. To investigate how Fbxo7 deletion affects the protein homeostasis in myelinating cells and support of axons, we subjected purified myelin isolated from brains of 3-month-old $\mathrm{Cnp} 1^{\mathrm{Cre} /+}$ and $\mathrm{Cnp} 1^{\mathrm{Cre} / \mathrm{H}} ; \mathrm{FbxO} 7^{\mathrm{fl} / \mathrm{fl}}$ mice to quantitative mass spectrometry analyses. Myelin purification from the CNS was performed by Ramona Jung and mass spectrometry analyses were done in collaboration with Dr. Olaf Jahn. The analysis identified 563 candidates, which were sorted according to a $\log _{2}$ ratio of $\mathrm{Cnp} 1^{\mathrm{Cre} /+} ; \mathrm{FbxO} 7^{\mathrm{fl} / \mathrm{fl}}$ values divided by $\mathrm{Cnp} 1^{\mathrm{Cre} /+}$ values. Among the proteins, those with $25 \%$ higher or lower expression levels as compared to control were grouped and selected candidates were analyzed. The upregulated proteins of CNS myelin included a range of proteins that were associated with the cellular response to endogenous stimuli, such as detoxification processes, regulation of apoptosis, cellular signaling cascades and CNS development processes (Figure 3.3.1a). The majority of down-regulated proteins in CNS myelin were associated with cytoskeletal arrangement and mitochondrial function (Figure 3.3.1b). These results indicate that loss of $\mathrm{FbxO} 7$ from oligodendrocytes triggers a cellular stress response and 
induces endogenous processes such as detoxification. Moreover, Fbxo7 deletion affects the stability of the cytoskeleton and the mitochondrial function.
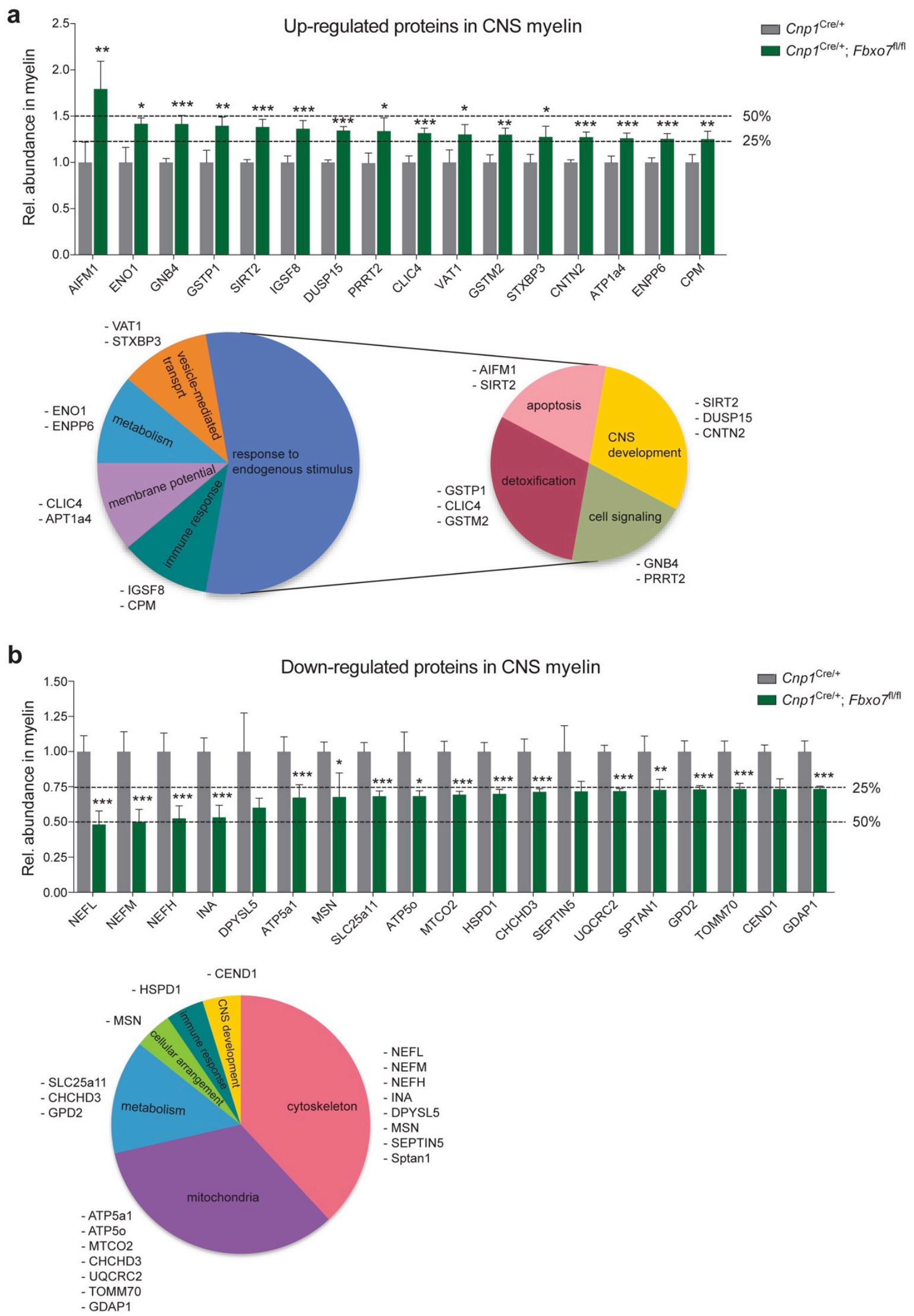

Figure 3.3.1 Up- and down-regulated proteins in CNS myelin upon deletion of Fbxo7. 
(a)-(b) Purified myelin from 3-month-old $\mathrm{Cnp} 1^{\mathrm{Cre} /+}$ and $\mathrm{Cnp} 1^{\mathrm{Cre} /+} ; \mathrm{FbxO} 7^{\mathrm{fl} / \mathrm{fl}}$ brains was analyzed by quantitative mass spectrometry. The mean of five mice per genotype and two repeats per animal was analyzed using the $\log _{2} \mathrm{CKO} /$ control ratio. Cnp $1^{\mathrm{Cre} /+} ; \mathrm{FbxO} 7^{\mathrm{fl} / \mathrm{fl}}$ values were normalized to control (unpaired t-test, ${ }^{*} \mathrm{P}<0.05$, ${ }^{* *} \mathrm{P}<$ $0.01,{ }^{* *} \mathrm{P}<0.001$, mean \pm s.e.m.). Shown are the $25 \%$ of (a) up-regulated proteins [AIFM1: Apoptosisinducing factor 1; ENO1: Enolase 1; GNB4: Guanine nucleotide-binding protein subunit beta 4; GSTP1: Glutathione S-transferase pi 1; SIRT2: NAD-dependent protein deacetylase sirtuin-2; IGSF8: Immunoglobulin superfamily member 8; DUSP15: Dual specificity protein phosphatase 15; PRRT2: Proline-rich transmembrane protein 2; CLIC4: Chloride intracellular channel protein 4; VAT1: Synaptic vesicle membrane protein VAT-1 homolog; GSTM2: Glutathione S-transferase mu; STXBP3: Syntaxin-binding protein 3; CNTN2: Contactin 2; ATP1A4: Sodium/potassium-transporting ATPase subunit alpha 4; ENPP6: Ectonucleotide; pyrophosphatase 6; CPM: Carboxypeptidase M] and (b) down-regulated proteins [NEFL: Neurofilament light; NEFM: Neurofilament medium; NEFH: Neurofilament heavy; INA: Alpha-internexin; DPYSL5: Dihydropyrimidinase-related protein 5; ATP5A1: ATP synthase subunit alpha; MSN: Moesin; SLC25A11: Mitochondrial 2-oxoglutarate/malate carrier protein; ATP5O: ATP synthase subunit O; MTCO2: Cytochrome $\mathrm{C}$ oxidase subunit 2; HSPD1: $60 \mathrm{kDa}$ heat shock protein; CHCHD3: MICOS complex subunit Mic19; SEPTIN5: Septin 5; UQCRC2: Cytochrome b-c1 complex subunit 2; SPTAN1: Spectrin alpha chain; GPD2: Glycerol-3phosphate dehydrogenase; TOMM70: Mitochondrial import receptor subunit TOM70; CEND1: Cell cycle exit and neuronal differentiation protein 1; GDAP1: Ganglioside-induced differentiation-associated protein 1] of CNS myelin from $\mathrm{Cnp}_{1}^{\mathrm{Cre} / \mathrm{+}} ; \mathrm{FbxO}^{\mathrm{fl} / \mathrm{fl} \mathrm{l}}$ brains as compared to control. Pie chart displays the biological function of selected candidates, which was gathered using the Toppgene database. Quantitative mass spectrometry was conducted by Dr. Olaf Jahn

In order to validate the results from mass spectrometry, I performed immunohistochemical stainings on spinal cord sections of 3 -month-old $\mathrm{Cnp} 1^{\mathrm{Cre} /+} ; \mathrm{FbxO} 7^{\mathrm{fl/+}}$ and $\mathrm{Cnp} 1^{\mathrm{Cre} /+} ; \mathrm{FbxO} 7^{\mathrm{fl/fl}}$ mice. The quantitative mass spectrometry analyses identified a range of proteins involved in the detoxification pathway. I decided to focus on glutathione S-transferase $\pi 1$ (GSTா1), whose levels were increase. Importantly, GSTா1 is specifically expressed in oligodendrocytes. I carried out immunohistochemical analyses on spinal cord sections of 3-month-old $\mathrm{FbxO} 7^{\mathrm{flflf}}, \mathrm{Cnp} 1^{\mathrm{Cre} /+}$ and $\mathrm{Cnp} 1^{\mathrm{Cre} /+} ; \mathrm{FbxO} 7^{\mathrm{fl} / \mathrm{fl}}$ mice and found a significant increase in GSTm1 signal in $\mathrm{Cnp} 1^{\mathrm{Cre} /+} ; \mathrm{FbxO} 7^{\mathrm{fl/fl}}$ mice as compared to control, verifying the up-regulated stress response in cKO mice (Figure 3.3.2a). Further on, I subjected brain lysates from $\mathrm{Cnp} 1^{\mathrm{Crel+}} ; \mathrm{FbxOO} 7^{\mathrm{fl} /+}$ and $\mathrm{Cnp} 1^{\mathrm{Cre} /+} ; \mathrm{FbxO} 7^{\mathrm{fl/fl}}$ mice to immunoblotting using the GSTח1 antibody. The lysates of developing cKO mouse brains indicated a stronger signal for GSTח1 at all ages examined (Figure 3.3.2b). With these results I showed that loss of Fbxo7 from oligodendrocytes induces an up-regulation of the stress sensor GSTT1. 
a

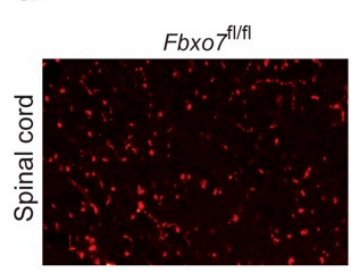

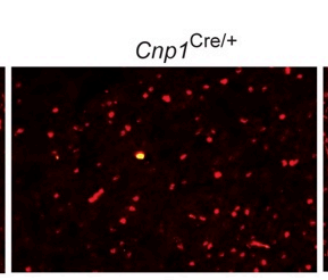

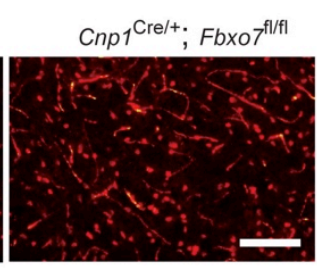

GST $\pi 1$

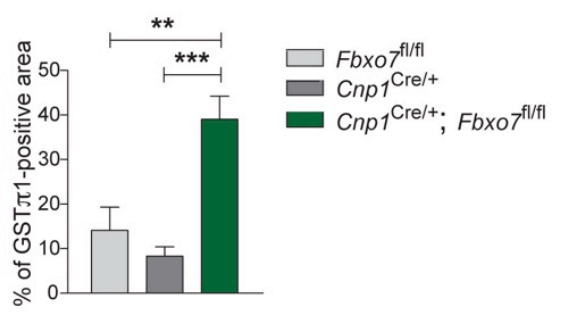

b

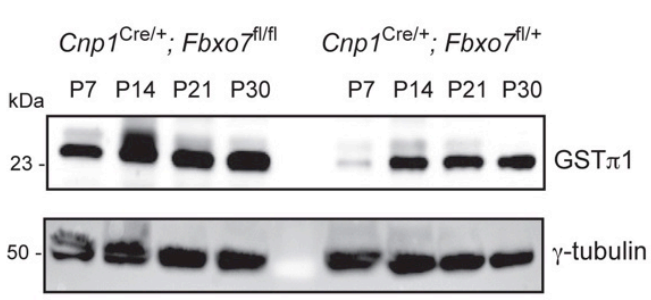

Figure 3.3.2 Increased GST 1 levels in the CNS due to Fbxo7 deletion.

(a) cross-sections of spinal cord from 3-month-old $\mathrm{FbxO} 7^{\mathrm{fl/fl}}, \mathrm{Cnp} 1^{\mathrm{Cre} / \mathrm{+}}$ and $\mathrm{Cnp} 1^{\mathrm{Cre} / \mathrm{t}} ; \mathrm{FbxO} 7^{\mathrm{flfl} / \mathrm{l}}$ mice were immunostained with a GSTח1 antibody. Sections were taken from lumbar segment 1-3 of the spinal cord and three mice per condition, as well as three samples per mouse were analyzed (one-way ANOVA, ${ }^{* *} P<0.01$, ${ }^{* * *} P<0.001$, mean \pm s.e.m). The percentage of area stained by GST 1 antibody was analyzed using a customized macro designed by Dr. Miso Mitkovski. Scale bar $=1 \mu \mathrm{m}$. (b) Brain lysates from postnatal day $(P)$

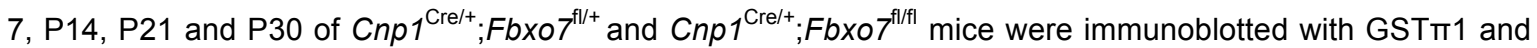
$y$-tubulin antibodies, while $y$-tubulin served as a loading control. (Sample was run on the same gradient gel as described in 3.3.4).

\subsubsection{Loss of Fbxo7 causes an immune response and down- regulation of cytoskeleton proteins in PNS myelin}

To assess any changes in protein homeostasis in PNS myelin upon Fbxo7 deletion, myelin was purified from sciatic nerves. Purification of myelin from sciatic nerve isolated from 3-month-old $\mathrm{Cnp}^{\mathrm{Cre} /+} ; \mathrm{FbxO}^{\mathrm{fl} /++}$ and $\mathrm{Cnp1}{ }^{\mathrm{Cre} /+} ; \mathrm{FbxO} 7^{\mathrm{fl/fl}}$ mice was performed with the help of Katja Lüders. Myelin was subjected to quantitative mass spectrometry analyses, performed by Dr. Olaf Jahn. 404 proteins were identified by quantitative mass spectrometry and further sorted by the $\log _{2}$ ratio of $\mathrm{Cnp}^{\mathrm{Cre} /+} ; \mathrm{FbxO} 7^{\mathrm{fl/fl}}$ values divided by $\mathrm{Cnp}^{\mathrm{Cre} / \mathrm{H}} ; \mathrm{FbxO}^{\mathrm{fl} /+}$ values. Among these candidates, the top $25 \%$ of up- and downregulated proteins were grouped together and selected candidates were analyzed. The analysis of up-regulated proteins in PNS myelin indicated a big cluster of proteins that was part of the immune response. Further on, a large group of proteins were associated to detoxification processes and the lipid metabolism (Figure 3.3.3a). Among the downregulated proteins, the majority of candidates were linked to the cytoskeleton. In addition, large clusters of mitochondrial proteins, proteins associated to ubiquitination and the 
metabolism were also down regulated (Figure 3.3.3b). Taken together these results show that loss of Fbxo7 from Schwann cells induces an inflammatory response and increases detoxification processes. Additionally, deletion of $\mathrm{Fbxo7}$ affects the stability of the cytoskeleton, mitochondrial integrity and the UPS.

a
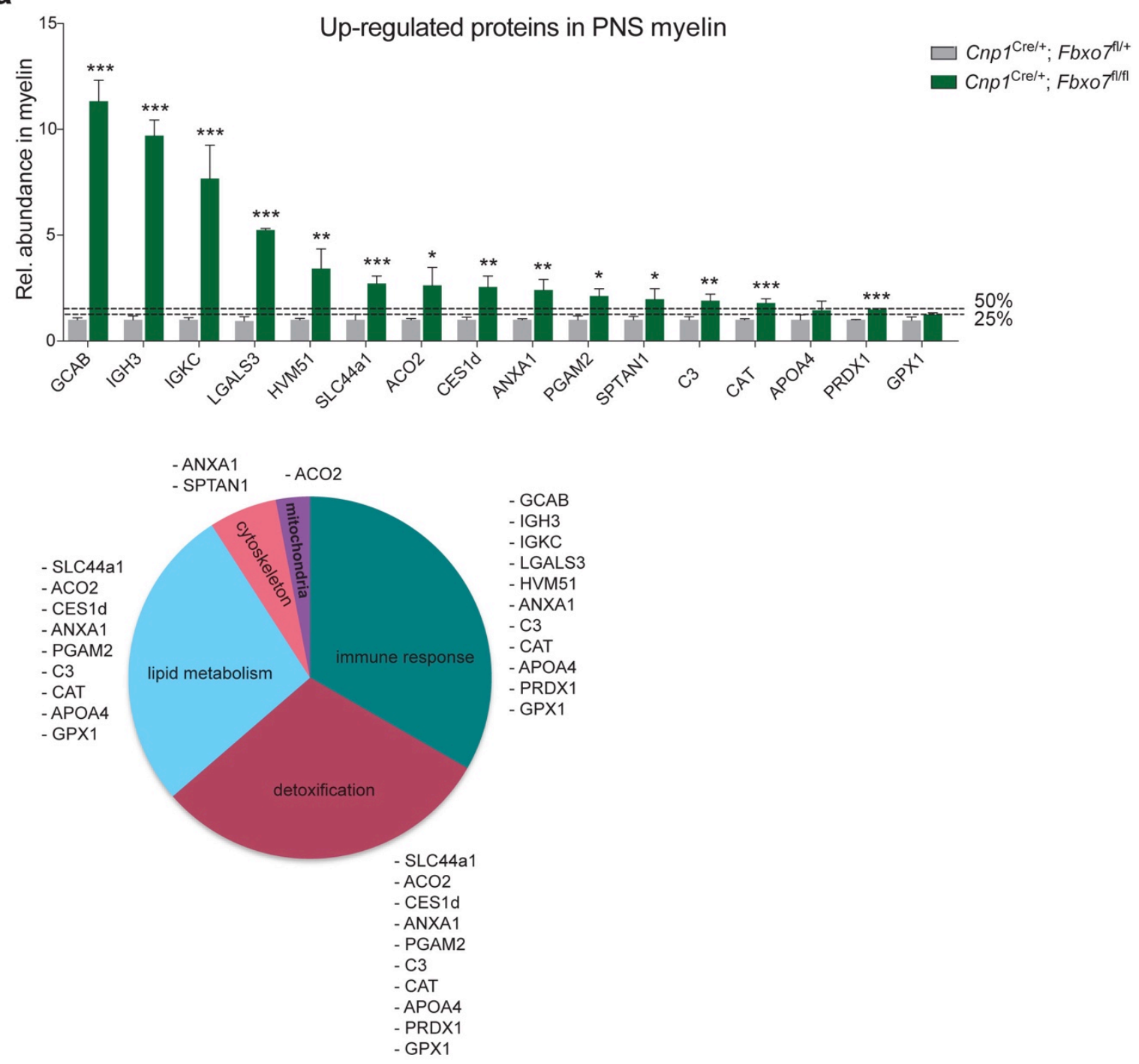
b
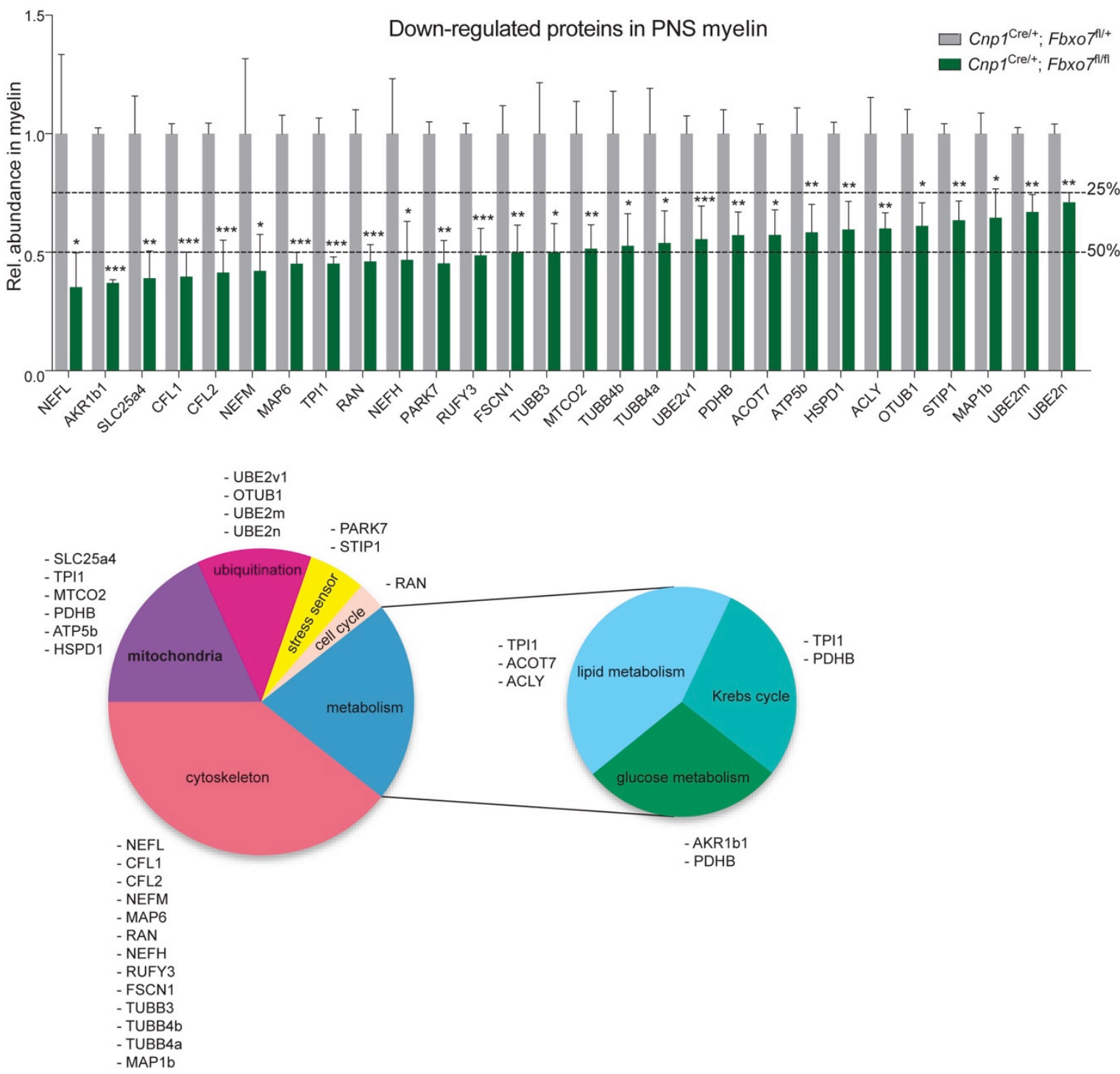

Figure 3.3.3 Up- and down-regulated proteins in PNS myelin upon Fbxo7 deletion.

(a)-(b) Purified myelin from sciatic nerves of 3-month-old $\mathrm{Cnp}^{\mathrm{Crel} /+} ; \mathrm{FbxO} 7^{\mathrm{nl/+}}$ and $\mathrm{Cnp}^{\mathrm{Crel+}+} ; \mathrm{FbxO} 7^{\mathrm{fl/fl}}$ mice were analyzed by quantitative mass spectrometry. Nine pairs of sciatic nerve per genotype were pooled into 3 groups, each measured twice and the total mean analyzed using the log2 $\mathrm{cKO} / \mathrm{control}$ ratio. Values from $\mathrm{Cnp}_{1}{ }^{\mathrm{Crel}+} ; \mathrm{FbxO} \mathrm{f}^{\mathrm{fl/fl}}$ mice were normalized to control (unpaired t-test, ${ }^{*} \mathrm{P}<0.05$, ${ }^{* *} \mathrm{P}<0.01$, ${ }^{* * *} \mathrm{P}<0.001$, mean \pm s.e.m.). From the identified proteins, the $25 \%$ of (a) up-regulated proteins [GCAB: Ig gamma $2 A$; IGH3: Ig gamma 2B; IGKC: Ig kappa; LGALS3: Galectin 3; HVM51: Ig heavy chain V; SLC44A1: Choline transporterlike protein 1; ACO2: Aconitate hydratase; CES1D: Carboxylesterase 1D; ANXA1: Annexin A1; PGAM2: Phosphoglycerate mutase 2; SPTAN1: Spectrin alpha chain; C3: Complement C3; CAT: Catalase; APOA4: Apolipoprotein A4; PRDX1: Peroxiredoxin 1; GPX1: Glutathione peroxidase 1] and (b) down-regulated proteins [NEFL: Neurofilament light; AKR1B1: Aldose reductase; SCL25A4: ADP/ATP translocase 1; CFL1: Cofilin 1; CFL2: Cofilin 2; NEFM: Neurofilament medium; MAP6: Microtubule-associated protein 6; TPI1: Triosephosphate isomerase; RAN: GTP-binding nuclear protein Ran; NEFH: Neurofilament heavy; PARK7: Protein deglycase DJ-1; RUFY3: Protein RUFY3; FSCN1: Fascin; TUBB3: Tubulin beta 3; MTCO2: Cytochrome c oxidase subunit; TUBB4B: Tubulin beta 4B; TUBB4A: Tubulin beta 4A; UBE2V1: Ubiquitin- 
conjugating enzyme E2 variant 1; PDHB: Pyruvate dehydrogenase E1 component subunit beta; ACOT7: Cytosolic acyl coenzyme A thioester hydrolase; ATP5B: ATP synthase subunit beta; HSPD1: 60 kDa heat shock protein; ACLY: ATP-citrate synthase; OTUB1: Ubiquitin thioesterase OTUB1; STIP1: Stress-inducedphosphoprotein; MAP1B: Microtubule-associated protein 1B; UBE2M: NEDD8-conjugating enzyme Ubc12; UBE2N: Ubiquitin-conjugating enzyme E2 N] in $\mathrm{Cnp}^{\mathrm{Cre} /+} ; \mathrm{Fbxo} 7^{\mathrm{fl} / \mathrm{fl}}$ myelin as compared to control were selected. Pie chart displays the biological function of selected candidates, which was gathered while using the Toppgene database. Quantitative mass spectrometry was conducted by Dr. Olaf Jahn.

Although the list of up-regulated myelin proteins from the PNS of $\mathrm{Cnp} 1^{\mathrm{Cre} /+} ; \mathrm{FbxO} 7^{\mathrm{fl/fl}}$ mice did not include GSTா1, as seen in CNS myelin, detoxification processes were still highly up-regulated. Therefore, I investigated if the stress marker GSTா1 undergoes any changes and performed an immunohistochemical analysis on sciatic nerve sections of 3month-old Fbxo7 $7^{\mathrm{fl/fl}}, \mathrm{Cnp}^{\mathrm{Cre} /+}$ and $\mathrm{Cnp} 1^{\mathrm{Cre} /+} ; \mathrm{FbxO} 7^{\mathrm{fl/fl}}$ mice using a GSTm1 antibody. The result showed significant increase in GSTH1 signals in sections of $\mathrm{Cnp}^{\mathrm{Cre} /+} ; \mathrm{FbxO} 7^{\mathrm{fl/fl}}$ sciatic nerve as compared to control sciatic nerve (Figure 3.3.4).
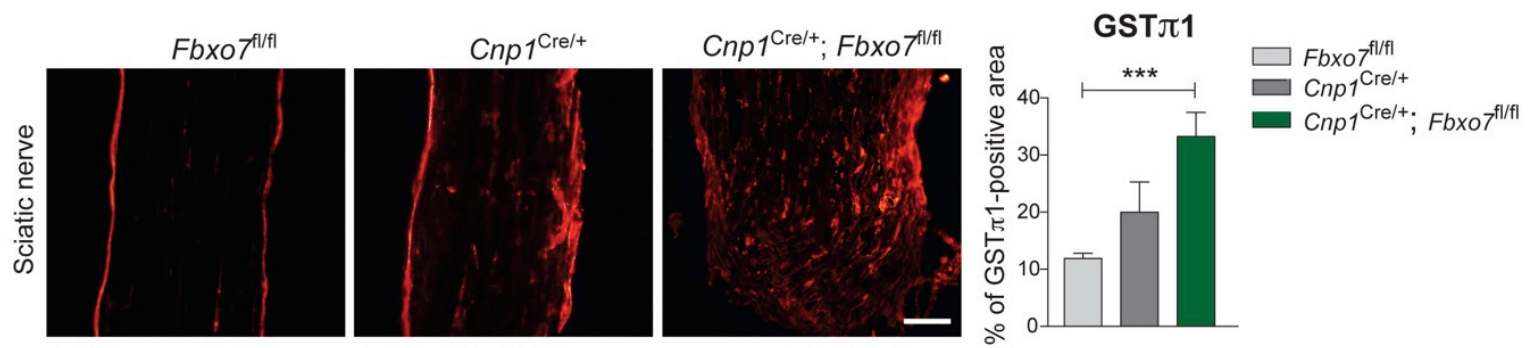

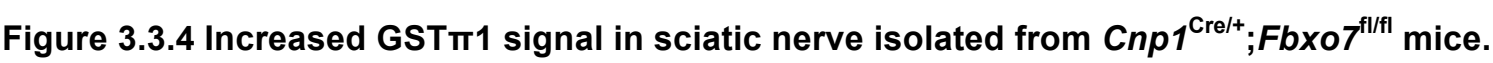

Immunohistochemical analyses were performed on longitudinal cryo-section of sciatic nerves from 3-monthold $\mathrm{FbxO} 7^{\mathrm{fl} / \mathrm{fl} l}, \mathrm{Cnp} 1^{\mathrm{Cre} /+}$ and $\mathrm{Cnp} 1^{\mathrm{Cre} /+} ; \mathrm{FbxO} 7^{\mathrm{fl} / \mathrm{fl}}$ mice using a GST 1 antibody. Three independent mice per genotype and three samples per mouse were analyzed (one-way ANOVA, Bonferroni post-test, ${ }^{* * *} P<0.001$, mean \pm s.e.m). The images were analyzed using a customized macro designed by Dr. Miso Mitkovski. Scale bar $=100 \mu \mathrm{m}$.

\subsubsection{Increased myelin maintenance in the CNS and signs of

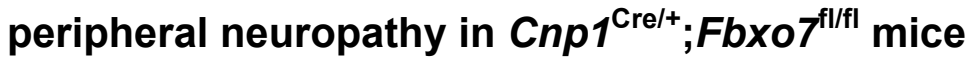

The quantitative mass spectrometry data were further analyzed with regard to changes in structural myelin proteins and candidates that are closely associated with myelination. Within purified myelin from the CNS, I found that proteins linked to myelin maintenance and stabilization were up-regulated in $\mathrm{Cnp}^{\mathrm{Cre} /+} ; \mathrm{FbxO}^{\mathrm{fl} / \mathrm{fl}}$ mice as compared to control. However, structural and myelin membrane specific proteins, including PLP, CNP, MBP 
and MAG did not show any alterations upon Fbxo7 deletion (Figure 3.3.5a). Similar to myelin proteins of the CNS, the analysis of PNS myelin did not show any change in myelin membrane-specific proteins (CNP, PLP, MAG, PMP2, MPZ and MBP). Interestingly, the trophic factor CNTF, which is important for axonal support, as well as proteins associated with peripheral neuropathy and cytoskeleton motility were significantly reduced in PNS myelin of $\mathrm{Cnp}^{\mathrm{Cre} /+} ; \mathrm{FbxO} 7^{\mathrm{fl} / \mathrm{fl}}$ mice (Figure 3.3.5b). Concluding from these results, I showed that loss of Fbxo7 from myelinating cells does not affect structural myelin proteins, which further supports my previous results. However, deletion of $\mathrm{FbxO} 7$ induces an increase in myelin maintenance in oligodendrocytes, whereas in Schwann cells loss of Fbxo7 decreases the supportive function of myelin and affects proteins, which are associated with peripheral neuropathy.

a

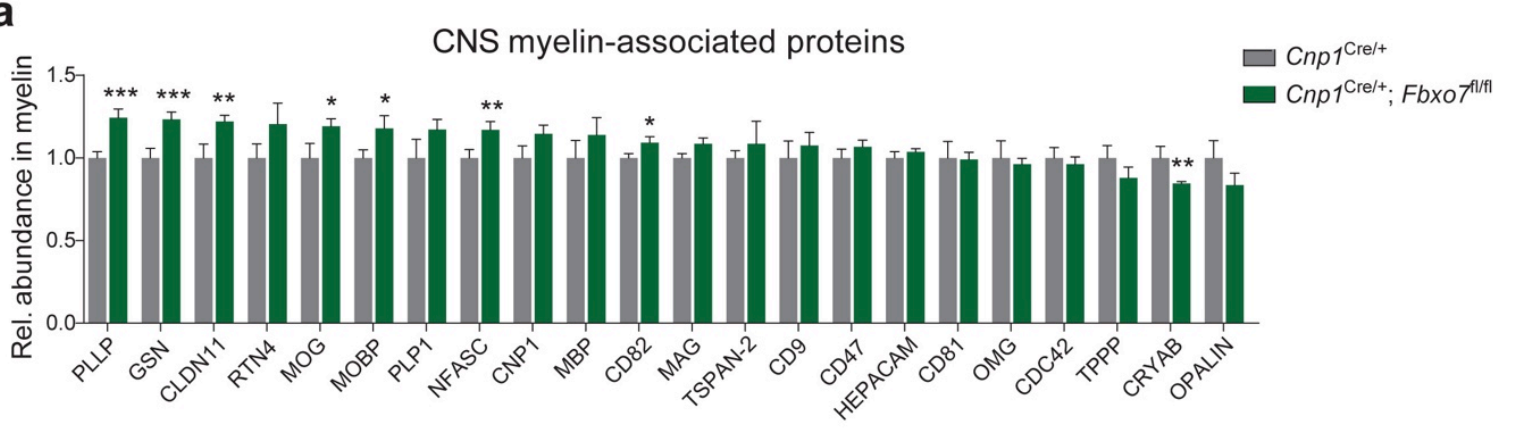

b

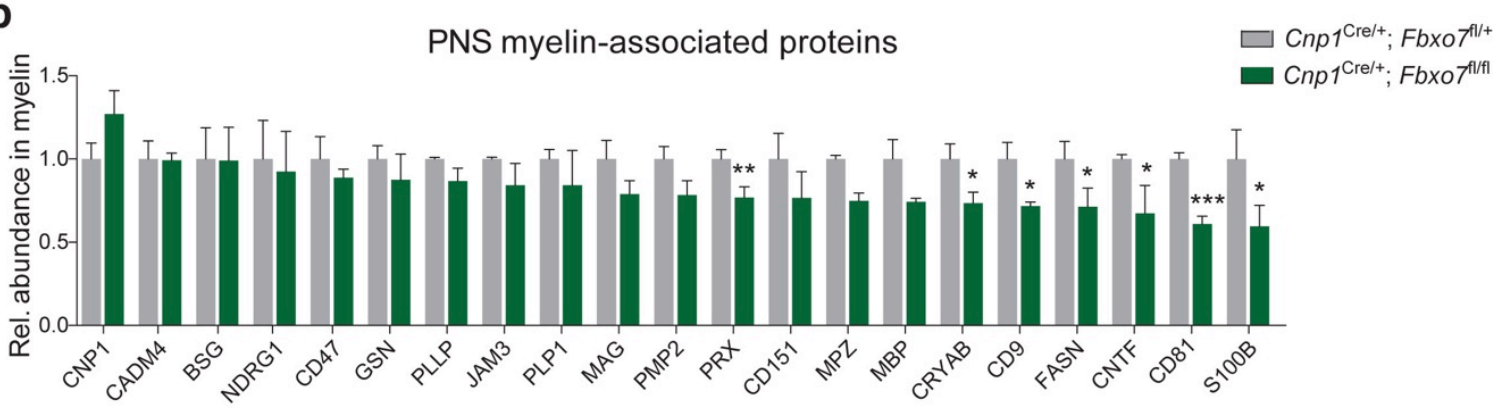

Figure 3.3.5 Loss of Fbxo7 induces an increase in CNS myelin maintenance and affects proteins, which are associated with peripheral neuropathy in the PNS.

(a) Purified myelin from brains of 3 -month-old $\mathrm{Cnp} 1^{\mathrm{Cre} /+}$ and $\mathrm{Cnp} 1^{\mathrm{Cre} /+} ; \mathrm{FbxO} 7^{\mathrm{fl/fl}}$ mice were subjected to quantitative mass spectrometry. The mean of five mice per genotype and two repeats per animal was analyzed using the $\log _{2} \mathrm{cKO} /$ control ratio. $\mathrm{Cnp}^{\mathrm{Cre} /+} ; \mathrm{FbxO}^{\mathrm{fl} / \mathrm{fl}}$ values were normalized to control (unpaired ttest, ${ }^{*} \mathrm{P}<0.05,{ }^{* *} \mathrm{P}<0.01,{ }^{* * *} \mathrm{P}<0.001$, mean \pm s.e.m.) [PLLP: Plasmolipin; GSN: Gelsolin; CLDN11: Claudin 11; RTN4: Reticulon 4; MOG: Myelin-oligodendrocyte glycoprotein; MOBP: Myelin-associated oligodendrocyte basic protein; PLP1: Proteolipid protein; NFASC: Neurofascin; CNP1: 2',3'-cyclic-nucleotide 3'phosphodiesterase; MBP: Myelin basic protein; CD82: CD82 antigen; MAG: Myelin-associated glycoprotein; TSPAN-2: Tetraspanin 2; CD9: CD9 antigen; CD47: Leukocyte surface antigen CD47; HEPACAM: Hepatocyte cell adhesion molecule; CD81: CD81 antigen; OMG: Oligodendrocyte-myelin glycoprotein; CDC42: Cell division control protein 42 homolog; TPPP: Tubulin polymerization-promoting protein; CRYAB: Alpha-crystallin B chain; OPALIN: Opalin]. (b) Purified myelin from sciatic nerves of 3-month-old 
$\mathrm{Cnp}^{\mathrm{Cre} /+} ; \mathrm{FbxO} 7^{\mathrm{fl} /+}$ and $\mathrm{Cnp} 1^{\mathrm{Cre} /+} ; \mathrm{FbxO} 7^{\mathrm{fl} / f \mathrm{ll}}$ mice were analyzed by mass spectrometry. Nine pairs of sciatic nerve per genotype were pooled into 3 groups, each measured twice and the total mean analyzed using the $\log _{2} \mathrm{cKO} /$ control ratio (unpaired t-test, ${ }^{*} \mathrm{P}<0.05$, ${ }^{* *} \mathrm{P}<0.01$, ${ }^{* * *} \mathrm{P}<0.001$, mean \pm s.e.m.) [CNP1: 2',3'-cyclicnucleotide 3'-phosphodiesterase; CADM4: Cell adhesion molecule 4; BSG: Basigin; NDRG1: Protein NDRG1; CD47: Leukocyte surface antigen CD47; GSN: Gelsolin; PLLP: Plasmolipin; JAM3: Junctional adhesion molecule C; PLP1: Proteolipid protein; MAG: Myelin-associated glycoprotein; PMP2: Myelin P2 protein; PRX: Periaxin; CD151: CD151 antigen; MPZ: Myelin protein P0; MBP: Myelin basic protein; CRYAB: Alphacrystallin B chain; CD9: CD9 antigen; FASN: Fatty acid synthase; CNTF: Ciliary neurotrophic factor; CD81: CD81 antigen; S100B: Protein S100 B]. Mass spectrometry was conducted by Dr. Olaf Jahn and analyses of data were supported by PD Dr. Hauke Werner.

\subsubsection{Cnp1 ${ }^{\mathrm{Cre} /+} ; F b x 07^{\mathrm{fl} / \mathrm{fl}}$ mice show unaltered development of oligodendrocytes regarding NG2 and CNP levels}

Fbxo7 is highly expressed in oligodendrocyte precursor cells (OPC's) and newly forming oligodendrocytes (Zhang et al., 2014). Hence, we speculated that loss of Fbxo7 might impact myelination at an early state of development. To test this hypothesis, I subjected brain lysates from $\mathrm{Cnp} 1^{\mathrm{Cre} /+} ; \mathrm{FbxO} 7^{\mathrm{fl} /+}$ and $\mathrm{Cnp} 1^{\mathrm{Cre} /+} ; \mathrm{FbxO} 7^{\mathrm{fl/fl}}$ mice of postnatal $(\mathrm{P})$ day 7 , 14,21 and 30 to immunoblotting analysis using an antibody against the oligodendrocyte precursor marker (NG2). Here, I observed no difference between $\mathrm{Cnp} 1^{\mathrm{Cre} / \mathrm{H}} ; \mathrm{FbxO} 7^{\mathrm{fl/fl}}$ mice and control. As expected, the levels of NG2 declined with age as OPCs differentiate into newly forming oligodendrocytes. Further on, I applied an antibody against 2',3'-cyclicnucleotide 3'-phosphodiesterase (CNP), which is a marker for myelinating oligodendrocytes. As anticipated, both cKO and control samples showed that the levels increased with age. In addition the samples were analyzed with an antibody against FBX07. FBXO7 levels showed an increase in control mice, but within the $\mathrm{Cnp}^{\mathrm{Cre} /+} ; \mathrm{FbxO}^{\mathrm{fl} / \mathrm{fl}}$ samples the intensity of $\mathrm{FBXO} 7$ was only elevated until P21 and showed an obvious reduction at P30. This verifies the proper function of our transgene in the cKO mouse line: the activity of the Cnp1 promoter is highly increased at P30, at the same time as the level of $\mathrm{FBXO7}$ decreases. An immunoblot with $\mathrm{y}$-tubulin served as loading control (Figure 3.3.6). 


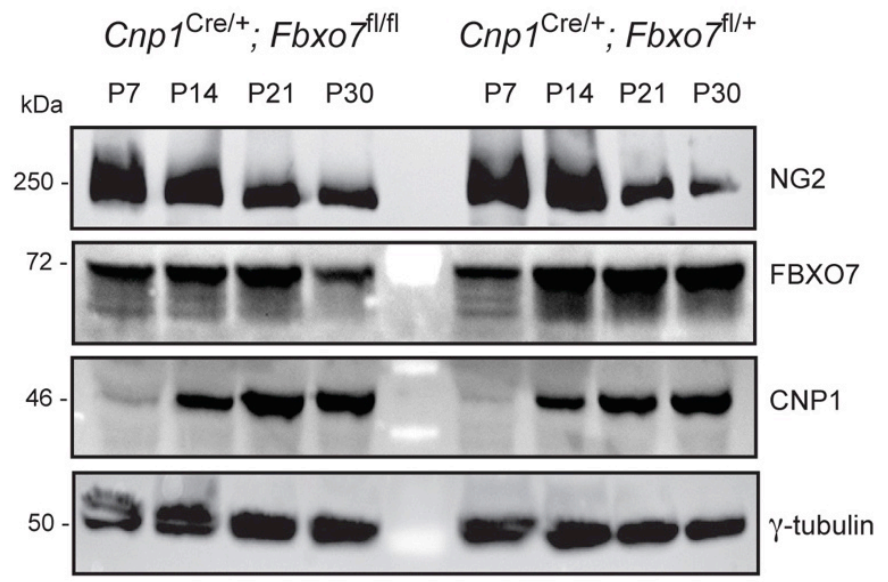

Figure 3.3.6 Fbxo7 deletion does not influence the development of oligodendrocytes.

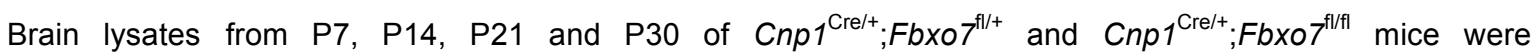
immunoblotted with NG2, FBXO7, CNP1 or y-tubulin antibodies. The latter served as a loading control. Western-blot analyses were repeated three times.

\subsubsection{Knockdown of the E3-ubiquitin ligase FBXO7 decreases proteasome activity}

The E3-ubiquitin ligase FBXO7 belongs to the multi-subunit SKP1-cullin1-FBOX7 (SCF)complex and as such is part of the ubiquitin-proteasome-system (UPS). Ubiquitination of target substrates by FBXO7 can either lead to functional modifications or proteasomal degradation (Nelson et al., 2013). In a co-immunoprecipitation (Co-IP) assay I verified, that the F-box domain of FBXO7 is crucial for binding of SKP1, which binds to cullin1 and altogether form the SCF-complex (Cardozo and Pagano, 2004). For this Co-IP, I transfected HEK cells with an empty vector p3xFLAG-CMV10, a plasmid encoding for Flag-tagged full-length $\mathrm{Fbxo7}$ ( $\mathrm{Fbxo7-wt)}$ or a plasmid encoding for a deletion mutant of Fbxo7 lacking the F-box domain (Fbxo7- $\Delta$ fbox) together with the myc-Skp1 plasmid. The lysates were subjected to immunoprecipitation using a myc antibody, which pulled down SKP1 and the attached complex. Afterwards, the precipitates were immunoblotted with a Flag antibody, visualizing the FBXO7 protein. Furthermore, I carried out an immunoprecipitation using the Flag antibody, followed by immunoblotting with a cullin1 antibody. The results show that in absence of the F-box domain, FBXO7 does not interact with SKP1 or cullin1 and therefore will not form an SCF-complex (Figure 3.3.7). 


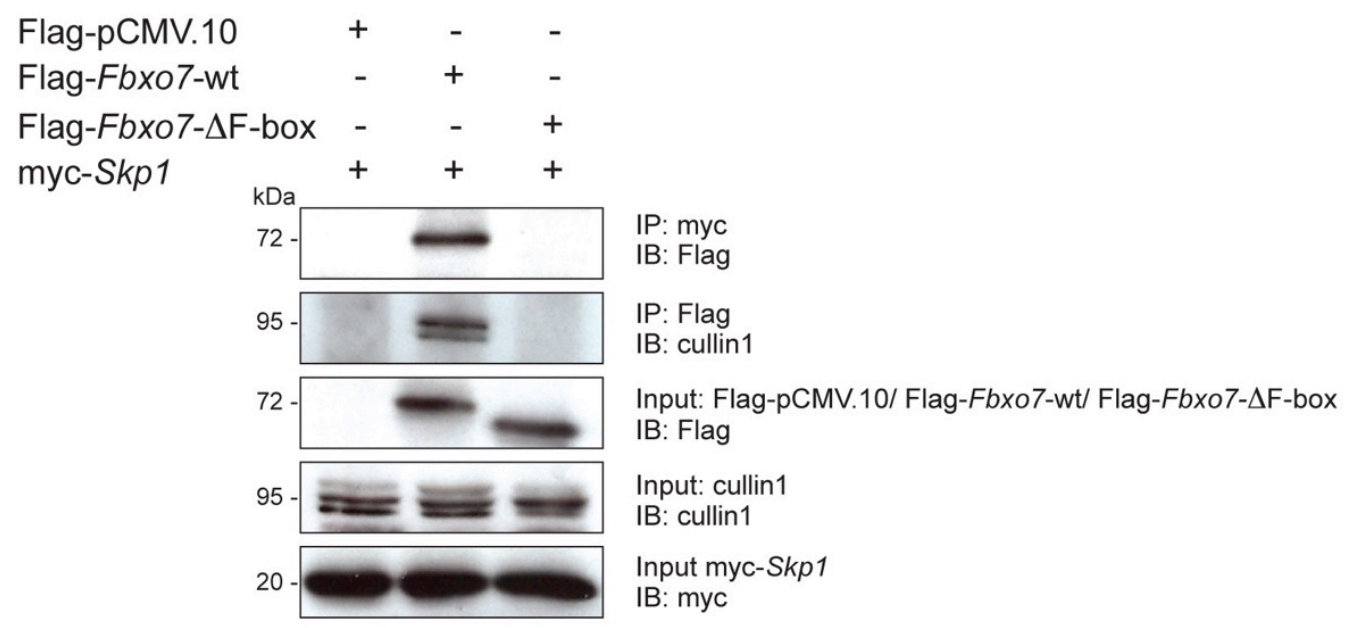

Figure 3.3.7 The FBXO7 F-box domain is crucial for the SCF-complex formation.

HEK293T cells were co-transfected with an empty vector, flag-tagged Fbxo7-wt or flag-tagged Fbxo7- $\mathrm{F}$-box and together with myc-tagged $S k p 1$. The cell lysates were subjected to co-immunoprecipitation analysis using a myc antibody, followed by immunoblotting with a Flag antibody.

In our lab, Dr. David Brockelt identified the proteasomal subunit PSMA2 as direct and novel interaction partner of FBXO7 and showed that the ubiquitination via K-63-linkage of PSMA2 by FBXO7 induces a functional modification. This modification of PSMA2 by FBXO7 was shown to be essential for a proper proteasomal assembly and function (Brockelt, 2015). Brain lysates from FBXO7 knockout mice revealed a significant reduction in proteasome activity as compared to control littermates. Hence, I investigated the importance of $\mathrm{FBXO7}$ for the proteasome function in myelinating cells and performed a proteasome activity assay in MSC80 Schwann cells. The aneuploid MSC80 Schwann cell line used in this study was established from primary mouse Schwann cell cultures (Boutry et al., 1992). I transfected MSC80 with the functional FBXO7 shRNA 1, the non-functional FBXO7 shRNA 4 and empty vector as control. In addition, I used as positive control a functional PSMA2 shRNA 7, which targets the proteasomal subunit PSMA2 and as negative control the non-functional PSMA2 shRNA 1. In addition, the cells were cotransfected with GFP to facilitate the sorting of the transfected cells by FluorescenceActivated Cell Sorting (FACS). This step was necessary, since the transfection efficiency in MSC80 cells only yielded approximately $40 \%$. Lysates of the transfected and sorted MSC80 cells were subjected to a proteasome activity assay, which measures the chymotrypsin-like activity of the proteasome using a fluorogenic substrate. The proteasome activity was measured, while quantifying the fluorescent signal. The specific readout of this assay was previously tested using the proteasome inhibitor lactacystin (Vingill et al., 2016). The result revealed a $31 \%$ reduction in proteasome activity in 
FBXO7-depleted cells. Control PSMA2 shRNA cells revealed a $39 \%$ reduction in activity (Figure 3.3.8a). To validate the knockdown of FBXO7 and PSMA2, I performed a western-blot analysis of lysates from transfected and sorted MSC80 cells and immunoblotted against FBXO7, PSMA2 and $y$-tubulin as loading control. Indeed, the functional shRNAs effectively knocked down FBXO7 and PSMA2, whereas non-functional shRNAs did not alter the protein levels of FBXO7 and PSMA2 (Figure 3.3.8b). Hence, I demonstrated that knockdown of FBXO7 in Schwann cells induces an impairment of proteasome activity.

a

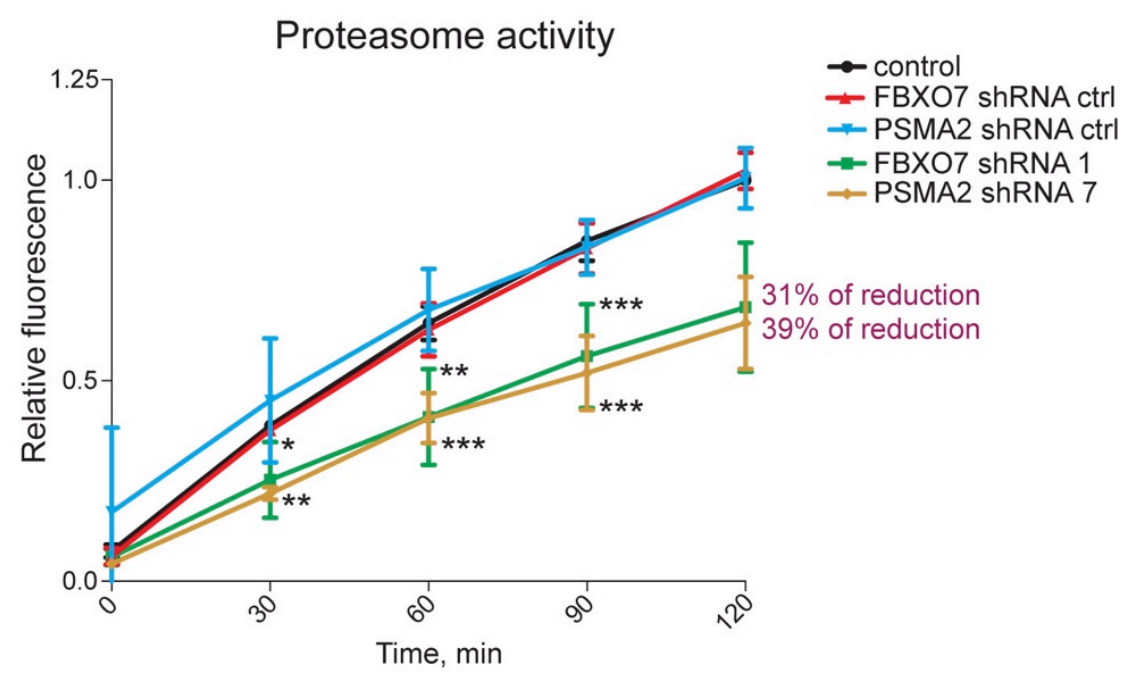

b
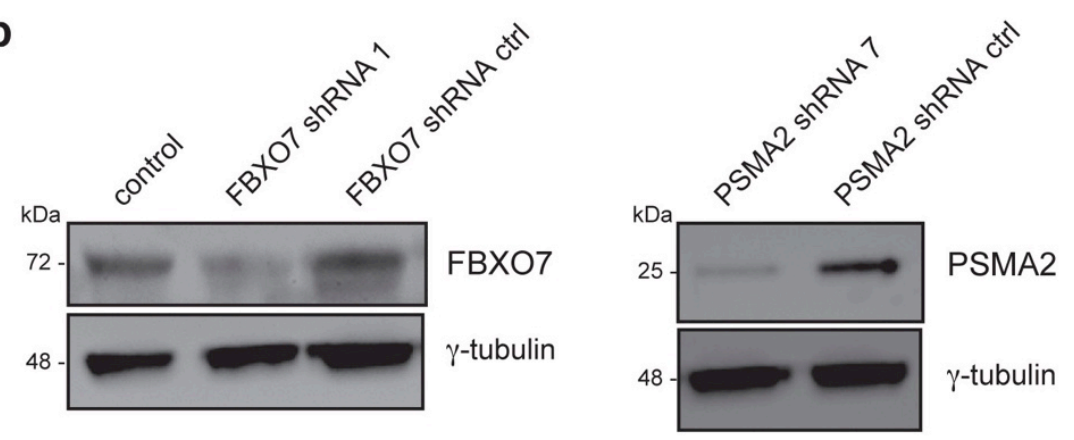

Figure 3.3.8 Knockdown of FBXO7 in Schwann cells leads to decreased proteasome activity

(a) MSC80 cells were transfected with a functional FBXO7 shRNA 1 and a functional PSMA2 shRNA 7. Transfections with a non-functional FBXO7 shRNA 4, non-functional PSMA2 shRNA 1 and empty vector served as control. Cell lysates were sorted and subjected to a proteasome activity assay (two-way ANOVA, *P $<0.05,{ }^{* *} P<0.01,{ }^{* * *} P<0.001$, mean \pm s.e.m). (b) Validation of shRNAs. Transfected MSC80 cell were lysed and a western-blot analysis was performed, while using antibodies against FBXO7, PSMA2 and $y-$ tubulin. The latter served as loading control. 


\subsection{The post-developmental contribution of FBXO7 to the maintenance of the axon-glia interaction}

With our $\mathrm{Cnp} 1^{\mathrm{Cre} /+} ; \mathrm{FbxO} 7^{\mathrm{fl} / \mathrm{fl}}$ mouse line we showed that FBXO7 severely affects the axonglia communication and that loss of $\mathrm{Fbxo7}$ in myelinating cells has a stronger impact on axon survival than on myelin stability. Since a previous publication has shown that Fbxo7 is highly expressed during early stages of oligodendrocyte development, we were wondering if the impact of $\mathrm{FBXO7}$ on the axon-glia interaction is only developmental based or whether FBXO7 also has a post-developmental contribution (Zhang et al., 2014). Hence, we generated a Tamoxifen-inducible Plp $1^{\mathrm{CreERT2/+}} ; \mathrm{FbxO} 7^{\mathrm{fl/fl}}$ mouse line (cKO-Tam), in which $\mathrm{Fbxo7}$ was deleted from myelinating cells at a selected time point.

\subsubsection{Generation of the PIp1 ${ }^{\mathrm{CreERT2/+}} ; F b \times 07^{\mathrm{fl/fl}}$ mouse line}

In collaboration with the department of Prof. Dr. Klaus-Armin Nave, we generated an inducible mouse line, in which Fbxo7 was deleted from myelinating cells upon injection of Tamoxifen. Here, we bred the $F b x o 7^{f / / 1 / 1}$ line (Vingill et al.) with the Tamoxifen-inducible Plp $1^{\text {CreERT2/+ }}$ mice (Leone et al., 2003). Tamoxifen, an agonist of the modified estrogen receptor $\left(E R^{\top 2}\right)$, was injected at 2 month of age, when myelination was completed (Figure 3.4.1a). Fbxo $7^{\mathrm{fl} / \mathrm{fl}}$ mice, injected with an equal amount of Tamoxifen, served as controls for

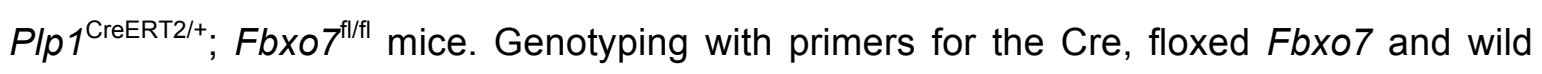
type Fbxo7 alleles ensured a correct breeding and were used to monitor the mouse line (Figure 3.4.1b). 
a

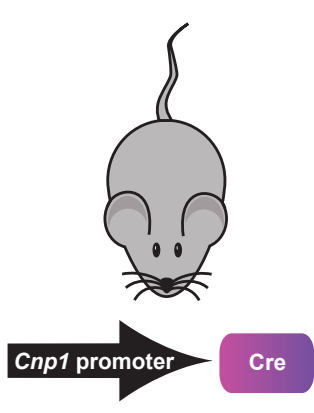

PIp1 CreERT2 - mouse line

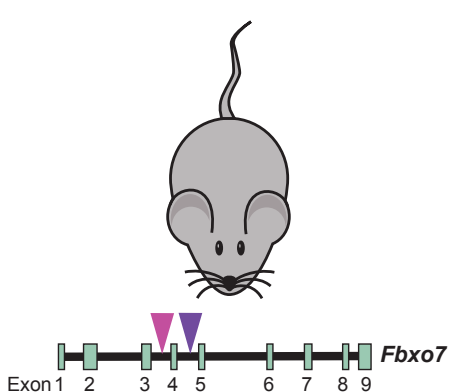

Fbxo7fl/fl - mouse line b

Cre

floxed Fbxo7

wild type Fbxo7

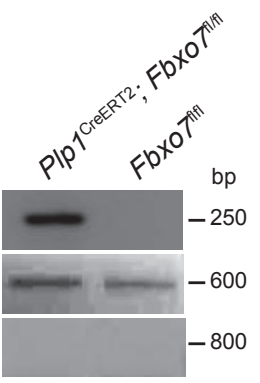

mating
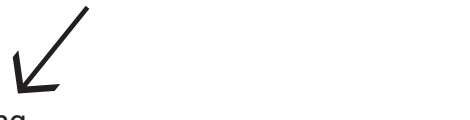

myelinating cells

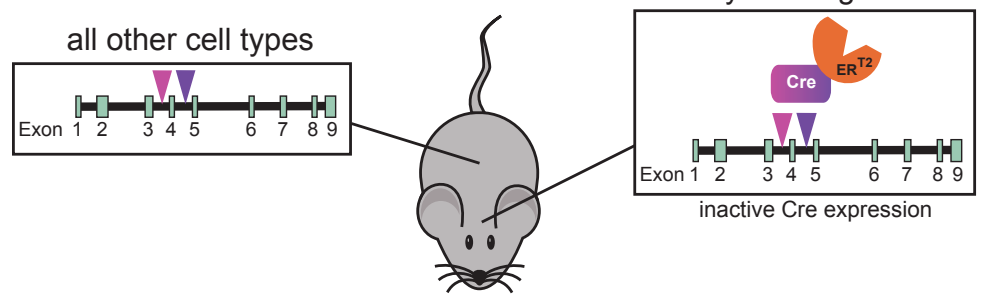

PIp1 CreERT2; Fbxo7 $^{f l / f l}$ - mouse line

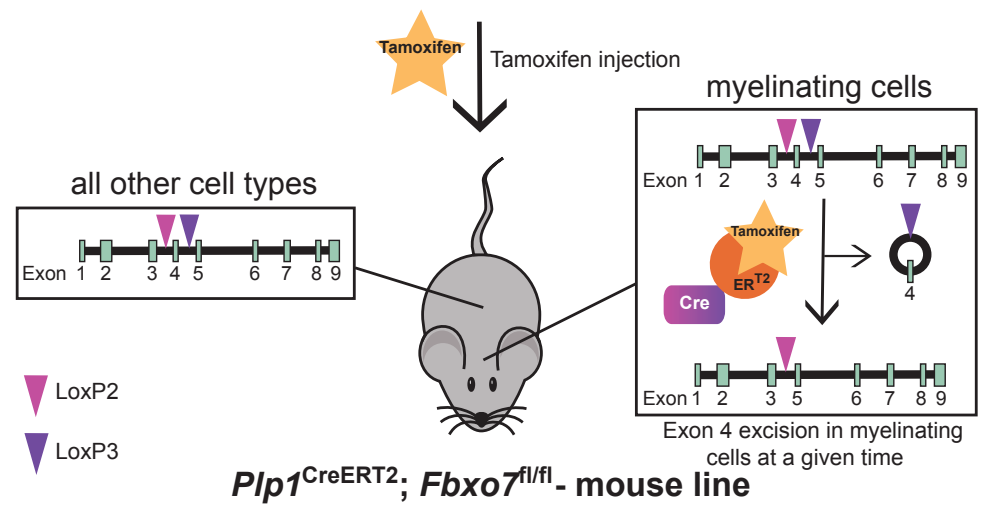

Plp1 ${ }^{\text {CreERT2; Fbxo }}{ }^{\text {fl/fl }}$ - mouse line

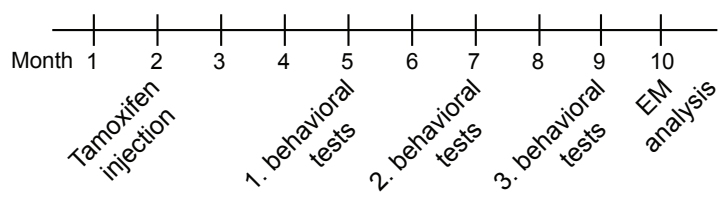

Figure 3.4.1 Validation of Tamoxifen-inducible PIp $1^{\mathrm{CreERT} 2 /+}$; Fbxo $7^{\mathrm{fl/fl}}$ mouse line.

(a) Schematic of Plp $1^{\mathrm{CreERT} 2 /+} ; \mathrm{FbxO} 7^{\text {tl/f/l }}$ breeding, including schedule of Tamoxifen injection and time points of behavioral and electron microscopic analyses. Modified from Erdmann et al. (Erdmann et al., 2008). (b) Genotyping PCR of $F b x o 7^{f / / f l}$ and $P l p 1^{\mathrm{CreERT} 2 /+} ; \mathrm{FbxO} 7^{\mathrm{fl/fl}}$ mice using primers for Cre, floxed allele and wild type Fbxo7. 


\subsubsection{Plp $1^{\text {CreERT2/+ }} ; \mathrm{FbxO} 7^{\mathrm{fl/fl}}$ mice show a moderate reduction of motor endurance and progressive muscle weakness}

Plp ${ }^{\text {CreERT2/+}} ;$ Fbxo7 $7^{\text {fl/fl }}$ mice did not display a strong phenotype and had a normal lifespan, comparable to those of control mice. To assess even mild changes in motor performance, I conducted an array of behavioral tests, in which I examined Fbxo $7^{\mathrm{fl/fl}}$ and Plp $1^{\mathrm{CreERT} 2 \mathrm{H}^{+}}$; Fbxo7 $7^{\text {fl/fl }}$ mice three, five and seven months after Tamoxifen injection. The analyses showed a stagnating bodyweight in $P / p 1^{\mathrm{CreERT} 2 /+} ; \mathrm{FbxO} 7^{\mathrm{fl/fl}}$ mice, which was significantly reduced at five and seven months post-Tamoxifen injected as compared to control (Figure 3.4.2a). Moreover, cKO-Tam mice scored significantly worse while performing a tail suspension test seven months post injection, indicating a progressive hind limb weakness (Figure 3.4.2b). In order to test the muscle strength of mice, an inverted grid test was performed and showed a decreased performance in $\mathrm{Plp} 1^{\mathrm{CreERT} 2 /+} ; \mathrm{FbxO} 7^{\mathrm{fl/fl}}$ mice, when tested three months after injection. However the performance on an inverted grid did not progress at later time points (Figure 3.4.2c). Furthermore, muscle weakness was assessed with a wire hang test. Here, cKO-Tam mice showed decreased muscle strength as compared to control, when tested seven months after injection (Figure 3.4.2d). With the rotarod test, their motor endurance was analyzed and revealed a significant reduction in knockout mice as compared to control at all time points (Figure 3.4.2e). A pole test was carried out to determine motor coordination, showing no difference between both groups (Figure 3.4.2f). Motor coordination was further tested with a balance beam test. Here, cKO-Tam mice showed no difference in performance on the $6 \mathrm{~mm}$ or $12 \mathrm{~mm}$ beam compared to control mice at any time (Figure 3.4.2g,h). Aside from these motor tests, I further analyzed the sensory performance of mice and conducted a hotplate test. Plp $1^{\text {CreERT2/+}} ;$ FbxO $^{\text {fl/fl }}$ mice showed signs of irritation a bit later than control mice, but did not differ significantly from control animals (Figure 3.4.2i). Anxiety and locomotion was monitored by performing an elevated plus maze and open field test. In both tests Plp $1^{\text {CreERT2/+}}$; Fbxo7 $7^{\text {fl/fl }}$ mice did not show any difference to control mice (Figure 3.4.2j,k). To summarize, I found that post-developmental loss of $\mathrm{Fbxo7}$ from myelinating cells leads to a mild but progressive muscle weakness, as well as a moderate reduction of motor endurance. Nonetheless, $P / p 1^{\mathrm{CreERT} 2 /+} ; \mathrm{FbxO} 7^{\mathrm{fl/fl} / \mathrm{l}}$ mice exhibit a predominantly normal motor and sensory behavior. 
3.4 The post-developmental contribution of $\mathrm{FBXO} 7$ to the maintenance of the axon-glia

interaction
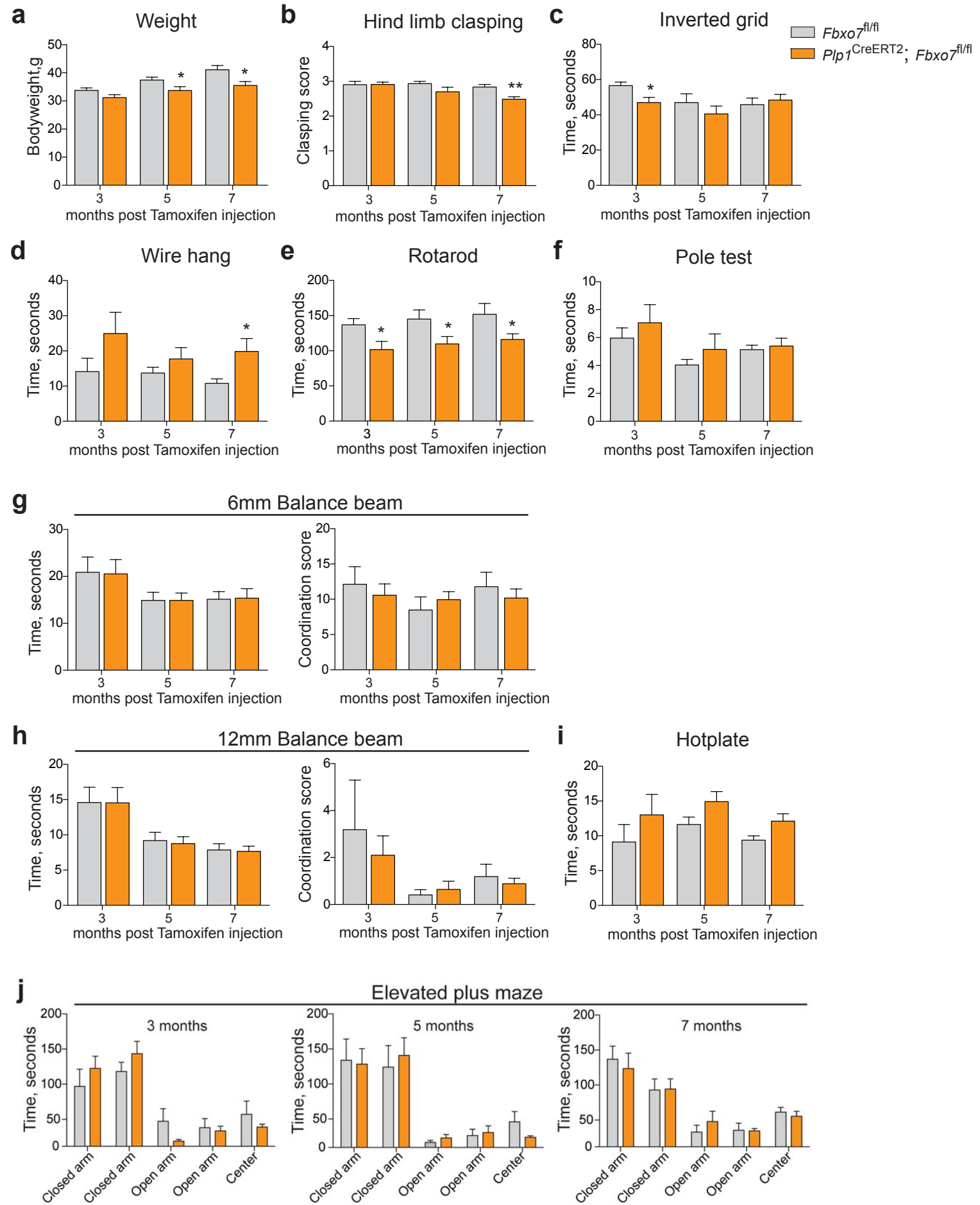

Elevated plus maze
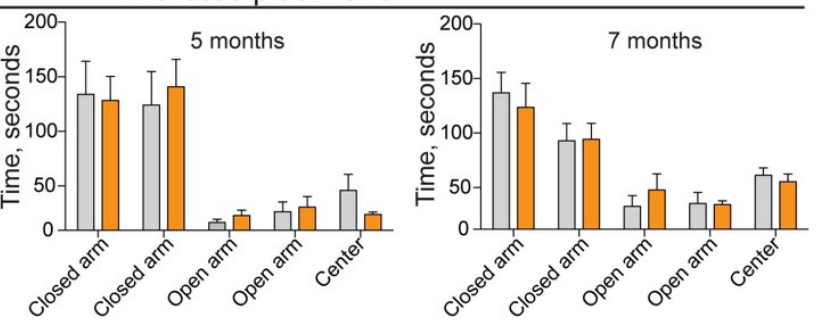

k

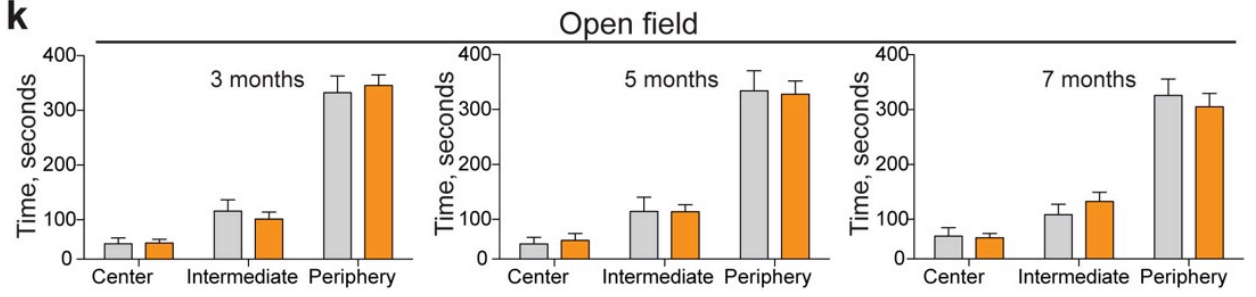

Figure 3.4.2 Plp1 ${ }^{\mathrm{CreERT} 2 /+} ; \mathrm{FbxO} 7^{\text {fl/fl }}$ mice show mild but progressive muscle weakness and reduced motor endurance. 
3 Results
3.4 The post-developmental contribution of FBXO7 to the maintenance of the axon-glia

(a)-(k) Behavioral analyses of $F b x o 7^{\mathrm{fl} / \mathrm{fl}}(\mathrm{n}=10)$ and $P l p 1^{\mathrm{CreERT} /++} ; F b x o 7^{\mathrm{fl} / \mathrm{fl}}(\mathrm{n}=11)$ mice three, five and seven months after Tamoxifen injection. Measurements showing (a) body weight, (b) tail suspension test $(3=$ normal, 0 = strong hind limb clasping), (c) inverted grid, (d) wire hang, (e) pole test, (f) rotarod, (g)-(h) balance beam of $6 \mathrm{~mm}$ and $12 \mathrm{~mm}(0=$ unable to cross beam, $7=$ normal $)$, (i) hotplate, (j) elevated plus maze and (k) open field test (unpaired t-test, ${ }^{*} P<0.05$, ${ }^{* *} P<0.01$, mean \pm s.e.m.).

\subsubsection{Post-developmental loss of Fbxo7 does not affect myelination, but induces a moderate axonal degeneration and immune response.}

The deletion of $\mathrm{FbxO} 7$ from myelinating cells in $\mathrm{Cnp} 1^{\mathrm{Cre} /+} ; \mathrm{FbxO} 7^{\mathrm{fl/fl}}$ mice induced a striking axonal degeneration and neuroinflammation in the sciatic nerve. To investigate whether post-developmental loss of $\mathrm{Fbxo7}$ also affects the integrity of axons or myelination, I decided to take electron microscopic images of sciatic nerve samples from Plp $1^{\text {CreERT2/+; }}$

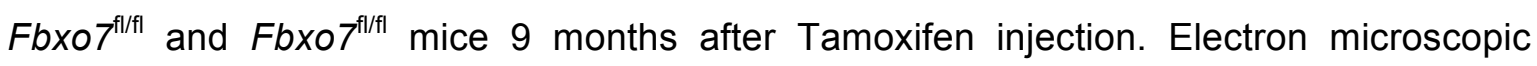
images were taken in collaboration with Prof. Dr. Joachim Weis. Both, embedding of samples and acquisition of images were done with the support of Claudia Krude, Hannelore Mader and Dr. Istvan Katona. The cross-sections of sciatic nerves were analyzed by measuring of the g-ratio, as previously described. Together with my colleague Yuhao Huang, I analyzed the sciatic nerve and found an equal distribution of $\mathrm{g}$ ratio values for cKO-Tam and control mice, indicating no change in myelination in the PNS of $P l p 1^{\mathrm{CreERT} 2 /+} ; \mathrm{FbxO} 7^{\mathrm{flffl}}$ mice (Figure 3.4.3a). Furthermore, I measured the average gratio of cKO-Tam and control axons and found that both indicated an equal average value of approximately 0.6 (Figure 3.4.3b). Additionally, I investigated the effect of postdevelopmental Fbxo7 deletion in Schwann cells on axonal integrity and assessed the number of degenerated axons in the sciatic nerve. Here, Plp $1^{\mathrm{CreERT} 2 /+} ; \mathrm{FbxO} 7^{\mathrm{fl} / \mathrm{fl}}$ mice displayed a sight but not significant increase in degenerated axons (Figure 3.4.3c). Since Cnp ${ }^{\mathrm{Cre} /+} ; \mathrm{FbxO}^{\mathrm{fl} / \mathrm{fl}}$ mice revealed a prominent infiltration of macrophages in the sciatic nerve, I further observed the electron microscopic images for signs of inflammation. Interestingly, in the 15 images of cKO-Tam mice and 15 images of control mice, I found slightly more macrophages in the sciatic nerve of cKO-Tam mice than in control. However, this signs of inflammation in Plp $1^{\mathrm{CreERT} 2 /+} ; \mathrm{FbxO} 7^{\mathrm{fl/fl}}$ sciatic nerve was certainly weaker than compared to $\mathrm{Cnp} 1^{\mathrm{Cre} /+} ; \mathrm{FbxO} 7^{\mathrm{fl/fl}}$ mice. While $\mathrm{Cnp} 1^{\mathrm{Cre} /+} ; \mathrm{FbxO} 7^{\mathrm{fl/fl}}$ mice displayed countless macrophages in cKO samples and non in control, Plp $1^{\mathrm{CreERT} 2 /+} ; \mathrm{FbxO} 7^{\mathrm{fl/fl}}$ mice showed roughly 9 macrophages in cKO-Tam sciatic nerve sections and about 3 in control mice (Figure 3.4.3d). Concluding, from these results I showed that post-developmental deletion 
of Fbxo7 from Schwann cells does not affect the integrity of myeliation, however moderately impacts the integrity of axons in the sciatic nerve and further induces a mild increase in inflammatory response.

a
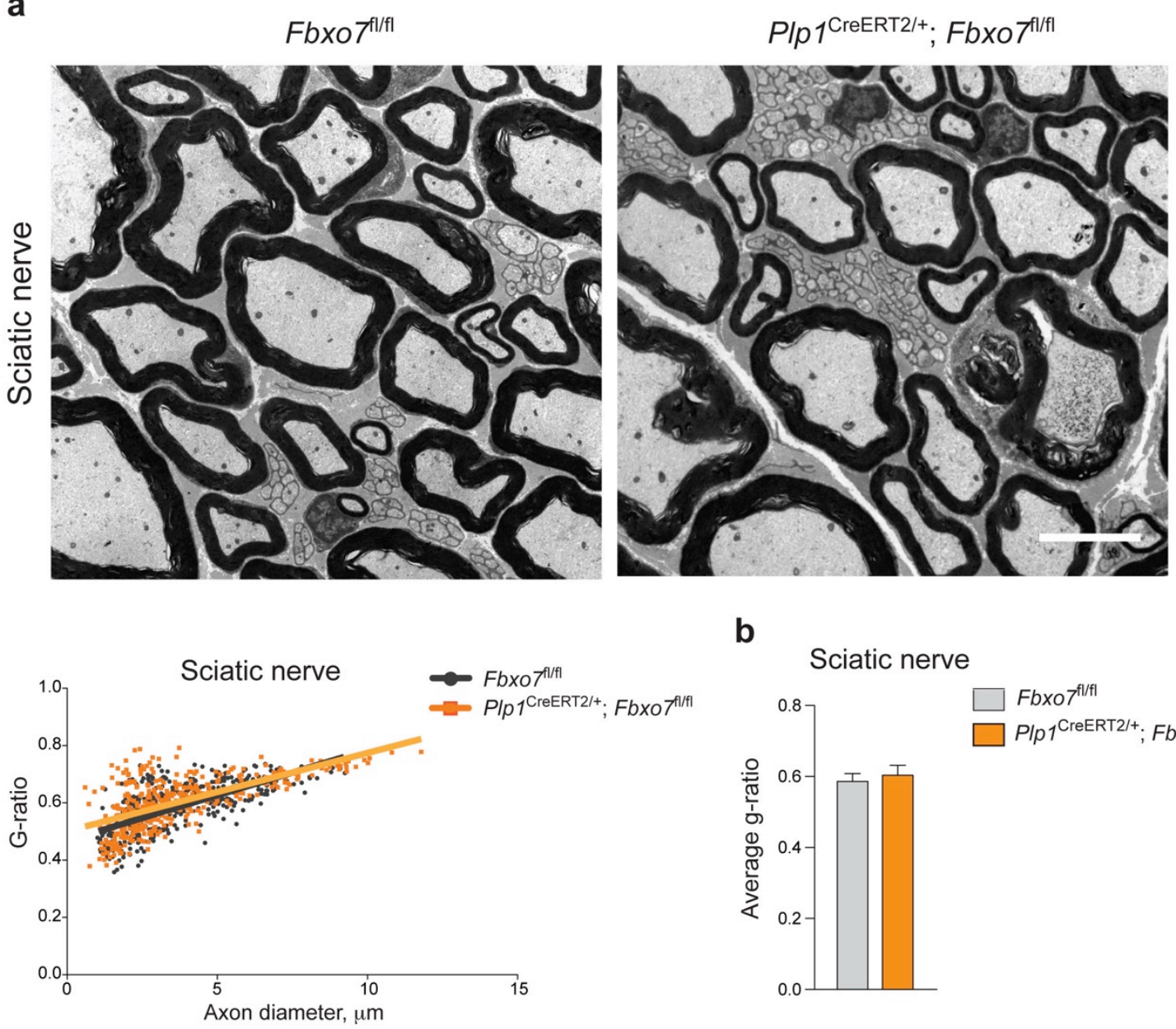

b

C

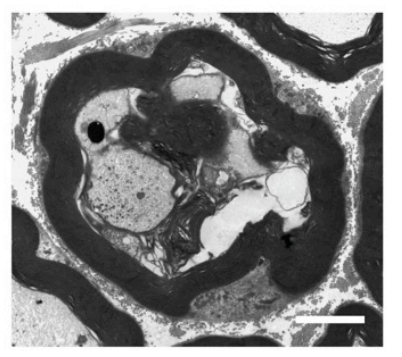

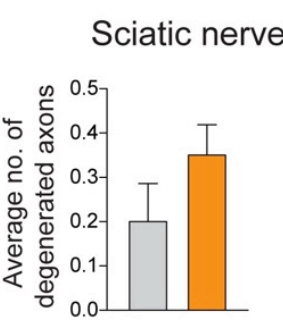

d
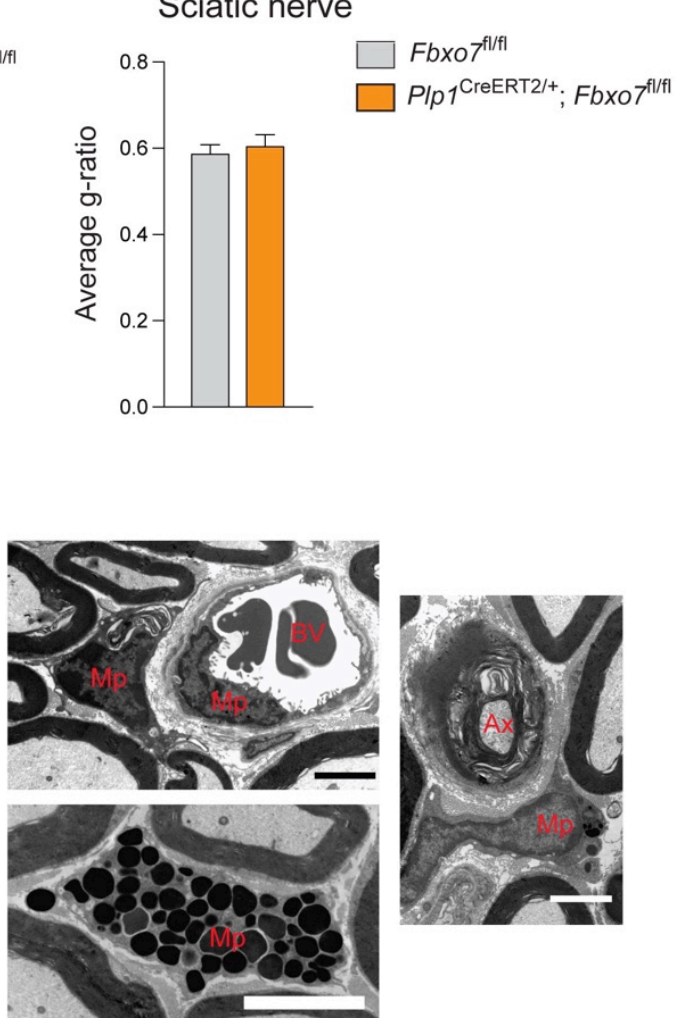

Figure 3.4.3 $\mathrm{Plp} 1^{\mathrm{CreERT} 2 /+} ; \mathrm{FbxO} 7^{\mathrm{fllfl}}$ mice display no alteration in PNS myelination and no significant but slight increase in axonal degeneration and inflammation.

(a)-(c) Representative electron microscopic images of sciatic nerve cross-sections from $\mathrm{Plp} 1^{\mathrm{CreERT2/+}} ; \mathrm{FbxO} 7^{\mathrm{fl/fl}}$ and of $F b x o 7^{\text {fl/fl }}$ mice 9 months after Tamoxifen injection. Four independent animals per condition and 15 images per mouse were included in the analyses. (a) G-ratio was measured and displayed as scatter plot, 
presenting 400 axons per genotype. Scale bar $=5 \mu \mathrm{m}$. G-ratio of sciatic nerve was measured with the help of Yuhao Hunag. (b) Average g-ratio of all measured axons from $F b x o 7^{f / / f l}$ and $P / p 1^{\mathrm{CreERT} 2 /+}$; Fbxo $7^{\mathrm{fl/fl}}$ mice (unpaired t-test, mean \pm s.e.m.). (c) Further on, the average number of degenerated axons was counted. Electron microscopic image from sciatic nerve represents axonal degeneration. Scale bar $=2 \mu \mathrm{m}$. (d) Images illustrate increased infiltration of sciatic nerve by macrophages engulfing dead, myelinated axons and migrating in from blood vessel. $\mathrm{Mp}=$ macrophage, $\mathrm{Ax}=$ axon, $\mathrm{BV}=$ blood vessel. Scale bar $=2 \mu \mathrm{m}$. 


\section{Discussion}

In this study, I investigated the functions of $\mathrm{Fbxo7}$ in myelinating cells and determined its impact on the integrity of myelination and the axon-myelin interaction using the newly generated $\mathrm{Cnp} 1^{\mathrm{Cre} /+} ; \mathrm{FbxO} 7^{\mathrm{fl} / \mathrm{fl}}$ mouse line. Additionally, I investigated the postdevelopmental relevance of FBXO7 in myelinating cells with the Tamoxifen-inducible Plp $1^{\text {CreERT2/+}} ;$ Fbxo7 $7^{\mathrm{fl/fl}}$ mouse line.

\subsection{Deletion of $\mathrm{FbxO7}$ in myelinating cells results in a strong motor phenotype in $\mathrm{Cnp}^{\mathrm{Cre} /+} ; \mathrm{FbxO}^{\mathrm{fl} / \mathrm{fl}}$ mice}

The $\mathrm{CnP}^{\mathrm{Cre} /+} ; \mathrm{FbxO}^{\mathrm{fl/fl}}$ (CKO) mice are characterized by a severe denervation and atrophy of the musculoskeletal system. This severe muscle weakness manifested itself in decreased motor performance at 6 weeks of age and in paresis, of the hind limbs. Moreover, cKO mice displayed a loss of tail tip tone, which further underlines a strong impact of Fbxo7 deletion on the PNS. The overall condition of $\mathrm{Cnp}^{\mathrm{Cre} /+} ; \mathrm{FbxO} 7^{\mathrm{fl/fl}}$ mice rapidly declined within 4 months of age, which dictated the endpoint of the experimental analyses. The loss of $\mathrm{Fbxo7}$ in myelinating cells therefore induced a rapid progression of severe symptoms. Generally, mutations in genes encoding for myelin proteins, or even deletions of such genes are not accompanied by embryonic lethality, as myelination only peaks postnatally in mammals. However such alterations can affect the development of myelin and induce progressive disorders (Nave, 2010a).

The prominent expression of FBXO7 in myelinating cells was previously shown in brain sections of conventional Fbxo7 knockout mice. My colleague Dr. Brockelt showed that FBXO7 is present in the white matter of cerebellum and corpus callosum, by performing a $\beta$-galactosidase staining of brain sections, in which the lacZ expression cassette was under the control of the endogenous Fbxo7 promoter (Brockelt, 2015). Additionally, an RNA sequencing transcriptome database, generated by Zhang et al. in 2014, compared the expression of different RNA sequences of purified neurons, astrocytes, oligodendrocyte precursor cells (Melander et al.), newly formed oligodendrocytes, myelinating oligodendrocytes, microglia and endothelial cells from mouse cerebral cortex and showed that FBXO7 expression is the highest in OPC and newly formed oligodendrocytes (Zhang et al., 2014). The comparison of FBXO7 expression further showed that FBXO7 is more abundant in glial cells than in neurons (Zhang et al., 2014). 
The mouse line we generated, harbors a Cnp1 promoter-driven deletion of $\mathrm{Fbxo7}$ in myelinating cells. Cnp is expressed in oligodendrocyte precursor cells (OPC) already in early stages of embryonic development at around E (embryonic day) 12.5 (Peyron et al., 1997; Yu et al., 1994). Cnp ${ }^{-/-}$mice develop comparably normal without any obvious signs of impairments until four months of age. However, these mice reveal progressive motor deficits and hind limb impairment at around 6 months of age. Further on, $\mathrm{Cnp}^{-/-}$mice display a similar phenotype as shown in $\mathrm{Cnp}^{\mathrm{Cre} /+} ; \mathrm{FbxO}^{\mathrm{fl/fl}}$ mice, since $\mathrm{Cnp}^{-/-}$mice also indicate muscle weakness, weight loss, gait abnormalities and a notable kyphosis. Nonetheless, $\mathrm{Cnp}^{-/}$mice live twice as long as cKO mice and die around 8-15 months of age (Lappe-Siefke et al., 2003). These similarities between Cnp-null and $C n p^{\mathrm{Cre} /+} ; \mathrm{FbxO} 7^{\mathrm{fl/fl}}$ mice, might raise the question whether the phenotype of the cKO mouse line might be due to the haplo-insufficiency of the $\mathrm{Cnp}$ gene. However, investigations of $\mathrm{Cnp}^{+/}$mice revealed no abnormalities in behavior or phenotype until 24 months of age and showed a normal lifespan comparable to wild type mice, indicating that lower Cnp levels are either sufficient or can be fully compensated (Hagemeyer et al., 2012; Lappe-Siefke et al., 2003). Cnp-Cre ${ }^{+/}$mice were therefore a suitable driver line in our mouse model.

Interestingly, loss of Fbxo7 induced a much stronger phenotype as seen in $\mathrm{Cnp} 1^{-1 /}$ mice, although CNP is a well established myelin protein that comprises approximately $4 \%$ of CNS and $0.5 \%$ of PNS myelin (de Monasterio-Schrader et al., 2012). Therefore, this early and strong phenotype of $\mathrm{Cnp} 1^{\mathrm{Cre} /+} ; \mathrm{FbxO} 7^{\mathrm{fl/fl}}$ mice demonstrates the vital role of FBXO7 and the crucial importance of a functional UPS in myelinating cells.

\subsection{Loss of Fbxo7 does not affect myelin integrity, but leads to degeneration of large-caliber axons in the PNS}

Loss of $\mathrm{FbxO} 7$ revealed a strong impact on the axon-myelin interaction, with little or no impact on myelin integrity. While myelinated axons of cKO mice from the sciatic nerve showed mild, but not significant hypomyelination as compared to control mice, the number of axons in the sciatic nerve were significantly reduced, indicating axonal degeneration. Alterations upon loss of $\mathrm{FbxO} 7$ in the PNS occurred without influencing the number of Schwann cells present in the sciatic nerve, but induced a remarkable shift of axon diameter. Measurements demonstrated a significant loss of large-caliber axons and a potential compensatory increase in small-caliber axons in the sciatic nerve of Cnp ${ }^{\mathrm{Cre} /+} ; \mathrm{FbxO}^{\mathrm{fl} / \mathrm{lfl}}$ mice. 
4 Discussion 4.2 Loss of Fbxo7 does not affect myelin integrity, but leads to degeneration of large-caliber axons in the PNS

Why large-caliber axons are more susceptible to degeneration is not fully understood. It is speculated that larger axons have higher metabolic and trophic demands, which render them more vulnerable to dysfunctions (Blight, 1991; Blight and Decrescito, 1986). Moreover, the intimate interaction of myelinating cells and their ensheathed axons is known to regulate axon diameter. Signaling of the axonal ligand neuregulin type III and its receptor ErbB3 on Schwann cells have been shown to be vital for myelination and the integrity of axons (Michailov et al., 2004; Riethmacher et al., 1997; Simon et al., 2010; Taveggia et al., 2005). While axon diameter is regulated by myelinating cells during development (Hsieh et al., 1994; Sanchez et al., 1996), dysmyelinating disease models with alterations in crucial myelin proteins, have been shown to reduce axon caliber (Brady et al., 1999; de Waegh et al., 1992). Charcot-Marie-Tooth (CMT) disease, also referred to as CMT1A, is the most common inherited neuropathy and can be caused by a duplication of the Pmp22 gene. This alteration will lead to a slow-progressing demyelination, axonal degeneration and eventually distal pronounced muscle atrophy (Krajewski et al., 2000; Patel et al., 1992; Timmerman et al., 1992). The amount of secondary axonal death determines the disease severity (Berciano et al., 2000).

In my results, I showed that $\mathrm{Fbxo7}$ deletion induced a subtle change in myelination of peripheral axons and that myelin proteins of the PNS indicated a down-regulation of proteins associated with neuropathy and cytoskeleton mobility. Since structural proteins of myelin were not affected by deletion of $\mathrm{Fbxo7}$, this further supports the assumption that FBXO7 acts as crucial UPS protein in the axon-myelin communication and helps to sustain the supportive function of myelinating cells for axonal integrity.

The investigation of our $\mathrm{Cnp}^{\mathrm{Cre} / \mathrm{r}} ; \mathrm{FbxO} 7^{\mathrm{fl} / \mathrm{fl}}$ mouse line indicated the important role of FBXO7 during development. Especially in the PNS, early deletion of Fbxo7 induced a strong impact on the axon-glia interaction and integrity of axons. The essential communication between Schwann cells and axons during development was previously shown, as disruption of the ErbB3 receptor leads to secondary axonal loss and severe neuropathy (Riethmacher et al., 1997). Genetic mutations that induce changes in myelinating cells, often affect PNS fibers innervating the most distal muscle groups first and cause a length-dependent axonal loss (Nave, 2010a; Suter and Scherer, 2003). This can be observed in the Plp $1^{-/-}$mouse model, in which the break down of axonal transport leads to axonal swellings and subsequently to a degeneration of distal axons (Garbern and Hobson, 2002; Griffiths et al., 1998). Neurons with long axons present a logistic problem, as their diameter often only measures a few micrometers but their length can be hundreds of centimeters in large mammals (Griffin and Watson, 1988; Nave, 2010b). Moreover, dysfunctional myelinating cells and the resulting lack of support appears to be 
4.3 Deletion of Fbxo7 causes a shift in axon diameter without affecting myelination in the CNS most vulnerable for long-traveling axons, since these axons have a higher demand in energy supply that is generally provided by myelinating cells (Funfschilling et al., 2012; Nave, 2010b; Simons and Nave, 2015).

The great influence of FBXO7 on the supportive function of myelinating cells towards axons and their integrity might lie in its remarkable function as being part of the ubiquitin proteasomal system (UPS). FBXO7 has multiple interaction partners and therefore many different sites of interaction within a myelinating cell that affects axonal survival. The vital role of the UPS for the stability of axons was demonstrated by other UPS-associated PARK genes - PARK5. PARK5 encodes for the deubiquitinase UCH-L1 and similarly as seen in $\mathrm{Cnp}^{\mathrm{Cre} / \mathrm{+}} ; \mathrm{FbxO} 7^{\mathrm{fl} / \mathrm{fl}}$ mice, conventional Uchl1 knockout mice display axonal death and denervation of muscles, progressive paralysis and premature death at around 7 months of age (Bishop et al., 2016; Chen et al., 2010). Moreover Uchl1-deficient mice present early-onset sensory and motor ataxia at 3 months of age (Mukoyama et al., 1989). These findings indicate an essential role of UCH-L1 for axonal health and stability and thus for neuronal survival (Bishop et al., 2016).

\subsection{Deletion of Fbxo7 causes a shift in axon diameter without affecting myelination in the CNS}

In the CNS, loss of $\mathrm{Fbxo7}$ did not induce dramatic changes on the axon-myelin interaction as seen in the PNS. However, oligodendrocytes responded to the loss of Fbxo7 with a significant shift in axon caliber. cKO mice displayed significantly larger axons in the CNS as compared to control mice, while the number of healthy myelinated axons in the optic nerve of $\mathrm{Cnp}^{\mathrm{Cre} / \mathrm{+}}$; $\mathrm{FbxO} 7^{\mathrm{fl} / \mathrm{fl}}$ mice remained unchanged. The axons of cKO mice optic nerve presented no signs of axonal swelling, but indicated a mild trend of increased axonal death compared to control mice. Oligodendrocytes further showed a slight but not significant increase in nuclei abundance, without alteration in myelin thickness.

Similar effects were observed in a study, in which the CNS-specific myelin-associated oligodendrocyte basic protein (MOBP) was deleted. The analysis of $\mathrm{Mobp}^{-/}$mice revealed that axons of the optic nerve had larger diameter and more myelin lamellae as compared to controls (Sadahiro et al., 2000). Since axonal growth determines the rate of myelin formation, the number of myelin lamellae increase in proportion to the axon diameter (Fraher, 1976; Friede and Miyagishi, 1972; Hildebrand and Hahn, 1978). Hence, Sadahiro and authors concluded that MOBP regulates axon diameter, while the number of myelin lamellae is dependent on the size of the axon (Sadahiro et al., 2000). Another regulator of axon size is myelin basic protein (MBP). Mice expressing decreased levels of the Mbp 
4 Discussion

gene display larger myelinated axons than control mice (Shine et al., 1992). In the $\mathrm{Cnp}^{\mathrm{Cre} /+} ; \mathrm{FbxO} 7^{\mathrm{fl} / \mathrm{fl}}$ mice, loss of Fbxo7 induced an increase in axon diameter in the optic nerve without significantly affecting myelination. Although I did not count the number of myelin lamellae of myelinated axons in the optic nerve, the g-ratio measurements indicated no significant change in myelin thickness. A potential secondary response of myelinating cells to an axonal shift, however might be the slight increase in oligodendrocyte abundance in $\mathrm{Cnp}^{\mathrm{Cre} /+} ; \mathrm{FbxO} 7^{\mathrm{fl} / \mathrm{fl}}$ optic nerve. Similar as MOBP and MBP, FBXO7 might have a regulatory function in axon diameter and act as a mediator of the interaction between myelinating cells and axons.

Interestingly, the function of FBXO7 appears to have a different impact on myelinating cells of the CNS as compared to the PNS. Why deletion of Fbxo7 lead to an increase in axonal diameter in the optic nerve, but led to more small-caliber axons in the sciatic nerve is unclear. So far, nothing is known about the expression level of FBXO7 in oligodendrocytes compared to Schwann cells. As loss of Fbxo7 affected the interaction of axons and Schwann cell more dramatically than the oligodendrocyte-axon communication, this might imply a higher expression or greater importance of FBXO7 in Schwann cells. Deletion of Fbxo7 potentially induces an increase in axon caliber in both nervous systems, however its possible greater impact on Schwann cells might lead to a more dramatic disturbance of myelin support of PNS axons. Hence, early loss of Fbxo7 in Schwann cells might contribute to a greater stress and vulnerability of long-traveling, peripheral axons, leading to increased axonal death in the PNS. To verify this hypothesis, further investigations are required that compare the expression levels of FBXO7 in both systems.

\subsection{FBX07 remains relevant for the post-developmental maintenance of the axon-myelin interaction}

As FBXO7 was shown to be highly expressed in OPCs and newly forming oligodendrocytes, deletion of $\mathrm{FBXO} 7$ in the $\mathrm{Cnp}^{\mathrm{Cre} /+} ; \mathrm{FbxO} 7^{\mathrm{fl} / \mathrm{fl}}$ mouse line revealed the developmental importance of FBXO7 (Zhang et al., 2014). I showed that Fbxo7 was deleted in $\mathrm{Cnp}^{\mathrm{Cre} /+} ; \mathrm{FbxO} 7^{\mathrm{fl/fl}}$ mice around postnatal day 30. Having established the strong developmental influence of FBXO7 on myelinating cells, the question arose as to how FBXO7 might affect the post-developmental axon-glia interface. I therefore generated and analyzed the Tamoxifen-inducible Plp $1^{\mathrm{CreERT} 2 /+} ; \mathrm{FbxO} 7^{\mathrm{fl/fl}}$ mouse line, in which Fbxo7 was 
deleted at 2 months of age when myelination was completed. The post-developmental effect of Fbxo7 deletion on myelinating cells was less severe, as cKO-Tam mice revealed a milder phenotype. Plp1 ${ }^{\mathrm{CreERT} 2 /+} ; \mathrm{FbxO7^{ \textrm {fl/fl } }}$ mice displayed progressive muscle weakness of hind limbs, resulting in a moderate reduction of motor endurance. Further more, cKOTam mice indicated a stagnating body weight, but otherwise presented no distinct phenotype or signs of pain and had a normal lifespan. Similar to the $\mathrm{Cnp}{ }^{\mathrm{Cre} / \mathrm{r}} ; \mathrm{FbxO} 7^{\mathrm{fl} / \mathrm{fl}}$ mouse line, $P l p 1^{\mathrm{CreERT} 2 /+} ; \mathrm{FbxO} 7^{\mathrm{fl} / \mathrm{fl}}$ mice showed no alterations in myelination of axons in the sciatic nerve. The number of degenerated axons in the sciatic nerve of cKO-Tam mice was slightly elevated as compared to control mice, but significantly lower as compared to Cnp $1^{\mathrm{Cre} /+} ; \mathrm{FbxO} 7^{\mathrm{fl} / \mathrm{fl}}$ mice. This demonstrates the vital importance of FBXO7 during development, but still shows that FBXO7 remains relevant for the post-developmental maintenance of the myelin-axon interplay and the supportive role of myelinating cells for axonal integrity.

\subsection{Lack of Fbxo7 elicits a strong inflammatory response and an increase in detoxification processes}

The significant increase in neuroinflammation was one very prominent event, which was induced by loss of Fbxo7 in both CNS and PNS as well as when post-developmentally deleted. $\mathrm{Cnp}^{\mathrm{Cre} /+} ; \mathrm{FbxO} 7^{\mathrm{fl/fl}}$ mice presented strong astrogliosis and microgliosis in the myelin areas of the CNS and the PNS. Moreover, electron microscopic images of the sciatic nerve from Plp $1^{\mathrm{CreERT} 2 /+} ; \mathrm{FbxO}^{\mathrm{fl} / \mathrm{fl}}$ and $\mathrm{Cnp} 1^{\mathrm{Cre} /+} ; \mathrm{FbxO} 7^{\mathrm{fl/fl}}$ mice showed a noticeable infiltration by macrophages.

Inflammation is a common phenotype seen in many neurodegenerative diseases and often precedes the onset of cellular degeneration and neurological disorders (Carson et al., 2006; Halliday and Stevens, 2011; Wyss-Coray and Mucke, 2002). Microglia sense even the smallest pathological changes, but only when the damage is severe enough activated microglia will initiate phagocytosis and secrete cytokines that activate astrocyte that lead to astrogliosis (Jansen et al., 2014). These activated astrocytes in turn influence the function of microglia, by releasing cytokines and thereby create a feedback loop in which both cells regulate each other (Amor et al., 2014; Zhang et al., 2010). Initial activation of astrocytes forms a protective border around damaged areas and is meant to be protective for neurons (Pekny and Pekna, 2014). However, persisting activation of astrocytes are unable to support neurons and therefore contribute to neuronal dysfunction (Pickering et al., 2005). 
4 Discussion

Dysfunctional oligodendrocytes are known to trigger an inflammatory response, and contribute to axonal degeneration and to the severity of the disease, as inflammation poses an additional burden for axonal survival (Ip et al., 2006; Kassmann et al., 2007; Lappe-Siefke et al., 2003; Wieser et al., 2013). During the process of inflammation, activated microglia generate nitric oxide, which readily diffuses into axons and perturbs the mitochondrial ATP generation (Nave, 2010b; Smith and Lassmann, 2002; Trapp and Stys, 2009). Interestingly, I found in mass spectrometry analyses that loss of Fbxo7 decreased mitochondrial proteins in purified myelin from CNS and PNS. This suggests that the strong inflammatory reaction induced by Fbxo7 deletion in the CNS and PNS of $\mathrm{Cnp}^{\mathrm{Cre} / \mathrm{H}} ; \mathrm{FbxO} 7^{\mathrm{fl} / \mathrm{fl}}$ mice triggers the generation of NO species, which act as free radicals and induce oxidative stress in the cell. Indeed, I further demonstrated the increase of oxidative stress in myelinating cells, as levels of the endogenous stress sensor GSTT1 were elevated in both the CNS and PNS.

The mass spectrometry analyses further showed a dramatic increase in proteins linked to inflammation in PNS myelin. Hence, it suggests that axons of the PNS are potentially exposed to more stress and toxic substances, such as nitric oxide generated by activated microglia, which would induce a stronger degeneration of axons. To validate this hypothesis, the levels of NO in PNS axons have to be measured. This would provide more evidence on whether the increase in inflammation is accountable for the stronger axonal degeneration in the PNS as compared to CNS, which I reported for $C n p 1^{\mathrm{Cre} /+} ; \mathrm{FbxO} 7^{\mathrm{fl} / \mathrm{fl}}$ mice. However, the question still remains as to why loss of $\mathrm{Fbxo7}$ induces a stronger immune response in the PNS than in the CNS.

The inflammatory response of glial cells further leads to an up-regulation of the NF-kB or JKN pathway, which is controlled by UPS components (Dalal et al., 2012; Stefanova et al., 2012). The E3 ubiquitin ligase RING finger protein 11 (RNF11) is known to be one of the key negative regulators of the NF-KB pathway (Dalal et al., 2012). Furthermore, FBXO7 indirectly decreases the NF-KB signaling pathway, by ubiquitinating proteins of the NF-KB cascade (Chang et al., 2006; Chen and Goeddel, 2002; Kuiken et al., 2012). Hence, the deletion of Fbxo7 might lead to an uncontrolled increase of the NF-KB signaling in $\mathrm{Cnp}{ }^{\mathrm{Cre} / \mathrm{H}} ; \mathrm{FbxO} 7^{\mathrm{fl} / \mathrm{fl}}$ mice, which results in a strong neuroinflammatory event as seen in both mouse models.

The contribution of the UPS to the course of inflammation is further shown by the transformation of proteasomes in glia cells. During an inflammatory response, the secretion of cytokines such as interferon gamma induces the formation of immunoproteasomes in glia cells, which contributes to a more efficient clearance of disease-causing proteins and further activates the immune response (Basler et al., 2013; 
4 Discussion

Sijts and Kloetzel, 2011). However, it is unknown whether the long-term induction of immunoproteasomes are beneficial or detrimental in neurodegenerative diseases, as chronic inflammation is known to contribute to the degeneration of neurons (Tansey et al., 2012).

While $\mathrm{Cnp} 1^{-1-}$ mice show progressive inflammation in the CNS, $\mathrm{Cnp1^{+/- }}$ mice do not exhibit any signs of inflammation until 12 months of age (Hagemeyer et al., 2012; Lappe-Siefke et al., 2003; Wieser et al., 2013). The prominent inflammatory events due to loss of Fbxo7 in the $\mathrm{Cnp}^{\mathrm{Cre/+}} ; \mathrm{FbxO} 7^{\mathrm{fl} / \mathrm{fl}}$ mice, therefore must originate from a dysfunctional UPS in myelinating cells.

As mentioned before, deletion of $\mathrm{Fbxo7}$ caused an up-regulation of proteins involved in the detoxification process. In both CNS and PNS, the levels of GSTח1 were increased in $\mathrm{Cnp}^{\mathrm{Cre} / \mathrm{H}} ; \mathrm{FbxO} 7^{\mathrm{fl} / \mathrm{fl}}$ mice. While the mass spectrometry of purified CNS myelin showed significant increase in GSTT1 levels, GSTT1 was not among the list of highly upregulated proteins in PNS myelin. Nonetheless, GSTா1 stainings of the sciatic nerve demonstrated increased levels of the enzyme. Furthermore, PNS myelin contained many other proteins linked to detoxification processes, which were up-regulated upon Fbxo7 deletion.

Glutathione S-transferase $\pi 1$ is a phase II detoxification enzyme that catalyzes the conjugation of xenobiotic and electrophilic components with reduced glutathione (GSH) (Sheehan et al., 2001; Udomsinprasert et al., 2005). There are three isoforms expressed

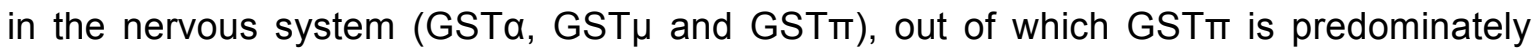
expressed in myelinating cells (Castro-Caldas et al., 2009; Tamura et al., 2007). Upon low cellular stress, GSTா1 prevents apoptosis while inhibiting C-jun phosphorylation by JNK (Adler et al., 1999; Laborde, 2010; Wang et al., 2001). However, increased cellular oxidative stress induces the oligomerization of GST $\pi 1$, inhibiting its function and resulting in apoptosis (Townsend and Tew, 2003).

A similar increase of proteins of the detoxification pathway was seen in glia cells of parkin knockout mice. Just like FBXO7, parkin functions as an E3-ubiquitin ligase is encoded by a PARK gene. Glia cells of parkin knockout mice showed increased levels of glutathione and glutathione S-transferase activity (Solano et al., 2008). An increased redox status is known to modulate the process of protein ubiquitination via reversible S-thiolation of E1 and E2 enzymes, presumably by glutathione (Jahngen-Hodge et al., 1997).

Oligodendrocytes seem to be particularly susceptible to oxidative stress and often appear as vulnerable as neurons to insults caused by oxidation or ischemia (Juurlink et al., 1998; Osterhout et al., 2002; Sypecka, 2003). This might be due to their high content of iron, 
4 Discussion

which is predominantly present in oligodendrocytes and myelin sheaths (Connor and Menzies, 1996; Todorich et al., 2009). Additionally, oligodendrocytes are low in glutathione and glutathione peroxidase, rendering them more sensitive to oxidative stress (Juurlink et al., 1998). The observed increase in GSTm1 levels might thus reflect an attempt of myelinating cells to overcome their deficiency in scavenging reactive oxygen species.

Another endogenous redox sensor that responds to oxidative stress is DJ-1 (Shadrach et al., 2013). DJ-1 is also known as PARK7 and further belongs to the 20 identified PARK genes. Interestingly, its level was significantly down-regulated in purified myelin from the PNS of $\mathrm{Cnp} 1^{\mathrm{Cre} /+} ; \mathrm{FbxO} 7^{\mathrm{fl} / \mathrm{fl}}$ mice. DJ-1 shows increased susceptibility to oxidative stress and regulates factors regarding stress-induced cell death (Chan and Chan, 2015; Shadrach et al., 2013). It has been suggested that DJ-1 functionally interacts with FBXO7 and parkin, since all three PARK genes have been linked to mediate mitochondrial function, but the direct interaction has so far not been validated. Since my data show a down-regulation of DJ-1 upon Fbxo7 deletion, it indicates that both proteins influence each other in their expression levels. Whether this influence is achieved via a direct or indirect interaction, remains to be elucidated.

These examples show that a dysfunctional UPS often lead to an up-regulation of detoxification processes, as the result of oxidative stress in the cells. Moreover, as mutations in FBXO7, Parkin and $D J-1$ are known to induce different forms of parkinsonism, it demonstrates the importance of a functional UPS for cellular vitality and further shows that disruption of the UPS leads to severe changes in the cell, contributing to the onset of neurological diseases.

\subsection{Mutation in the FBXO7 gene cause Parkinsonian- Pyramidal syndrome}

Mutations in the Fbxo7 (PARK15) gene cause a genetic form of parkinsonism, known as Parkinsonian-Pyramidal Syndrome (PPS) (Di Fonzo et al., 2009; Shojaee et al., 2008). Symptoms seen in these PARK15 patients are very heterogenic, with signs of parkinsonism and pyramidal tract features, but also additional atypical symptoms (Di Fonzo et al., 2009; Lohmann et al., 2015; Shojaee et al., 2008). So far, research groups that had the opportunity to diagnose and examine these rare cases of PPS, neither reported on peripheral neuropathies, nor on potential defects in myelin, mostly since there is no PARK15 patient material available. 
However, as previously mentioned, Fbxo7 was found to be stronger expressed in glia cells than in neurons (Zhang et al., 2014). Therefore, glia cells that are affected by FBXO7 dysfunction have to be considered as equally important in their contribution to the disease onset as affected neurons. Interestingly, a brain scan of one PPS patient revealed white matter lesions, indicating a potential influence of Fbxo7 mutations on myelin integrity (Lohmann et al., 2015). Nonetheless, this finding was only reported in one patient and has to be verified in more PARK15 patients, since not all reported cases were subjected to MRI scanning. Owing to the immense impact of glia cells on the nervous system, further investigation are relevant and help to elucidate the general role of the E3-ubiquitin ligase FBXO7 in the axon-glia interaction. Deleting Fbxo7 from myelinating cells in Cnp ${ }^{\mathrm{Cre} /+} ; \mathrm{FbxO} 7^{\mathrm{fl} / \mathrm{fl}}$ mice triggered loss of motor control and a severe impairment of gait, which is reminiscent of pyramidal symptoms seen in PPS patients (Conedera et al., 2016; Paisan-Ruiz et al., 2010; Yalcin-Cakmakli et al., 2014). One of the atypical symptoms that some patients carry is dysarthria, a motor speech disorder resulting from neurological injuries (Lohmann et al., 2015). Here, muscles that are involved in the creation of speech are affected and include those of respiration, resonance or phonation. Although I did not investigated how loss of Fbxo7 in myelinating cells affected the diaphragm or intercostal muscles of respiration, I did found a pronounced muscle atrophy of the same type of skeletal muscle throughout the body of the cKO mice. Furthermore, I showed a severe atrophy of cKO lungs, indicating substantial problems of the respiratory system due to potential denervation.

\subsection{Molecular changes induced by loss of Fbxo7}

Loss of Fbxo7 led to significant down-regulation of proteins associated with the cytoskeleton and mitochondrial functions in both CNS and PNS. While screening for new interaction partners of FBXO7, our lab identified the light chain 1 of the microtubuleassociated protein 1B (MAP1B-LC1), MAP1A-LC2 and MAP1S as novel substrates of FBXO7 (Brockelt, 2015). My colleague demonstrated the ubiquitination of MAP1B-LC1 and MAP1A-LC2 by FBXO7 and hypothesized a potential K63 linage of ubiquitination (Brockelt, 2015). As K63-linked ubiquitination is often thought to induce a functional modification of the target protein, loss of $\mathrm{Fbxo7}$ and the resulting dysfunction of the UPS might affect the stability of these novel interactors. Indeed, purified myelin from the PNS indicated a significant down-regulation of MAP1B in $\mathrm{Cnp} 1^{\mathrm{Cre} /+} ; \mathrm{FbxO} 7^{\mathrm{fl/fl}}$ mice as compared to control. Hence, supporting the speculated interaction of FBXO7 and MAP1B in vivo and suggesting a possible stabilization of MAP1B by FBXO7 ubiquitination. In order to further 
elucidate the interaction of both proteins and to understand the impact of FBXO7 on the cytoskeleton system, additional experiments are required.

Interestingly, DJ-1 (PARK7) is known to bind MAP1B and inhibits MAP1B aggregates (Wang et al., 2011). Since DJ-1 as well was decreased upon Fbxo7 deletion, it potentially influences the cytoskeleton stability as well and illustrates the multi-layered interaction and complex influence that FBXO7 has within many different pathways of the cell.

Changes in the cytoskeletal arrangement can influence the integrity of mitochondria. MAP1B is not only important for microtubule stabilization, it is also required of a proper anterograde transport of mitochondria. In addition, deregulation of MAP1B-LC1 has been shown to induce mitochondrial aggregation (Jimenez-Mateos et al., 2006; Yonashiro et al., 2012). Furthermore, FBXO7 was reported to participate in the mitochondrial quality control mechanism, while acting as scaffold protein for parkin and PINK1, which are recruited to the depolarized mitochondrial membrane (Burchell et al., 2013). The lack of FBXO7 therefore compromises mitochondrial integrity and as seen in the mass spectrometry of purified CNS and PNS myelin induces a significant decrease in mitochondrial proteins in $\mathrm{Cnp} 1^{\mathrm{Cre} /+} ; \mathrm{Fb} \times \mathrm{O} 7^{\mathrm{fl/fl}}$ mice.

In our previous publication our lab identified the proteasome subunit $\alpha 2$ (PSMA2) as direct interactor and ubiquitination substrate of FBXO7 (Vingill et al., 2016). While my colleagues showed that lack of $\mathrm{Fbxo7}$ reduced proteasome activity in neurons, I investigated the activity of proteasomes in Schwann cells and performed a proteasome activity assay by measuring the chymotrypsin-like activity of the proteasome, using a fluorogenic peptide substrate. The results showed a reduced proteasome activity in cultured Schwann cells upon FBXO7 knockdown.

Changes in the function of the proteasome have been shown to cause similar pathological symptoms as seen in $\mathrm{Cnp} 1^{\mathrm{Cre} /+} ; \mathrm{FbxO} 7^{\mathrm{fl/fl}}$ mice. Rats treated with the proteasome inhibitor bortezomib have demonstrated Schwann cell and myelin disturbances associated with mild axonal degenerations (Cavaletti et al., 2007). Moreover, patients treated with bortezomib were reported to develop a dose-dependent neuropathy, including sensory ataxia and axonal changes that slightly improved after the treatment was stopped for six months (Filosto et al., 2007). As high doses of bortezomib-related neuropathy induced myelin damage in the PNS, the authors hypothesized that inhibition of proteasomes in myelinating cells may be a target for the drug-induced injury (Filosto et al., 2007). Additionally, it was reported that cultured primary oligodendrocytes were highly susceptible to proteasome inhibition when treated with MG-132, which caused oxidative stress, mitochondrial dysfunction and apoptosis (Goldbaum et al., 2006). 
The mass spectrometry of CNS and PNS myelin did not identify a prominent alteration of proteasome-associated proteins. This was not surprising, since ubiquitination of PSMA2 by FBXO7 facilitates the assembly of the proteasome complex, however does not influence the stability of PSMA2. Consistent with my results, brain lysates of conventional Fbxo7 $^{-1-}$ mice did also not show any difference in PSMA2 protein levels as compared to control (Vingill et al., 2016). While FBXO7 clearly is important for proteasome assembly and activity, lack of Fbxo7 does not affect levels of proteins that are part of the core or regulatory particles of the proteasome. 


\section{Conclusion and perspectives}

In this study, I showed that FBXO7 plays a crucial role in myelinating cells and their support of axonal integrity. Particularly in Schwann cells, FBXO7 promotes the proper axon-myelin interaction while providing a balanced protein homeostasis and the prerequisite for Schwann cells to ensure axonal stability. While loss of Fbxo7 induced severe axonal degeneration, myelination of axons in the optic and sciatic nerve was not affected by Fbxo7 deletion, indicating that FBXO7 has little or no effect on the process of myelination. On comparing the phenotype of $\mathrm{Cnp}_{1}^{\mathrm{Cre} /+} ; \mathrm{FbxO} 7^{\mathrm{fl/fl}}$ mice with those observed in PIp ${ }^{\mathrm{CreERT2/+}}$; FbXO $7^{\mathrm{fl/fl}}$ mice, I concluded that FBXO7 has a predominant importance for the axon-myelin axis during development and remains relevant for the postdevelopmental maintenance of the axon-glia interaction, although to a far lesser extent. As part of the UPS, the E3 ubiquitin-ligase FBXO7 plays an essential role in protein homeostasis in the cell. Dysfunction of the UPS is often linked to neurodegenerative disease, but the precise disease-causing mechanisms have only started to be elucidated. In my project, I gathered the first results on FBXO7's impact on myelinating cells and their immediate environment. Further investigations are required to enhance our understanding of the functions of FBXO7 on the axon-myelin interaction. As loss of Fbxo7 induced different effects in the CNS and PNS, the comparison of FBXO7's expression levels in both systems will add to a better understanding of these differences. While the abundance of FBXO7 in each part of the nervous system might reflect its relevance, FBXO7 may also have different functions in Schwann cells as compared to oligodendrocytes. In order to dissect FBXO7's impact on Schwann cells apart from its affect on oligodendrocytes, additional genetic approaches are required that use cell type-specific driver lines for the PNS or CNS. Moreover, while taking advantage of a different driver-line, the basic results should be reproducible and further underscore the role of FBXO7, independent of any potential ectopic activity of the driver line. FBXO7 is known to directly or indirectly affect and interact with several different pathways and compartments in the cell. The molecular changes in myelin upon Fbxo7 deletion support the notion that FBXO7 plays a complex role in the cell and provide further foundation for detailed investigations of different pathways affected in myelinating cells. Our lab previously established that proteasomal integrity and thus its activity depends on proper FBXO7 function. Hence, additional investigations are required of how FBXO7 regulates proteasome assembly and the impact that decreased proteasome activity has on e.g. mitochondrial function in myelinating cells. This will help to unravel the complexity of FBXO7's function and the impact that the UPS has on myelinating cells and their axonal interaction, guiding us to a better understanding of the disease-causing mechanism of neurodegenerative disorders. 


\section{List of abbreviations}

(n)S

Aa

ACLY

ACO2

ACOT7

AD

AIFM1

AKR1B1

ALS

ANOVA

ANXA1

AP

APOA4

APP

APS

AR

ATP

ATP1A4

ATP5A1

ATP5B

ATP50

$\mathrm{Bcl}^{\mathrm{XL}}$

BDNF

BME

BSA

BSG

C-Terminus

C3

CADM4

CAMP

CAT

CB

CD151

CD47

CD81
Sedimentation region

Amino acids

ATP-citrate synthase

Aconitate hydratase

Cytosolic acyl coenzyme A thioester hydrolase

Alzheimer's disease

Apoptosis-inducing factor 1

Aldose reductase

Amyotrophic lateral sclerosis

Analysis of variance

Annexin A1

Action potential

Apolipoprotein A-IV

Amyloid precursor protein

Ammonium persulfate

Autosomal recessive

Adenosine triphosphate

Sodium/potassium-transporting ATPase subunit alpha-4

ATP synthase subunit alpha

ATP synthase subunit beta

ATP synthase subunit $O$

B-cell lymphoma-extra large

Brain-derived neurotrophic factor

Basal medium eagle

Bovine serum albumin

Basigin

Carboxyl-terminus $(-\mathrm{COOH})$

Complement $\mathrm{C} 3$

Cell adhesion molecule 4

Compound muscle action potential

Catalase

Cerebellum

CD151 antigen

Leukocyte surface antigen CD47

CD81 antigen 


\begin{tabular}{|c|c|}
\hline CD82 & CD82 antigen \\
\hline CD9 & Tetraspanin-29 \\
\hline CDC42 & Cell division control protein 42 homolog \\
\hline CDK6 & Cyclin-depended kinase 6 \\
\hline cDNA & complementary DNA \\
\hline CEND1 & Cell cycle exit and neuronal differentiation protein 1 \\
\hline CES1D & Carboxylesterase 1D \\
\hline CFL1 & Cofilin-1 \\
\hline CFL2 & Cofilin-2 \\
\hline CHCHD3 & MICOS complex subunit Mic19 \\
\hline clAP1 & Cellular inhibitor of apoptosis 1 \\
\hline cKO & Conditional knockout $\left(\mathrm{Cnp} 1^{\mathrm{Cre} /+} ; \mathrm{Fb} \times \mathrm{xo} 7^{\mathrm{fl/fl}}\right)$ \\
\hline cKO-Tam & Tamoxifen-induced conditional knockout $\left(P / p 1^{\mathrm{CreERT} 2 /+} ; F b x o 7^{\mathrm{fl/fl}}\right.$ mice $)$ \\
\hline CLDN11 & Claudin 11 \\
\hline CLIC4 & Chloride intracellular channel protein 4 \\
\hline CMT & Charcot-Marie-Tooth \\
\hline CNP & 2',3'-cyclic nucleotide 3'-phosphodiesterase \\
\hline CNS & Central nervous system \\
\hline CNTF & Ciliary neurotrophic factor \\
\hline CNTN2 & Contactin-2 \\
\hline Co-IP & Co-Immunoprecipitation \\
\hline CP & Core particle \\
\hline CPM & Carboxypeptidase M \\
\hline CR & Corona radiata \\
\hline Cre & Cyclization recombinase \\
\hline CRYAB & Alpha-crystallin B chain \\
\hline CS & Calf serum \\
\hline $\mathbf{C}_{\mathrm{T}}$ & Cycle threshold \\
\hline СTX & Cortex \\
\hline CUL1 & Cullin 1 \\
\hline Cy2/3 & Cyanine $2 / 3$ \\
\hline DAB & 3-3'-diaminobenzidine \\
\hline DAPI & 4'6-diamidino-2-phenylindole \\
\hline $\mathrm{ddH}_{2} \mathrm{O}$ & Double distillated water \\
\hline DJ-1 & Protein deglycase 1 \\
\hline DMEM & Dulbecco's modified eagle's medium \\
\hline DML & Distal motor latency \\
\hline
\end{tabular}




\begin{tabular}{|c|c|}
\hline DNA & Deoxyribonucleic acid \\
\hline dNTP & Deoxyribonucleotide triphosphate \\
\hline DPYSL5 & Dihydropyrimidinase-related protein 5 \\
\hline DTT & Dithiothreitol \\
\hline DUB & Deubiquitinating enzymes \\
\hline DUSP15 & Dual specificity protein phosphatase 15 \\
\hline E1 & Ubiquitin-activating enzyme \\
\hline E2 & Ubiquitin-conjugating enzyme \\
\hline E3 & Ubiquitin ligase enzyme \\
\hline ECL & Enhanced chemiluminescence \\
\hline EDTA & Ethylenediaminetetraacetic acid \\
\hline ENO1 & Enolase 1 \\
\hline ENPP6 & Ectonucleotide pyrophosphatase 6 \\
\hline ER & Endoplasmic reticulum \\
\hline ERAD & ER-associated degradation \\
\hline FACS & Fluorescence-Activated Cell Sorting \\
\hline FASN & Fatty acid synthase \\
\hline FBP & F-box protein \\
\hline FBS & Fetal bovine serum \\
\hline FBXL & F-box protein with leucine-rich repeats \\
\hline FBXO & F-box protein with only / other domain motifs \\
\hline FBXW & F-box protein with WD40 domains \\
\hline FP & FBOX7-PI31 interaction domain \\
\hline FSCN1 & Fascin \\
\hline Fwd & Forward \\
\hline $\mathbf{G}_{1}$-Phase & Gap-phase \\
\hline GCAB & Ig gamma-2A chain $\mathrm{C}$ regio \\
\hline GDAP1 & Ganglioside-induced differentiation-associated protein 1 \\
\hline GDNF & Glial cell-derived neurotrophic factor \\
\hline GFAP & Glial fibrillary acidic protein \\
\hline GFP & Green fluorescent protein \\
\hline GLUT1 & Glucose transporter 1 \\
\hline GNB4 & Guanine nucleotide-binding protein subunit beta- 4 \\
\hline GPD2 & Glycerol-3-phosphate dehydrogenase \\
\hline GPX1 & Glutathione peroxidase 1 \\
\hline GS & Goat serum \\
\hline GSN & Gelsolin \\
\hline
\end{tabular}




\begin{tabular}{|c|c|}
\hline GSTM2 & Glutathione S-transferase Mu \\
\hline GSTm1 & Glutathione S-transferase $\pi 1$ \\
\hline HBSS & Hank's balanced salt solution \\
\hline HECT & Homologous to E6-associated protein carboxy terminal \\
\hline HEK293T & Human Embryonic Kidney 293T cells \\
\hline HEPACAM & Hepatocyte cell adhesion molecule \\
\hline HEPES & 4-(2-hydroxyethyl)-1-piperazineethanesulfonic acid \\
\hline HRP & Horseradish peroxidase \\
\hline HS & Horse serum \\
\hline HSPD1 & $60 \mathrm{kDa}$ heat shock protein \\
\hline HURP & Hepatoma up-regulated protein \\
\hline HVM51 & Ig heavy chain $V$ region AC38 205.12 \\
\hline IB & Immunoblot \\
\hline Iba1 & Ionized calcium-binding adapter molecule 1 \\
\hline IGF1 & Insulin-like growth factor 1 \\
\hline IgG & Immunoglobulin G \\
\hline IGH3 & Ig gamma-2B chain $\mathrm{C}$ region \\
\hline IGKC & Ig kappa chain $\mathrm{C}$ region \\
\hline IGSF8 & Immunoglobulin superfamily member 8 \\
\hline IHC & Immunohistochemistry \\
\hline IL & Interleukin \\
\hline IL-1RA & Interleukin 1 receptor antagonist \\
\hline INA & Alpha-internexin \\
\hline IP & Immunoprecipitation \\
\hline IP-10 & Interferon $\mathrm{y}$-induced protein 10 \\
\hline JAM3 & Junctional adhesion molecule C \\
\hline JKN & c-Jun N-terminale Kinasen \\
\hline LacZ & Lactose operon Z \\
\hline LC-MS & Liquid chromatography-mass spectrometry \\
\hline LGALS3 & Galectin-3 \\
\hline LIF & Leukemia inhibitory factor \\
\hline M-phase & Mitosis \\
\hline Mac3 & Macrophage antigen 3 \\
\hline MAG & Myelin-associated glycoprotein \\
\hline MAP (nx) & Microtubule-associated protein (nx) \\
\hline MAP1B & Microtubule-associated protein 1B \\
\hline MAP1B LC1 & Microtubule-associated protein 1B light chain 1 \\
\hline
\end{tabular}




\begin{tabular}{|c|c|}
\hline MAP6 & Microtubule-associated protein 6 \\
\hline MBP & Myelin basic protein \\
\hline MCP-1 & Monocyte chemoattractant protein 1 \\
\hline MCT (n) & Monocarboxylate transporter $(n)$ \\
\hline MHC & Major histocompatibility complex \\
\hline MIB1 & Mind bomb-1 \\
\hline Mm & Mus musculus \\
\hline MOBP & Myelin-associated oligodendrocytic basic protein \\
\hline MOG & Myelin-oligodendrocyte glycoprotein \\
\hline MPZ & Myelin protein $\mathrm{PO}$ \\
\hline MRI & Magnet resonance imaging \\
\hline mRNA & Messenger RNA \\
\hline MSC80 & Mouse Schwann cells 80 \\
\hline MSN & Moesin \\
\hline MTCO2 & Cytochrome c oxidase subunit 2 \\
\hline mTOR & The mechanistic target of rapamycin \\
\hline $\mathrm{N}$-Terminus & Amino-terminus $\left(-\mathrm{NH}_{2}\right)$ \\
\hline NCV & Nerve conductance velocity \\
\hline NDRG1 & Protein NDRG1 \\
\hline NEDD4 & $\begin{array}{l}\text { Neural precursor cell expressed developmentally down-regulated } \\
\text { protein } 4\end{array}$ \\
\hline NEFH & Neurofilament heavy \\
\hline NEFL & Neurofilament light \\
\hline NEFM & Neurofilament medium \\
\hline NF- $k B$ & Nuclear factor 'kappa-light-chain-enhancer' of activated B-cells \\
\hline NFASC & Neurofascin \\
\hline NO & Nitric oxide \\
\hline No. & Number \\
\hline NRG1 & Neuregulin1 type III \\
\hline NT3 & Neurotrophin 3 \\
\hline OCT & Optimal cutting temperature \\
\hline OMG & Oligodendrocyte-myelin glycoprotein \\
\hline OPALIN & Opalin \\
\hline OPC & Oligodendrocyte precursor cells \\
\hline OTUB1 & Ubiquitin thioesterase OTUB1 \\
\hline$P(n)$ & Postnatal Day (n) \\
\hline PARK & PD-associated gene locus \\
\hline
\end{tabular}




\begin{tabular}{|c|c|}
\hline PARK7 & Protein deglycase DJ-1 \\
\hline PBS & Phosphate-buffered saline \\
\hline PBST & Phosphate-buffered saline with Triton-X \\
\hline PCR & Polymerase chain reaction \\
\hline PD & Parkinson's disease \\
\hline PDGF & Platelet derived growth factor \\
\hline PDHB & Pyruvate dehydrogenase E1 component subunit beta \\
\hline PFA & Paraformaldehyde \\
\hline PGAM2 & Phosphoglycerate mutase 2 \\
\hline PI31 & Proteasomal inhibitor 31 \\
\hline PINK1 & PTEN Induced Putative Kinase 1 \\
\hline PLL & Poly-L-Lysin \\
\hline PLLP & Plasmolipin \\
\hline PLP & Proteolipid protein \\
\hline PMP2 & Myelin P2 protein \\
\hline PMP22 & Peripheral myelin protein 22 \\
\hline PNS & Peripheral nervous system \\
\hline PPS & Parkinsonian-Pyramidal Syndrome \\
\hline PRDX1 & Peroxiredoxin-1 \\
\hline PRR & Proline-rich region \\
\hline PRRT2 & Proline-rich transmembrane protein 2 \\
\hline PRX & Periaxin \\
\hline PSG & Penicillin/Streptomycin/GlutaMax \\
\hline PSMA2 & Proteasomal subunit alpha 2 \\
\hline PTEN & Phosphatase and tensin homolog \\
\hline RAN & GTP-binding nuclear protein Ran \\
\hline RBX1 & RING-box protein 1 \\
\hline $\operatorname{Rev}$ & Reverse \\
\hline RING & Really Interesting New Gene \\
\hline RIPA & Radio-immunoprecipitation assay buffer \\
\hline RNA & Ribonucleic acid \\
\hline RP & Regulatory particle \\
\hline RT & Room temperature \\
\hline RT-PCR & Real time polymerase chain reaction \\
\hline RTN4 & Reticulon 4 \\
\hline RUFY3 & Protein RUFY3 \\
\hline s.e.m. & Standard error of the mean \\
\hline
\end{tabular}




\begin{tabular}{|c|c|}
\hline S100B & Protein S100 B \\
\hline SCF & SKP, Cullin, F-box-containing complex \\
\hline SCL25A4 & ADP/ATP translocase 1 \\
\hline SDS & Sodium dodecyl sulfate \\
\hline SDS-PAGE & SDS-Polyacrylamide gel electrophoresis \\
\hline SEPTIN5 & Septin-5 \\
\hline ShRNA & Short hairpin RNA \\
\hline SIMPLE & Small integral membrane protein of lysosome/late endosome \\
\hline SIRT2 & NAD-dependent protein deacetylase sirtuin-2 \\
\hline SKP1 & S-phase kinase-associated protein 1 \\
\hline SLC25A11 & Mitochondrial 2-oxoglutarate/malate carrier protein \\
\hline SLC44A1 & Choline transporter-like protein 1 \\
\hline SNCA & Synuclein, alpha \\
\hline SNP & Single nucleotide polymorphism \\
\hline SPTAN1 & Spectrin alpha chain \\
\hline STIP1 & Stress-induced-phosphoprotein \\
\hline STXBP3 & Syntaxin-binding protein 3 \\
\hline Suc-LLVY-AMC & N-Succinyl-Leu-Leu-Val-Tyr-AMC (7-amino-4-methylcoumarin) \\
\hline TAE & Tris base, acetic acid and EDTA \\
\hline TBS & Tris-buffered saline \\
\hline TE & Trypsin/EDTA \\
\hline TEMED & Tetramethylethylenediamine \\
\hline TNF & Tumor necrosis factor \\
\hline TOMM70 & Mitochondrial import receptor subunit TOM70 \\
\hline TPI1 & Triosephosphate isomerase \\
\hline TPPP & Tubulin polymerization-promoting protein \\
\hline TRAF2 & TNF receptor-associated factor 2 \\
\hline TSPAN-2 & Tetraspanin 2 \\
\hline TUBB3 & Tubulin beta-3 chain \\
\hline TUBB4A & Tubulin beta-4A chain \\
\hline TUBB4B & Tubulin beta-4B chain \\
\hline TUNEL & TdT-mediated dUTP nick-end labeling \\
\hline Ub & Ubiquitin \\
\hline UBE2M & NEDD8-conjugating enzyme Ubc12 \\
\hline UBE2N & Ubiquitin-conjugating enzyme E2 N \\
\hline UBE2V1 & Ubiquitin-conjugating enzyme E2 variant 1 \\
\hline UbR & Ubiquitin-related domain \\
\hline
\end{tabular}




$\begin{array}{ll}\text { UCH-L1 } & \text { Ubiquitin carboxyl-terminal esterase L1 } \\ \text { UPLC } & \text { Ultra Performance Liquid Chromatography } \\ \text { UPS } & \text { Ubiquitin-proteasome system } \\ \text { UQCRC2 } & \text { Cytochrome b-c1 complex subunit } 2 \\ \text { UV } & \text { Ultra violet } \\ \text { VAT1 } & \text { Synaptic vesicle membrane protein VAT-1 homolog } \\ \text { WB } & \text { Western blot } \\ \text { WT } & \text { Wild type } \\ \text { ZNRF1 } & \text { Zinc and ring finger 1 } \\ \boldsymbol{\alpha} & \text { Anti } \\ \beta-G a l & \beta-G a l a c t o s i d a s e\end{array}$

Nucleotide

Single-letter code

Adenine

A

Cytosine

C

Guanine

G

Thymine

$\mathrm{T}$

\begin{tabular}{|c|c|c|}
\hline Amino acids & 3-letter code & Single-letter code \\
\hline Arginine & Arg & $\mathrm{R}$ \\
\hline Cysteine & Cys & $\mathrm{C}$ \\
\hline Glycine & Gly & $G$ \\
\hline Isoleucine & lle & I \\
\hline Leucine & Leu & $\mathrm{L}$ \\
\hline Lysine & Lys & $\mathrm{K}$ \\
\hline Methionine & Met & $M$ \\
\hline Proline & Pro & $\mathrm{P}$ \\
\hline Termination & l & $x$ \\
\hline Threonine & Thr & $\mathrm{T}$ \\
\hline Tyrosine & Tyr & $\mathrm{Y}$ \\
\hline Valine & Val & V \\
\hline
\end{tabular}




\section{Units}

cm

$\mathrm{Mm}$

$\mu \mathrm{m}$

$\mathrm{nm}$

$\mathbf{L}$

ml

$\mu l$

$\mathrm{Kg}$

g

mg

$\mu \mathrm{g}$

ng

M

$\mathrm{mM}$

$\mu \mathrm{M}$

h

$\min$

s/sec

ms

$\mathrm{m} / \mathrm{s}$

mA

V

mV

${ }^{\circ} \mathrm{C}$

$\%$

rpm

g

kDa

bp

kb
Centimeter

Millimeter

Micrometer

Nanometer

Liter

Milliliter

Microliter

Kilogram

Gram

Milligram

Microgram

Nanogram

Molar

Milimolar

Micromolar

Hour

Minute

Second

Milliseconds

Meter per seconds

Milliampere

Volt

Millivolt

Degrees Celsius

Percentage

Revolutions per minute

Gravity

Kilodalton

Base pairs

Kilobase 


\section{Nomenclature}

According to the guidelines of the HUGO Gene Nomenclature Committee (HGNC) and the Mouse Genome Informatics (MGI), human as well as mouse gene and protein names were referred to in this study as following:

Example: F-box only protein 7

\begin{tabular}{c|cc}
\hline Species & Gene symbol & Protein symbol \\
Human & FBXO7 & FBXO7 \\
Mouse & FbXO7 & FBXO7 \\
\hline
\end{tabular}




\section{References}

Aartsma-Rus, A., and van Putten, M. (2014). Assessing functional performance in the $\mathrm{mdx}$ mouse model. J Vis Exp.

Adler, V., Yin, Z., Fuchs, S.Y., Benezra, M., Rosario, L., Tew, K.D., Pincus, M.R., Sardana, M., Henderson, C.J., Wolf, C.R., et al. (1999). Regulation of JNK signaling by GSTp. EMBO J 18, 1321-1334.

Allen, N.J., and Barres, B.A. (2009). Neuroscience: Glia - more than just brain glue. Nature 457, 675-677.

Amor, S., Peferoen, L.A., Vogel, D.Y., Breur, M., van der Valk, P., Baker, D., and van Noort, J.M. (2014). Inflammation in neurodegenerative diseases--an update. Immunology 142, 151-166.

An, S.F., Giometto, B., Groves, M., Miller, R.F., Beckett, A.A., Gray, F., Tavolato, B., and Scaravilli, F. (1997). Axonal damage revealed by accumulation of beta-APP in HIVpositive individuals without AIDS. J Neuropathol Exp Neurol 56, 1262-1268.

Araki, T., Nagarajan, R., and Milbrandt, J. (2001). Identification of genes induced in peripheral nerve after injury. Expression profiling and novel gene discovery. J Biol Chem 276, 34131-34141.

Asi, Y.T., Simpson, J.E., Heath, P.R., Wharton, S.B., Lees, A.J., Revesz, T., Houlden, H., and Holton, J.L. (2014). Alpha-synuclein mRNA expression in oligodendrocytes in MSA. Glia 62, 964-970.

Azevedo, F.A., Carvalho, L.R., Grinberg, L.T., Farfel, J.M., Ferretti, R.E., Leite, R.E., Jacob Filho, W., Lent, R., and Herculano-Houzel, S. (2009). Equal numbers of neuronal and nonneuronal cells make the human brain an isometrically scaled-up primate brain. J Comp Neurol 513, 532-541.

Basler, M., Kirk, C.J., and Groettrup, M. (2013). The immunoproteasome in antigen processing and other immunological functions. Curr Opin Immunol 25, 74-80.

Bence, N.F., Sampat, R.M., and Kopito, R.R. (2001). Impairment of the ubiquitinproteasome system by protein aggregation. Science 292, 1552-1555.

Bennett, V., and Lambert, S. (1999). Physiological roles of axonal ankyrins in survival of premyelinated axons and localization of voltage-gated sodium channels. J Neurocytol 28, 303-318.

Berciano, J., Garcia, A., Figols, J., Munoz, R., Berciano, M.T., and Lafarga, M. (2000). Perineurium contributes to axonal damage in acute inflammatory demyelinating polyneuropathy. Neurology 55, 552-559. 
Bheda, A., Gullapalli, A., Caplow, M., Pagano, J.S., and Shackelford, J. (2010). Ubiquitin editing enzyme UCH L1 and microtubule dynamics: implication in mitosis. Cell Cycle 9, 980-994.

Bishop, P., Rocca, D., and Henley, J.M. (2016). Ubiquitin C-terminal hydrolase L1 (UCHL1): structure, distribution and roles in brain function and dysfunction. Biochem J 473, 2453-2462.

Blight, A.R. (1991). Morphometric analysis of a model of spinal cord injury in guinea pigs, with behavioral evidence of delayed secondary pathology. J Neurol Sci 103, 156-171.

Blight, A.R., and Decrescito, V. (1986). Morphometric analysis of experimental spinal cord injury in the cat: the relation of injury intensity to survival of myelinated axons. Neuroscience 19, 321-341.

Bochtler, M., Ditzel, L., Groll, M., Hartmann, C., and Huber, R. (1999). The proteasome. Annu Rev Biophys Biomol Struct 28, 295-317.

Boutry, J.M., Hauw, J.J., Gansmuller, A., Di-Bert, N., Pouchelet, M., and Baron-Van Evercooren, A. (1992). Establishment and characterization of a mouse Schwann cell line which produces myelin in vivo. J Neurosci Res 32, 15-26.

Bradford, M.M. (1976). A rapid and sensitive method for the quantitation of microgram quantities of protein utilizing the principle of protein-dye binding. Anal Biochem 72, 248-254.

Brady, S.T., Witt, A.S., Kirkpatrick, L.L., de Waegh, S.M., Readhead, C., Tu, P.H., and Lee, V.M. (1999). Formation of compact myelin is required for maturation of the axonal cytoskeleton. J Neurosci 19, 7278-7288.

Brockelt, D. (2015). The role of the E3 ubiquitin ligase FBXO7-SCF in early-onset Parkinson's disease (Göttingen, Georg-August university, doctoral thesis).

Burchell, V.S., Nelson, D.E., Sanchez-Martinez, A., Delgado-Camprubi, M., Ivatt, R.M., Pogson, J.H., Randle, S.J., Wray, S., Lewis, P.A., Houlden, H., et al. (2013). The Parkinson's disease-linked proteins Fbxo7 and Parkin interact to mediate mitophagy. Nat Neurosci 16, 1257-1265.

Cardozo, T., and Pagano, M. (2004). The SCF ubiquitin ligase: insights into a molecular machine. Nat Rev Mol Cell Biol 5, 739-751.

Carson, M.J., Thrash, J.C., and Walter, B. (2006). The cellular response in neuroinflammation: The role of leukocytes, microglia and astrocytes in neuronal death and survival. Clin Neurosci Res 6, 237-245.

Castro-Caldas, M., Neves Carvalho, A., Peixeiro, I., Rodrigues, E., Lechner, M.C., and Gama, M.J. (2009). GSTpi expression in MPTP-induced dopaminergic 
neurodegeneration of C57BL/6 mouse midbrain and striatum. J Mol Neurosci 38, 114127.

Cavaletti, G., Gilardini, A., Canta, A., Rigamonti, L., Rodriguez-Menendez, V., Ceresa, C., Marmiroli, P., Bossi, M., Oggioni, N., D'Incalci, M., et al. (2007). Bortezomib-induced peripheral neurotoxicity: a neurophysiological and pathological study in the rat. Exp Neurol 204, 317-325.

Cenciarelli, C., Chiaur, D.S., Guardavaccaro, D., Parks, W., Vidal, M., and Pagano, M. (1999). Identification of a family of human F-box proteins. Curr Biol 9, 1177-1179.

Chan, J.Y., and Chan, S.H. (2015). Activation of endogenous antioxidants as a common therapeutic strategy against cancer, neurodegeneration and cardiovascular diseases: A lesson learnt from DJ-1. Pharmacol Ther 156, 69-74.

Chang, Y.F., Cheng, C.M., Chang, L.K., Jong, Y.J., and Yuo, C.Y. (2006). The F-box protein Fbxo7 interacts with human inhibitor of apoptosis protein clAP1 and promotes clAP1 ubiquitination. Biochem Biophys Res Commun 342, 1022-1026.

Chen, C.M., Chen, I.C., Huang, Y.C., Juan, H.F., Chen, Y.L., Chen, Y.C., Lin, C.H., Lee, L.C., Lee, C.M., Lee-Chen, G.J., et al. (2014a). FBXO7 Y52C polymorphism as a potential protective factor in Parkinson's disease. PLoS One 9, e101392.

Chen, F., Sugiura, Y., Myers, K.G., Liu, Y., and Lin, W. (2010). Ubiquitin carboxyl-terminal hydrolase $L 1$ is required for maintaining the structure and function of the neuromuscular junction. Proc Natl Acad Sci U S A 107, 1636-1641.

Chen, G., and Goeddel, D.V. (2002). TNF-R1 signaling: a beautiful pathway. Science 296, 1634-1635.

Chen, J., Liu, Q.J., Wang, D., Zhou, X.Y., Xiong, D., Li, H.J., and Li, C.L. (2014b). Hepatoma upregulated protein expression is involved in the pathogenesis of human breast carcinogenesis. Oncol Lett 8, 2543-2548.

Chen, L., Thiruchelvam, M.J., Madura, K., and Richfield, E.K. (2006). Proteasome dysfunction in aged human alpha-synuclein transgenic mice. Neurobiol Dis 23, 120126.

Chomiak, T., and Hu, B. (2009). What is the optimal value of the g-ratio for myelinated fibers in the rat CNS? A theoretical approach. PLoS One 4, e7754.

Ciechanover, A., and Schwartz, A.L. (2002). Ubiquitin-mediated degradation of cellular proteins in health and disease. Hepatology 35, 3-6.

Clark, K., Sakowski, L., Sperle, K., Banser, L., Landel, C.P., Bessert, D.A., Skoff, R.P., and Hobson, G.M. (2013). Gait abnormalities and progressive myelin degeneration in a new murine model of Pelizaeus-Merzbacher disease with tandem genomic duplication. J Neurosci 33, 11788-11799. 
Conedera, S., Apaydin, H., Li, Y., Yoshino, H., Ikeda, A., Matsushima, T., Funayama, M., Nishioka, K., and Hattori, N. (2016). FBXO7 mutations in Parkinson's disease and multiple system atrophy. Neurobiol Aging 40, 192 e191-195.

Connor, J.R., and Menzies, S.L. (1996). Relationship of iron to oligodendrocytes and myelination. Glia 17, 83-93.

Corfas, G., Velardez, M.O., Ko, C.P., Ratner, N., and Peles, E. (2004). Mechanisms and roles of axon-Schwann cell interactions. J Neurosci 24, 9250-9260.

D'Urso, D., Brophy, P.J., Staugaitis, S.M., Gillespie, C.S., Frey, A.B., Stempak, J.G., and Colman, D.R. (1990). Protein zero of peripheral nerve myelin: biosynthesis, membrane insertion, and evidence for homotypic interaction. Neuron 4, 449-460.

Dai, X., Lercher, L.D., Clinton, P.M., Du, Y., Livingston, D.L., Vieira, C., Yang, L., Shen, M.M., and Dreyfus, C.F. (2003). The trophic role of oligodendrocytes in the basal forebrain. J Neurosci 23, 5846-5853.

Dalal, N.V., Pranski, E.L., Tansey, M.G., Lah, J.J., Levey, A.I., and Betarbet, R.S. (2012). RNF11 modulates microglia activation through NF-kappaB signalling cascade. Neurosci Lett 528, 174-179.

Damier, P., Hirsch, E.C., Zhang, P., Agid, Y., and Javoy-Agid, F. (1993). Glutathione peroxidase, glial cells and Parkinson's disease. Neuroscience 52, 1-6.

Dantuma, N.P., and Bott, L.C. (2014). The ubiquitin-proteasome system in neurodegenerative diseases: precipitating factor, yet part of the solution. Front Mol Neurosci 7,70 .

Dantuma, N.P., and Salomons, F.A. (2016). Ubiquitin versus misfolding: The minimal requirements for inclusion body formation. J Cell Biol 213, 147-149.

De Jonghe, P., Timmerman, V., Ceuterick, C., Nelis, E., De Vriendt, E., Lofgren, A., Vercruyssen, A., Verellen, C., Van Maldergem, L., Martin, J.J., et al. (1999). The Thr124Met mutation in the peripheral myelin protein zero (MPZ) gene is associated with a clinically distinct Charcot-Marie-Tooth phenotype. Brain 122 ( Pt 2), 281-290.

de Lau, L.M., and Breteler, M.M. (2006). Epidemiology of Parkinson's disease. Lancet Neurol 5, 525-535.

de Monasterio-Schrader, P., Jahn, O., Tenzer, S., Wichert, S.P., Patzig, J., and Werner, H.B. (2012). Systematic approaches to central nervous system myelin. Cell Mol Life Sci 69, 2879-2894.

de Waegh, S.M., Lee, V.M., and Brady, S.T. (1992). Local modulation of neurofilament phosphorylation, axonal caliber, and slow axonal transport by myelinating Schwann cells. Cell $68,451-463$. 
Delgado-Camprubi, M., Esteras, N., Soutar, M.P., Plun-Favreau, H., and Abramov, A.Y. (2017). Deficiency of Parkinson's disease-related gene Fbxo7 is associated with impaired mitochondrial metabolism by PARP activation. Cell Death Differ 24, 120 131.

Deshaies, R.J., and Joazeiro, C.A. (2009). RING domain E3 ubiquitin ligases. Annu Rev Biochem 78, 399-434.

Di Fonzo, A., Dekker, M.C., Montagna, P., Baruzzi, A., Yonova, E.H., Correia Guedes, L., Szczerbinska, A., Zhao, T., Dubbel-Hulsman, L.O., Wouters, C.H., et al. (2009). FBXO7 mutations cause autosomal recessive, early-onset parkinsonian-pyramidal syndrome. Neurology 72, 240-245.

Diaz-Hernandez, M., Valera, A.G., Moran, M.A., Gomez-Ramos, P., Alvarez-Castelao, B., Castano, J.G., Hernandez, F., and Lucas, J.J. (2006). Inhibition of 26S proteasome activity by huntingtin filaments but not inclusion bodies isolated from mouse and human brain. J Neurochem 98, 1585-1596.

Dickson, D.W. (2012). Parkinson's disease and parkinsonism: neuropathology. Cold Spring Harb Perspect Med 2.

Dikic, I. (2017). Proteasomal and Autophagy Degradation Systems. Annu Rev Biochem.

Distler, U., Kuharev, J., Navarro, P., Levin, Y., Schild, H., and Tenzer, S. (2014). Drift time-specific collision energies enable deep-coverage data-independent acquisition proteomics. Nat Methods 11, 167-170.

Distler, U., Kuharev, J., Navarro, P., and Tenzer, S. (2016). Label-free quantification in ion mobility-enhanced data-independent acquisition proteomics. Nat Protoc 11, 795-812.

Du, Y., and Dreyfus, C.F. (2002). Oligodendrocytes as providers of growth factors. J Neurosci Res 68, 647-654.

Dupouey, P., Jacque, C., Bourre, J.M., Cesselin, F., Privat, A., and Baumann, N. (1979). Immunochemical studies of myelin basic protein in shiverer mouse devoid of major dense line of myelin. Neurosci Lett 12, 113-118.

Eddy, N.B., and Leimbach, D. (1953). Synthetic analgesics. II. Dithienylbutenyl- and dithienylbutylamines. J Pharmacol Exp Ther 107, 385-393.

Edgar, J.M., McLaughlin, M., Werner, H.B., McCulloch, M.C., Barrie, J.A., Brown, A., Faichney, A.B., Snaidero, N., Nave, K.A., and Griffiths, I.R. (2009). Early ultrastructural defects of axons and axon-glia junctions in mice lacking expression of Cnp1. Glia 57, 1815-1824.

Ehlers, M.D. (2003). Activity level controls postsynaptic composition and signaling via the ubiquitin-proteasome system. Nat Neurosci 6, 231-242. 
Erdmann, G., Berger, S., and Schutz, G. (2008). Genetic dissection of glucocorticoid receptor function in the mouse brain. J Neuroendocrinol 20,655-659.

Eric R. Kandel, J.H.S., Thomas M. Jessell (2000). Principles of neuronal scienc, fourth edition edn (McGraw-Hill).

Feltri, M.L., Poitelon, Y., and Previtali, S.C. (2016). How Schwann Cells Sort Axons: New Concepts. Neuroscientist 22, 252-265.

Filosto, M., Rossi, G., Pelizzari, A.M., Buzio, S., Tentorio, M., Broglio, L., Mancuso, M., Rinaldi, M., Scarpelli, M., and Padovani, A. (2007). A high-dose bortezomib neuropathy with sensory ataxia and myelin involvement. J Neurol Sci 263, 40-43.

Finley, D. (2009). Recognition and processing of ubiquitin-protein conjugates by the proteasome. Annu Rev Biochem 78, 477-513.

Fraher, J.P. (1976). The growth and myelination of central and peripheral segments of ventral motoneurone axons. A quantitative ultrastructural study. Brain Res 105, $193-$ 211.

Friede, R.L., and Miyagishi, T. (1972). Adjustment of the myelin sheath to changes in axon caliber. Anat Rec 172, 1-14.

Funfschilling, U., Supplie, L.M., Mahad, D., Boretius, S., Saab, A.S., Edgar, J., Brinkmann, B.G., Kassmann, C.M., Tzvetanova, I.D., Mobius, W., et al. (2012). Glycolytic oligodendrocytes maintain myelin and long-term axonal integrity. Nature 485, 517521.

Gallyas, F. (1979). Silver staining of myelin by means of physical development. Neurol Res 1, 203-209.

Garbern, J., and Hobson, G. (2002). Prenatal diagnosis of Pelizaeus-Merzbacher disease. Prenat Diagn 22, 1033-1035.

Garbern, J.Y. (2007). Pelizaeus-Merzbacher disease: Genetic and cellular pathogenesis. Cell Mol Life Sci 64, 50-65.

Garbern, J.Y., Yool, D.A., Moore, G.J., Wilds, I.B., Faulk, M.W., Klugmann, M., Nave, K.A., Sistermans, E.A., van der Knaap, M.S., Bird, T.D., et al. (2002). Patients lacking the major CNS myelin protein, proteolipid protein 1, develop length-dependent axonal degeneration in the absence of demyelination and inflammation. Brain 125, 551-561.

Glickman, M.H., and Ciechanover, A. (2002). The ubiquitin-proteasome proteolytic pathway: destruction for the sake of construction. Physiol Rev 82, 373-428. 
Goldbaum, O., Vollmer, G., and Richter-Landsberg, C. (2006). Proteasome inhibition by MG-132 induces apoptotic cell death and mitochondrial dysfunction in cultured rat brain oligodendrocytes but not in astrocytes. Glia 53, 891-901.

Gregori, L., Fuchs, C., Figueiredo-Pereira, M.E., Van Nostrand, W.E., and Goldgaber, D. (1995). Amyloid beta-protein inhibits ubiquitin-dependent protein degradation in vitro. J Biol Chem 270, 19702-19708.

Griffin, J.W., and Watson, D.F. (1988). Axonal transport in neurological disease. Ann Neurol 23, 3-13.

Griffiths, I., Klugmann, M., Anderson, T., Yool, D., Thomson, C., Schwab, M.H., Schneider, A., Zimmermann, F., McCulloch, M., Nadon, N., et al. (1998). Axonal swellings and degeneration in mice lacking the major proteolipid of myelin. Science $280,1610-1613$.

Guardiola-Diaz, H.M., Ishii, A., and Bansal, R. (2012). Erk1/2 MAPK and mTOR signaling sequentially regulates progression through distinct stages of oligodendrocyte differentiation. Glia 60, 476-486.

Guyenet, S.J., Furrer, S.A., Damian, V.M., Baughan, T.D., La Spada, A.R., and Garden, G.A. (2010). A simple composite phenotype scoring system for evaluating mouse models of cerebellar ataxia. J Vis Exp.

Hagemeyer, N., Goebbels, S., Papiol, S., Kastner, A., Hofer, S., Begemann, M., Gerwig, U.C., Boretius, S., Wieser, G.L., Ronnenberg, A., et al. (2012). A myelin gene causative of a catatonia-depression syndrome upon aging. EMBO Mol Med 4, 528539 .

Hall, C.S. (1932). A study of the rat's behavior in a field: a contribution to method in comparative psychology. University of California Publications in Psychology 6, 1-12.

Halliday, G.M., and Stevens, C.H. (2011). Glia: initiators and progressors of pathology in Parkinson's disease. Mov Disord 26, 6-17.

Hara, T., Hashimoto, Y., Akuzawa, T., Hirai, R., Kobayashi, H., and Sato, K. (2014). Rer1 and calnexin regulate endoplasmic reticulum retention of a peripheral myelin protein 22 mutant that causes type 1A Charcot-Marie-Tooth disease. Sci Rep 4, 6992.

Hartmann-Petersen, R., and Gordon, C. (2004). Integral UBL domain proteins: a family of proteasome interacting proteins. Semin Cell Dev Biol 15, 247-259.

Helmut Kettenmann, B.R.R. (2013). Neuroglia, Third edition edn (Oxford).

Hershko, A., and Ciechanover, A. (1998). The ubiquitin system. Annu Rev Biochem 67, 425-479. 
Hildebrand, C., and Hahn, R. (1978). Relation between myelin sheath thickness and axon size in spinal cord white matter of some vertebrate species. J Neurol Sci 38, 421-434.

Hsieh, S.T., Kidd, G.J., Crawford, T.O., Xu, Z., Lin, W.M., Trapp, B.D., Cleveland, D.W., and Griffin, J.W. (1994). Regional modulation of neurofilament organization by myelination in normal axons. J Neurosci 14, 6392-6401.

Hsu, J.M., Lee, Y.C., Yu, C.T., and Huang, C.Y. (2004). Fbx7 functions in the SCF complex regulating $\mathrm{Cdk} 1$-cyclin $\mathrm{B}$-phosphorylated hepatoma up-regulated protein (HURP) proteolysis by a proline-rich region. J Biol Chem 279, 32592-32602.

Huang, Y.L., Chiu, A.W., Huan, S.K., Wang, Y.C., Ju, J.P., and Lu, C.L. (2003). Prognostic significance of hepatoma-up-regulated protein expression in patients with urinary bladder transitional cell carcinoma. Anticancer Res 23, 2729-2733.

Ilyin, G.P., Rialland, M., Pigeon, C., and Guguen-Guillouzo, C. (2000). cDNA cloning and expression analysis of new members of the mammalian F-box protein family. Genomics 67, 40-47.

Ip, C.W., Kroner, A., Bendszus, M., Leder, C., Kobsar, I., Fischer, S., Wiendl, H., Nave, K.A., and Martini, R. (2006). Immune cells contribute to myelin degeneration and axonopathic changes in mice overexpressing proteolipid protein in oligodendrocytes. J Neurosci 26, 8206-8216.

Jahn, O., Tenzer, S., and Werner, H.B. (2009). Myelin proteomics: molecular anatomy of an insulating sheath. Mol Neurobiol 40, 55-72.

Jahngen-Hodge, J., Obin, M.S., Gong, X., Shang, F., Nowell, T.R., Jr., Gong, J., Abasi, H., Blumberg, J., and Taylor, A. (1997). Regulation of ubiquitin-conjugating enzymes by glutathione following oxidative stress. J Biol Chem 272, 28218-28226.

Jansen, A.H., Reits, E.A., and Hol, E.M. (2014). The ubiquitin proteasome system in glia and its role in neurodegenerative diseases. Front Mol Neurosci 7, 73.

Jessen, K.R., and Mirsky, R. (2005). The origin and development of glial cells in peripheral nerves. Nat Rev Neurosci 6, 671-682.

Jimenez-Mateos, E.M., Gonzalez-Billault, C., Dawson, H.N., Vitek, M.P., and Avila, J. (2006). Role of MAP1B in axonal retrograde transport of mitochondria. Biochem $\mathrm{J}$ 397, 53-59.

Jin, J., Cardozo, T., Lovering, R.C., Elledge, S.J., Pagano, M., and Harper, J.W. (2004). Systematic analysis and nomenclature of mammalian F-box proteins. Genes Dev 18, 2573-2580.

Juurlink, B.H., Thorburne, S.K., and Hertz, L. (1998). Peroxide-scavenging deficit underlies oligodendrocyte susceptibility to oxidative stress. Glia $22,371-378$. 
Kabuta, T., Furuta, A., Aoki, S., Furuta, K., and Wada, K. (2008). Aberrant interaction between Parkinson disease-associated mutant UCH-L1 and the lysosomal receptor for chaperone-mediated autophagy. J Biol Chem 283, 23731-23738.

Kamholz, J., Sessa, M., Scherer, S., Vogelbacker, H., Mokuno, K., Baron, P., Wrabetz, L., Shy, M., and Pleasure, D. (1992). Structure and expression of proteolipid protein in the peripheral nervous system. J Neurosci Res 31, 231-244.

Kang, K., Lee, D., Hong, S., Park, S.G., and Song, M.R. (2013). The E3 ligase Mind bomb-1 (Mib1) modulates Delta-Notch signaling to control neurogenesis and gliogenesis in the developing spinal cord. J Biol Chem 288, 2580-2592.

Kassmann, C.M., Lappe-Siefke, C., Baes, M., Brugger, B., Mildner, A., Werner, H.B., Natt, O., Michaelis, T., Prinz, M., Frahm, J., et al. (2007). Axonal loss and neuroinflammation caused by peroxisome-deficient oligodendrocytes. Nat Genet 39, 969-976.

Kawabe, H., and Brose, N. (2011). The role of ubiquitylation in nerve cell development. Nat Rev Neurosci 12, 251-268.

Kazunori Sango, J.Y. (2014). Schwann cell development and pathology (Japan, Springer).

Kearns, C.A., Ravanelli, A.M., Cooper, K., and Appel, B. (2015). Fbxw7 Limits Myelination by Inhibiting mTOR Signaling. J Neurosci 35, 14861-14871.

Keeney, P.M., Xie, J., Capaldi, R.A., and Bennett, J.P., Jr. (2006). Parkinson's disease brain mitochondrial complex I has oxidatively damaged subunits and is functionally impaired and misassembled. J Neurosci 26, 5256-5264.

Keswani, S.C., Buldanlioglu, U., Fischer, A., Reed, N., Polley, M., Liang, H., Zhou, C., Jack, C., Leitz, G.J., and Hoke, A. (2004). A novel endogenous erythropoietin mediated pathway prevents axonal degeneration. Ann Neurol 56, 815-826.

Kirk, R., Laman, H., Knowles, P.P., Murray-Rust, J., Lomonosov, M., Meziane el, K., and McDonald, N.Q. (2008). Structure of a conserved dimerization domain within the Fbox protein Fbxo7 and the PI31 proteasome inhibitor. J Biol Chem 283, 22325-22335.

Kisselev, A.F., and Goldberg, A.L. (2005). Monitoring activity and inhibition of $26 \mathrm{~S}$ proteasomes with fluorogenic peptide substrates. Methods Enzymol 398, 364-378.

Klugmann, M., Schwab, M.H., Puhlhofer, A., Schneider, A., Zimmermann, F., Griffiths, I.R., and Nave, K.A. (1997). Assembly of CNS myelin in the absence of proteolipid protein. Neuron 18, 59-70.

Komander, D., and Rape, M. (2012). The ubiquitin code. Annu Rev Biochem 81, 203-229. 
Kondziela, W. (1964). Eine neue methode zur messung der muskularen relaxtion bei weissen mausen. Arch Int Pharmacodyn 152, 277-284.

Konishi, Y., Stegmuller, J., Matsuda, T., Bonni, S., and Bonni, A. (2004). Cdh1-APC controls axonal growth and patterning in the mammalian brain. Science 303, 10261030.

Krajewski, K.M., Lewis, R.A., Fuerst, D.R., Turansky, C., Hinderer, S.R., Garbern, J., Kamholz, J., and Shy, M.E. (2000). Neurological dysfunction and axonal degeneration in Charcot-Marie-Tooth disease type 1A. Brain 123 (Pt 7), 1516-1527.

Kuharev, J., Navarro, P., Distler, U., Jahn, O., and Tenzer, S. (2015). In-depth evaluation of software tools for data-independent acquisition based label-free quantification. Proteomics 15, 3140-3151.

Kuiken, H.J., Egan, D.A., Laman, H., Bernards, R., Beijersbergen, R.L., and Dirac, A.M. (2012). Identification of F-box only protein 7 as a negative regulator of NF-kappaB signalling. J Cell Mol Med 16, 2140-2149.

Laborde, E. (2010). Glutathione transferases as mediators of signaling pathways involved in cell proliferation and cell death. Cell Death Differ 17, 1373-1380.

Laman, H. (2006). Fbxo7 gets proactive with cyclin D/cdk6. Cell Cycle 5, 279-282.

Laman, H., Funes, J.M., Ye, H., Henderson, S., Galinanes-Garcia, L., Hara, E., Knowles, P., McDonald, N., and Boshoff, C. (2005). Transforming activity of Fbxo7 is mediated specifically through regulation of cyclin D/cdk6. EMBO J 24, 3104-3116.

Laman, H., Funes, J.M., Ye, H., Henderson, S., Galinanes-Garcia, L., Hara, E., Knowles, P., McDonald, N., and Boshoff, C. (2005). Transforming activity of Fbxo7 is mediated specifically through regulation of cyclin D/cdk6. EMBO J 24, 3104-3116.

Lappe-Siefke, C., Goebbels, S., Gravel, M., Nicksch, E., Lee, J., Braun, P.E., Griffiths, I.R., and Nave, K.A. (2003). Disruption of Cnp1 uncouples oligodendroglial functions in axonal support and myelination. Nat Genet 33, 366-374.

Larocca, J.N., and Norton, W.T. (2007). Isolation of myelin. Curr Protoc Cell Biol Chapter 3, Unit3 25.

Lee, H.K., Shin, Y.K., Jung, J., Seo, S.Y., Baek, S.Y., and Park, H.T. (2009). Proteasome inhibition suppresses Schwann cell dedifferentiation in vitro and in vivo. Glia 57, 1825-1834.

Lee, S.M., Chin, L.S., and Li, L. (2012a). Protein misfolding and clearance in demyelinating peripheral neuropathies: Therapeutic implications. Commun Integr Biol 5, 107-110. 
Lee, Y., Morrison, B.M., Li, Y., Lengacher, S., Farah, M.H., Hoffman, P.N., Liu, Y., Tsingalia, A., Jin, L., Zhang, P.W., et al. (2012b). Oligodendroglia metabolically support axons and contribute to neurodegeneration. Nature 487, 443-448.

Leone, D.P., Genoud, S., Atanasoski, S., Grausenburger, R., Berger, P., Metzger, D., Macklin, W.B., Chambon, P., and Suter, U. (2003). Tamoxifen-inducible glia-specific Cre mice for somatic mutagenesis in oligodendrocytes and Schwann cells. Mol Cell Neurosci 22, 430-440.

Li, G.Z., Vissers, J.P., Silva, J.C., Golick, D., Gorenstein, M.V., and Geromanos, S.J. (2009). Database searching and accounting of multiplexed precursor and product ion spectra from the data independent analysis of simple and complex peptide mixtures. Proteomics 9, 1696-1719.

Lilienbaum, A. (2013). Relationship between the proteasomal system and autophagy. Int J Biochem Mol Biol 4, 1-26.

Lindsten, K., de Vrij, F.M., Verhoef, L.G., Fischer, D.F., van Leeuwen, F.W., Hol, E.M., Masucci, M.G., and Dantuma, N.P. (2002). Mutant ubiquitin found in neurodegenerative disorders is a ubiquitin fusion degradation substrate that blocks proteasomal degradation. J Cell Biol 157, 417-427.

Lohmann, E., Coquel, A.S., Honore, A., Gurvit, H., Hanagasi, H., Emre, M., Leutenegger, A.L., Drouet, V., Sahbatou, M., Guven, G., et al. (2015). A new F-box protein 7 gene mutation causing typical Parkinson's disease. Mov Disord 30, 1130-1133.

Lowry, O.H., Rosebrough, N.J., Farr, A.L., and Randall, R.J. (1951). Protein measurement with the Folin phenol reagent. J Biol Chem 193, 265-275.

Luft, J.H. (1961). Improvements in epoxy resin embedding methods. J Biophys Biochem Cytol 9, 409-414.

Luong, T.N., Carlisle, H.J., Southwell, A., and Patterson, P.H. (2011). Assessment of motor balance and coordination in mice using the balance beam. $\mathrm{J}$ Vis Exp.

Mandelkow, E., and Mandelkow, E.M. (1995). Microtubules and microtubule-associated proteins. Curr Opin Cell Biol 7, 72-81.

Mandrekar, S., Jiang, Q., Lee, C.Y., Koenigsknecht-Talboo, J., Holtzman, D.M., and Landreth, G.E. (2009). Microglia mediate the clearance of soluble Abeta through fluid phase macropinocytosis. J Neurosci 29, 4252-4262.

Martini, R., Zielasek, J., Toyka, K.V., Giese, K.P., and Schachner, M. (1995). Protein zero (P0)-deficient mice show myelin degeneration in peripheral nerves characteristic of inherited human neuropathies. Nat Genet 11, 281-286. 
Matsuura, K., Kabuto, H., Makino, H., and Ogawa, N. (1997). Pole test is a useful method for evaluating the mouse movement disorder caused by striatal dopamine depletion. $\mathrm{J}$ Neurosci Methods 73, 45-48.

McCutchen-Maloney, S.L., Matsuda, K., Shimbara, N., Binns, D.D., Tanaka, K., Slaughter, C.A., and DeMartino, G.N. (2000). cDNA cloning, expression, and functional characterization of PI31, a proline-rich inhibitor of the proteasome. J Biol Chem 275, 18557-18565.

McNaught, K.S., Mytilineou, C., Jnobaptiste, R., Yabut, J., Shashidharan, P., Jennert, P., and Olanow, C.W. (2002). Impairment of the ubiquitin-proteasome system causes dopaminergic cell death and inclusion body formation in ventral mesencephalic cultures. J Neurochem 81, 301-306.

Melander, A., Olsson, J., Lindberg, G., Salzman, A., Howard, T., Stang, P., Lydick, E., Emslie-Smith, A., Boyle, D.I., Evans, J.M., et al. (1999). 35th Annual Meeting of the European Association for the Study of Diabetes : Brussels, Belgium, 28 September-2 October 1999. Diabetologia 42, A1-A330.

Meziane el, K., Randle, S.J., Nelson, D.E., Lomonosov, M., and Laman, H. (2011). Knockdown of $\mathrm{Fbxo7}$ reveals its regulatory role in proliferation and differentiation of haematopoietic precursor cells. J Cell Sci 124, 2175-2186.

Michailov, G.V., Sereda, M.W., Brinkmann, B.G., Fischer, T.M., Haug, B., Birchmeier, C., Role, L., Lai, C., Schwab, M.H., and Nave, K.A. (2004). Axonal neuregulin-1 regulates myelin sheath thickness. Science 304, 700-703.

Morgan, D.O. (1995). Principles of CDK regulation. Nature 374, 131-134.

Morland, C., Henjum, S., Iversen, E.G., Skrede, K.K., and Hassel, B. (2007). Evidence for a higher glycolytic than oxidative metabolic activity in white matter of rat brain. Neurochem Int 50, 703-709.

Mukoyama, M., Yamazaki, K., Kikuchi, T., and Tomita, T. (1989). Neuropathology of gracile axonal dystrophy (GAD) mouse. An animal model of central distal axonopathy in primary sensory neurons. Acta Neuropathol 79, 294-299.

Mulder, S.D., Nielsen, H.M., Blankenstein, M.A., Eikelenboom, P., and Veerhuis, R. (2014). Apolipoproteins $E$ and $J$ interfere with amyloid-beta uptake by primary human astrocytes and microglia in vitro. Glia 62, 493-503.

Naef, R., Adlkofer, K., Lescher, B., and Suter, U. (1997). Aberrant protein trafficking in Trembler suggests a disease mechanism for hereditary human peripheral neuropathies. Mol Cell Neurosci 9, 13-25.

Nave, K.A. (2010a). Myelination and support of axonal integrity by glia. Nature 468, 244252. 
Nave, K.A. (2010b). Myelination and the trophic support of long axons. Nat Rev Neurosci $11,275-283$.

Nave, K.A., and Salzer, J.L. (2006). Axonal regulation of myelination by neuregulin 1. Curr Opin Neurobiol 16, 492-500.

Nelson, D.E., Randle, S.J., and Laman, H. (2013). Beyond ubiquitination: the atypical functions of Fbxo7 and other F-box proteins. Open Biol 3, 130131.

Nguyen, M.D., Lariviere, R.C., and Julien, J.P. (2000). Reduction of axonal caliber does not alleviate motor neuron disease caused by mutant superoxide dismutase 1 . Proc Natl Acad Sci U S A 97, 12306-12311.

Noiges, R., Eichinger, R., Kutschera, W., Fischer, I., Nemeth, Z., Wiche, G., and Propst, F. (2002). Microtubule-associated protein 1A (MAP1A) and MAP1B: light chains determine distinct functional properties. J Neurosci 22, 2106-2114.

Norton, W.T., and Autilio, L.A. (1965). The Chemical Composition of Bovine Cns Myelin. Ann N Y Acad Sci 122, 77-85.

Norton, W.T., and Poduslo, S.E. (1973a). Myelination in rat brain: changes in myelin composition during brain maturation. J Neurochem 21, 759-773.

Norton, W.T., and Poduslo, S.E. (1973b). Myelination in rat brain: method of myelin isolation. J Neurochem 21, 749-757.

Ogawa, N., Hirose, Y., Ohara, S., Ono, T., and Watanabe, Y. (1985). A simple quantitative bradykinesia test in MPTP-treated mice. Res Commun Chem Pathol Pharmacol 50, 435-441.

Orban-Nemeth, Z., Simader, H., Badurek, S., Trancikova, A., and Propst, F. (2005). Microtubule-associated protein 1S, a short and ubiquitously expressed member of the microtubule-associated protein 1 family. J Biol Chem 280, 2257-2265.

Osaka, H., Wang, Y.L., Takada, K., Takizawa, S., Setsuie, R., Li, H., Sato, Y., Nishikawa, K., Sun, Y.J., Sakurai, M., et al. (2003). Ubiquitin carboxy-terminal hydrolase L1 binds to and stabilizes monoubiquitin in neuron. Hum Mol Genet 12, 1945-1958.

Osterhout, D.J., Marin-Husstege, M., Abano, P., and Casaccia-Bonnefil, P. (2002). Molecular mechanisms of enhanced susceptibility to apoptosis in differentiating oligodendrocytes. J Neurosci Res 69, 24-29.

Paisan-Ruiz, C., Guevara, R., Federoff, M., Hanagasi, H., Sina, F., Elahi, E., Schneider, S.A., Schwingenschuh, P., Bajaj, N., Emre, M., et al. (2010). Early-onset L-doparesponsive parkinsonism with pyramidal signs due to ATP13A2, PLA2G6, FBXO7 and spatacsin mutations. Mov Disord 25, 1791-1800. 
Parker, W.D., Jr., Boyson, S.J., and Parks, J.K. (1989). Abnormalities of the electron transport chain in idiopathic Parkinson's disease. Ann Neurol 26, 719-723.

Patel, P.I., Roa, B.B., Welcher, A.A., Schoener-Scott, R., Trask, B.J., Pentao, L., Snipes, G.J., Garcia, C.A., Francke, U., Shooter, E.M., et al. (1992). The gene for the peripheral myelin protein PMP-22 is a candidate for Charcot-Marie-Tooth disease type 1A. Nat Genet 1, 159-165.

Patzig, J., Jahn, O., Tenzer, S., Wichert, S.P., de Monasterio-Schrader, P., Rosfa, S., Kuharev, J., Yan, K., Bormuth, I., Bremer, J., et al. (2011). Quantitative and integrative proteome analysis of peripheral nerve myelin identifies novel myelin proteins and candidate neuropathy loci. J Neurosci 31, 16369-16386.

Pekny, M., and Pekna, M. (2014). Astrocyte reactivity and reactive astrogliosis: costs and benefits. Physiol Rev 94, 1077-1098.

Pellow, S., Chopin, P., File, S.E., and Briley, M. (1985). Validation of open:closed arm entries in an elevated plus-maze as a measure of anxiety in the rat. $J$ Neurosci Methods 14, 149-167.

Perry, G., Friedman, R., Shaw, G., and Chau, V. (1987). Ubiquitin is detected in neurofibrillary tangles and senile plaque neurites of Alzheimer disease brains. Proc Natl Acad Sci U S A 84, 3033-3036.

Peyron, F., Timsit, S., Thomas, J.L., Kagawa, T., Ikenaka, K., and Zalc, B. (1997). In situ expression of PLP/DM-20, MBP, and CNP during embryonic and postnatal development of the jimpy mutant and of transgenic mice overexpressing PLP. J Neurosci Res 50, 190-201.

Pfeiffer, S.E., Warrington, A.E., and Bansal, R. (1993). The oligodendrocyte and its many cellular processes. Trends Cell Biol 3, 191-197.

Pickart, C.M. (2000). Ubiquitin biology: an old dog learns an old trick. Nat Cell Biol 2, E139-141.

Pickart, C.M., and Eddins, M.J. (2004). Ubiquitin: structures, functions, mechanisms. Biochim Biophys Acta 1695, 55-72.

Pickart, C.M., and Fushman, D. (2004). Polyubiquitin chains: polymeric protein signals. Curr Opin Chem Biol 8, 610-616.

Pickering, M., Cumiskey, D., and O'Connor, J.J. (2005). Actions of TNF-alpha on glutamatergic synaptic transmission in the central nervous system. Exp Physiol 90, 663-670.

Pickrell, A.M., and Youle, R.J. (2015). The roles of PINK1, parkin, and mitochondrial fidelity in Parkinson's disease. Neuron 85, 257-273. 
Poliak, S., and Peles, E. (2003). The local differentiation of myelinated axons at nodes of Ranvier. Nat Rev Neurosci 4, 968-980.

Polymeropoulos, M.H., Hurko, O., Hsu, F., Rubenstein, J., Basnet, S., Lane, K., Dietz, H., Spetzler, R.F., and Rigamonti, D. (1997). Linkage of the locus for cerebral cavernous hemangiomas to human chromosome $7 q$ in four families of Mexican-American descent. Neurology 48, 752-757.

Preibisch, S., Saalfeld, S., and Tomancak, P. (2009). Globally optimal stitching of tiled 3D microscopic image acquisitions. Bioinformatics 25, 1463-1465.

Randle, S.J., Nelson, D.E., Patel, S.P., and Laman, H. (2015). Defective erythropoiesis in a mouse model of reduced Fbxo7 expression due to decreased p27 expression. J Pathol 237, 263-272.

Reynolds, E.S. (1963). The use of lead citrate at high $\mathrm{pH}$ as an electron-opaque stain in electron microscopy. J Cell Biol 17, 208-212.

Richardson, K.C., Jarett, L., and Finke, E.H. (1960). Embedding in epoxy resins for ultrathin sectioning in electron microscopy. Stain Technol 35, 313-323.

Riethmacher, D., Sonnenberg-Riethmacher, E., Brinkmann, V., Yamaai, T., Lewin, G.R., and Birchmeier, C. (1997). Severe neuropathies in mice with targeted mutations in the ErbB3 receptor. Nature 389, 725-730.

Rosenbluth, J., Nave, K.A., Mierzwa, A., and Schiff, R. (2006). Subtle myelin defects in PLP-null mice. Glia 54, 172-182.

Rushton, W.A. (1951). A theory of the effects of fibre size in medullated nerve. J Physiol $115,101-122$.

Saab, A.S., Tzvetanova, I.D., and Nave, K.A. (2013). The role of myelin and oligodendrocytes in axonal energy metabolism. Curr Opin Neurobiol 23, 1065-1072.

Sadahiro, S., Yoshikawa, H., Yagi, N., Yamamoto, Y., Yanagihara, T., Kimura, M., and Sakoda, S. (2000). Morphometric analysis of the myelin-associated oligodendrocytic basic protein-deficient mouse reveals a possible role for myelin-associated oligodendrocytic basic protein in regulating axonal diameter. Neuroscience 98, 361367.

Saiki, R.K., Scharf, S., Faloona, F., Mullis, K.B., Horn, G.T., Erlich, H.A., and Arnheim, N. (1985). Enzymatic amplification of beta-globin genomic sequences and restriction site analysis for diagnosis of sickle cell anemia. Science 230, 1350-1354.

Sanchez, I., Hassinger, L., Paskevich, P.A., Shine, H.D., and Nixon, R.A. (1996). Oligodendroglia regulate the regional expansion of axon caliber and local accumulation of neurofilaments during development independently of myelin formation. J Neurosci 16, 5095-5105. 
Scarffe, L.A., Stevens, D.A., Dawson, V.L., and Dawson, T.M. (2014). Parkin and PINK1: much more than mitophagy. Trends Neurosci 37, 315-324.

Schapira, A.H., Cooper, J.M., Dexter, D., Jenner, P., Clark, J.B., and Marsden, C.D. (1989). Mitochondrial complex I deficiency in Parkinson's disease. Lancet 1, 1269.

Scheffner, M., Nuber, U., and Huibregtse, J.M. (1995). Protein ubiquitination involving an E1-E2-E3 enzyme ubiquitin thioester cascade. Nature 373, 81-83.

Schlesinger, D.H., and Goldstein, G. (1975). Molecular conservation of 74 amino acid sequence of ubiquitin between cattle and man. Nature 255, 423-424.

Shadrach, K.G., Rayborn, M.E., Hollyfield, J.G., and Bonilha, V.L. (2013). DJ-1-dependent regulation of oxidative stress in the retinal pigment epithelium (RPE). PLoS One 8, e67983.

Sheehan, D., Meade, G., Foley, V.M., and Dowd, C.A. (2001). Structure, function and evolution of glutathione transferases: implications for classification of non-mammalian members of an ancient enzyme superfamily. Biochem J 360, 1-16.

Sherr, C.J. (1996). Cancer cell cycles. Science 274, 1672-1677.

Shine, H.D., Readhead, C., Popko, B., Hood, L., and Sidman, R.L. (1992). Morphometric analysis of normal, mutant, and transgenic CNS: correlation of myelin basic protein expression to myelinogenesis. J Neurochem 58, 342-349.

Shirk, A.J., Anderson, S.K., Hashemi, S.H., Chance, P.F., and Bennett, C.L. (2005). SIMPLE interacts with NEDD4 and TSG101: evidence for a role in lysosomal sorting and implications for Charcot-Marie-Tooth disease. J Neurosci Res 82, 43-50.

Shojaee, S., Sina, F., Banihosseini, S.S., Kazemi, M.H., Kalhor, R., Shahidi, G.A., Fakhrai-Rad, H., Ronaghi, M., and Elahi, E. (2008). Genome-wide linkage analysis of a Parkinsonian-pyramidal syndrome pedigree by $500 \mathrm{~K}$ SNP arrays. Am J Hum Genet $82,1375-1384$.

Sijts, E.J., and Kloetzel, P.M. (2011). The role of the proteasome in the generation of MHC class I ligands and immune responses. Cell Mol Life Sci 68, 1491-1502.

Simon, C.M., Jablonka, S., Ruiz, R., Tabares, L., and Sendtner, M. (2010). Ciliary neurotrophic factor-induced sprouting preserves motor function in a mouse model of mild spinal muscular atrophy. Hum Mol Genet 19, 973-986.

Simons, M., and Nave, K.A. (2015). Oligodendrocytes: Myelination and Axonal Support. Cold Spring Harb Perspect Biol 8, a020479.

Smith, K.J., and Lassmann, H. (2002). The role of nitric oxide in multiple sclerosis. Lancet Neurol 1, 232-241. 
Snyder, H., Mensah, K., Theisler, C., Lee, J., Matouschek, A., and Wolozin, B. (2003). Aggregated and monomeric alpha-synuclein bind to the S6' proteasomal protein and inhibit proteasomal function. J Biol Chem 278, 11753-11759.

Snyder, J.L., Kearns, C.A., and Appel, B. (2012). Fbxw7 regulates Notch to control specification of neural precursors for oligodendrocyte fate. Neural Dev 7, 15.

Solano, R.M., Casarejos, M.J., Menendez-Cuervo, J., Rodriguez-Navarro, J.A., Garcia de Yebenes, J., and Mena, M.A. (2008). Glial dysfunction in parkin null mice: effects of aging. J Neurosci 28, 598-611.

Somlai, J.a.K., Tibor (2016). Neuro-Ophthalmology (Springer).

Spillantini, M.G., Schmidt, M.L., Lee, V.M., Trojanowski, J.Q., Jakes, R., and Goedert, M. (1997). Alpha-synuclein in Lewy bodies. Nature 388, 839-840.

Sprinkle, T.J., McMorris, F.A., Yoshino, J., and DeVries, G.H. (1985). Differential expression of 2':3'-cyclic nucleotide 3'-phosphodiesterase in cultured central, peripheral, and extraneural cells. Neurochem Res 10, 919-931.

Stefanis, L., Larsen, K.E., Rideout, H.J., Sulzer, D., and Greene, L.A. (2001). Expression of A53T mutant but not wild-type alpha-synuclein in PC12 cells induces alterations of the ubiquitin-dependent degradation system, loss of dopamine release, and autophagic cell death. J Neurosci 21, 9549-9560.

Stefanova, N., Bucke, P., Duerr, S., and Wenning, G.K. (2009). Multiple system atrophy: an update. Lancet Neurol 8, 1172-1178.

Stefanova, N., Kaufmann, W.A., Humpel, C., Poewe, W., and Wenning, G.K. (2012). Systemic proteasome inhibition triggers neurodegeneration in a transgenic mouse model expressing human alpha-synuclein under oligodendrocyte promoter: implications for multiple system atrophy. Acta Neuropathol 124, 51-65.

Steru, L., Chermat, R., Thierry, B., and Simon, P. (1985). The tail suspension test: a new method for screening antidepressants in mice. Psychopharmacology (Berl) 85, 367370 .

Suter, U., and Scherer, S.S. (2003). Disease mechanisms in inherited neuropathies. Nat Rev Neurosci 4, 714-726.

Sypecka, J. (2003). Different vulnerability to cytotoxicity and susceptibility to protection of progenitors versus mature oligodendrocytes. Pol J Pharmacol 55, 881-885.

Tait, S., Gunn-Moore, F., Collinson, J.M., Huang, J., Lubetzki, C., Pedraza, L., Sherman, D.L., Colman, D.R., and Brophy, P.J. (2000). An oligodendrocyte cell adhesion molecule at the site of assembly of the paranodal axo-glial junction. J Cell Biol 150, 657-666. 
Tamura, Y., Kataoka, Y., Cui, Y., Takamori, Y., Watanabe, Y., and Yamada, H. (2007). Intracellular translocation of glutathione S-transferase pi during oligodendrocyte differentiation in adult rat cerebral cortex in vivo. Neuroscience $148,535-540$.

Tansey, K.E., McKay, W.B., and Kakulas, B.A. (2012). Restorative neurology: consideration of the new anatomy and physiology of the injured nervous system. Clin Neurol Neurosurg 114, 436-440.

Taveggia, C., Zanazzi, G., Petrylak, A., Yano, H., Rosenbluth, J., Einheber, S., Xu, X., Esper, R.M., Loeb, J.A., Shrager, P., et al. (2005). Neuregulin-1 type III determines the ensheathment fate of axons. Neuron 47, 681-694.

Timmerman, V., Nelis, E., Van Hul, W., Nieuwenhuijsen, B.W., Chen, K.L., Wang, S., Ben Othman, K., Cullen, B., Leach, R.J., Hanemann, C.O., et al. (1992). The peripheral myelin protein gene PMP-22 is contained within the Charcot-Marie-Tooth disease type $1 \mathrm{~A}$ duplication. Nat Genet 1, 171-175.

Todorich, B., Pasquini, J.M., Garcia, C.I., Paez, P.M., and Connor, J.R. (2009). Oligodendrocytes and myelination: the role of iron. Glia 57, 467-478.

Townsend, D.M., and Tew, K.D. (2003). The role of glutathione-S-transferase in anticancer drug resistance. Oncogene 22, 7369-7375.

Trapp, B.D., and Stys, P.K. (2009). Virtual hypoxia and chronic necrosis of demyelinated axons in multiple sclerosis. Lancet Neurol 8, 280-291.

Tsou, A.P., Yang, C.W., Huang, C.Y., Yu, R.C., Lee, Y.C., Chang, C.W., Chen, B.R., Chung, Y.F., Fann, M.J., Chi, C.W., et al. (2003). Identification of a novel cell cycle regulated gene, HURP, overexpressed in human hepatocellular carcinoma. Oncogene 22, 298-307.

Tyler, W.A., Gangoli, N., Gokina, P., Kim, H.A., Covey, M., Levison, S.W., and Wood, T.L. (2009). Activation of the mammalian target of rapamycin (mTOR) is essential for oligodendrocyte differentiation. J Neurosci 29, 6367-6378.

Udomsinprasert, R., Pongjaroenkit, S., Wongsantichon, J., Oakley, A.J., Prapanthadara, L.A., Wilce, M.C., and Ketterman, A.J. (2005). Identification, characterization and structure of a new Delta class glutathione transferase isoenzyme. Biochem $\mathrm{J} 388$, 763-771.

van Tijn, P., Hol, E.M., van Leeuwen, F.W., and Fischer, D.F. (2008). The neuronal ubiquitin-proteasome system: murine models and their neurological phenotype. Prog Neurobiol 85, 176-193

Veitenhansl, M., Stegner, K., Hierl, F.X., Dieterle, C., Feldmeier, H., Gutt, B., Landgraf, R., Garrow, A.P., Vileikyte, L., Findlow, A., et al. (2004). 40th EASD Annual Meeting of 
the European Association for the Study of Diabetes : Munich, Germany, 5-9 September 2004. Diabetologia 47, A1-A464.

Verma, P., Chierzi, S., Codd, A.M., Campbell, D.S., Meyer, R.L., Holt, C.E., and Fawcett, J.W. (2005). Axonal protein synthesis and degradation are necessary for efficient growth cone regeneration. J Neurosci 25, 331-342.

Vingill, S. (2016). Characterization of FBXO7 (PARK15) knockout mice modeling Parkinsonian-Pyramidal Syndrome (Göttingen, Georg-August university, doctoral thesis).

Vingill, S., Brockelt, D., Lancelin, C., Tatenhorst, L., Dontcheva, G., Preisinger, C., Schwedhelm-Domeyer, N., Joseph, S., Mitkovski, M., Goebbels, S., et al. (2016). Loss of FBXO7 (PARK15) results in reduced proteasome activity and models a parkinsonism-like phenotype in mice. EMBO J 35, 2008-2025.

Wahl, S.E., McLane, L.E., Bercury, K.K., Macklin, W.B., and Wood, T.L. (2014). Mammalian target of rapamycin promotes oligodendrocyte differentiation, initiation and extent of CNS myelination. J Neurosci 34, 4453-4465.

Wang, T., Arifoglu, P., Ronai, Z., and Tew, K.D. (2001). Glutathione S-transferase P1-1 (GSTP1-1) inhibits C-Jun N-terminal kinase (JNK1) signaling through interaction with the C terminus. J Biol Chem 276, 20999-21003.

Wang, X. (2017). Destructive Cellular Paths Underlying Familial and Sporadic Parkinson Disease Converge on Mitophagy. Autophagy, 0.

Wang, Z., Zhang, Y., Zhang, S., Guo, Q., Tan, Y., Wang, X., Xiong, R., Ding, J., and Chen, S. (2011). DJ-1 can inhibit microtubule associated protein $1 \mathrm{~B}$ formed aggregates. Mol Neurodegener 6, 38.

Weber, K., and Osborn, M. (1969). The reliability of molecular weight determinations by dodecyl sulfate-polyacrylamide gel electrophoresis. J Biol Chem 244, 4406-4412.

Wieser, G.L., Gerwig, U.C., Adamcio, B., Barrette, B., Nave, K.A., Ehrenreich, H., and Goebbels, S. (2013). Neuroinflammation in white matter tracts of Cnp1 mutant mice amplified by a minor brain injury. Glia $61,869-880$.

Wilkins, A., Majed, H., Layfield, R., Compston, A., and Chandran, S. (2003). Oligodendrocytes promote neuronal survival and axonal length by distinct intracellular mechanisms: a novel role for oligodendrocyte-derived glial cell line-derived neurotrophic factor. J Neurosci 23, 4967-4974.

Winston, J.T., Koepp, D.M., Zhu, C., Elledge, S.J., and Harper, J.W. (1999). A family of mammalian F-box proteins. Curr Biol 9, 1180-1182.

Wisniewski, J.R., Zougman, A., Nagaraj, N., and Mann, M. (2009). Universal sample preparation method for proteome analysis. Nat Methods 6, 359-362. 
Woodward, K.J. (2008). The molecular and cellular defects underlying PelizaeusMerzbacher disease. Expert Rev Mol Med 10, e14.

Wyss-Coray, T., Loike, J.D., Brionne, T.C., Lu, E., Anankov, R., Yan, F., Silverstein, S.C., and Husemann, J. (2003). Adult mouse astrocytes degrade amyloid-beta in vitro and in situ. Nat Med 9, 453-457.

Wyss-Coray, T., and Mucke, L. (2002). Inflammation in neurodegenerative disease--a double-edged sword. Neuron 35, 419-432.

Yalcin-Cakmakli, G., Olgiati, S., Quadri, M., Breedveld, G.J., Cortelli, P., Bonifati, V., and Elibol, B. (2014). A new Turkish family with homozygous FBXO7 truncating mutation and juvenile atypical parkinsonism. Parkinsonism Relat Disord 20, 1248-1252.

Yamamoto, A., Lucas, J.J., and Hen, R. (2000). Reversal of neuropathology and motor dysfunction in a conditional model of Huntington's disease. Cell 101, 57-66.

Yin, X., Crawford, T.O., Griffin, J.W., Tu, P., Lee, V.M., Li, C., Roder, J., and Trapp, B.D. (1998). Myelin-associated glycoprotein is a myelin signal that modulates the caliber of myelinated axons. J Neurosci 18, 1953-1962.

Yonashiro, R., Kimijima, Y., Shimura, T., Kawaguchi, K., Fukuda, T., Inatome, R., and Yanagi, S. (2012). Mitochondrial ubiquitin ligase MITOL blocks S-nitrosylated MAP1B-light chain 1-mediated mitochondrial dysfunction and neuronal cell death. Proc Natl Acad Sci U S A 109, 2382-2387.

Yu, W.P., Collarini, E.J., Pringle, N.P., and Richardson, W.D. (1994). Embryonic expression of myelin genes: evidence for a focal source of oligodendrocyte precursors in the ventricular zone of the neural tube. Neuron 12, 1353-1362.

Zaiss, D.M., Standera, S., Kloetzel, P.M., and Sijts, A.J. (2002). PI31 is a modulator of proteasome formation and antigen processing. Proc Natl Acad Sci U S A 99, 1434414349.

Zhang, D., Hu, X., Qian, L., O'Callaghan, J.P., and Hong, J.S. (2010). Astrogliosis in CNS pathologies: is there a role for microglia? Mol Neurobiol 41, 232-241.

Zhang, Y., Chen, K., Sloan, S.A., Bennett, M.L., Scholze, A.R., O'Keeffe, S., Phatnani, H.P., Guarnieri, P., Caneda, C., Ruderisch, N., et al. (2014). An RNA-sequencing transcriptome and splicing database of glia, neurons, and vascular cells of the cerebral cortex. J Neurosci 34, 11929-11947

Zheng, N., Schulman, B.A., Song, L., Miller, J.J., Jeffrey, P.D., Wang, P., Chu, C., Koepp, D.M., Elledge, S.J., Pagano, M., et al. (2002). Structure of the Cul1-Rbx1-Skp1-F boxSkp2 SCF ubiquitin ligase complex. Nature 416, 703-709. 
Zhou, Z.D., Xie, S.P., Sathiyamoorthy, S., Saw, W.T., Sing, T.Y., Ng, S.H., Chua, H.P., Tang, A.M., Shaffra, F., Li, Z., et al. (2015). F-box protein 7 mutations promote protein aggregation in mitochondria and inhibit mitophagy. Hum Mol Genet 24, 6314-6330.

Zuchero, J.B., and Barres, B.A. (2011). Between the sheets: a molecular sieve makes myelin membranes. Dev Cell 21, 385-386. 
